\title{
Comparison of emissions measurement between a sensor-based compact emissions meter and a standard PEMS
}

Jordan Matthew Leatherman

West Virginia University, jmleatherman@mix.wvu.edu

Follow this and additional works at: https://researchrepository.wvu.edu/etd

Part of the Automotive Engineering Commons, and the Mechanical Engineering Commons

\author{
Recommended Citation \\ Leatherman, Jordan Matthew, "Comparison of emissions measurement between a sensor-based compact \\ emissions meter and a standard PEMS" (2018). Graduate Theses, Dissertations, and Problem Reports. \\ 3683. \\ https://researchrepository.wvu.edu/etd/3683
}

This Thesis is protected by copyright and/or related rights. It has been brought to you by the The Research Repository @ WVU with permission from the rights-holder(s). You are free to use this Thesis in any way that is permitted by the copyright and related rights legislation that applies to your use. For other uses you must obtain permission from the rights-holder(s) directly, unless additional rights are indicated by a Creative Commons license in the record and/ or on the work itself. This Thesis has been accepted for inclusion in WVU Graduate Theses, Dissertations, and Problem Reports collection by an authorized administrator of The Research Repository @ WVU. For more information, please contact researchrepository@mail.wvu.edu. 


\title{
Comparison of emissions measurement between a sensor-based compact emissions meter and a standard PEMS
}

\author{
Jordan Leatherman \\ Thesis Submitted to the \\ Benjamin M. Statler College of Engineering and Mineral Resources at \\ West Virginia University \\ In partial fulfillment of the requirements for the degree of \\ Master of Science \\ in \\ Mechanical Engineering \\ Marc C. Besch, Ph. D., Chair \\ Ross Ryskamp, Ph. D. \\ Arvind Thiruvengadam, Ph. D. \\ Berk Demirgok, Ph. D. \\ Department of Mechanical and Aerospace Engineering \\ West Virginia University \\ Morgantown, West Virginia \\ 2018
}

Keywords: In-Use Emissions, NCEM, OBS-One 


\section{Abstract}

\section{Comparison of emissions measurement between a sensor-based compact emissions meter, and a standard PEMS}

The emissions produced by diesel engines are detrimental to human health, and the environment. To reduce these harmful emissions, engine manufacturers have used exhaust after treatment systems. The main objective of these after-treatment systems is to reduce exhaust emissions with minimal impact on an engines performance. The increase in emission regulations resulted in the need for a portable device to measure emissions. Portable emissions measurement systems (PEMS) are used to ensure engines comply with regulations in the real world. Although these systems are portable and can be installed on a vehicle they are bulky, expensive and time consuming to install. More recently a compact version of the PEMS based on lower cost, smaller sensors have come to market. These devices are not recognized for in-use compliance but potentially have a use for rapid testing of a larger fleet of vehicles.

The main objective of this study was to perform a sensor-based emissions measurement comparison of the oxides of nitrogen $\left(\mathrm{NO}_{\mathrm{x}}\right)$ and particle number $(\mathrm{PN})$ emissions collected between the NTK Compact Emissions Meter (NCEM) and a Horiba OBS-ONE GS with PN analyzer unit. The NCEM is a newly marketed device that measures exhaust $\mathrm{NO}_{\mathrm{x}}$ and Oxygen $\left(\mathrm{O}_{2}\right)$ concentrations through the use of a zirconiumoxide sensor, and PN with a diffusion-charging type sensor. Using the Horiba OBS-One PEMS as the reference to the accuracy of the NCEM at different operating conditions was examined. The Horiba OBS-One PEMS is compliant with the Code of Federal (CFR) regulations, Title 40, Part-1065, Subpart J, which details in-use emissions compliance testing for a vehicle equipped with heavy-duty engines. Both units were installed on a heavy-duty on-highway Mercedes Benz Actros cab-over truck. This truck was tested over a number of different routes that included various terrain, and traffic situations. One of the test routes was created to satisfy the European Union (EU) Real Driving Emissions (RDE) characteristics. This route was repeated three times. This test route included stop and go, low speed constant flow, and highway operation. The second test route consisted of highway driving an elevation change of 400 meters to examine altitude on the analyzers. The third and final test route was a highway route with relatively constant altitude. All data sets were subsequently analyzed using linear regression, and binning technique. 


\section{Acknowledgements}

I want to thank everyone who helped me during my graduate career. First I would like to thank my amazing wife, Kirsten. Thank you for always being there when I wanted to quit, and always yelling at me when I got off task. I also want to thank my parents, Randal and Barbara Leatherman. For providing me with endless support and large amounts of compassion during my whole academic career.

Marc Besch, thank you for everything you have done for me. Thank you for continuous amounts of hard work, and massive amounts of endless knowledge. I admire and appreciate you very much. Thank you for taking me on as an adopted student.

Ross Ryskamp, thank you for giving me the opportunity to join this fine organization, and for always being there for me when I doubted myself, even when things got bumpy. I want to thank you very much.

Marc and Ross have influenced me greatly through my academic career, from the CFR project/ LD Engine Test Cell with Ross, to the PEMS testing in Southern California with Marc. I want to thank you both for your never ending support.

I would like to thank my committee member, Arvind Thiruvengadam for the ongoing support and wealth of knowledge. Thank you very much sir.

I would like to thank Berk Demirgok, for putting up with me during my research trip to LA. Thank you very much man, you made it fun, even though we did not get much sleep.

I want to sincerely thank all four of you gentlemen for your massive amounts of support and taking the time to review my thesis paper.

Thank you to Rasik Pondicherry for always being there and for the large amounts of support and wealth of knowledge.

Thank you to Diego for answering a thousand questions and rereading the my messed up wording. As well as the endless amounts of knowledge and support.

Thank you to all the friends who have made Morgantown home feel like home for so long, Chakradhar Reddy Vardhireddy, Adam James, William Waggy, Samuel Okeleye, Anirudh Tirunahari, Cem Baki, and many others. Thank you guys for the experiences, and the fun times. 


\section{Table of Contents}

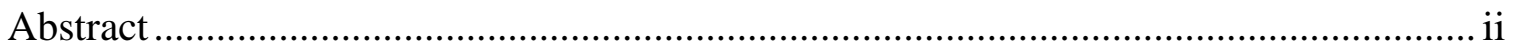

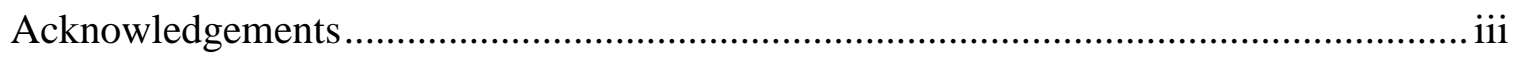

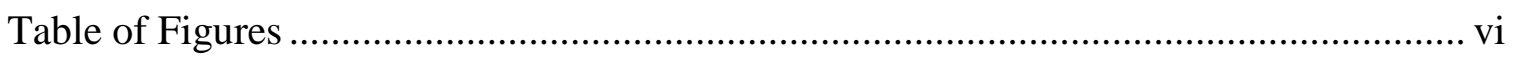

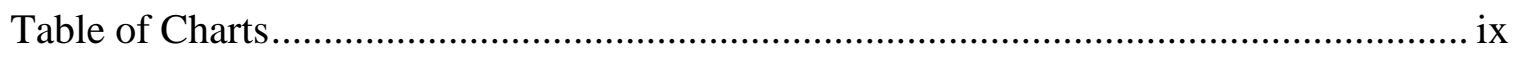

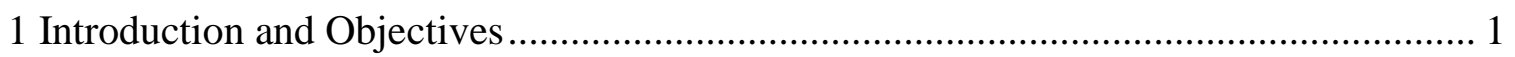

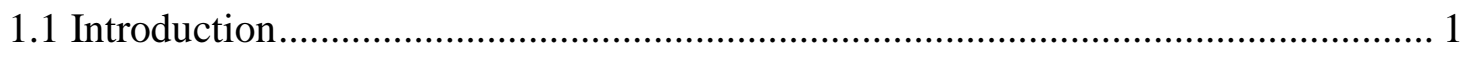

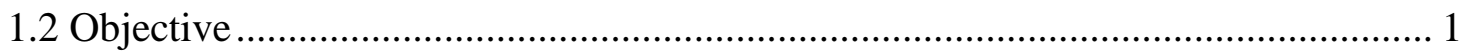

2 Background Knowledge...................................................................................... 2

2.1 Portable Emissions Measurement Systems......................................................... 2

2.2 Particulate Matter.................................................................................................... 3

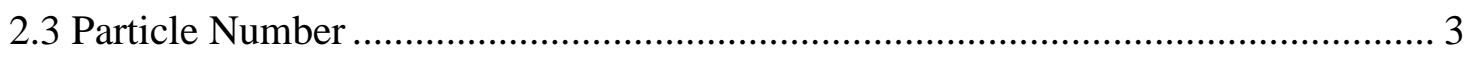

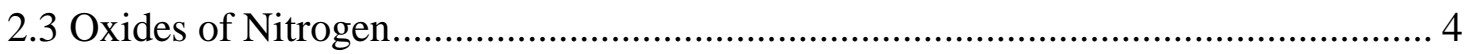

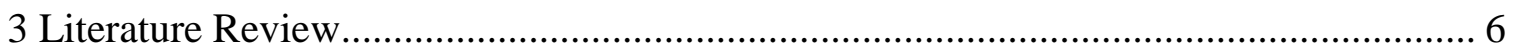

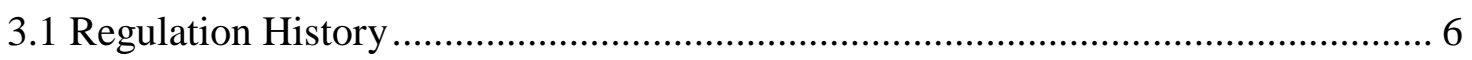

3.2 Current Emissions Standards in the United States................................................. 7

3.3 Real Driving Emissions Requirements ................................................................ 7

3.4 University of California, Riverside PEMS Comparison........................................... 8

3.5 Comparison of PEMS with Laboratory Grade Equipment ....................................... 10

3.6 Experiences and Results with different PEMS ………......................................... 11

3.7 $\mathrm{NO}_{\mathbf{x}}$ Sensors Cross Sensitivity............................................................................. 12

3.8 Influence of Altitude on $\mathrm{NO}_{\mathrm{x}}$ Concentration Levels ............................................... 14

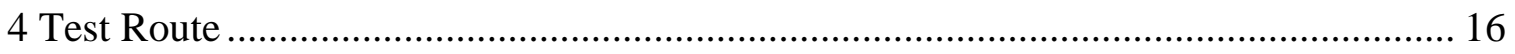

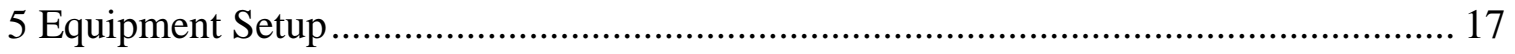

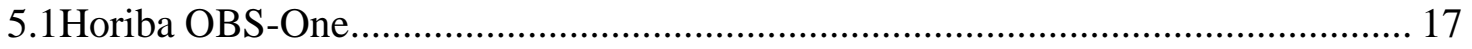

5.1.1 General System Description ....................................................................... 17

5.1.2 Measurement Principles............................................................................... 18

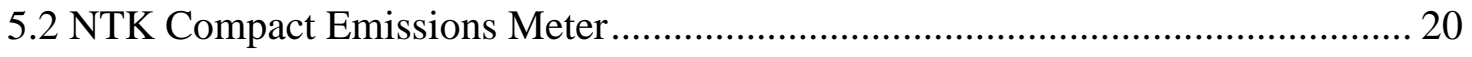

5.2.1 General System Description ...................................................................... 20

5.2.2 Measurement Principles................................................................................... 21

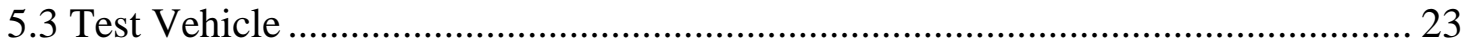

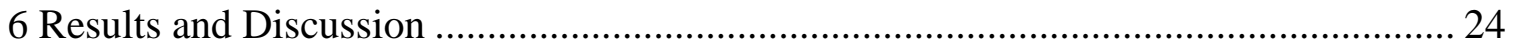

6.1 Overview of Data.......................................................................................... 24

6.2 Comparison of $\mathrm{NO}_{\mathrm{x}}$ PEMS Data …………………............................................ 24 
6.2.1 Real Driving Emissions Route - Urban/Rural/Highway Operation................. 24

6.2.2 Tavannes Route - Highway Operation with Grade ....................................... 44

6.2.3 Highway Loop - Highway Operation on Flat Terrain..................................... 52

6.3 Comparison of PN Concentration Measurements ............................................. 60

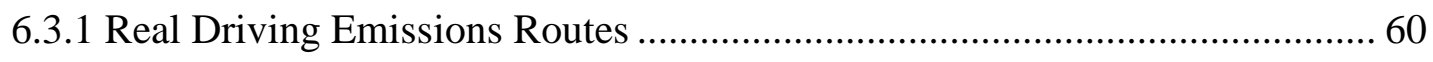

6.3.2 Tavannes Routes - Highway Operation with Grade ....................................... 63

6.3.3 Highway Loop - Highway Operation on Flat Terrain..................................... 65

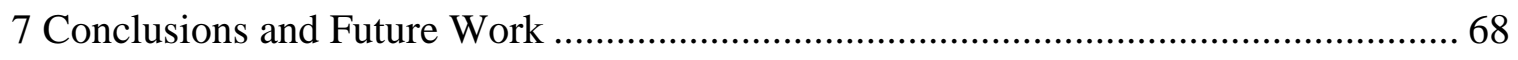

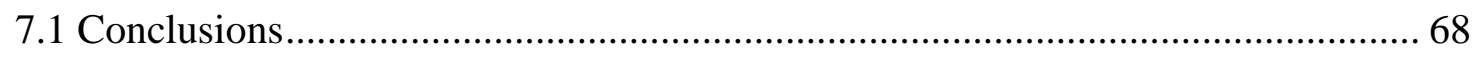

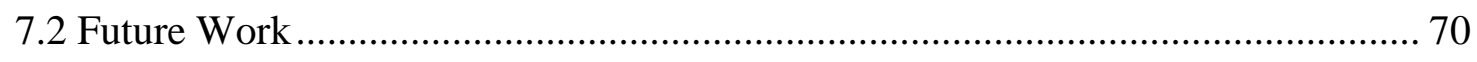

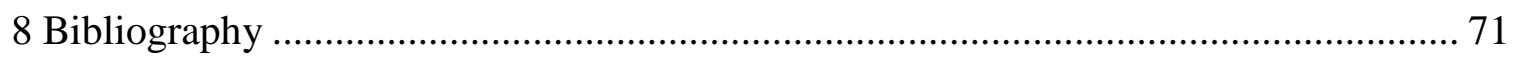

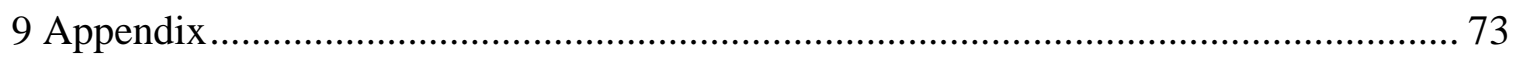




\section{Table of Figures}

Figure 1: Horiba OBS-ONE............................................................................... 18

Figure 2: Condensation Particle Counter [24] ......................................................... 19

Figure 3: Chemiluminescence Detector[26] …………….......................................... 20

Figure 4: NTK Compact Emissions Meter ………………………………………..... 21

Figure 5: NCEM PN Sensor Diagram [28] ............................................................. 22

Figure 6: Zirconium Oxide Sensor Diagram [30]............................................................ 23

Figure 7: RDE $2 \mathrm{NO}_{\mathrm{x}}$ Raw Data with Vehicle Speed................................................. 26

Figure 8: Linear Regression for RDE $2 \mathrm{NO}_{\mathrm{x}}$ Overall ...................................................... 27

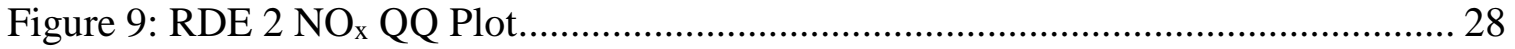

Figure 10: RDE $2 \mathrm{NO}_{\mathrm{x}}$ Cold Start Raw Data with Vehicle Speed ..................................... 29

Figure 11: Linear Regression for RDE $2 \mathrm{NO}_{\mathrm{x}}$ Cold Start................................................. 30

Figure 12: $\mathrm{RDE} 2$ Urban $\mathrm{NO}_{\mathrm{x}}$ Raw Data with Vehicle Speed............................................ 31

Figure 13: Linear Regression for RDE $2 \mathrm{NO}_{\mathrm{x}}$ Urban ....................................................... 32

Figure 14: RDE 2 Rural $\mathrm{NO}_{x}$ Raw Data with Vehicle Speed............................................. 34

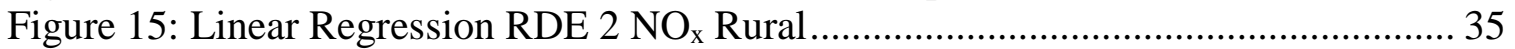

Figure 16: RDE 2 Highway Raw Data with Vehicle Speed ............................................... 36

Figure 17: Linear Regression for $\mathrm{RDE} 2 \mathrm{NO}_{\mathrm{x}}$ Highway ................................................ 38

Figure 18: Linear Regression for RDE $2 \mathrm{NO}_{\mathrm{x}}$ Concentration Binning - 10 ppm Bins..... 39

Figure 19:Error Percentage for RDE $2 \mathrm{NO}_{\mathrm{x}}$ Concentration Binning - 10 ppm Bins........ 40

Figure 20: Linear Regression for RDE $2 \mathrm{NO}_{\mathrm{x}}$ Concentration Binning - 20 ppm Bins..... 42

Figure 21: Error Percentage for RDE $2 \mathrm{NO}_{\mathrm{x}}$ Concentration Binning - 20 ppm Bins....... 43

Figure 22:Tavannes $1 \mathrm{NO}_{\mathrm{x}}$ Raw Data with Vehicle Speed ............................................... 45

Figure 23: Tavannes $1 \mathrm{NO}_{\mathrm{x}} \mathrm{QQ}$ Plot............................................................................. 46

Figure 24: Linear Regression for Tavannes $1 \mathrm{NO}_{\mathrm{x}}$ Overall............................................ 47

Figure 25: Linear Regression Tavannes $1 \mathrm{NO}_{\mathrm{x}}$ Concentration Binning - 10 ppm Bins ... 48

Figure 26: Error Percentage Tavannes $1 \mathrm{NO}_{\mathrm{x}}$ Concentration Binning - 10 ppm Bins..... 49

Figure 27: Linear Regression Tavannes $1 \mathrm{NO}_{\mathrm{x}}$ Concentration Binning - 20 ppm Bins ... 51

Figure 28: Error Percentage Tavannes $1 \mathrm{NO}_{\mathrm{x}}$ Concentration Binning - 20 ppm Bins ..... 52

Figure 29: Highway $2 \mathrm{NO}_{\mathrm{x}}$ Raw Data with Vehicle Speed .............................................. 53

Figure 30: Highway $2 \mathrm{NO}_{\mathrm{x}} \mathrm{QQ}$ Plot............................................................................. 54

Figure 31: Linear Regression for Highway $2 \mathrm{NO}_{\mathrm{x}}$ Overall .............................................. 55

Figure 32: Linear Regression Highway $2 \mathrm{NO}_{\mathrm{x}}$ Concentration Binning - 10 ppm Bins.... 56

Figure 33: Error Percentage Highway $2 \mathrm{NO}_{\mathrm{x}}$ Concentration Binning - 10 ppm Bins...... 57

Figure 34: Linear Regression Highway $2 \mathrm{NO}_{\mathrm{x}}$ Concentration Binning - 20 ppm Bins.... 59

Figure 35: Error Percentage Highway $2 \mathrm{NO}_{\mathrm{x}}$ Concentration Binning - 20 ppm Bins...... 60

Figure 36: RDE 1 PN Raw Data with Vehicle Speed...................................................... 61

Figure 37: Linear Regression for RDE 1 PN Overall ........................................................ 62

Figure 38:Tavannes 2 PN Raw Data with Vehicle Speed ................................................... 64

Figure 39: Linear Regression for Tavannes 2 PN Overall.............................................. 65

Figure 40: Highway 1 PN Raw Data with Vehicle Speed .................................................. 66

Figure 41: Linear Regression for Highway 1 PN Overall .................................................. 67

Figure 42: Tavannes Test Route ……………………….............................................. 73

Figure 43: RDE Test Route................................................................................ 74

Figure 44: Highway Test Route.............................................................................. 74 


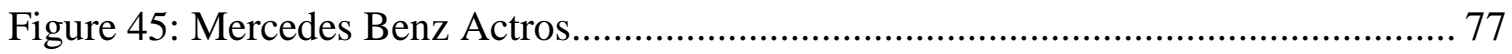

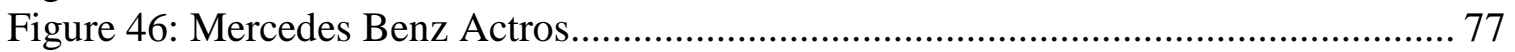

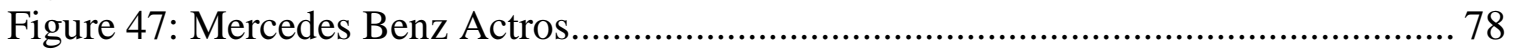

Figure 48: Truck Exhaust Tip, Sensor Layout............................................................ 79

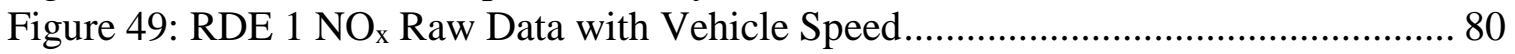

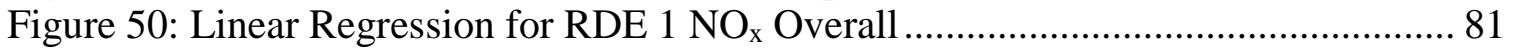

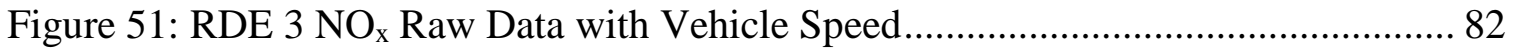

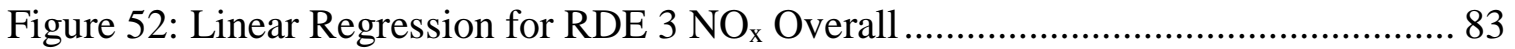

Figure 53: RDE 1 Cold Start $\mathrm{NO}_{\mathrm{x}}$ Raw Data with Vehicle Speed ................................. 84

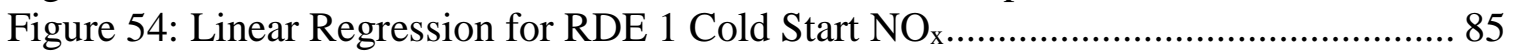

Figure 55: RDE $3 \mathrm{NO}_{\mathrm{x}}$ Cold Start Raw Data with Vehicle Speed ................................. 86

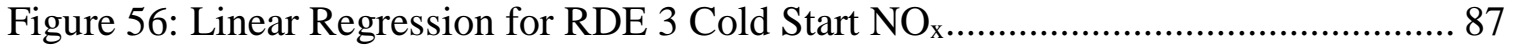

Figure 57: RDE $1 \mathrm{NO}_{\mathrm{x}}$ Urban Raw Data with Vehicle Speed........................................ 88

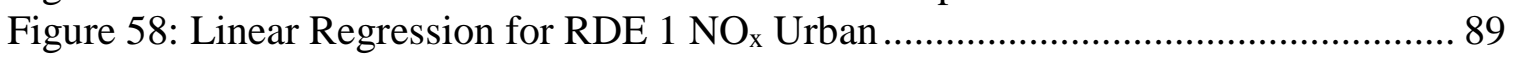

Figure 59: RDE $3 \mathrm{NO}_{\mathrm{x}}$ Urban Raw Data with Vehicle Speed....................................... 90

Figure 60: Linear Regression for RDE $3 \mathrm{NO}_{\mathrm{x}}$ Urban ................................................ 91

Figure 61: RDE $1 \mathrm{NO}_{\mathrm{x}}$ Rural Raw Data with Vehicle Speed...................................... 92

Figure 62: Linear Regression for RDE $1 \mathrm{NO}_{\mathrm{x}}$ Rural ................................................. 93

Figure 63: RDE $3 \mathrm{NO}_{\mathrm{x}}$ Rural Raw Data with Vehicle Speed ....................................... 94

Figure 64: Linear Regression for RDE $3 \mathrm{NO}_{\mathrm{x}}$ Rural .................................................. 95

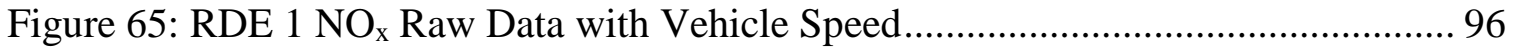

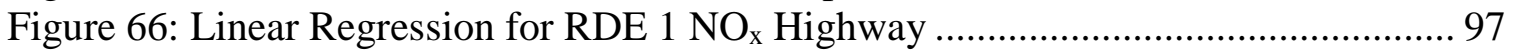

Figure 67: RDE $3 \mathrm{NO}_{\mathrm{x}}$ Highway Raw Data with Vehicle Speed ................................... 98

Figure 68: Linear Regression for RDE $3 \mathrm{NO}_{\mathrm{x}}$ Highway .............................................. 99

Figure 69: Linear Regression for RDE $1 \mathrm{NO}_{\mathrm{x}}$ Concentration Binning - 10 ppm Bins... 100

Figure 70: Linear Regression for RDE $3 \mathrm{NO}_{\mathrm{x}}$ Concentration Binning - 10 ppm Bins... 101

Figure 71: Error Percentage for RDE $1 \mathrm{NO}_{\mathrm{x}}$ Concentration Binning - 10 ppm Bins ..... 102

Figure 72: Error Percentage for RDE $3 \mathrm{NO}_{\mathrm{x}}$ Concentration Binning - 10 ppm Bins ..... 103

Figure 73: Linear Regression for RDE $1 \mathrm{NO}_{\mathrm{x}}$ Concentration Binning - 20 ppm Bins... 104

Figure 74: Linear Regression for RDE $3 \mathrm{NO}_{\mathrm{x}}$ Concentration Binning - 20 ppm Bins... 105

Figure 75: Error Percentage for RDE $1 \mathrm{NO}_{\mathrm{x}}$ Concentration Binning - 20 ppm Bins ..... 106

Figure 76: Error Percentage for RDE $3 \mathrm{NO}_{\mathrm{x}}$ Concentration Binning - 20 ppm Bins ..... 107

Figure 77: Tavannes $2 \mathrm{NO}_{\mathrm{x}}$ Raw Data with Vehicle Speed ......................................... 108

Figure 78: Linear Regression Tavannes $2 \mathrm{NO}_{\mathrm{x}}$ Overall ............................................... 109

Figure 79: Linear Regression Tavannes $2 \mathrm{NO}_{\mathrm{x}}$ Concentration Binning - 10 ppm Bins 110

Figure 80: Error Percentage Tavannes $2 \mathrm{NO}_{\mathrm{x}}$ Concentration Binning - 10 ppm Bins ... 111

Figure 81: Linear Regression Tavannes $2 \mathrm{NO}_{\mathrm{x}}$ Concentration Binning - 20 ppm Bins 112

Figure 82: Error Percentage Tavannes $2 \mathrm{NO}_{\mathrm{x}}$ Concentration Binning - 20 ppm Bins ... 113

Figure 83: Highway $1 \mathrm{NO}_{\mathrm{x}}$ Raw Data with Vehicle Speed ......................................... 113

Figure 84: Linear Regression for Highway $1 \mathrm{NO}_{\mathrm{x}}$ Overall .......................................... 114

Figure 85: Linear Regression Highway $1 \mathrm{NO}_{\mathrm{x}}$ Concentration Binning - 10 ppm Bins.. 115 Figure 86: Error Percentage Highway $1 \mathrm{NO}_{\mathrm{x}}$ Concentration Binning - 10 ppm Bins .... 116 Figure 87: Linear Regression Highway $1 \mathrm{NO}_{\mathrm{x}}$ Concentration Binning - 20 ppm Bins.. 117 Figure 88: Error Percentage Highway $1 \mathrm{NO}_{\mathrm{x}}$ Concentration Binning - 20 ppm Bins .... 118

Figure 89: RDE 2 PN Raw Data with Vehicle Speed................................................ 119

Figure 90: Linear Regression for RDE 2 PN Overall ................................................ 120 


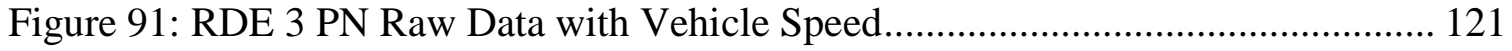

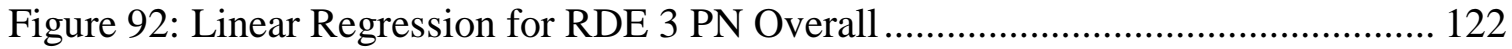

Figure 93: Tavannes 1 PN Raw Data with Vehicle Speed .......................................... 123

Figure 94: Linear Regression for Tavannes 1 PN Overall............................................ 124

Figure 95: Highway 2 PN Raw Data with Vehicle Speed ........................................... 125

Figure 96: Linear Regression for Highway 2 PN Overall ............................................ 126 


\section{Table of Charts}

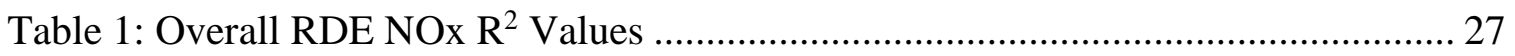

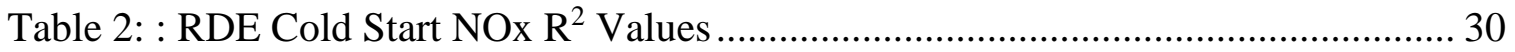

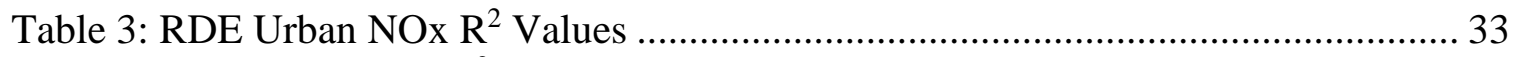

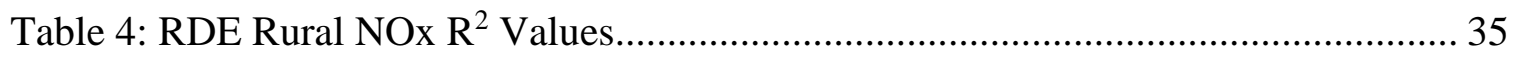

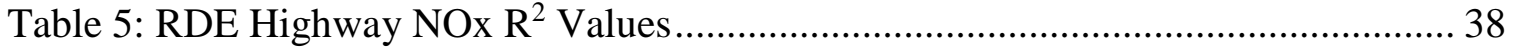

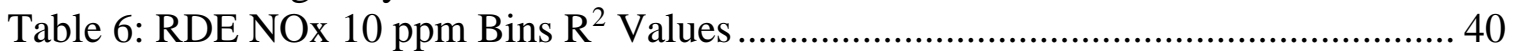

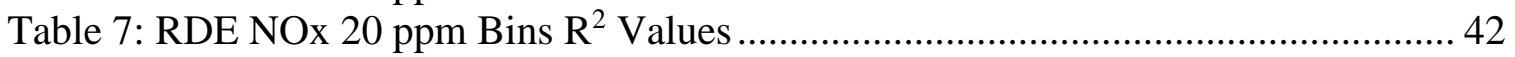

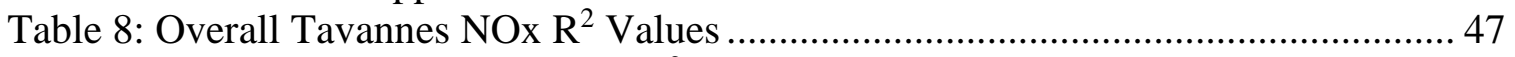

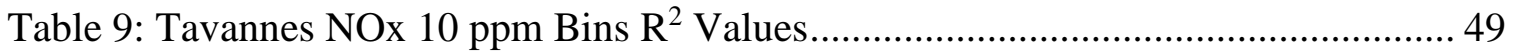

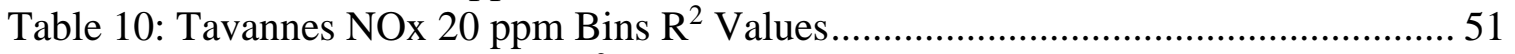

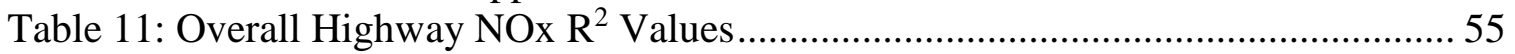

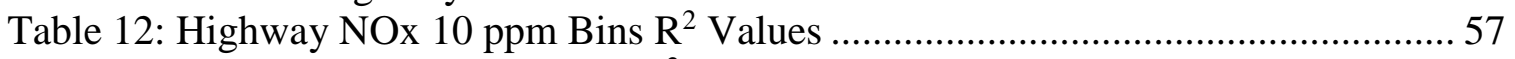

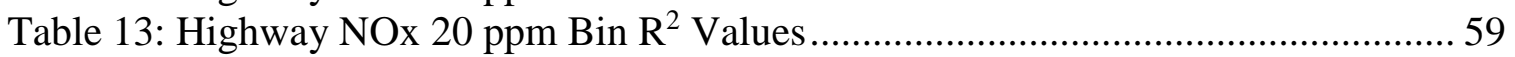

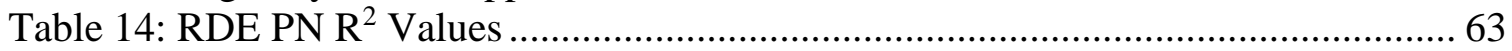

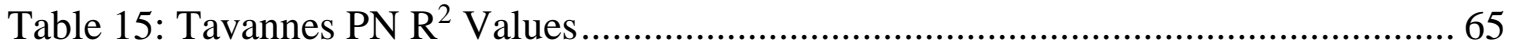

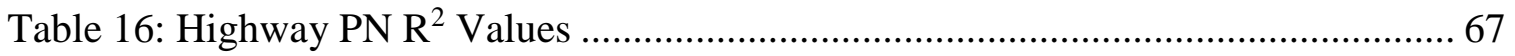

Table 18: Horiba OBS-One Specifications Chart [18] .................................................. 75

Table 19: Horiba OBS-One Measurement Principles of Gaseous Emissions [18]........... 75

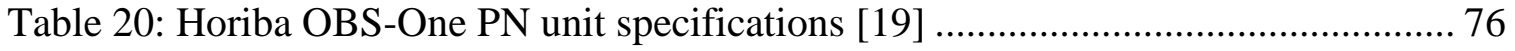

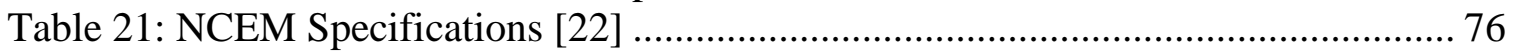

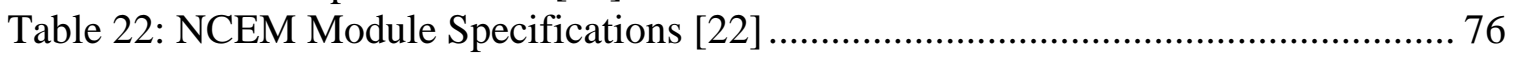

Table 23: Mercedes Benz Actros Specifications Chart ................................................ 79

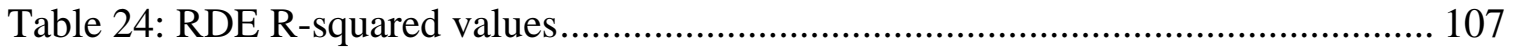




\section{List of Abbreviations}

\begin{tabular}{|c|c|}
\hline CAA & Clean Air Act \\
\hline CAFEE & Center of Alternate Fuels Engines and Emissions \\
\hline CARB & California Air Resource Board \\
\hline CFR & Code of Federal \\
\hline CLD & Chemiluminescence \\
\hline $\mathrm{CO}$ & Carbon Monoxide \\
\hline $\mathrm{CO}_{2}$ & Carbon dioxide \\
\hline DOC & Diesel Oxidation Catalyst \\
\hline DOJ & Department of Justice \\
\hline DPF & Diesel Particulate Filter \\
\hline ECU & Engine Control Unit \\
\hline EGR & Exhaust Gas Recirculation \\
\hline EPA & Environmental Protection Agency \\
\hline EU & European Union \\
\hline FID & Flame Ionization \\
\hline FTP & Federal Test Procedure \\
\hline GPS & Global Positioning System \\
\hline GVWR & Gross Vehicle Weight Rating \\
\hline $\mathrm{HC}$ & Hydrocarbons \\
\hline HDD & Heavy Duty Diesel \\
\hline HDDE & Heavy Duty Diesel Engine \\
\hline HDDV & Heavy Duty Diesel Vehicles \\
\hline HDIUT & Heavy Duty In-Use Testing \\
\hline KG & Kilograms \\
\hline KM & Kilometers \\
\hline NCEM & NTK Compact Emissions Meter \\
\hline NDIR & Non Dispersive Infrared Detection \\
\hline NO & Nitric Oxide \\
\hline $\mathrm{NO}_{2}$ & Nitrogen Dioxide \\
\hline $\mathrm{NO}_{\mathrm{x}}$ & Oxides of Nitrogen \\
\hline NTE & Not-To-Exceed \\
\hline $\mathrm{O}_{2}$ & Oxygen \\
\hline OEM & Original Equipment Manufacturers \\
\hline PEMS & Portable Emissions Measurement Systems \\
\hline PM & Particulate Matter \\
\hline PN & Particle Number \\
\hline PPM & Parts Per Million \\
\hline $\mathrm{RDE}$ & Real Driving Emissions \\
\hline SCR & Selective Catalytic Reduction \\
\hline THC & Total Hydrocarbons \\
\hline U.S. EPA & United States Environmental Protection Agency \\
\hline WVU & West Virginia University \\
\hline
\end{tabular}




\section{Introduction and Objectives}

\subsection{Introduction}

Diesel engines produce exhaust emissions that are detrimental to the environment. The United States Environmental Protection Agency has enacted strict regulations to decrease these harmful emissions. These strict regulations have influenced engine manufacturers to use after treatment systems to reduce emissions. In addition to these strict emissions standards, the regulations for heavy-duty vehicles also require in-use emissions testing with portable emissions measurement systems (PEMS). PEMS give engine manufacturers and research corporations a tool to examine emissions from these diesel engines while operating in the real world. Now researchers and engine manufacturers are burdened with the task of testing large truck fleets. The need for a more compact and portable emissions measurement tool is necessary.

\subsection{Objective}

The objective of this study was to compare the oxides of nitrogen $\left(\mathrm{NO}_{\mathrm{x}}\right)$ and particle number (PN) measured by the NTK compact emissions meter (NCEM); and the Horiba OBS-ONE. The accuracy measured by the sensors attached to the NCEM were compared to the analyzers attached to the Horiba OBS-ONE. This accuracy and repeatability would then be used to determine if the NCEM could be used as a tool to determine compliance with emissions standards. 


\section{Background Knowledge}

\subsection{Portable Emissions Measurement Systems}

PEMS were invented to compare real-world driving emissions to laboratory based engine dynamometer emissions for heavy-duty engines. PEMS are compact enough install in the back of automobiles and truck cabs, however they provide accurate means to demonstrate compliance with emission standards. PEMS units are very important for their major role in emissions research and regulations certification [1]. They bring a different aspect to emissions testing that dynamometer and stationary equipment do not allow. Laboratory based emissions measurement systems use a dynamometer that allows for alike testing, if a certain testing program is used. PEMS allow for the use of emissions testing equipment during real-time driving conditions [2]. These conditions can vary in ever changing traffic conditions such as, urban, rural, highway routes. Geographic changes can be observed by terrain changes that vary from mountain terrain, to flat land. Even weather conditions can be factored into real driving conditions. PEMS have the ability to measure a much wider variety of gases and compounds when compared to other compact measurement systems, such as the NCEM. Many PEMS have the capability to measure particulate matter (PM), particle number (PN), carbon monoxide (CO), carbon dioxide $\left(\mathrm{CO}_{2}\right)$, total hydrocarbons (THC), and oxides of nitrogen $\left(\mathrm{NO}_{\mathrm{x}}\right)$ [3]. They have the capability to record air-to fuel ratio, exhaust flow rate, atmospheric temperature, humidity, pressure, and location using global positioning systems (GPS) [3]. These units have a few disadvantages, the first being the upfront investment associated with purchasing a PEMS. Another disadvantage associated with PEMS is the amount of support equipment needed in order to operate them correctly. This support equipment is large gas bottles which are needed for zero span checks. Another disadvantage with PEMS units is the required setup times and subsequent downtime of the vehicle. A benefit associated with PEMS is the ability to measure real-time emissions data with laboratory accuracy. Another benefit to the newer PEMS is that they have the ability to have an optional On Board Diagnostic (OBD) interface unit [1]. This allows for PEMS to be able to record data from the engine 
control unit (ECU) attached to the vehicle. This allows for an easier user-interface and more options when it comes to analyzing data.

\subsection{Particulate Matter}

Particulate Matter (PM), is a mixture of emission particles that are present in the air, they are detrimental to the human health. These particles are found in many different sizes, and can be composed of thousands of different chemicals and compounds [4]. This is one of the most harmful diesel emissions. Most of these particles react with one another in the atmosphere; some examples of these are a product of chemicals such as oxides of nitrogen, and oxides of sulfur [4]. These are mainly emitted from industry facilities, and engine powered vehicle such as automobiles, heavy-duty trucks, and marine vessels. When compared to other fuel engines, diesel has always had relatively the highest of PM emissions [5]. That is the cause for the massive push to check and reduce diesel emissions.

Particle matter can be split into two size categories; the larger category is composed of particles generally 10 micrometers and smaller in diameter [4]. This is referred to PM10. The smaller of the two categories is the finer particles that are generally 2.5 micrometers and smaller in diameter [4]. They are labeled as PM2.5. These particles are inhalable by human beings, they are the most dangerous to human beings because they remain deep in your respiratory system, and have the possibility to enter the bloodstream [4]. While in the United States of America, we have become more worried with how these have been redirected through the introduction that occurred in 1997 when new air quality standards were introduced [6]. These new standards only are for elements or particles that are smaller than $2.5 \mu \mathrm{m}(\mathrm{PM})$ and with the new standards for elements and particles that are below 10 $\mu \mathrm{m}$ (PM). They are responsible for the air pollution that causes reduced visibility [7].

\subsection{Particle Number}

One of the emission parameters investigated in this study was PN. PN has been gaining attention due to its ability to characterize harmful emissions even further. PN is based on the amount of particles instead of the mass of the particulate matter (PM). The measurement is recorded by number of particles per volumetric flow rate. The most 
commonly used label is number of particles per cubic centimeters $\left(\frac{\#}{\mathrm{~cm}^{3}}\right)$. This measurement quality is used to better understand the solid emissions [7]. PN emissions can be increased by a variety of different factors. The $\mathrm{PN}$ is increased in the exhaust when the in-cylinder temperatures are reduced. This results in a higher formation of soot, which is PM but affects PN [7]. Diesel particulate filters (DPF) are used to filter out the soot particles. They can be composed of thousands of different chemicals and compounds [8]. The emissions particles can be large enough for the human eye to see, but it most cases can be microscopic [9]. The health effects of the small fine particles have the potential to be much more harmful then the larger ones, due to the fact of the particles being so fine that they are able to basically slip pass the human body’s respiratory system filtration. The European Union (EU) in recent years has introduced emissions limits for PN. A PN dimension method is established by the platform that was implemented for the basis for the EU particle number emission restrictions [10]. They have seen great inconsistences, due to a variation in testing and measurement strategies. The EU has a calculated protocol that requires for reliable classification of the PN limits, these limits were then adopted by the EU PN emission regulations [10]. The United States Environmental Protection Agency (EPA) has yet to follow suit on regulations based on PN for emission limits [9]. The EPA has enforced strict emissions limits on the PM emissions, the current limit is 0.01 grams per brake horsepower - hour (g/bhp-hr), but there is no PN emissions limit in current use.

\subsection{Oxides of Nitrogen}

One of the other major exhaust species, Oxides of Nitrogen (NOx), was investigated in this study. $\mathrm{NO}_{\mathrm{x}}$ is a common term used to cover a wide variety of gaseous emissions. The $\mathrm{NO}_{\mathrm{x}}$ compounds are nitrous oxide $\left(\mathrm{N}_{2} \mathrm{O}\right)$, nitric oxide $(\mathrm{NO})$, dinitrogen dioxide $\left(\mathrm{N}_{2} \mathrm{O}_{2}\right)$, dinitrogen trioxide $\left(\mathrm{N}_{2} \mathrm{O}_{3}\right)$, nitrogen dioxide $\left(\mathrm{NO}_{2}\right)$, dinitrogen tetroxide $\left(\mathrm{N}_{2} \mathrm{O}_{4}\right)$, and dinitrogen pentoxide $\left(\mathrm{N}_{2} \mathrm{O}_{5}\right)$ [11]. $\mathrm{NO}_{\mathrm{x}}$ is considered as one of the major emissions gases that flow out of internal combustion engines [12]. They are responsible for a large portion of smog development in the earth's atmosphere [13]. Higher $\mathrm{NO}_{\mathrm{x}}$ concentrations are formed from a variety of causes. The vehicle is equipped with aftertreatment systems that limit and reduce the amount of $\mathrm{NO}_{\mathrm{x}}$. The after treatment system that aids in the reduction of $\mathrm{NO}_{\mathrm{x}}$ is the selective reduction catalyst (SCR). The SCR is 
responsible for reducing the $\mathrm{NO}_{\mathrm{x}}$ levels by injecting a urea solution into the exhaust stream. The urea when heated turns into ammonia $\left(\mathrm{NH}_{3}\right)$. This urea starts a chemical reaction which transforms $\mathrm{NO}_{\mathrm{x}}$ into $\mathrm{N}_{2}$, water $\left(\mathrm{H}_{2} \mathrm{O}\right)$, and trace amounts of carbon dioxide $\left(\mathrm{CO}_{2}\right)$. The issue with the SCR is that there is a residual amount of $\mathrm{NH}_{3}$ remaining in the exhaust. This amount of unreacted $\mathrm{NH}_{3}$ can result in what is consider $\mathrm{NH}_{3}$ slip. $\mathrm{NH}_{3}$ slip is the result of an incomplete chemical reaction between the $\mathrm{NO}_{x}$ particles, and the $\mathrm{NH}_{3}$ [11]. This causes an amount of unreacted $\mathrm{NH}_{3}$ to proceed through the exhaust downstream. $\mathrm{NH}_{3}$ could form into ammonium sulfates, and these can corrode, or hinder after treatment compounds downstream [11]. Another issue is that the potential for emissions of $\mathrm{NH}_{3}$ gases is always possible. 


\section{Literature Review}

\subsection{Regulation History}

The first federal legislation that enacted research on air pollution was the Air Pollution Control Act of 1955. This act increased funding for research into air pollution. The act also funded the discovery of sources of air pollution [6]. The Clean Air Act of 1963 was introduced to limit the amount of air pollution in the United States of America. The act was effective at providing research to monitor and minimize the amount of pollution in the air. In 1967 the United States Congress enacted the Air Quality movement. This act's sole purpose was to provide more in-depth research on emission control techniques. That same year the state of California was the very first state to enforce vehicle emissions. In 1970 Congress passed another more stringent Clean Air Act, this act gave the Environmental Protection Agency the power to regulate emissions from a large majority of vehicles [6]. The National Emission Standards for Hazardous Air Pollutants was established as well because of the 1970 CAA [6]. In 1974 federal regulations on heavyduty emissions began in the United States [6]. In 1977 Amendments were added to the Clean Air Act of 1970, these amendments included revising some areas of the National Ambient Air Quality Standards [6]. The latest amendments to the Clean Air Act of 1970, was the most recent which were established in 1990. These amendments included increase monitoring and emissions enforcement. It created a program to establish control techniques of 189 toxic pollutants [6]. The Clean Air Act was proposed to regulate the levels of vehicle emissions. In the 1990s the EPA discovered that many heavy-duty diesel manufacturers were using computer programs to conceal elevated engine emissions. The engine manufacturers who were involved represented over "95\%" of the HD diesel engine market [14]. This resulted in a large amount of imposed regulations on these engine manufacturers. One of the regulations was that these engines had to meet a certain emission standard during in-use operation. It also introduced the need for PEMS. 


\subsection{Current Emissions Standards in the United States}

The US and California have various emissions standards for compression ignition engines that are used in heavy duty vehicles. These standards apply to all compression ignition engines, including dual fuel diesel, natural gas, and other compression ignition fuels. For the United States and the state of California, heavy duty diesel vehicles are not required to be chassis certified. They only require the engines to be certified. These certifications include basic standards that are listed as specific tests that were performed and the emission levels based on g/bhp*hr. A PEMS units is used to collect gaseous and particulate matter emissions to perform this compliance test. The method is based on the engine operating within set boundaries of a control area which is on the engine map. Certain engine and after treatment boundary conditions are set as the lower threshold in order to consider a valid NTE data point. Another stipulation to make sure the event is a valid NTE test is that the engine operation must have a duration of greater than or equal to 30 seconds. In order for the engine to pass the compliance test the vehicle pass ratio must be greater than or equal to 0.90 [15]-[17]. The current federal standard for PM emissions from heavyduty engines is $0.01 \mathrm{~g} / \mathrm{bhp}-\mathrm{hr}$, and $0.20 \mathrm{~g} / \mathrm{bhp} * \mathrm{hr}$ for $\mathrm{NO}_{\mathrm{x}}$ emissions. The EPA also require diesel fuel standards that limit the amount of sulfur content allowable in the fuel. The current sulfur content limit is 15 ppm. The EPA regulates sulfur content in diesel fuel in way to combat sulfur oxides $\left(\mathrm{SO}_{\mathrm{x}}\right)$, which are a health concern for humans and the environment.

\subsection{Real Driving Emissions Requirements}

The requirements for RDE tests are as follows, the data acquisition device must record at minimum of 1 hertz[18]. The percentage of the total divided trip distance is 34\% urban, 33\% rural, and 33\% highway. The route must be continuous, no breaks. The speed thresholds are urban must be less than $60 \mathrm{~km} / \mathrm{h}$, the rural must be between $60-90 \mathrm{~km} / \mathrm{h}$, and the highway must be greater than $90 \mathrm{~km} / \mathrm{h}[18]$. The maximum vehicle speed achieved during the test route is $145 \mathrm{~km} / \mathrm{h}$. The average urban speed that must include stops are traffic signals, must be between $15-30 \mathrm{~km} / \mathrm{h}$. When the vehicle approaches to a complete stop, it must be less than $1 \mathrm{~km} / \mathrm{h}$. All urban stops must add up to at least $10 \%$ of the time of 
the urban portion of the test route[18]. The urban portion must contain stop portions that have a time duration of at least 10 seconds or longer. The highway speed must have a 5minute time duration where the speed is greater than $110 \mathrm{~km} / \mathrm{h}$. The entire route must be between 90-120 minutes in duration. The elevation change between the start and end point must be less than $100 \mathrm{~m}$. The minimum total distance of each single mode must be greater than $16 \mathrm{~km}$. The vehicle speed must be compared between the ECU and the GPS unit on the PEMS unit. The test route can not include any off-road portions, and must be performed during a single workday[18]. Combing data to 'fill-in' missing data from a different route is not allowed, and cold start must be recorded but dissuaded during emissions data analysis. All of these rules are combined from information from a variety of sources, all combined in source [18].

\subsection{University of California, Riverside PEMS Comparison}

In recent years PEMS has been used to measure emissions from light duty, heavy duty and construction vehicles [19]. The goal of using PEMS is to reproduce functioning of equipment used in the laboratory. PEMS that are fully 1065 complaint consist of companies such as AVL, Horiba, and Sensors Inc. The 1065 compliant PEMS units are boxy, bulky and very costly. The 1065 compliant PEMS components are also very multifaceted to use during the set up and operation of the components [19]. There has been a stress on the necessity to collect "in-use emissions from a wider range of operating vehicles” in the past few years [19]. In recent years’ people have become more interested in mini PEMS because they are cost effective, smaller and still deliver dependable emissions amounts. Mini PEMS can be used by the government agencies, engine and vehicle manufactures so that they can recognize any matters that can potentially be bad. Yang et al. found that Maha established a "PEMS that can measure $\mathrm{NO}_{\mathrm{x}}, \mathrm{CO}_{2}$, and $\mathrm{PM}$ " [19]. A few other manufactures have also established PEMS units that are reliable as well.

The goal of this study was to relate the 1065 compliant PEMS and a current generation mini PEMS that were both mounted onto a 2012 Chevrolet Silverado 2500HD Duramax. The Chevrolet Silverado was re-fueled at the same service station throughout the study. They drove the Chevrolet Silverado for two days and used three different driving routes in Los Angeles, California. The three driving routes represent highway, local and 
downtown driving in Los Angeles, California [19]. The mini PEMS used in the Yang et al. study was an NTK NCEM which measures PN, $\mathrm{NO}_{\mathrm{x}}, \mathrm{O}_{2}, \mathrm{PM}$ mass as well as Air/fuel ratio [19]. The NCEM model has direct sensors that measure instead of dilution sampling. This results in having no time delay and the receptiveness can be measured in real-time. The system can be set up in about less than 10 minutes, and weighs about $12 \mathrm{~kg}$. The unit can be powered through a DC12/24 V battery for a vehicle [19]. The $\mathrm{NO}_{\mathrm{x}}$ sensor will identify $\mathrm{NO}_{\mathrm{x}}$ through the capacity of $\mathrm{O} 2$ ions by the disconnection of $\mathrm{NO}_{\mathrm{x}}$ in the $\mathrm{N}_{2}$ and $\mathrm{O}_{2}$ detection chamber. This was intended to trap the layer before the gases are able to spread to the detection lot of the component [19]. The results that the University of California compiled are somewhat close, within 3 percent for the highway and LA downtown test routes. This was for the $\mathrm{NO}_{\mathrm{x}}$ emissions for both machines, the A.V.L. MOVE and the NCEM emissions meter. The other routes which included the local and the idle/creep were relatively higher. These routes results were within $10 \%$ of each other. For the Total PM results, the faired rather large in percent difference. When compared to the results between the two machines, the differences ranged from $-31 \%$ to $109 \%$. The highest being the LA downtown route. For the PN emissions, the results again were slightly different, the emissions meter machine was slightly higher than that of the 1065 Complaint machine across all speed variations. The University of California Riverside was able to come to the conclusion that while the NCEM was able to read relatively close number when compared to the 1065 compliant, it still should only be used for screening tool, or a monitoring tool. The 1065 compliant machine was much more accurate in all tests, when compared to that of the emissions meter. The local route $\mathrm{NO}_{\mathrm{x}}$ readings for the emissions meter and the 1065 complaint respectively is $4.44 \mathrm{~g} / \mathrm{mi}$ for the emissions meter and 4.07 for the 1065 complaint. That is recordings for the local routes, this route represented the second largest percent difference in $\mathrm{NO}_{\mathrm{x}}$ readings at a percent (\%) of 9.20. The highway and LA downtown test routes showed much lower percent differences, with the highway average being $-2.90 \%$ and the LA downtown being $2.70 \%$. The greatest percent difference was recording on the idle and creep test, which represented a reading of $-9.40 \%$. Some of the error that might have been there is that the UCER only performed one of those tests, so the sample size was small. The Local average total PM for the emissions meter unit was $0.18 \mathrm{mg} / \mathrm{mi}$, and for the 1065 complaint unit was 0.25 , this resulted in a $-31.10 \%$ difference. The Highway total pm 
recording resulted in a slightly less percent difference, reading -17.20 percent. The LA downtown total pm had the highest percent difference, coming in at $109 \%$. And the idle and creep reported a total pm percent difference of $-24.30 \%$. The PN results for the local test average are as followed, $8.49 \times 10^{11}$ \# per mile for the mini PEMS, and $4.81 \times 10^{10}$ \# per mile for the 1065 complaint. This resulted in a percent difference of 178.5553 percent. The results for the highway average are $4.82 \times 10^{11}$ \# per mile for the mini PEMS, and the 1065 complaint PEMS recording $2.77 \times 10^{10}$ \# per mile. These averages resulted in a percent difference of $199.77 \%$. The LA downtown resulted in an average of $2.11 \times 10^{12} \#$ per mile for the mini PEMS, and $3.76 \times 10^{10}$ \# per mile for the 1065 complaint machine. These values resulted in a percent difference of $193.26 \%$. The last test route, which was the idle and creep, recorded the following values. The emissions meter had a result of $3.87 \times 10^{12}$ \# per mile, and 7.62x $10^{10}$ \# per mile for the 1065 complaint PEMS unit. The difference between the study conducted by University of California and the study in this paper is the vehicles used, the data analysis, and the routes in which the study were conducted.

\subsection{Comparison of PEMS with Laboratory Grade Equipment}

In Europe, the European Union created a list of emission limits for all new vehicles being produced. These emission limits have defined what adequate limits are to be considered for those vehicles being produced and sold. Such pollutants of these standards are $\mathrm{CO}, \mathrm{HC}, \mathrm{NO}_{\mathrm{x}}$, particle matter, and particle number [20]. Researchers had to verify the validity of compliance through various procedures to ensure certification standards. These certification standards include performance driving routes that have been attached to a chassis dynamometer in a meticulous laboratory where research can be conducted [20]. In the European Union they created the new Worldwide Harmonized Light Vehicle Test Procedure in which they base the driving standards of collection of emissions on real driving situations. The PEMS must include portable analyzers, exhaust mass flow meters (EFM), weather station, and a GPS [20]. The European Union (EU) also regulates the trip requirements for testing, for example the maximum and minimum length of trip, distance, speed, boundary conditions, altitude (maximums and minimums) as well as [20]. Conditions must also include in the real driving situations urban, suburban, rural and highway types of driving conditions. The measurements of PEMS have improved over the 
years and will continue to rise in the coming years for the European Union's regulations [20]. These PEMS units are very robust and reliable to use on vehicles that are driven on roads [20]. In a study that was conducted by the Joint Research Centre (JRC) they found areas of uncertainty in the exhaust flow meter, gas analyzers and drift. Since that research was collected they created a conformity factor which only allows a certain amount of the maximum emission levels of all vehicles on the roads today. That study even compared PEMS with some laboratory equipment during a test to assure that the proper setup and configurations were correct [20]. Varella, et. al found that very few studies have been conducted on the differences of PEMS and laboratory equipment [20]. The two PEMS units were compared to laboratory size analyzers, some were connected to tailpipe, some situations a dilution tunnel was used, and some were bagged emissions. For the tailpipe emissions, the $\mathrm{NO}_{\mathrm{x}}$ emissions measured from the PEMS units were within $5 \%$ for 20ppm and higher levels of concentration. The lower the concentrations went the higher the percent error rose. For 7 ppm, the error percent was 15\%, and they recorded measurements as low as $1 \mathrm{ppm}$, and it had a corresponding percent error of $30 \%$. These results show that current PEMS units have the ability to provide portability with good accuracy when compared to a lab based unit [20]. The study conducted by Roberto, and colleagues, was conducted on two light duty vehicles, one which was compression ignition, and the other spark ignited. This study was based on comparing various PEMS units to laboratory-based equipment. The study in this paper, was based on comparing one of the units used by Roberto to a new NCEM PEMS unit.

\subsection{Experiences and Results with different PEMS}

The vehicle that was used for research by Czerwinski, Zimmerli, Comte, and Bütler was a rented 2014 Seat Leon 1.4 TSI with approximately 20,800 kilometers (km) on it. When testing the vehicle the driver drove about 2,000 km [18]. Summer gasoline was used from the Swiss Marker, with no change in the lube oil. Some of the tests that were run by Czerwinksi, et al. were accomplished using a 4WD-chassis dynamometer [18]. The controlled variable is the dilution ratio from the CVS-dilution tunnel, and it is controlled by the $\mathrm{CO}_{2}$ analysis [18]. From the tests that were completed on the test vehicle, the researchers were able to know that the OBM Mark IV has no flowmeter for the 
measurement of the exhaust flow. This is allowed because it can calculate from the onboard data, which makes it more easy to use and adapts better to the vehicle [18]. Czerwinksi, et al. performed three tests that were used on a chassis dynamometer. In the first round of tests each was completed with a cold start of 20-25 degrees $C$ the second round of tests were completed with a warm engine start. Each route has at least 3 minutes

of constant speed going $80 \mathrm{~km} / \mathrm{h}$ while being in $4^{\text {th }}$ gear [18]. Several types of road were used for testing with each test lasting for 1 hour on roads such as urban, rural and highways. The RDE routes used in this study all met the requirements for Euro 6c regulations. In conclusion, the PEMS units that were used recorded greater $\mathrm{CO}_{2}$ data than that of the laboratory grade equipment. The $\mathrm{NO}_{\mathrm{x}}$ that was measured had great differences present between the units.

\section{7 $\mathrm{NO}_{\mathrm{x}}$ Sensors Cross Sensitivity}

According to Frobert, Raux, Yann and Jeudy here is a need to decrease the amount of greenhouse gases that escape into the atmosphere as well as constraint the amount of local pollutants that escape [21]. New technologies have been created to combat these harmful effects to our environment through using newer internal combustion engine developments [21]. These new technologies include having direct high-pressure injections, variable valve timing, actuation as well as advanced exhaust gas recirculation and more efficient after treatment systems. While using these features one must have absolute and accurate control on diagnosis strategies [21]. According to Frobert et al. when using $\mathrm{NO}_{\mathrm{x}}$ after treatment with the selective catalytic reduction for using lean engines it is obligatory that at least one $\mathrm{NO}_{\mathrm{x}}$ sensor when doing the control and analysis. NOx sensors were created from zirconia-based potentiometric oxygen sensors. This type of sensor has a double cavity and mixed potential [21]. One disadvantage is that it is an issue to distinguish the dissimilar apparatuses of gas mixtures. Although, planar potentiometric sensors are currently being developed. These sensors are much more modest and delicate for temperature differences and exhaust gas flow changes [21].

According to Frobert, et al. NGK recently created their own technology, which includes amperometric sensors that have multi-electrodes in the system. Each of these are divided into three cavities which the first references the contact with the air, the second, 
measures the cavity that has been developed for $\mathrm{O}_{2}$ sensors, and the third, allows a second cavity to be developed for $\mathrm{O}_{2}$ removal and $\mathrm{NO}$ sensors [21]. According to Frobert et al. the declines that are left are then transformed in the dispersal barrier, which are then found around the exhaust gas and first cavity. In this section the $\mathrm{NO}_{2}$ is theoretically, to be altered to NO in the first and second cavities. Afterwards the NO is then theoretically to be decreased while in the second cavity when the $\mathrm{O}_{2}$ - is being thrusted out [21]. During this phase the $\mathrm{NO}_{\mathrm{x}}$ sensor can be utilized as an ammonia sensor. This allows for device feedback when relating to a $\mathrm{NO}_{\mathrm{x}}$ approximation. While the ammonia is supposed to be oxidized when in the first cavity due to an advanced functioning temperature of $>600{ }^{\circ} \mathrm{C}$ and the reacting properties of the zirconia [21].

According to Frobert et al. the all tests that have been executed with sensors come from the same generation and have related histories. The tests also include diesel engine with a diesel particulate filter free exhaust line with approximately 200 hours on it. There is also no aging or poisoning because it is a brand-new system being used [21].

Frobert et al. found that when considering the exhaust gas temperature, it is often the first thing that is studied. The furnace temperature consists of having three different sensors with temperature differences. The temperature differences consist of 150, 250, and $350{ }^{\circ} \mathrm{C}$. When each temperature is tested it has 5 concentrations of $\mathrm{NO}$ or $\mathrm{NO}_{2}$ that are being tested as well. Ammonia can somewhat have an influence on the gas temperature, especially at $150{ }^{\circ} \mathrm{C}[21]$. Higher gas temperatures were needed for the tests completed by Frobert et al. because the sensor requires higher temperatures for the furnace to work [21]. For the experiments conducted with Frobert et al. they used petite reply times, snappy accurateness and robust reliability [21].

The $\mathrm{NO}_{\mathrm{x}}$ sensor can be seen to record a value from 5 to $15 \%$ greater when vaporized water is introduced into the gas mixture [21]. The value associated with a $\mathrm{NO}_{\mathrm{x}}$ sensor is typically 15 to $20 \%$ lower than that what would be recorded by a CLD technology unit. When adding $\mathrm{NH}_{3}$ into the mixture gas the $\mathrm{NO}_{\mathrm{x}}$ sensor shows to be extremely sensitive to the $\mathrm{NH}_{3}$ amount [21]. In today's society, $\mathrm{NO}_{\mathrm{x}}$ sensors are an important part of life for exhaust systems. The research has shown that $\mathrm{NO}_{\mathrm{x}}$ has allowed for less $\mathrm{NO}_{2}$ to be released because of the NO being released into the two cavities. Exhaust gases have had a 
significant impact on water and oxygen as they relate to $\mathrm{NO}_{\mathrm{x}}$ measurement [21]. When the circumstances are great with the impact of $\mathrm{H}_{2} \mathrm{O}$ and $\mathrm{O}_{2}$, the impact is much lower for ethanol, aldehydes, and NO. Of course an perfect number is required to obtain for the $\mathrm{NO}_{\mathrm{x}}$ and $\mathrm{NH}_{3}$ [21].

\subsection{Influence of Altitude on $\mathrm{NO}_{\mathrm{x}}$ Concentration Levels}

China has various areas of plains and mountains which include a wide variety of altitude variations. Some altitudes are as high as 2,000 meters and as low as 1,000 meters [22]. The temperature variations also fluctuate in the above plains and mountains as well as the $\mathrm{O}_{2}$ content. The air intake differs as well as the air-fuel ratio which allows for alterations to occur in the cylinders and fuel consumption [22]. The altitude is taken into account when PEMS is being tested. During this process the highest altitude allowed for testing is 2,400 meters. The OBD and PEMS are great methods to use in RDE testing situations [22]. The OBD detection allows for the sensors to be monitored so that the driver can be aware of the status of the equipment during testing [22]. A signal will light up to show any malfunctions that could allow for high emissions to be collected. These OBD ideas are being used in the United States, EU, China, India, and Brazil [22]. In this current study the primary focus has been on the altitude and temperature of when doing RDE in higher altitudes. This study also collects $\mathrm{NO}_{\mathrm{x}}$, fuel, and how the vehicle operates during $\mathrm{RDE}$ while also testing the OBD. This also allows for comparison between the test vehicles based on specific formulas [22].

The study used three diesel trucks that were equipped with OBD and was tested during an RDE route. Each of the vehicles were the same make and model. The mileage was approximately less than $110,000 \mathrm{~km}$ on them [22]. The $\mathrm{NO}_{\mathrm{x}}$ emissions and fuel consumption during the tests were measured at various speeds. The trucks were listed as A, B, and C. The benchmark was set to be Truck B for the analysis of difference [22]. The errors and fuel consumption rates have been within $+-3.5 \%$ between the vehicles. The trucks were set to full load condition during the real driving portion. The cities that were used for testing with the different altitudes were Jinan, Chifeng, and Lhasa [22]. Those altitudes ranged between $<1,000 \mathrm{~m}$ to $4,000 \mathrm{~m}$. The tests that were conducted included altitudes that would normally be found in parts of China [22]. During the testing the 
temperature also played a role. The temperatures that were collected ranged between $-10^{\circ}$ $\mathrm{C} \sim 10^{\circ} \mathrm{C}, 10^{\circ} \mathrm{C}-20^{\circ} \mathrm{C}$ and $20^{\circ} \mathrm{C}-35^{\circ} \mathrm{C}$ [22]. The tests were also completed during the same time frame which was 8:00-17:00 over the course of three days [22]. The conclusions from this study show that altitude has influence on the $\mathrm{NO}_{\mathrm{x}}$ emission rate[22]. For altitudes ranging from 3000- $4000 \mathrm{~m}$ resulted in lower $\mathrm{NO}_{\mathrm{x}}$ emissions[22]. This is because the lower in-cylinder temperatures associated with a decreasing intake air amount[22]. 


\section{Test Route}

The vehicle was tested over a duration of 8 weeks. The tests were conducted through the use of 3 driving routes, a real driving emissions (RDE) route, which included three different types of terrain. The figure 43, located in the appendix, shows a map of the RDE route. The second route was referred to as Tavannes, which was a village in the large mountains. The figure 42, located in the appendix, shows a map of the Tavannes test route. The third route was referred to as Highway loop, this was a flat highway route. The figure 44, located in the appendix, shows a map of the Highway route. The first driving portion of the RDE was designed to replicate urban driving. The second was designed to represent a rural driving, and the third was designed to replicate a highway driving experience. The overall total distance traveled was $95.9 \mathrm{~km}$, with a total test duration of 1 hour, 53 minutes, and 12 seconds. The first driving portion was designed to replicate urban driving. The distance traveled for the first portion was $25.1 \mathrm{~km}$, with an average speed of $27.6 \mathrm{~km} / \mathrm{h}$. The duration of this portion was 54 minutes, and 35 seconds. The second was designed to represent a rural driving, the distance traveled was equal to $35.4 \mathrm{~km}$, with a duration of 33 minutes and 29 seconds. The average speed for the rural portion was $63.4 \mathrm{~km} / \mathrm{h}$. The third was designed to represent a highway driving. The distance traveled was equivalent to 35.3 $\mathrm{km}$, with a duration of 25 minutes and 7 seconds. The average speed of this portion was $84.4 \mathrm{~km} / \mathrm{h}$. The Tavannes route included steep inclines at highway speeds. The Tavannes route had a duration of about 44.8 minutes. The third route, also known as the highway loop included flat highway driving experiences. The entire route was supposed to simulate consist speed, flat terrain. 


\section{Equipment Setup}

The equipment setup included the NTK Compact Emissions Meter, and the Horiba OBS-ONE GS with PN unit. The power system for this setup is two 24-volt deep cycle batteries configured in a parallel circuit. Each pair of batteries lasted about 4 hours per pair. The batteries provided consist uninterrupted power supply for the duration of half the testing day.

\subsection{Horiba OBS-One}

\subsubsection{General System Description}

The PEMS that will be focused on in this study is the Horiba OBS-ONE. This company has been designing and manufacturing vehicle emissions and testing equipment for decades. The Horiba OBS-One is one of the most advanced PEMS available on the market. It can be used in certification of CFR 1065 Regulations, and Euro VI regulations [3]. It has the ability to perform cert testing for PEMS, it can measure $\mathrm{NO}_{\mathrm{x}}, \mathrm{PM}, \mathrm{PN}, \mathrm{CO}$, $\mathrm{CO}_{2}$, and THC. OBS-ONE PM unit is the industry-leading on-board PM measurement system. The Horiba unit included the PN unit, as well as the PM addition. This unit has

specifications listed in the Table 17: Horiba OBS-One Specifications Chart [18] located in the appendix. The OBS-ONE records data at a rate of 10 hertz. This unit is supported as an OBD interface unit. There is a picture of the unit used in testing below in figure 1 . This pictures shows the gaseous emission measurement unit (GS), and the PN measurement unit. 


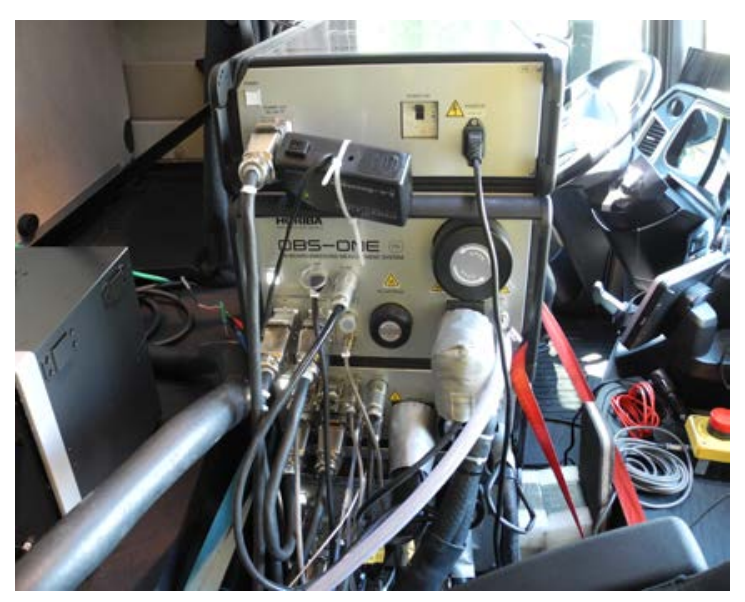

Figure 1: Horiba OBS-ONE

\subsubsection{Measurement Principles}

\subsubsection{Particle Number}

$\mathrm{PN}$ is measured through the use of a condensation particle counter (CPC). The Figure 2: Condensation Particle Counter [24] shows a diagram of how the CPC measures particle number. The emissions particles enter through the inlet, as they proceed through the tube, they increase in size, collected butanol. At the end of the device, a laser, and the photodiode is used to measure the particles. A disadvantage of this measurement principle is since this device particle measurement programme (PMP), it has a size measurement cut off of 23 nanometers [18]. An advantage of this measurement principle is that it conditions the particles as they enter the device. Making it less likely for the emissions to read unrelated substances. For the PN the 23 nanometers to 1000 nanometers, and 0$5 \times 10^{7}$ particles per $\mathrm{cm}^{3}[23]$. 


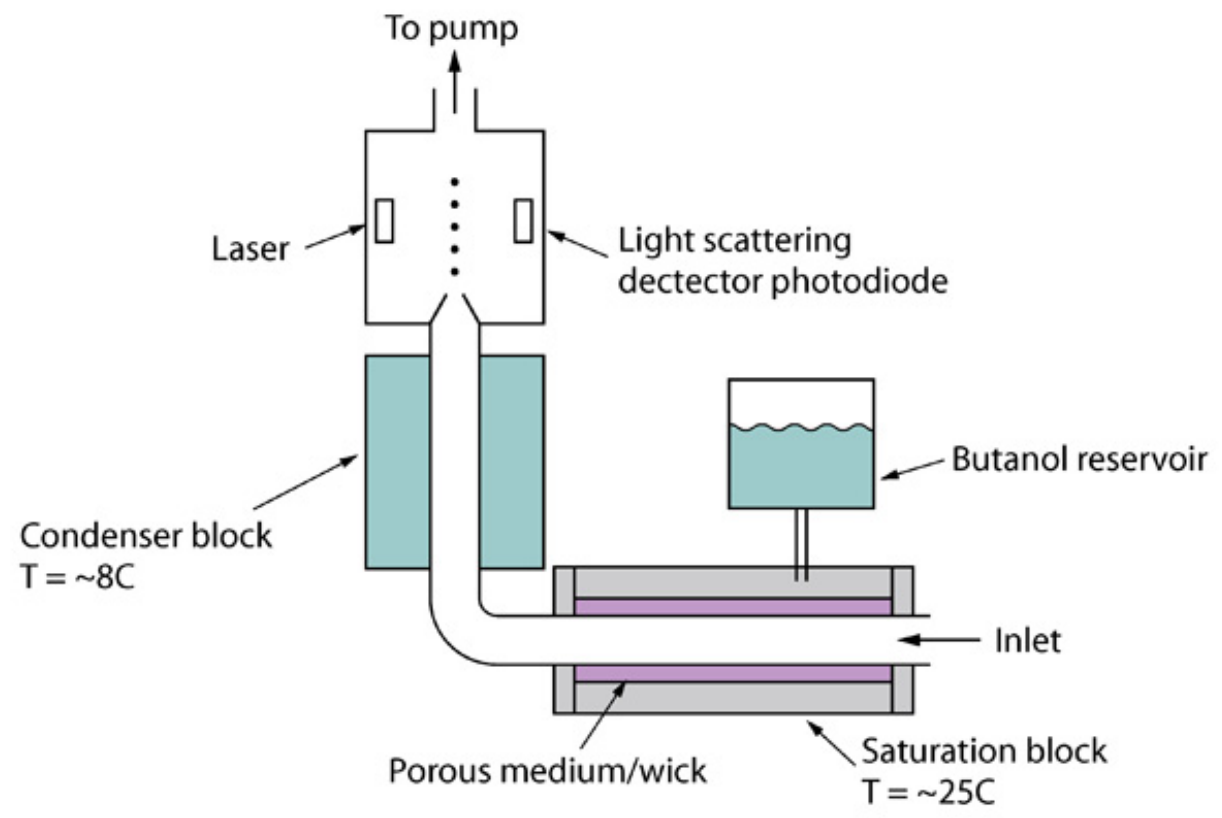

Figure 2: Condensation Particle Counter [24]

\subsubsection{Oxides of Nitrogen}

The OBS-One uses a process called chemiluminescence (CLD) to measure the amount of $\mathrm{NO}_{\mathrm{x}}$ in the emissions. In Figure 3 it shows a diagram of how the measurement tool operates. The CLD detector uses a chemical reaction to aid in the detection of exhaust emissions. The process is known for the emission of light that occurs as a result of a chemical reaction. The reaction that occurs in between NO and ozone particle; when this reaction takes place it produces light [25]. The photons that are produced are used to measure in a photo multiplier tube. The output signal is related to the NO concentration that is present in the emission sample. The total $\mathrm{NO}_{\mathrm{x}}$ can also be measured by a CLD instrument. The sample is sent through a heating element, where the $\mathrm{NO}_{2}$ is exposed to high temperature, then it decomposes to $\mathrm{NO}$ and $\mathrm{O}_{2}$. This entire reaction is incredibly fast, this means that the instrumentation is very sensitive, and responsive. The disadvantage of this measurement type when compared to the direct mount $\mathrm{NO}_{\mathrm{x}}$ sensor found on the NCEM is that the emission gases must travel through a tube to the unit. The range on the sensor is 0-100 to 0-3000 parts per million (PPM). 


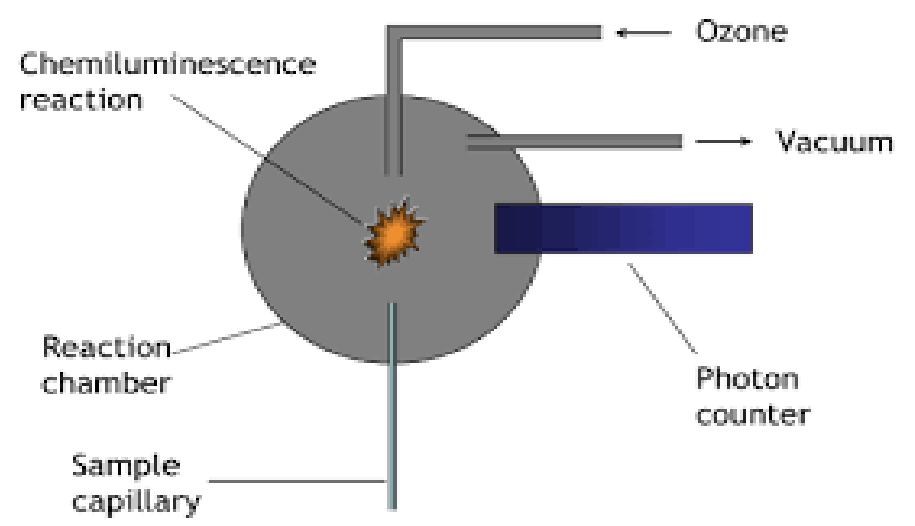

Figure 3: Chemiluminescence Detector[26]

\subsection{NTK Compact Emissions Meter}

\subsubsection{General System Description}

The emissions meter that will be focused on in this study is the NTK Compact Emissions Meter. It is manufacturer by NGK/NTK. This company has been designing and manufacturing sensor and automotive parts for ages. The NCEM is an ultra-portable and simple emissions measurement instrument. It has the ability to measure exhaust gas composition, particularly $\mathrm{NO}_{\mathrm{x}}, \mathrm{O}_{2}, \mathrm{PM}$ and $\mathrm{PN}$. It is different from the OBS-One because it is not capable of certification. Since this inability, the instrument could be considered a meter. It has limited measurement capabilities when compared to the Horiba OBS-One. The NCEM is more useful as an emissions monitoring meter. They have great portability, and the ease of use is second to none. They are very lightweight and very small. They can be used in lab monitoring and real-world driving tests. They also require short wait times, and have a very user-friendly interface. NTK has the ability to operate on vehicle power, and will not greatly load the engine. Currently in addition to the exhaust gases measurement ability they have the ability to measure Air/Fuel Ratio. These emissions meters have the ability to also interface with the OBD-II, and a Global Position Sensor. This is beneficial because the engine data information and sensor data can be sampled simultaneously. The Global Position Sensor is used to track terrain changes and traffic situation. The NCEM is equipped with an on-board LCD screen that displays the real-time measurements. Data can be easily reviewed on computer via NTK software package NCEM viewer. The 
specifications are listed in the chart below. It was equipped with the $\mathrm{NO}_{\mathrm{x}}$ module, and the $\mathrm{PM} / \mathrm{PN}$ module. The NCEM records data at a rate of 1 hertz. In figure 4 below, there is a picture of the NCEM used in this study [27].

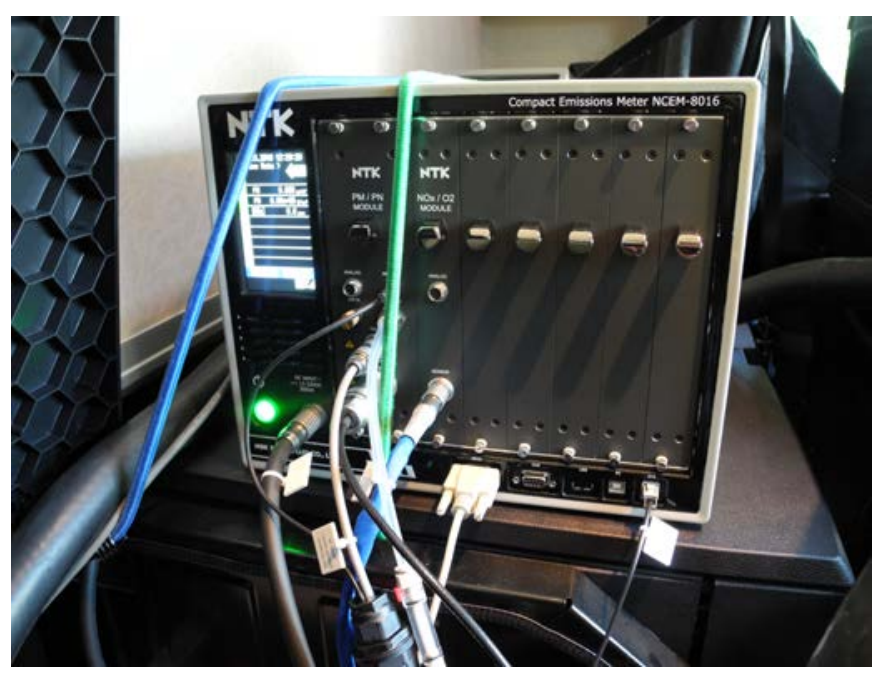

Figure 4: NTK Compact Emissions Meter

\subsubsection{Measurement Principles}

\subsubsection{Particle Number}

NTK compact emissions meter utilizes pipe direct measurement for its PN emissions data collection. It utilizes the same technology found in a Pegasor PPS-M. The Figure 5: NCEM PN Sensor Diagram [28] shows how the sensor operates. The first step is clean air is forced past a positivity charged element, where it becomes a positive charge ion. While this is occurring an emissions sample is introduced, these two specimens interact at the location labeled the ejector throat. At this time, the soot particles and positively charged ions mate. An important thing to note here is the larger the soot particle, the more charge it will pick up. After the positively charged ions attach to the soot particles they are then sent by a positively charged ion trap, this trap is designed to repel unattached ions, so they attach to the negatively charger or grounded shell (green). The soot particles will not attach to either and will proceed out of the chamber. The measurement is calculated by a wire that is attached to the positive charge element at the beginning, and a wire that is attached to the grounded shell. The difference of these two elements result in the amount of soot particles. This method is called escaping current method [21]. A disadvantage 
associated with this measurement method is there is no conditioning of the particles, so this could result in condensed water vapor, or volatile particles being measured. Another disadvantage associated with this principle is that the user must know the size distribution of particles before the test can begin. This ensures that the proper particle size is being analyzed [21]. The range for the PN is 0 to $1.0 \times 10^{8} \# / \mathrm{cm}^{3}$. The PN has the ability to read particle sizes below 23 nanometers.

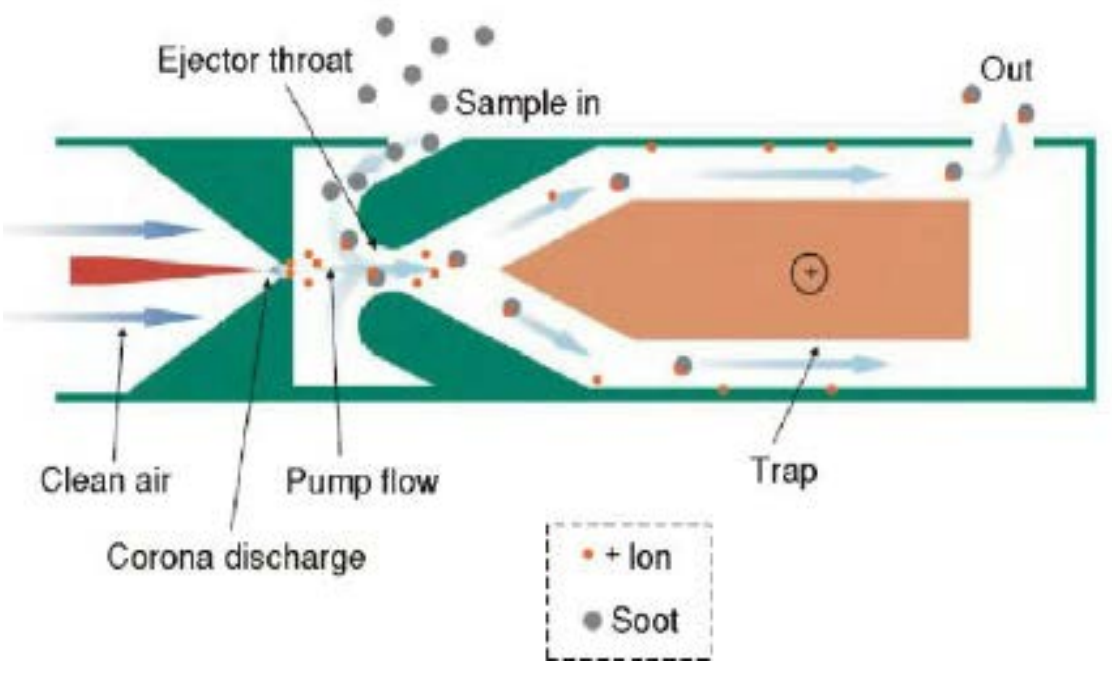

Figure 5: NCEM PN Sensor Diagram [28]

\subsubsection{Oxides of Nitrogen}

The NCEM's sensor feature a zirconium oxide $\left(\mathrm{ZrO}_{2}\right)$ sensor that has the ability to measure oxygen $\left(\mathrm{O}_{2}\right)$ and $\mathrm{NO}_{\mathrm{x}}$. The Figure 6: Zirconium Oxide Sensor Diagram [30] shows a diagram of the sensor. It is equipped with a two chamber design where one chamber is used for each gas measurement [29]. The $\mathrm{ZrO}_{2}$ sensor detects oxides of nitrogen by first measuring ions of $\mathrm{O}_{2}$ that were created by the detachment of $\mathrm{NO}_{x}$ particles into $\mathrm{O}_{2}$ and $\mathrm{N}_{2}$. This reaction and measurement all occurred in the detection chamber. The design utilized for this sensor turns $\mathrm{NO}_{2}$ molecules into $\mathrm{NO}$ and $\mathrm{O}_{2}$ molecules. This process is performed in a layer that traps the gases before they reach the detection portion of the sensor. An advantage seen is that this direct mount sensor is superior in a sense that the gaseous emission is measured directly in the tailpipe. This differs from the OBS in a way that the OBS has tubing that transports the emission sample back to the unit inside of the cab of the vehicle. For $\mathrm{NO}_{\mathrm{x}}$ the NCEM has a range of 0 to $1500 \mathrm{ppm}$. 


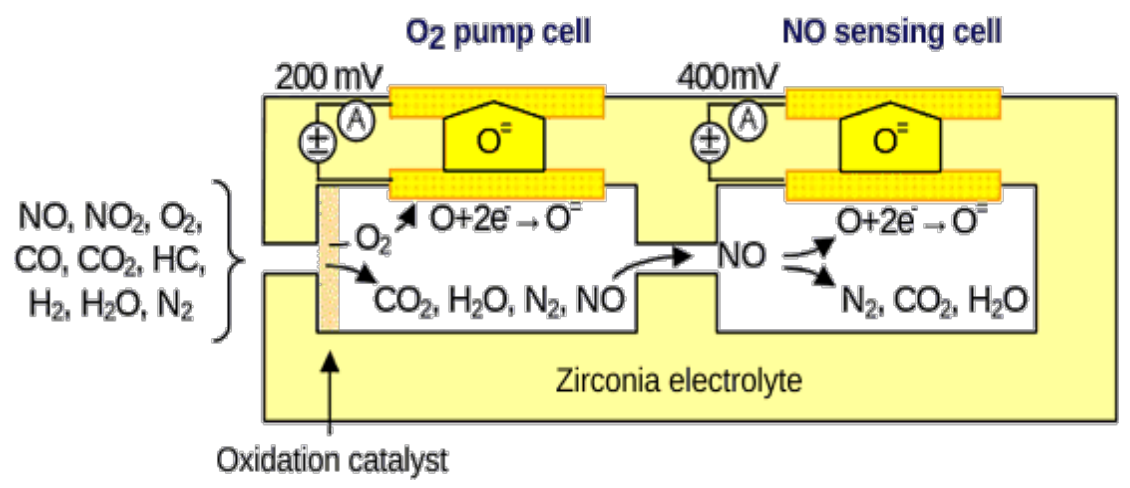

Figure 6: Zirconium Oxide Sensor Diagram [30]

\subsection{Test Vehicle}

The tests were performed on a 2015 Mercedes Benz Actros 1848LS 4X2 F13. This truck is equipped with an inline 6-cylinder engine with a displacement of 12.8 liters. This truck has a power output of 354 kilowatts $(\mathrm{kW})$. It had an odometer reading of 118,000 $\mathrm{km}$. This truck and trailer combination had a combined test weight of 31425 kilograms (kg). This vehicle is equipped with advanced after treatment technologies such as

Exhaust gas recirculation (EGR), diesel oxidation catalyst (DOC), diesel particulate filter (DPF), and a selective catalyst reduction (SCR). The gas sensors, and collection lines were connected to an exhaust tip, the Horiba OBS-ONE and the NTK Compact Emissions Meter was attached simultaneously. Pictures of the truck and exhaust system used in this study can be found in the appendix, Figure 45, Figure 46, and Figure 47. A more in-depth truck specifications of the truck used in this study can be found in the appendix. 


\section{Results and Discussion}

\subsection{Overview of Data}

The Data consisted of three routes, a Real Driving Emissions Route, a highway with elevation terrain, and a highway with flat terrain. The data was analyzed using several different methods. The first method was a raw comparison that compared the $\mathrm{NO}_{\mathrm{x}}$ recorded from the NCEM vs that of the reference unit the Horiba OBS-ONE. Then the Real Driving Emissions route was broken up into 4 portions. The first being the cold start portion which had a duration of 500 seconds. The second being the urban portion which consisted of 25.1 $\mathrm{km}$. The third portion had a duration of time that corresponded to that of $60.5 \mathrm{~km}$. And then the fourth and final was from the $60.5 \mathrm{~km}$ to the end of the route. There were some time deviations between each test route, which was to be expected. After this there was binning of certain ppm levels. The first being the 10 ppm levels, while using the OBS as the reference, the NCEM was recorded and analyzed based on its percent error at certain ppm levels. This also was performed for the $20 \mathrm{ppm}$ levels. The next data set that was analyzed was that from the RDE routes for the PN data. This included a very simple analysis that consisted of a raw data comparison of the NCEM to the reference unit the Horiba OBSOne.

\subsection{Comparison of $\mathrm{NO}_{\mathrm{x}}$ PEMS Data}

\subsubsection{Real Driving Emissions Route - Urban/Rural/Highway Operation}

This section covers the $\mathrm{NO}_{\mathrm{x}}$ emission analysis performed on all three $\mathrm{RDE}$ routes, these routes consisted of four portions. The first portion which had a duration of 500 seconds was considered the cold start portion. The second portion which lasted until the distance traveled reached a value of $25.1 \mathrm{~km}$, this portion was called the urban portion. The third portion which included data from the end of the second portion to a distance of 60.5 $\mathrm{km}$, was considered the rural portion. The last portion of the RDE test route, was called the highway portion it consisted of the data after $60.5 \mathrm{~km}$ had been traveled. Figure 43 in the appendix can be used as a reference. 


\subsubsection{Overall RDE Route $\mathrm{NO}_{\mathrm{x}}$ Emissions Comparison}

The Figure 7 below shows the report data on a raw $\mathrm{NO}_{\mathrm{x}}$ gaseous emissions with the corresponding vehicle speed that was collected for the RDE route 2 from both PEMS units, the red is NCEM, and the blue is the OBS-ONE, and the Green is the vehicle speed. The second $\mathrm{RDE}$ route was used as a visual representation because of the $\mathrm{R}^{2}$ values associated with the regression plots. The route consisted of four different types of driving, the first 500 seconds is considered a cold start simulation, this usually produces high NOx emissions. Next is the urban type of driving environment, this simulates a heavy traffic, stop and go traffic situations. The next portion of the trip consisted of a rural driving simulation. The last portion of the trip the highway portion, produced a low concentration of $\mathrm{NO}_{\mathrm{x}}$. Between the four different test portions, the cold start resulted in the highest, $\mathrm{NO}_{\mathrm{x}}$ concentrations, due to the after-treatment system being cold. The highest value seen in this portion was equal to $632 \mathrm{ppm}$. The next highest level of $\mathrm{NO}_{\mathrm{x}}$ concentrations can be seen during the urban portion; this can be attributed to the stop-n-start traffic situations that resulted in changing load conditions. The highest value seen in the urban portion was equal to $392 \mathrm{ppm}$. The next highest level of $\mathrm{NO}_{\mathrm{x}}$ concentrations seen in this test route was associated with the rural portion, the highest concentration seen in this portion is equal to $267 \mathrm{ppm}$. The lowest concentration of $\mathrm{NO}_{\mathrm{x}}$ seen during this entire test can be associated with the highway portion. The highest concentration seen in this portion is equal to $83 \mathrm{ppm}$. This low concentration of $\mathrm{NO}_{\mathrm{x}}$ can be attributed to a highway speed, and the SCRs' ability to operate at optimum temperatures. 


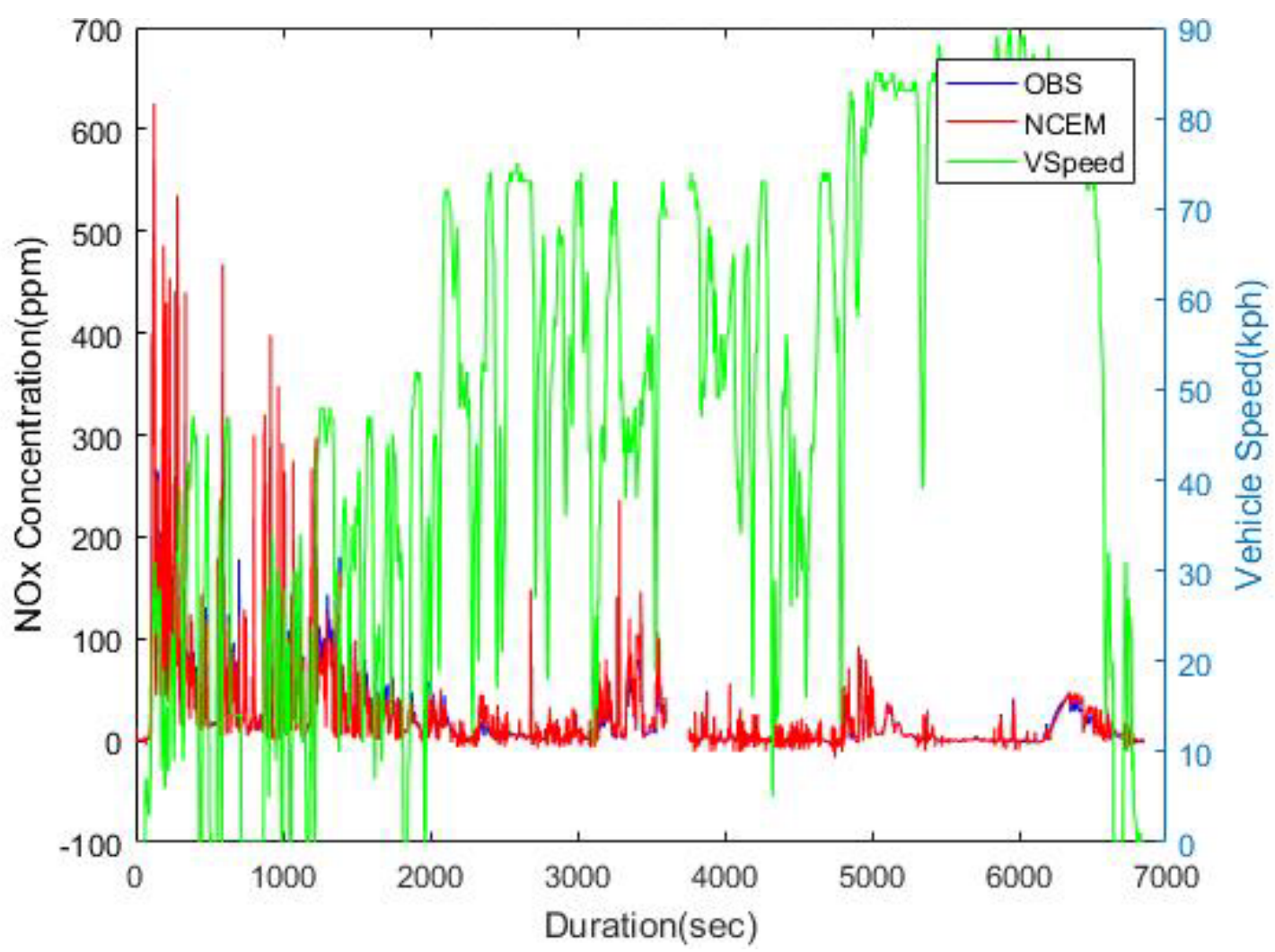

Figure 7: RDE 2 NO$_{x}$ Raw Data with Vehicle Speed

The Figure 8 below shows the report data on a linear regression plot of $\mathrm{NO}_{\mathrm{x}}$ gaseous emissions collected for the RDE trip 2 from both PEMS units. The corresponding $\mathrm{R}^{2}$-value to this linear regression is 0.96742 . This is the second highest $\mathrm{R}^{2}$ value recorded for all three RDE test routes. The lowest being RDE route 1 equal to 0.9524 . And the highest being the RDE 3, which was equal to 0.96865 . An overall trend that can be seen with the linear regression is that at higher $\mathrm{NO}_{\mathrm{x}}$ concentrations, the NCEM measured higher values. In example, the NCEM read a value of 486 ppm, while the OBS read a value of $363.6 \mathrm{ppm}$. Another example while the NCEM measured a value of 535 ppm, OBS read a value of $407.9 \mathrm{ppm}$. For these instances, there is a percentage error equal to $33.66 \%$, and $31.16 \%$, respectively. This might be associated with the different location of the $\mathrm{NO}_{\mathrm{x}}$ measurement equipment. For the NCEM the $\mathrm{NO}_{\mathrm{x}}$ measurement is a direct mount sensor, for the OBS, the gas emission sample must be routed to the unit. 


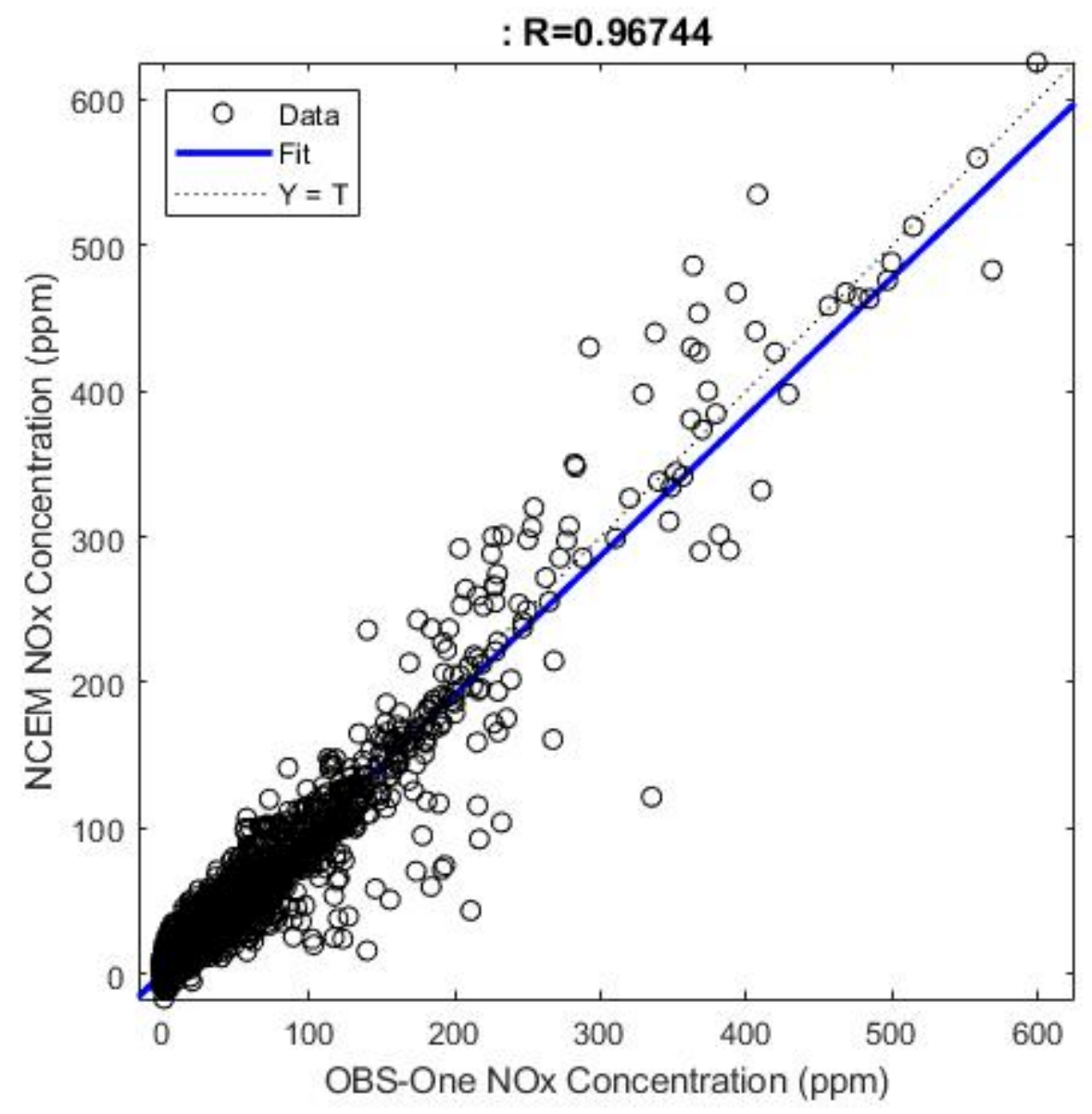

Figure 8: Linear Regression for RDE $2 \mathrm{NO}_{\mathrm{x}}$ Overall

Table 1: Overall RDE NOx $\mathrm{R}^{2}$ Values

\begin{tabular}{|l|l|}
\hline RDE 1 & 0.95444 \\
\hline RDE 2 & 0.96744 \\
\hline RDE 3 & 0.96865 \\
\hline
\end{tabular}

The Figure 9 below shows the report data on a QQ plot of the raw $\mathrm{NO}_{\mathrm{x}}$ gaseous emissions collected for the RDE trip 2 from both PEMS units. The red line is the linear comparison line, the closer the blue marks are to the line they more comparable the data. The Quantile-Quantile (QQ) plot displays the linearity of the two sensors, as the increase 
in $\mathrm{NO}_{\mathrm{x}}$ concentration. Some points at on the graph will show a representation of the data. A QQ plot is a plot that displays the quantiles of one data set to the quantiles of a second data set [31]. At the 100 ppm concentration level, the NCEM measured 93 ppm, while the OBS measured 100.19 ppm. At the 200 ppm concentration level, the NCEM measured 188 ppm, and the OBS measured 199.73 ppm. At the 400 ppm level, the NCEM measured 440 ppm, and the OBS measured 393.28 ppm. At the 600 ppm level, the NCEM measured 625, while the OBS measured 599 ppm. The corresponding percent error with these values are $-7.17 \%$ for the 100 ppm concentration, $-1.9454 \%$ for the 200 ppm concentration, 11.879 $\%$ for the $400 \mathrm{ppm}$ concentration, and the percent error $600 \mathrm{ppm}$ concentration is $4.341 \%$. As shown in the trend provided by the values, at the higher $\mathrm{NO}_{\mathrm{x}}$ concentrations the NCEM measured higher values.

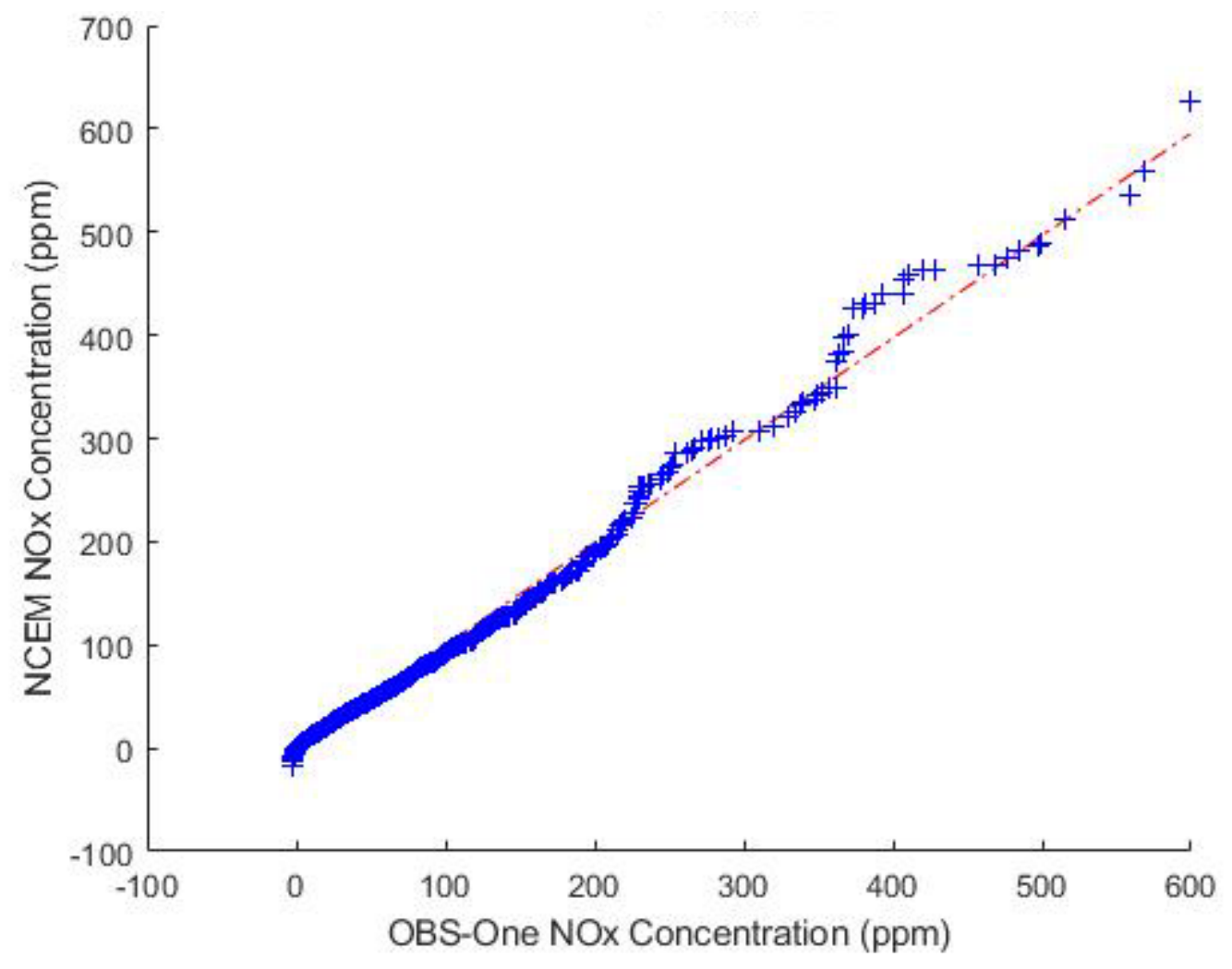

Figure 9: RDE $2 \mathrm{NO}_{\mathrm{x}} \mathrm{QQ}$ Plot

\subsubsection{Cold Start}

The cold start portion of the RDE routes is used to display the $\mathrm{NO}_{\mathrm{x}}$ that is produced while an engine is in its warmup session. This portion of the test route had a duration of 
500 seconds for the beginning of the test route. Cold start procedures typically produce elevated $\mathrm{NO}_{\mathrm{x}}$ concentrations due to the fact that the emissions suppression system has not had the time to properly heat up to peak operating temperatures. The graph below Figure 10 displays the raw data of the NOx concentration levels in relationship with the vehicle speed.

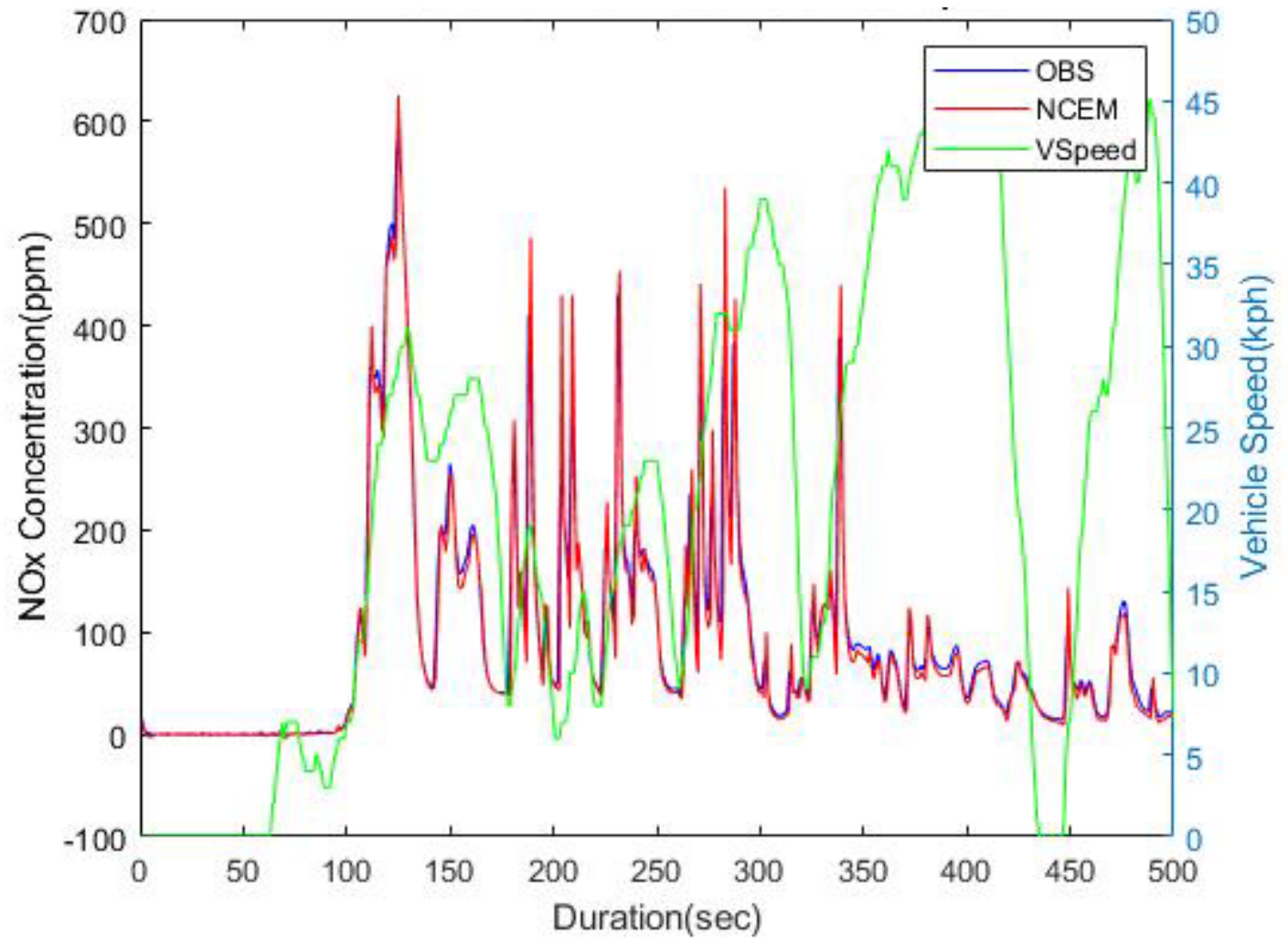

Figure 10: RDE 2 NO $_{x}$ Cold Start Raw Data with Vehicle Speed

The measured NOx concentrations during the cold start procedure of the second RDE test route are displayed in Figure 11 pictured below. The corresponding $\mathrm{R}^{2}$ value associated with this graph is equal to 0.97165 . This value is the second highest of the three RDE test routes. RDE 1 had a value of 0.96003, and RDE 3 had a value of 0.97903 . The trend on this graph is similar to that seen on the overall RDE 2 graph shown in figure 7 . At the $100 \mathrm{ppm}$ concentration level, the NCEM measured a value of $102 \mathrm{ppm}$, while the OBS measured a value of $107.9 \mathrm{ppm}$. At the $300 \mathrm{ppm}$ concentration level, the NCEM measured a value of $430 \mathrm{ppm}$, while the OBS measured a value of $292.4 \mathrm{ppm}$. At the $400 \mathrm{ppm}$ concentration level, the NCEM measured a value of $535 \mathrm{ppm}$, while the OBS recorded a concentration of $407.9 \mathrm{ppm}$. The corresponding percent errors associated with these 
differences are, $-5.468 \%$ for the $100 \mathrm{ppm}$ concentration level. For the $300 \mathrm{ppm}$ concentration level, the percent error was equal to $47.06 \%$. For the $400 \mathrm{ppm}$ concentration level, the percent error was equal to $31.16 \%$. The trend is showing as the $\mathrm{NO}_{\mathrm{x}}$ concentrations increase, so does the percent error between the sensors.

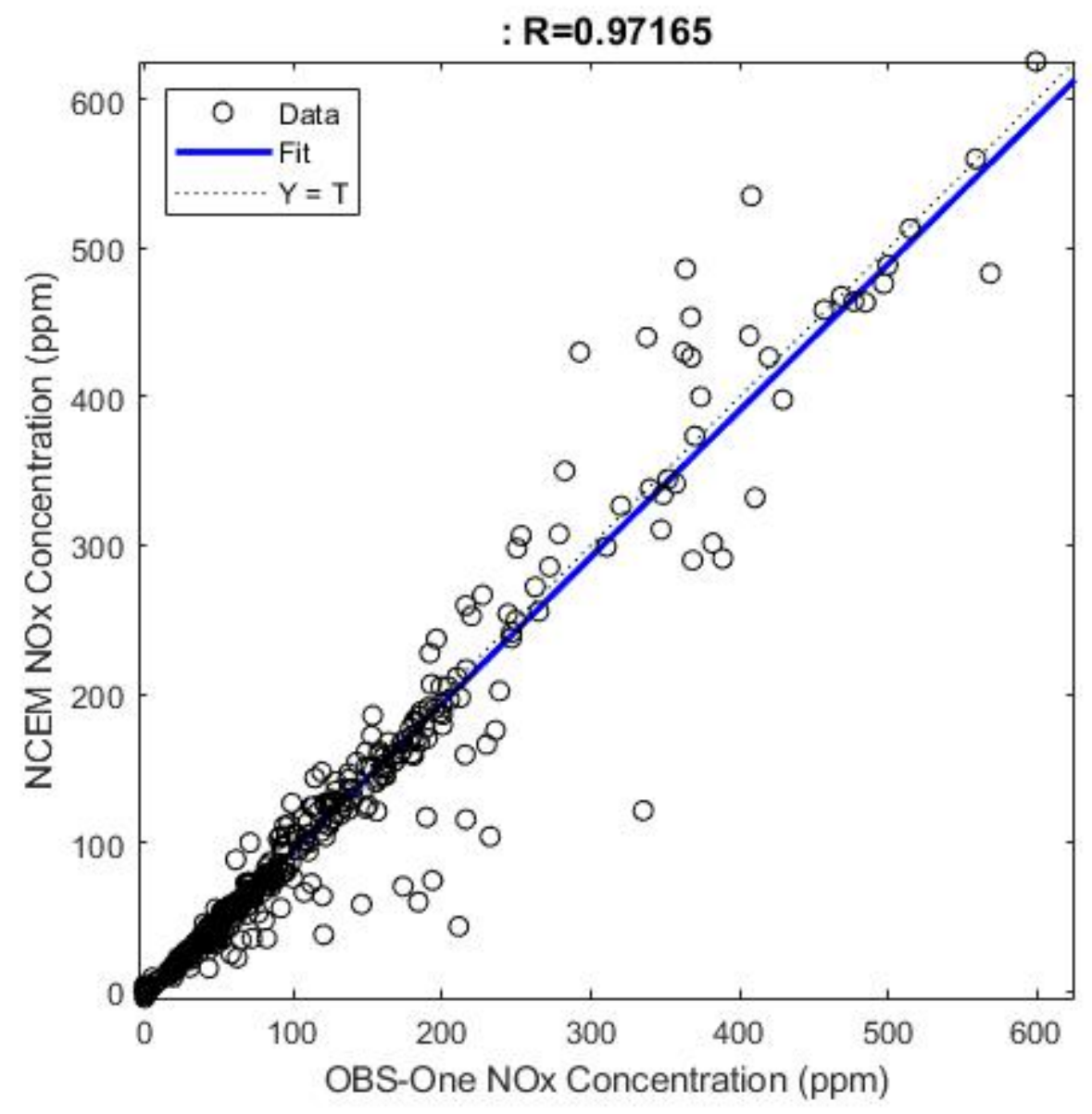

Figure 11: Linear Regression for RDE 2 NO$_{\mathrm{x}}$ Cold Start

Table 2: : RDE Cold Start NOx $\mathbf{R}^{2}$ Values

\begin{tabular}{|l|l|}
\hline RDE 1 & 0.96003 \\
\hline RDE 2 & 0.97165 \\
\hline RDE 3 & 0.97903 \\
\hline
\end{tabular}




\subsubsection{Urban Portion}

The urban portion of the RDE routes is used to display the $\mathrm{NO}_{\mathrm{x}}$ that is produced while a vehicle is in stop and go traffic situations. This portion of the test route had a distance of $25.1 \mathrm{~km}$, there was not a time associated with this test portion because of the different traffic situations, and the traffic control devices. Urban driving situations typically produce elevated $\mathrm{NO}_{\mathrm{x}}$ concentrations due to the constant stop and start driving simulation. This constant changes in load result in changing $\mathrm{NO}_{\mathrm{x}}$ emissions. The graph below Figure 12 displays the raw data of the $\mathrm{NO}_{\mathrm{x}}$ concentration levels in relationship with the vehicle speed.

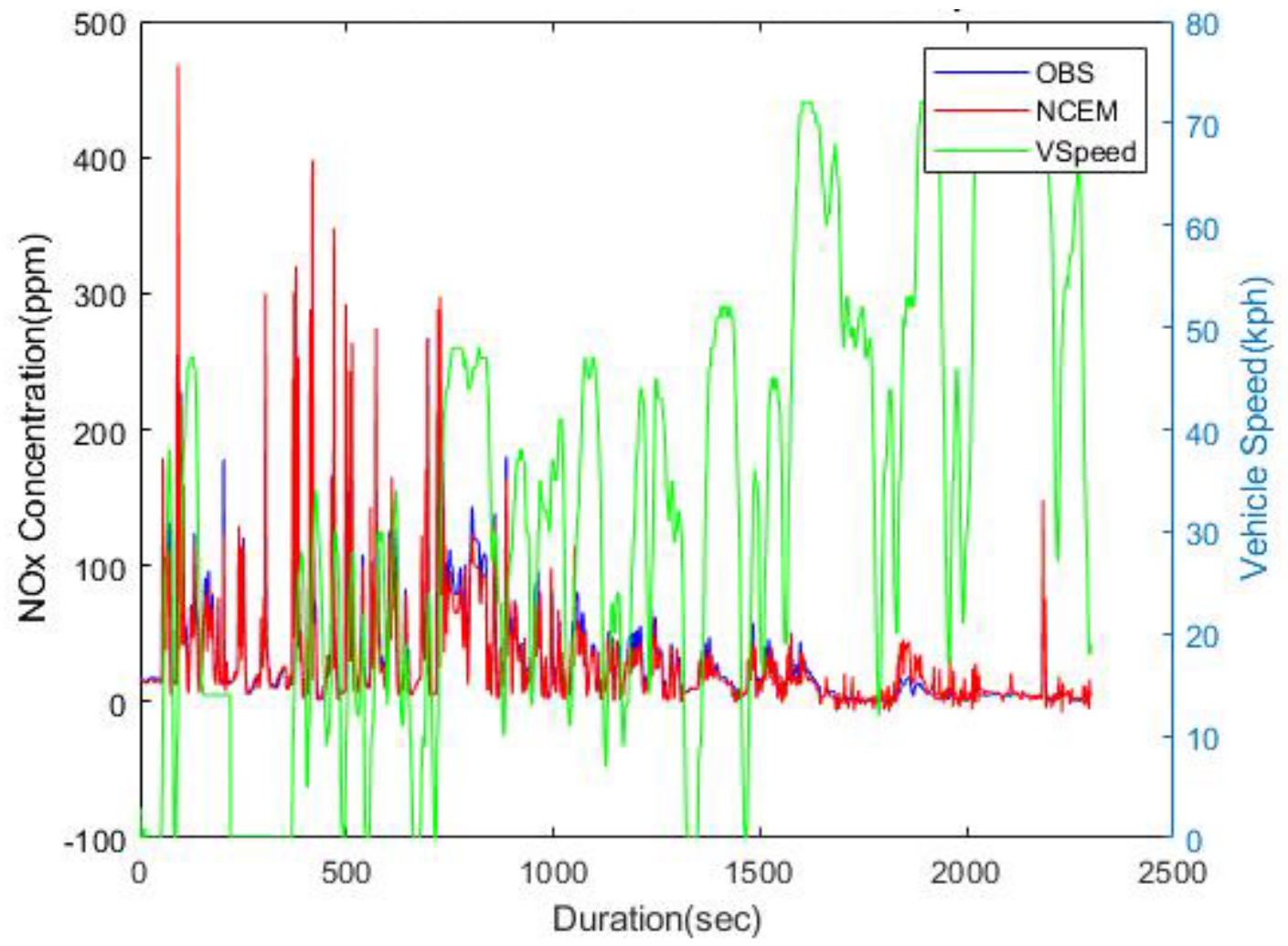

Figure 12: RDE 2 Urban NO$_{x}$ Raw Data with Vehicle Speed

The measured $\mathrm{NO}_{\mathrm{x}}$ concentrations during the urban portion of the second RDE test route are displayed in Figure 13 pictured below. The corresponding $\mathrm{R}^{2}$ value associated with this graph is equal to 0.95419 . This value is the highest of the three RDE test routes. RDE 1 had a value of 0.86994 , and RDE 3 had a value of 0.87167 . The trend on this graph is similar to that seen on the overall RDE 2 graph shown in Figure 7. The urban portion of 
the test route does not produce $\mathrm{NO}_{\mathrm{x}}$ concentrations as elevated as the cold start portion. At the 100 ppm concentration level, the NCEM measured a value of 83 ppm, while the OBS measured a value of $101.8 \mathrm{ppm}$. At the $200 \mathrm{ppm}$ concentration level, the NCEM measured a value of $172.5 \mathrm{ppm}$, while the OBS measured a value of $191.4 \mathrm{ppm}$. At the $400 \mathrm{ppm}$ concentration level, the NCEM measured a value of $467.5 \mathrm{ppm}$, while the OBS recorded a concentration of $393.3 \mathrm{ppm}$. The corresponding percent errors associated with these differences are, $-18.468 \%$ for the 100 ppm concentration level. For the 200 ppm concentration level, the percent error was equal to $-9.875 \%$. For the $400 \mathrm{ppm}$ concentration level, the percent error was equal to $18.87 \%$. The trend is showing as the $\mathrm{NO}_{\mathrm{x}}$ concentrations increase, so does the percent error between the sensors. Another trend that is shown with this data, is as the $\mathrm{NO}_{\mathrm{x}}$ concentrations decrease, so does the percent error between the sensors.

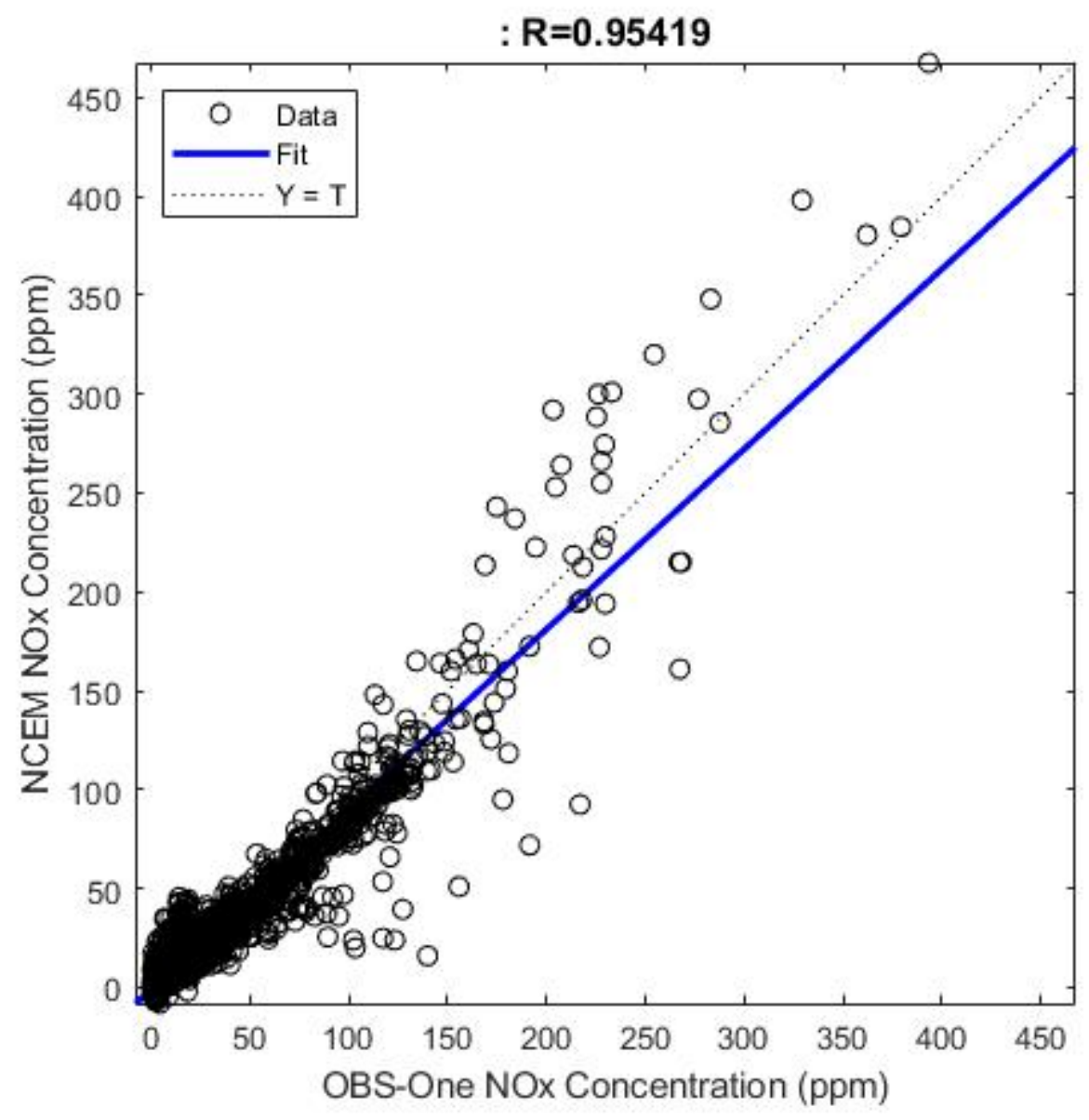

Figure 13: Linear Regression for RDE $2 \mathrm{NO}_{\mathrm{x}}$ Urban 
Table 3: RDE Urban NOx $\mathbf{R}^{2}$ Values

\begin{tabular}{|l|l|}
\hline RDE 1 & 0.86994 \\
\hline RDE 2 & 0.95419 \\
\hline RDE 3 & 0.87167 \\
\hline
\end{tabular}

\subsubsection{Rural Portion}

The rural portion of the RDE routes is used to display the $\mathrm{NO}_{\mathrm{x}}$ that is produced while a vehicle is in a rural setting, meaning consist flow of traffic, but at lower top speeds from highway. This portion of the test route had a distance of $35.4 \mathrm{~km}$, there was not a time associated with this test portion because of the different traffic situations, and the traffic control devices. Rural driving situations typically produce low $\mathrm{NO}_{\mathrm{x}}$ concentrations due to the constant speed, compared to the highway portion the rural, is lower speed, and there still are stop and start situations, but they are limited when compared to the urban portion. This changes in load will result in elevated $\mathrm{NO}_{\mathrm{x}}$ emissions. The graph below Figure 14 displays the raw data of the NOx concentration levels in relationship with the vehicle speed. 


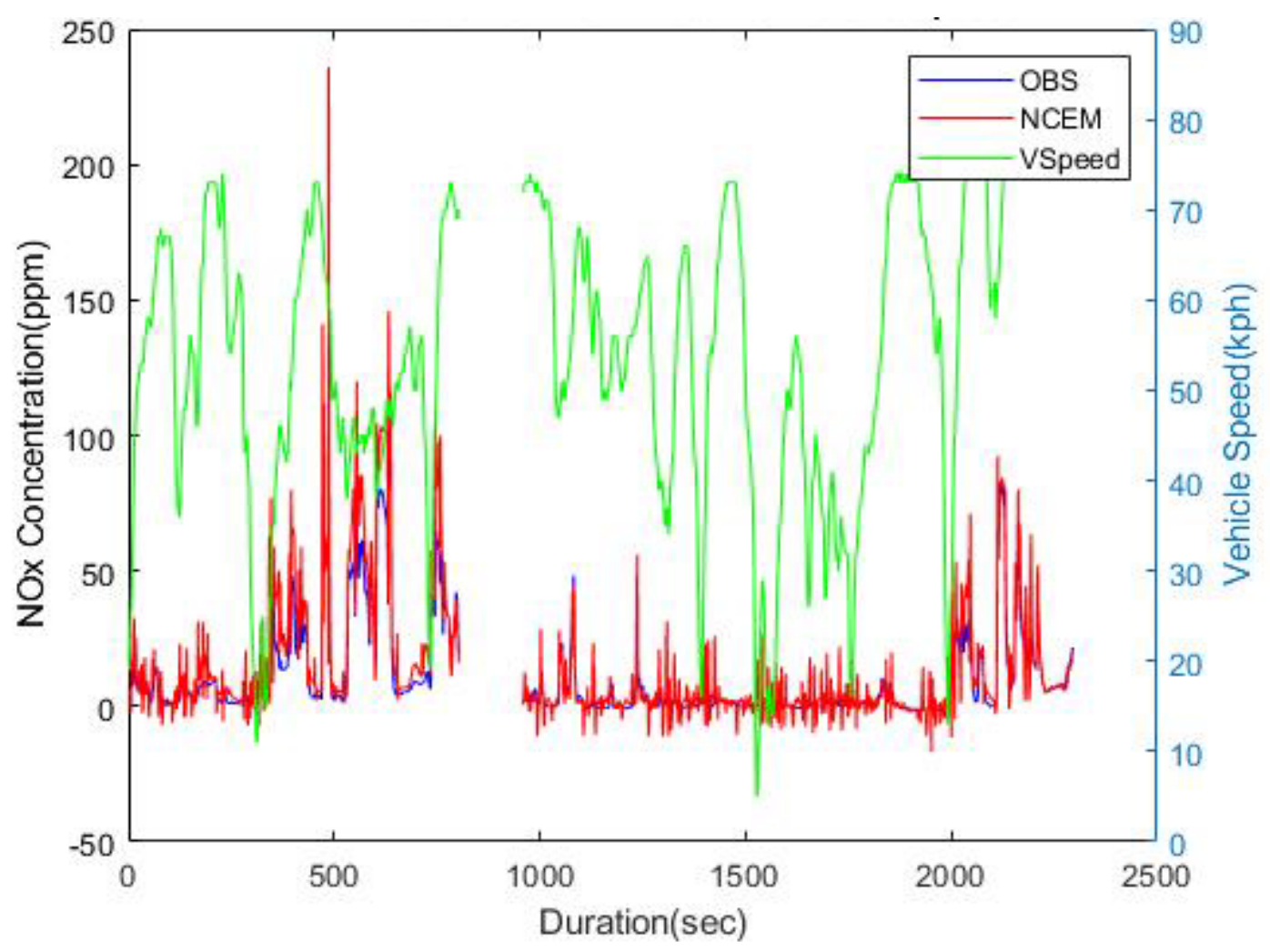

Figure 14: RDE 2 Rural NOx Raw Data with Vehicle Speed

The measured $\mathrm{NO}_{\mathrm{x}}$ concentrations during the rural portion of the second $\mathrm{RDE}$ test route are displayed in Figure 15 pictured below. The corresponding $\mathrm{R}^{2}$ value associated with this graph is equal to 0.95419 . This value is the second highest of the three RDE test routes. RDE 1 had a value of 0.92926, and RDE 3 had a value of 0.96209 . The trend on this graph is similar to that seen on the overall RDE 2 graph shown in Figure 7. The rural portion of the test route typically does not produce elevated $\mathrm{NO}_{\mathrm{x}}$ concentrations. This is due to the constant speed, and the load not dramatically changing during the test. As shown on the graph, during a $0 \mathrm{ppm} \mathrm{NO}_{\mathrm{x}}$ concentrations, it is recorded negative $\mathrm{NO}_{\mathrm{x}}$ concentrations. At the $50 \mathrm{ppm}$ concentration level, the NCEM measured a value of $68 \mathrm{ppm}$, while the OBS measured a value of $50.67 \mathrm{ppm}$. At the $100 \mathrm{ppm}$ concentration level, the NCEM measured a value of 119 ppm, while the OBS recorded a concentration of 105.1 ppm. The corresponding percent errors associated with the differences are, $34.20 \%$ for the $50 \mathrm{ppm}$ concentration level. For the $100 \mathrm{ppm}$ concentration level, the percent error was equal to $-13.225 \%$. The trend is showing if at low $\mathrm{NO}_{\mathrm{x}}$ concentrations, the NCEM measures elevated values when compared to the OBS measurement. Another trend that is shown with this data, is as the negative $\mathrm{NO}_{\mathrm{x}}$ concentrations. 


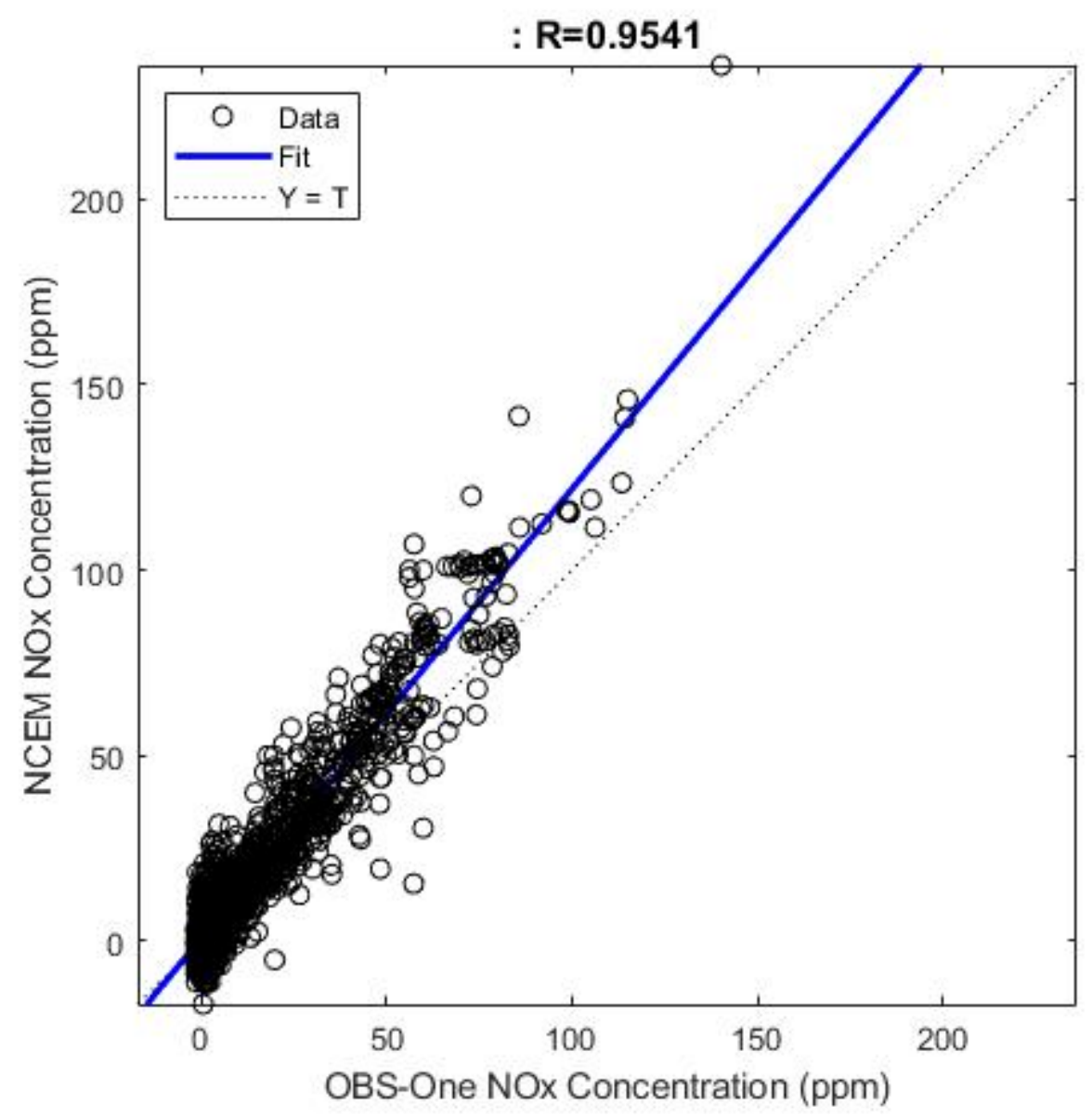

Figure 15: Linear Regression RDE 2 NO$_{x}$ Rural

Table 4: RDE Rural NOx R $^{2}$ Values

\begin{tabular}{|l|l|}
\hline RDE 1 & 0.92926 \\
\hline RDE 2 & 0.9541 \\
\hline RDE 3 & 0.96205 \\
\hline
\end{tabular}

\subsubsection{Highway Portion}

The highway portion of the RDE routes is used to display the $\mathrm{NO}_{\mathrm{x}}$ that is produced while a vehicle is on highway, at highway speeds, it is supposed to represent high constant speed, without any stop and goes. This portion of the test route had a distance of $35.3 \mathrm{~km}$, 
there was not a time associated with this test portion because of the different traffic situations, and congestion that would be encounter on highways. Highway driving situations typically produce the lowest $\mathrm{NO}_{\mathrm{x}}$ concentrations due to the constant speed. The graph below Figure 16 displays the raw data of the NOx concentration levels in relationship with the vehicle speed.

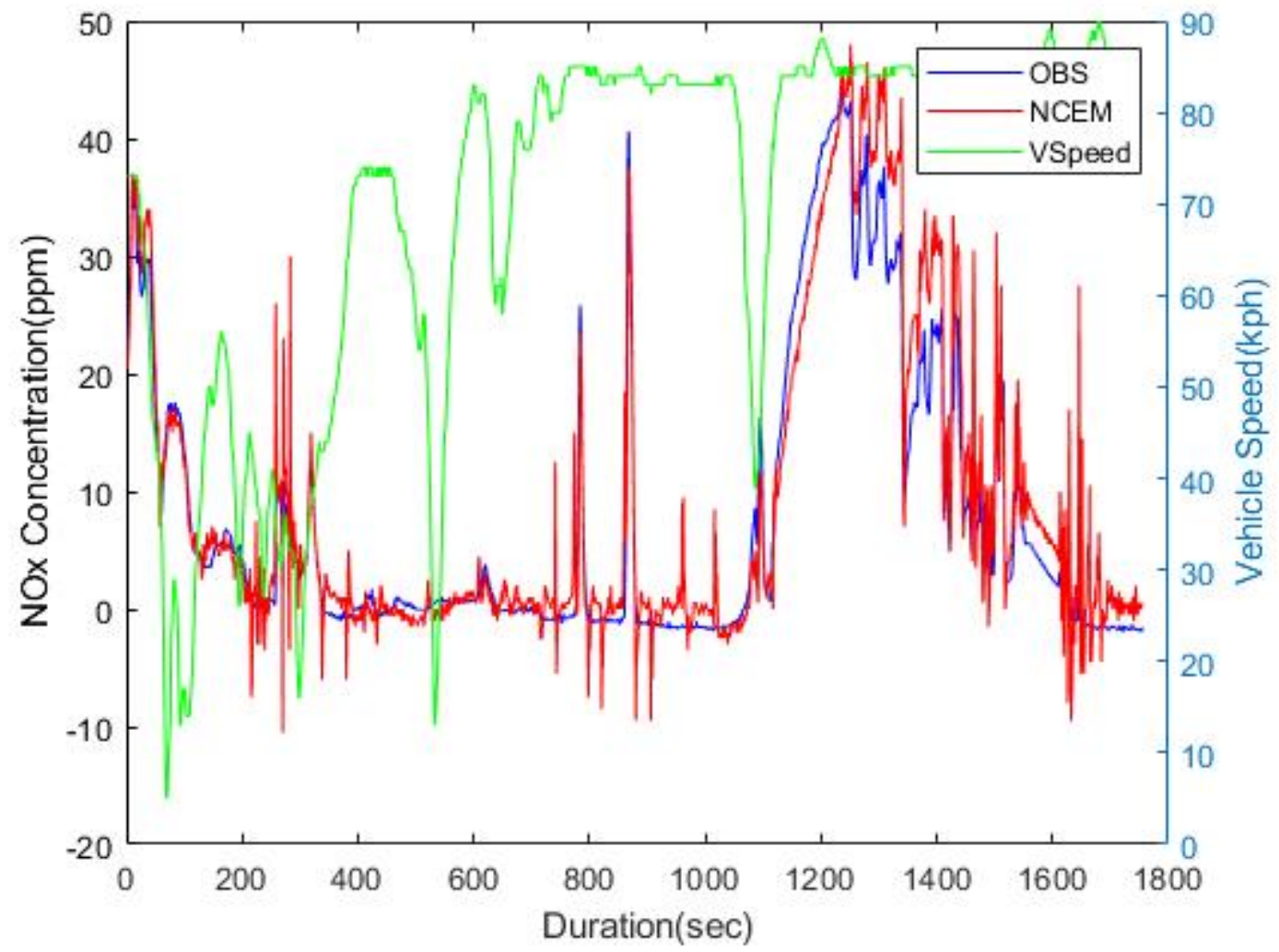

Figure 16: RDE 2 Highway Raw Data with Vehicle Speed

The measured $\mathrm{NO}_{\mathrm{x}}$ concentrations during the highway portion of the second $\mathrm{RDE}$ test route are displayed in Figure 17 pictured below. The corresponding $\mathrm{R}^{2}$ value associated with this graph is equal to 0.96092 . This value is the second highest of the three RDE test routes. RDE 1 had a value of 0.92107, and RDE 3 had a value of 0.90777 . The trend on this graph is similar to that seen on the overall RDE 2 graph shown in Figure 7. The highway portion of the test route typically produces the lowest $\mathrm{NO}_{\mathrm{x}}$ concentrations. This is due to the constant high speed, and the load not dramatically changing during the test. During the highway test the $\mathrm{NO}_{\mathrm{x}}$ concentration levels ranged from $-9.5 \mathrm{ppm}$ to $48 \mathrm{ppm}$. The negative $\mathrm{NO}_{\mathrm{x}}$ concentrations can be seen in the test route, mainly recorded by the 
NCEM sensors. As shown on the graph, during a $0 \mathrm{ppm} \mathrm{NO}_{\mathrm{x}}$ concentrations, it is recorded negative $\mathrm{NO}_{\mathrm{x}}$ concentrations. For this portion the test route the NCEM measured values that were elevated or lowered concentrations. At the $10 \mathrm{ppm}$ concentration level, for one data point the NCEM measured a value of $10 \mathrm{ppm}$, while the OBS measured a value of $10.91 \mathrm{ppm}$. For another data point the NCEM measured a value of $12 \mathrm{ppm}$, while the OBS measured a value of $10.36 \mathrm{ppm}$. At the $30 \mathrm{ppm}$ concentration level, the NCEM measured a value of $31.5 \mathrm{ppm}$, while the OBS recorded a concentration of $29.95 \mathrm{ppm}$. For another data point the NCEM measured a value of $24.5 \mathrm{ppm}$, while the OBS measured a value of $29.86 \mathrm{ppm}$. These data points do not display repeatability. The corresponding percent errors associated with the differences are, $-8.34 \%$ for the first $10 \mathrm{ppm}$ concentration level data point. For the second $10 \mathrm{ppm}$ concentration level data point, the percent error was equal to $15.83 \%$. For the first $30 \mathrm{ppm}$ concentration level data point, the percent error was equal to $5.17 \%$, and for the second $30 \mathrm{ppm}$ concentration level data point the percent error was equal to $-17.92 \%$. The trend is showing at low $\mathrm{NO}_{\mathrm{x}}$ concentrations, the NCEM displays variations in measured values, when compared to like values measured from the OBS. Negative $\mathrm{NO}_{\mathrm{x}}$ concentrations are measured the NCEM during this test route. 


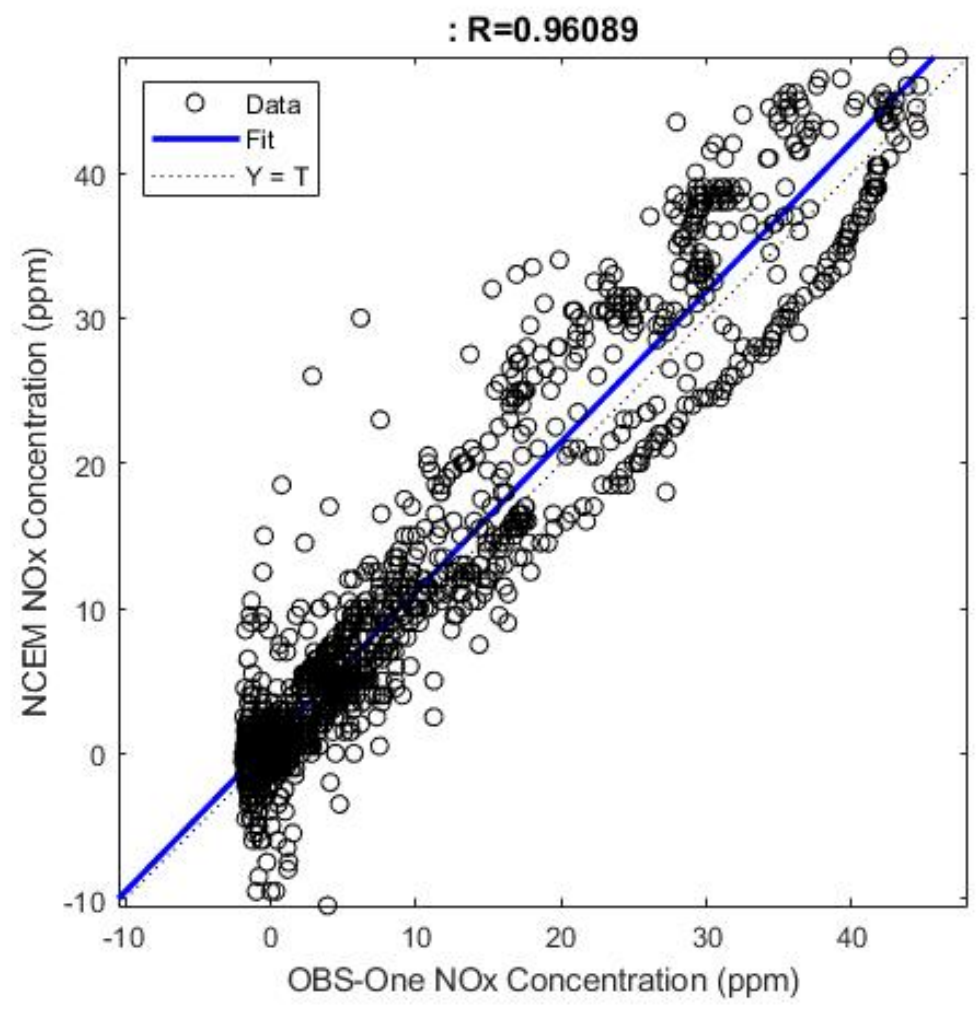

Figure 17: Linear Regression for RDE $2 \mathrm{NO}_{\mathrm{x}}$ Highway

Table 5: RDE Highway NOx $R^{2}$ Values

\begin{tabular}{|l|l|}
\hline RDE 1 & 0.92107 \\
\hline RDE 2 & 0.96089 \\
\hline RDE 3 & 0.90774 \\
\hline
\end{tabular}

\subsubsection{8 $\mathrm{NO}_{\mathrm{x}}$ Concentration Binning - $10 \mathrm{ppm}$ Bin Size}

The $10 \mathrm{ppm}$ bin data analysis was set up to analyze data from a $10 \mathrm{ppm}$ increment. This analysis averaged the $\mathrm{NO}_{\mathrm{x}}$ concentrations within a range of 0-10 ppm, 10-20 ppm, and etc. This technique of data analysis is used to take the average, and in some instances reduce outliers in the data set. In Figure 18 below, the data was recorded during the second test route RDE route. This data was used because of its higher $\mathrm{R}^{2}$ values on the regression plots associated with this test route. The $\mathrm{R}^{2}$ value of RDE 2 is equal to 0.97562 . RDE 1 has an $\mathrm{R}^{2}$-value of 0.94602 , for the $10 \mathrm{ppm}$ increment binning technique. For RDE 3, the associated $\mathrm{R}^{2}$ value equals 0.96796 . At the $100 \mathrm{ppm}$ concentration level, the NCEM 
measured a value of $92.35 \mathrm{ppm}$, while the OBS measured a value of $105.5 \mathrm{ppm}$. At the 200 ppm concentration level, the NCEM measured a value of $223.2 \mathrm{ppm}$, while the OBS recorded a concentration of $204.2 \mathrm{ppm}$. At the $400 \mathrm{ppm}$ concentration level, the NCEM measured a value of $467.5 \mathrm{ppm}$, while the OBS recorded a concentration of $393.3 \mathrm{ppm}$. The corresponding percent errors associated with the differences are, $-12.464 \%$ for the 100 ppm concentration level data point. For the 200 ppm concentration level data point, the percent error was equal to $9.305 \%$. For the first 400 ppm concentration level data point, the percent error was equal to $18.87 \%$. The trend is showing a repeated trend throughout this analysis, as the $\mathrm{NO}_{\mathrm{x}}$ concentrations, the NCEM measured values were elevated when compared to the OBS. The percent error increased as the $\mathrm{NO}_{\mathrm{x}}$ concentrations increased.

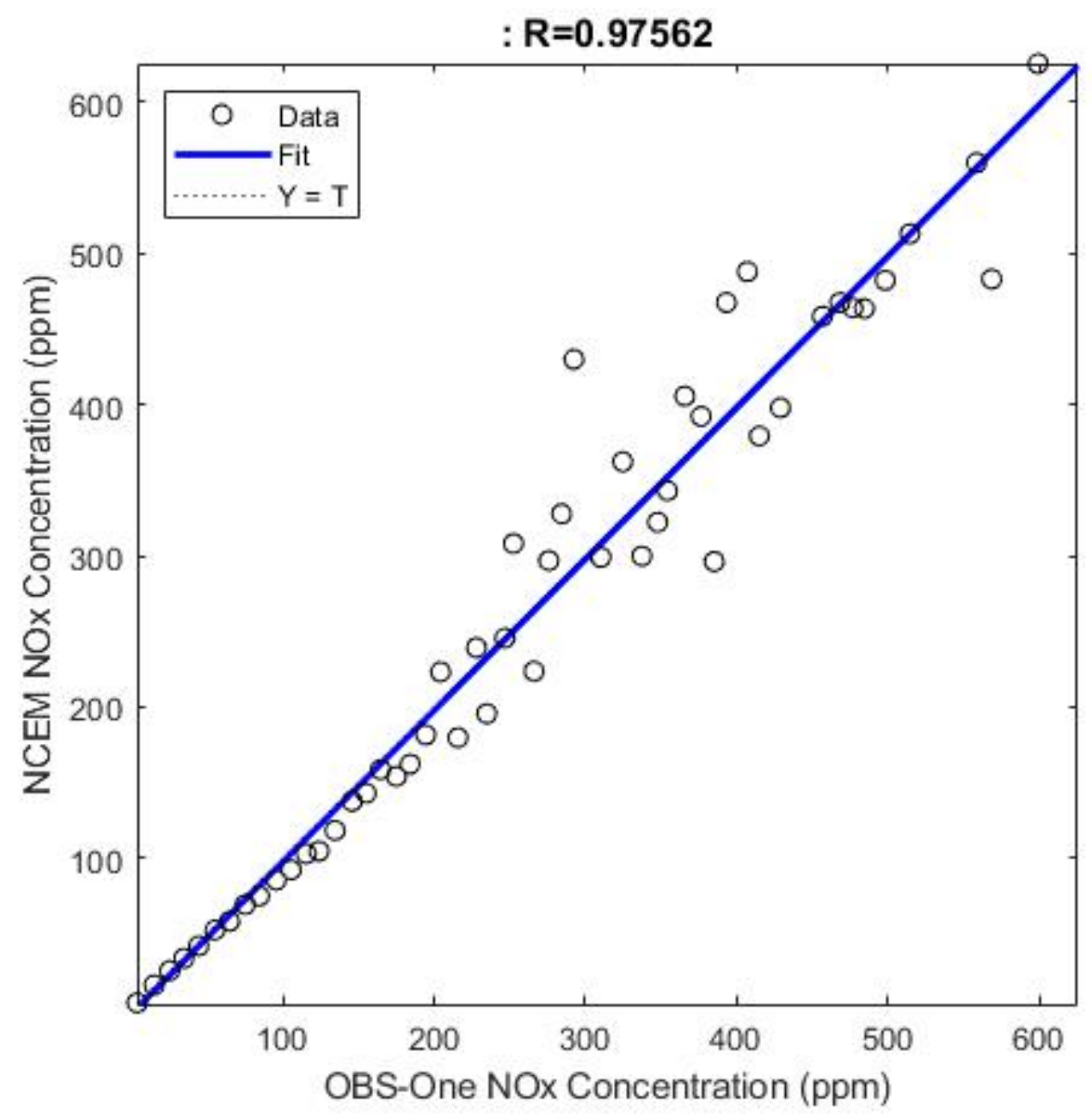

Figure 18: Linear Regression for RDE 2 NO$_{\mathrm{x}}$ Concentration Binning - 10 ppm Bins 
Table 6: RDE NOx 10 ppm Bins $\mathbf{R}^{2}$ Values

\begin{tabular}{|l|l|}
\hline RDE 1 & 0.94605 \\
\hline RDE 2 & 0.97562 \\
\hline RDE 3 & 0.96796 \\
\hline
\end{tabular}

The $10 \mathrm{ppm}$ bin data analysis was set up to analyze data in a $10 \mathrm{ppm}$ average increment. Figure 19 show the error percentage that is calculated in these three $10 \mathrm{ppm}$ binning graphs. The RDE routes all showed a maximum of $\pm 23 \%$ error, and a minimum of $0 \%$ error. All three RDE test routes display similar results, but there are some differences. The RDE 1 test shows a more negative percent error, which shows that the NCEM was reading lower values than the reference unit the OBS. The RDE 2 test repeats this trend, but the RDE 3 test shows more positive percent errors, which tells us that the NCEM is reading higher $\mathrm{NO}_{\mathrm{x}}$ concentrations than the OBS.

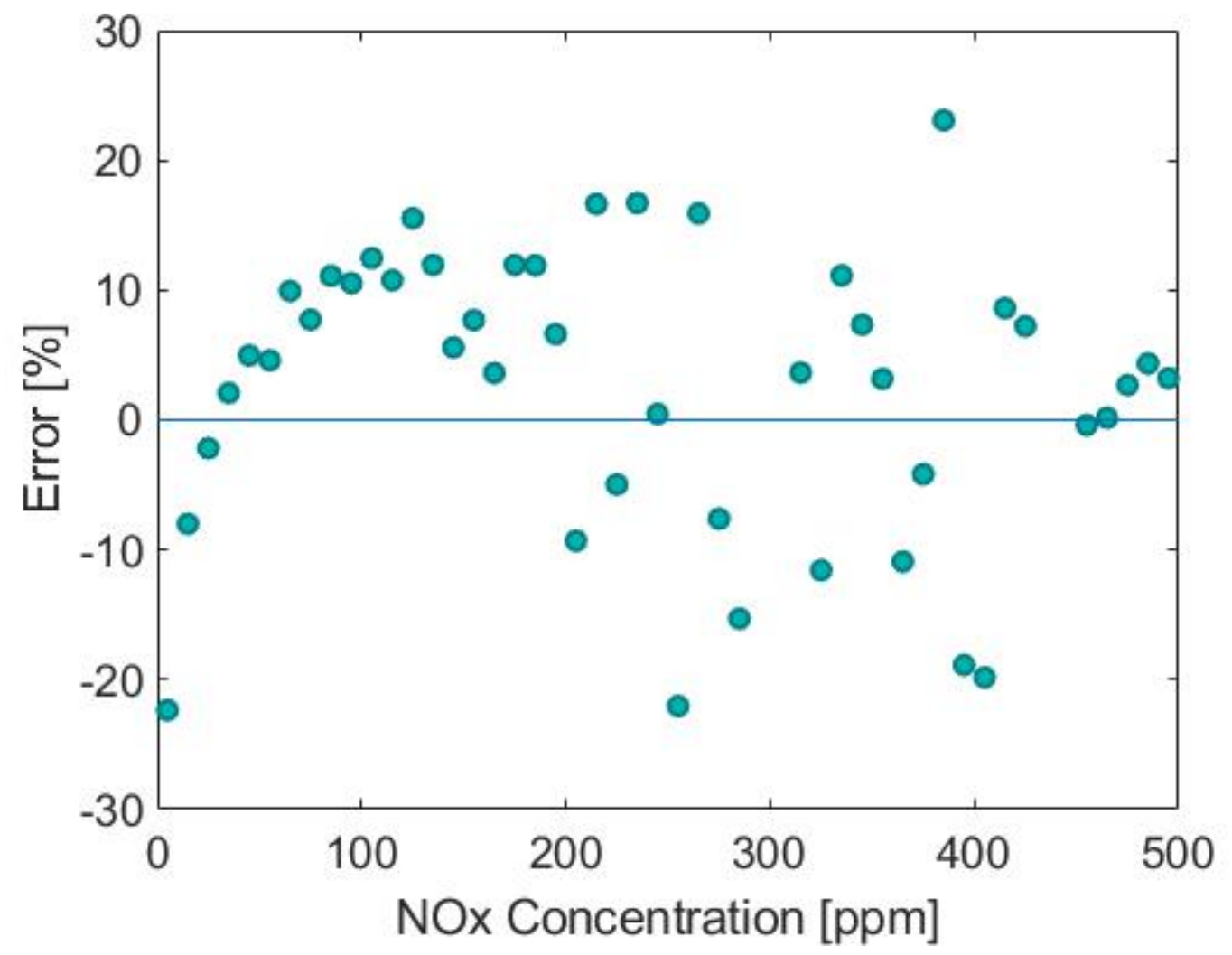

Figure 19:Error Percentage for RDE 2 NO$_{x}$ Concentration Binning - 10 ppm Bins 


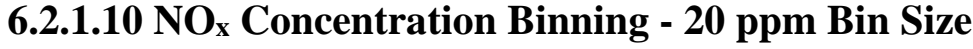

The 20 ppm bin data analysis was set up to analyze data from a 20 ppm increment. This analysis averaged the $\mathrm{NO}_{\mathrm{x}}$ concentrations within a range of 0-20 ppm, 20-40 ppm, and etc. This technique of data analysis is used to take the average, and in some instances reduce outliers in the data set. In Figure 20 below, the data was recorded during the second test route RDE route. This data was used because of its higher $\mathrm{R}^{2}$ values on the regression plots associated with this test route. The $\mathrm{R}^{2}$ value of RDE 2 is equal to 0.98921 . RDE 1 has an $\mathrm{R}^{2}$-value of 0.96582 , for the $20 \mathrm{ppm}$ increment binning technique. For RDE 3, the associated $\mathrm{R}^{2}$ value equals 0.98701 . At the $100 \mathrm{ppm}$ concentration level, the NCEM measured a value of 96.95 ppm, while the OBS measured a value of $109.8 \mathrm{ppm}$. At the 300 ppm concentration level, the NCEM measured a value of 299 ppm, while the OBS recorded a concentration of $310.3 \mathrm{ppm}$. At the $500 \mathrm{ppm}$ concentration level, the NCEM measured a value of $513 \mathrm{ppm}$, while the OBS recorded a concentration of $514.7 \mathrm{ppm}$. The corresponding percent errors associated with the differences are, $-11.702 \%$ for the 100 ppm concentration level data point. For the 300 ppm concentration level data point, the percent error was equal to $-3.642 \%$. For the first 500 ppm concentration level data point, the percent error was equal to $-0.3303 \%$. The trend is showing a repeated trend is repeated across all three data sets. When binned in 20 ppm intervals the data points start to trend toward a linear relationship. 


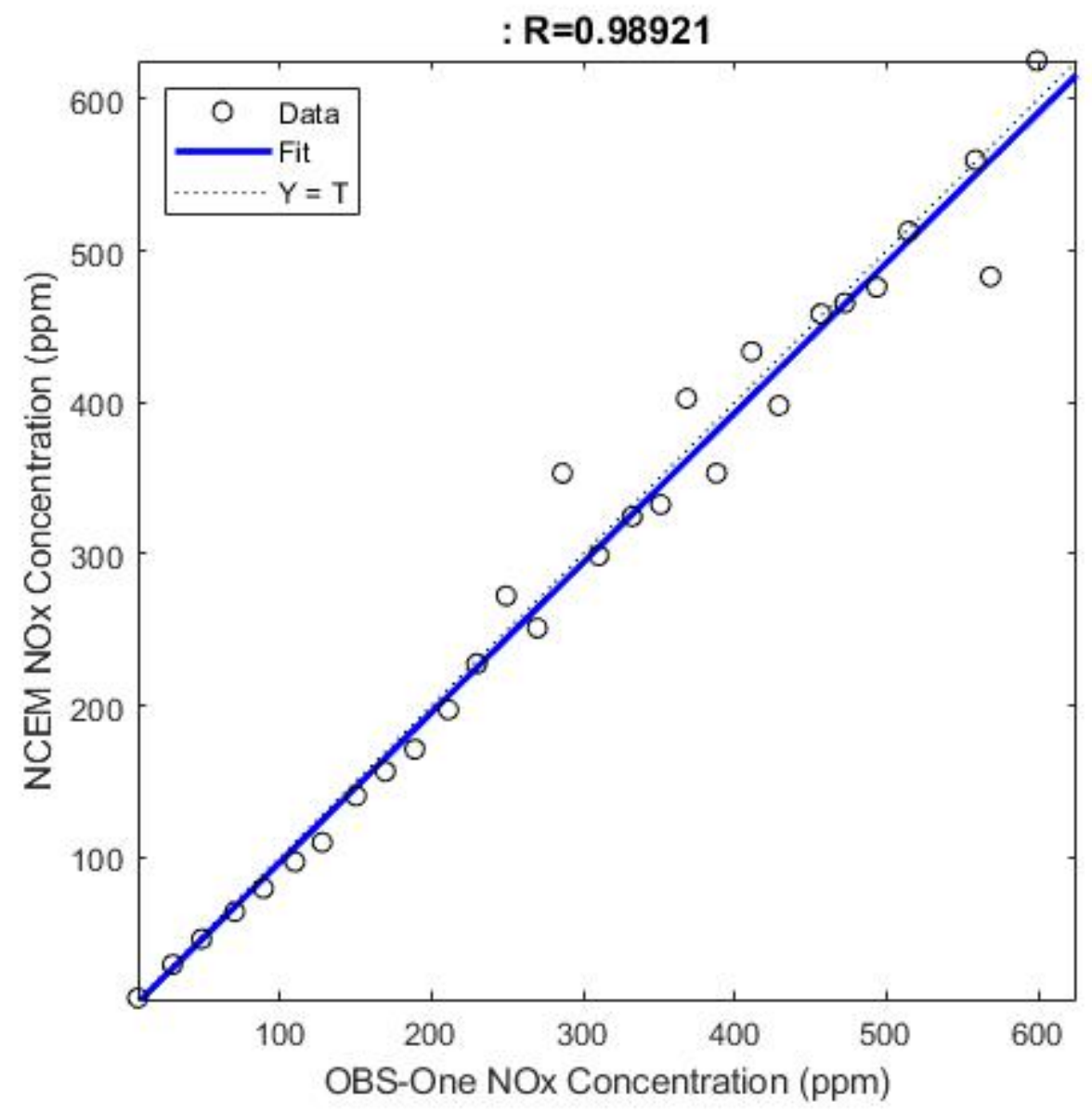

Figure 20: Linear Regression for RDE 2 NO $_{x}$ Concentration Binning - 20 ppm Bins

Table 7: RDE NOx 20 ppm Bins $\mathbf{R}^{2}$ Values

\begin{tabular}{|l|l|}
\hline RDE 1 & 0.94587 \\
\hline RDE 2 & 0.98921 \\
\hline RDE 3 & 0.98701 \\
\hline
\end{tabular}


The $20 \mathrm{ppm}$ bin data analysis was set up to analyze data in a $20 \mathrm{ppm}$ average increment. Figure 21 shows the error percentage that is displayed in these three binning graphs. The RDE routes all showed a maximum of $25 \%$ error, and a minimum of $0 \%$ error. For the $20 \mathrm{ppm}$ error percentage there were some differences between each individual test route. For RDE 1 and RDE 2 the test results displayed an increase in the number of negative error percentages, which explains that the NCEM was reading lower values than the OBS. RDE 2 test route both displayed a range of $-15 \%$ to $25 \%$ error percentages. The largest range of data can be seen on RDE 2.

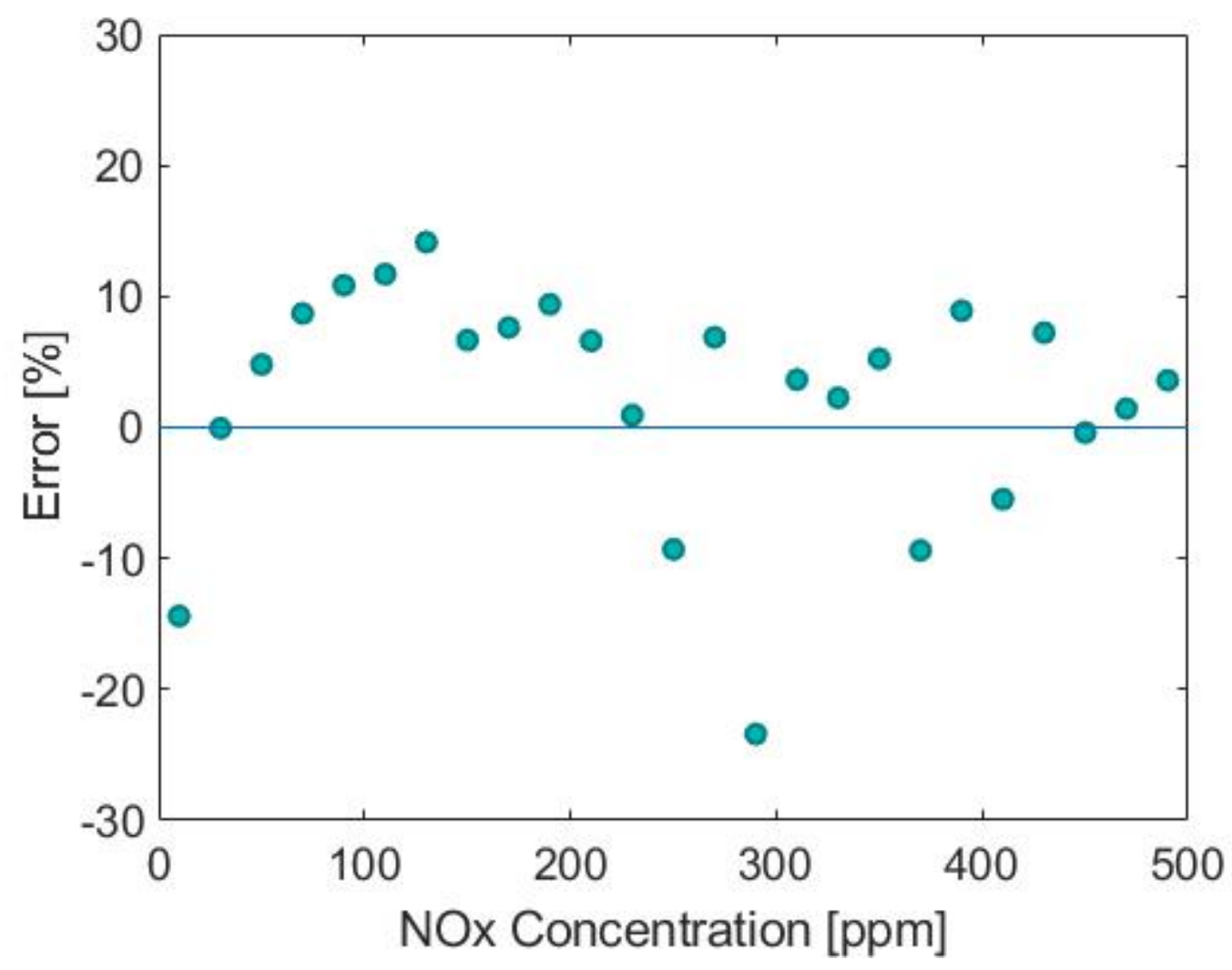

Figure 21: Error Percentage for RDE 2 NO$_{\mathrm{x}}$ Concentration Binning - 20 ppm Bins 


\subsubsection{Tavannes Route - Highway Operation with Grade}

The Tavannes test route performed in a higher altitude. There are many different elevation changes, that are associated with this route. The first important trend to observe is whether or not the altitude effects the $\mathrm{NO}_{\mathrm{x}}$ concentration levels emitted from this truck during operation. This test route began with a warm start which resulted in elevated $\mathrm{NO}_{\mathrm{x}}$ concentrations. This trip included what would be considered as highway speeds mixed with moderate to severe inclines that resulted in heavy load situations. The elevation changes also result in high load changes which can result in higher $\mathrm{NO}_{\mathrm{x}}$ concentration levels. Figure 42 in the appendix can be used as a reference.

\subsubsection{Overall Tavannes Route NOx Emissions Comparison}

The Figure 22 below shows the test data on a raw $\mathrm{NO}_{\mathrm{x}}$ gaseous emissions with the corresponding vehicle speed that was collected for the Tavannes test route 1 from both PEMS units, the red is NCEM, and the blue is the OBS-ONE, and the green is the vehicle speed. As displayed below, the first 250 seconds resulted in higher $\mathrm{NO}_{\mathrm{x}}$ emissions because of the associated start up routine. This duration of start-up operation was considerably less than what was observed in the RDE routes. The graphs a correlation between elevated $\mathrm{NO}_{\mathrm{x}}$ concentrations during vehicle acceleration. However, it can be observed that during constant speed, the $\mathrm{NO}_{\mathrm{x}}$ concentrations were decreased. 


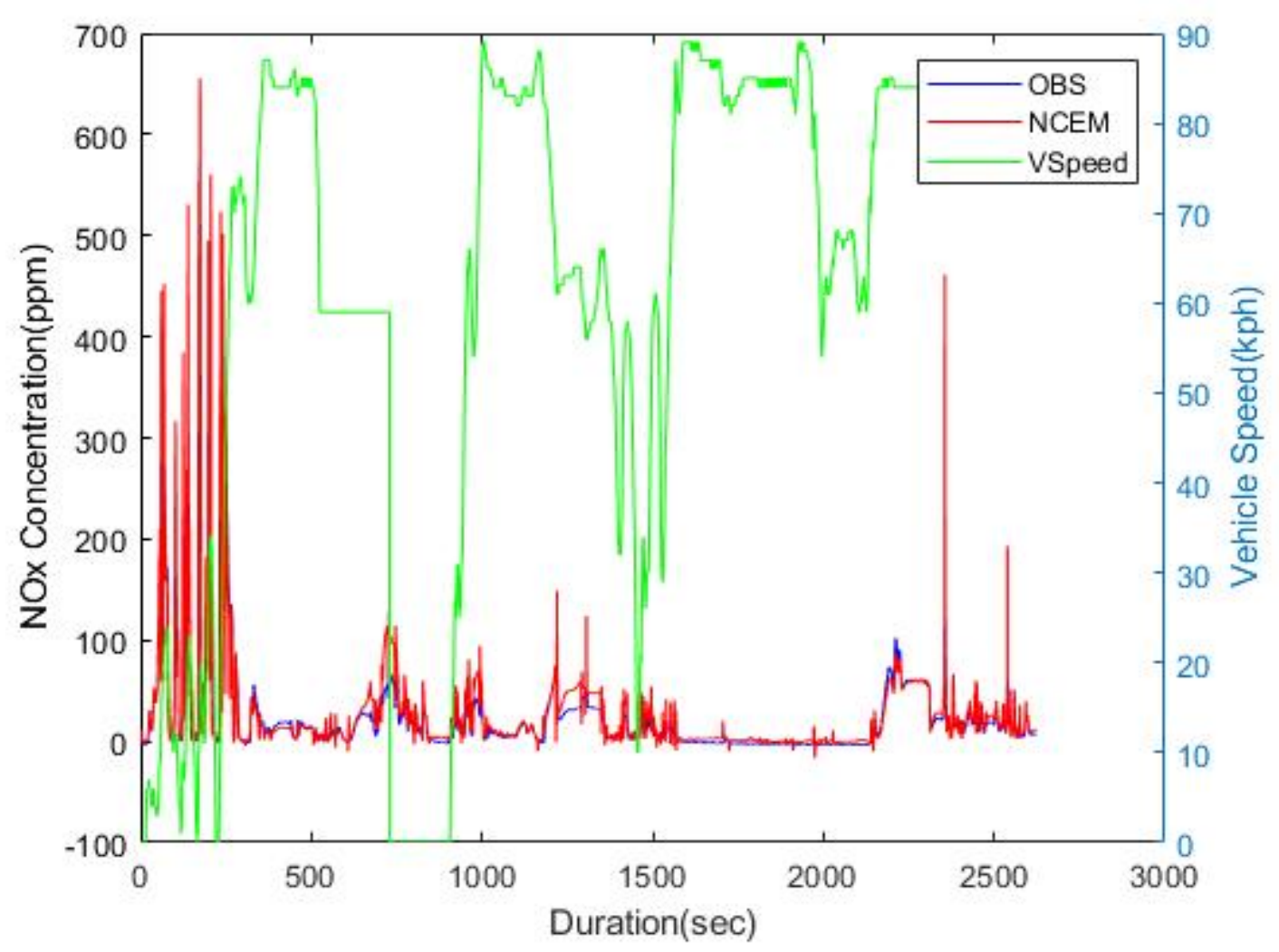

Figure 22:Tavannes 1 NO$_{x}$ Raw Data with Vehicle Speed

The Figure 23 below shows the report data on a QQ plot of the raw $\mathrm{NO}_{\mathrm{x}}$ gaseous emissions collected for the Tavannes test route 1 from both PEMS units. The QQ plot displays the linearity of the two sensors, but as the $\mathrm{NO}_{\mathrm{x}}$ concentration level increases there is a deviation from the linearity. Some points at on the graph will show a representation of the data. At the $100 \mathrm{ppm}$ concentration level, the NCEM measured $122 \mathrm{ppm}$, while the OBS measured $108.49 \mathrm{ppm}$. At the $200 \mathrm{ppm}$ concentration level, the NCEM measured $182.5 \mathrm{ppm}$, and the OBS measured $202.4632 \mathrm{ppm}$. At the $400 \mathrm{ppm}$ level, the NCEM measured $461.5 \mathrm{ppm}$, and the OBS measured $396.52 \mathrm{ppm}$. The corresponding percent error with these values are $3.235 \%$ for the $100 \mathrm{ppm}$ concentration, $-9.8597 \%$ for the $200 \mathrm{ppm}$ concentration, $16.4 \%$ for the $400 \mathrm{ppm}$ concentration. As shown in the trend provided by the values, at the higher $\mathrm{NO}_{\mathrm{x}}$ concentrations the NCEM measured higher values. 


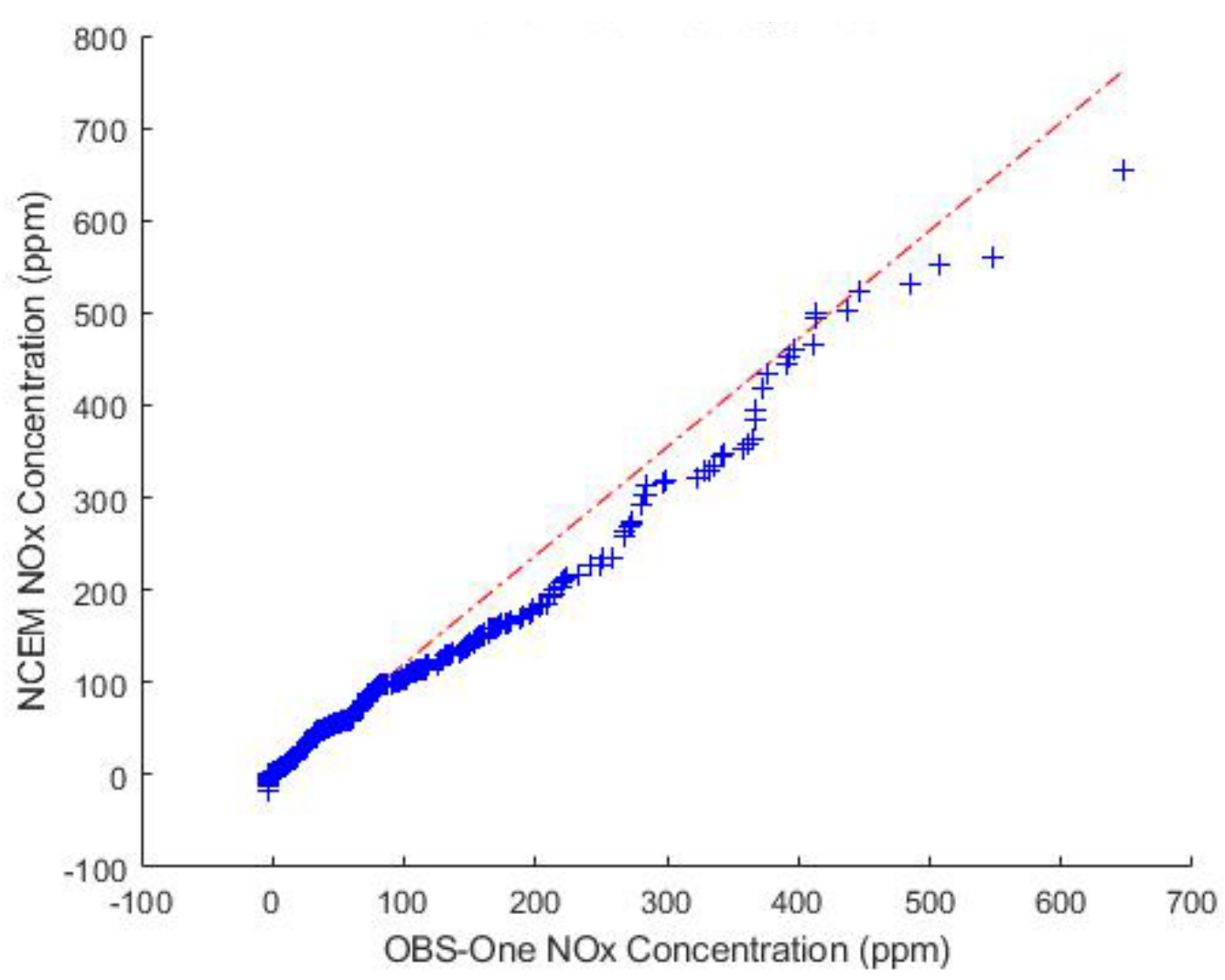

Figure 23: Tavannes $1 \mathrm{NO}_{\mathrm{x}} \mathrm{QQ}$ Plot

The Figure 24 below shows the report data on a linear regression plot of $\mathrm{NO}_{\mathrm{x}}$ gaseous emissions collected for the first Tavannes test route from both PEMS units. The corresponding $\mathrm{R}^{2}$-value to this linear regression is 0.96276 . This is the highest $\mathrm{R}^{2}$ value recorded for both Tavannes test routes. The lowest being Tavannes route 2 which was equal to 0.94284 . An overall trend that can be seen with the linear regression is that at higher $\mathrm{NO}_{\mathrm{x}}$ concentrations, the NCEM measured higher values. In example, the NCEM read a value of $208.5 \mathrm{ppm}$, while the OBS read a value of $198.2 \mathrm{ppm}$. Another example while the NCEM measured a value of $418.5 \mathrm{ppm}$, OBS read a value of $396.5 \mathrm{ppm}$. For these instances, there is a percentage error equal to $5.196 \%$, and $5.548 \%$, respectively. This might be associated with the different location of the $\mathrm{NO}_{\mathrm{x}}$ measurement equipment. For the NCEM the $\mathrm{NO}_{\mathrm{x}}$ measurement is a direct mount sensor, for the OBS, the gas emission sample must be routed to the unit. 


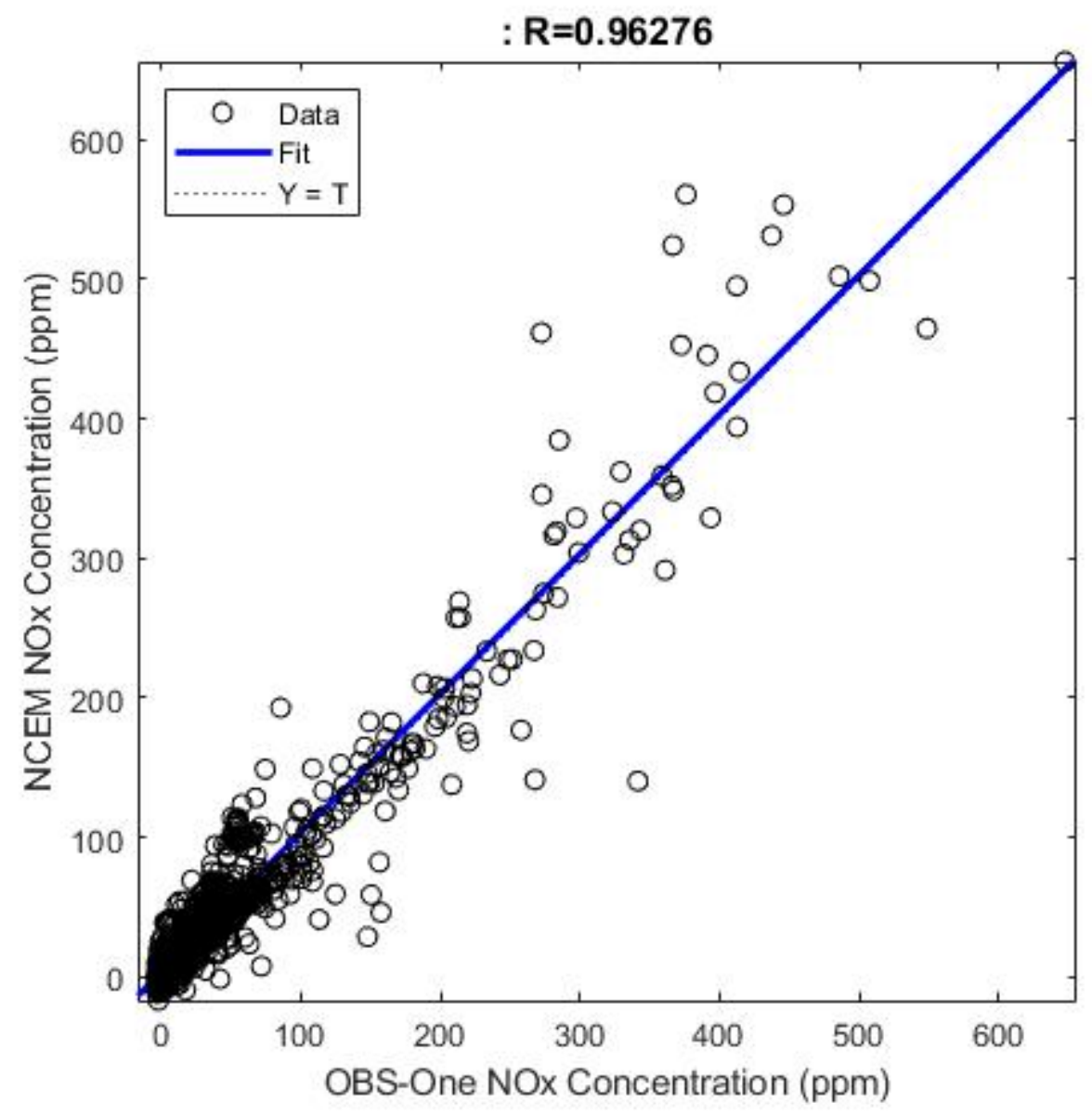

Figure 24: Linear Regression for Tavannes $1 \mathrm{NO}_{\mathrm{x}}$ Overall

Table 8: Overall Tavannes NOx $\mathbf{R}^{2}$ Values

\begin{tabular}{|l|l|}
\hline Tavannes 1 & 0.96276 \\
\hline Tavannes 2 & 0.95116 \\
\hline
\end{tabular}

\subsubsection{3 $\mathrm{NO}_{\mathrm{x}}$ Concentration Binning - $10 \mathrm{ppm}$ Bin Size}

The $10 \mathrm{ppm}$ bin data analysis was set up to analyze data from a $10 \mathrm{ppm}$ increment. This analysis averaged the $\mathrm{NO}_{\mathrm{x}}$ concentrations within a range of 0-10 ppm, 10-20 ppm, and etc. This technique of data analysis is used to take the average, and in some instances reduce outliers in the data set. In Figure 25 below, the data was recorded during the second test route RDE route. This data was used because of its higher $\mathrm{R}^{2}$ values on the regression 
plots associated with this test route. The $\mathrm{R}^{2}$ value of RDE 2 is equal to 0.97562 . Tavannes 2 has an $\mathrm{R}^{2}$-value of 0.93836 , for the $10 \mathrm{ppm}$ increment binning technique. At the $100 \mathrm{ppm}$ concentration level, the NCEM measured a value of $91.79 \mathrm{ppm}$, while the OBS measured a value of $104.5 \mathrm{ppm}$. At the $200 \mathrm{ppm}$ concentration level, the NCEM measured a value of $191 \mathrm{ppm}$, while the OBS recorded a concentration of $197.6 \mathrm{ppm}$. At the $400 \mathrm{ppm}$ concentration level, the NCEM measured a value of $397.7 \mathrm{ppm}$, while the OBS recorded a concentration of $393.7 \mathrm{ppm}$. The corresponding percent errors associated with the differences are, $-12.163 \%$ for the 100 ppm concentration level data point. For the $200 \mathrm{ppm}$ concentration level data point, the percent error was equal to $-3.340 \%$. For the first 400 ppm concentration level data point, the percent error was equal to $1.016 \%$. The trend is displayed in this data point analysis is that the lower $\mathrm{NO}_{\mathrm{x}}$ concentration is associated with correlation between the sensors.

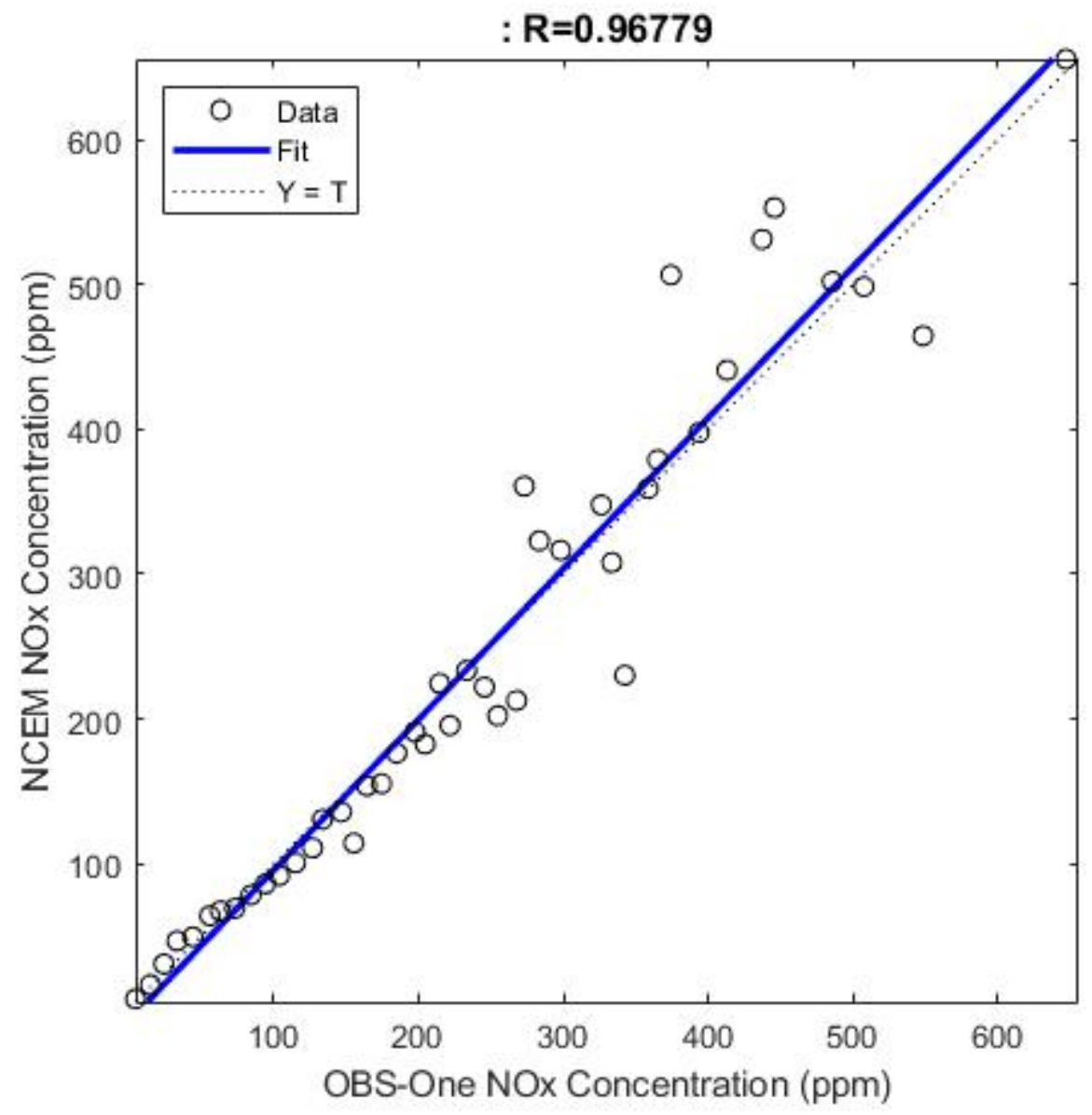

Figure 25: Linear Regression Tavannes 1 NO$_{\mathrm{x}}$ Concentration Binning - 10 ppm Bins 
Table 9: Tavannes NOx 10 ppm Bins $R^{2}$ Values

\begin{tabular}{|l|l|}
\hline Tavannes 1 & 0.96779 \\
\hline Tavannes 2 & 0.93836 \\
\hline
\end{tabular}

The 10 ppm bin data analysis was set up to analyze data in a 10 ppm average increment. Figure 26 show the error percentage that is shown in the $10 \mathrm{ppm}$ binning of this dataset. The error percentage displays the NCEMs data points error offset when compared to the OBS data points. The Tavannes 1 route had a maximum percent error of $28 \%$, and a minimum of $0 \%$ error. The Tavannes 1 test route displays a maximum range of $-28 \%$ to 28\%. The negative error percentage shows the NCEM is recording lower concentration levels than the reference unit, and the positive error percentage shows the NCEM is recording higher concentrations than the OBS.

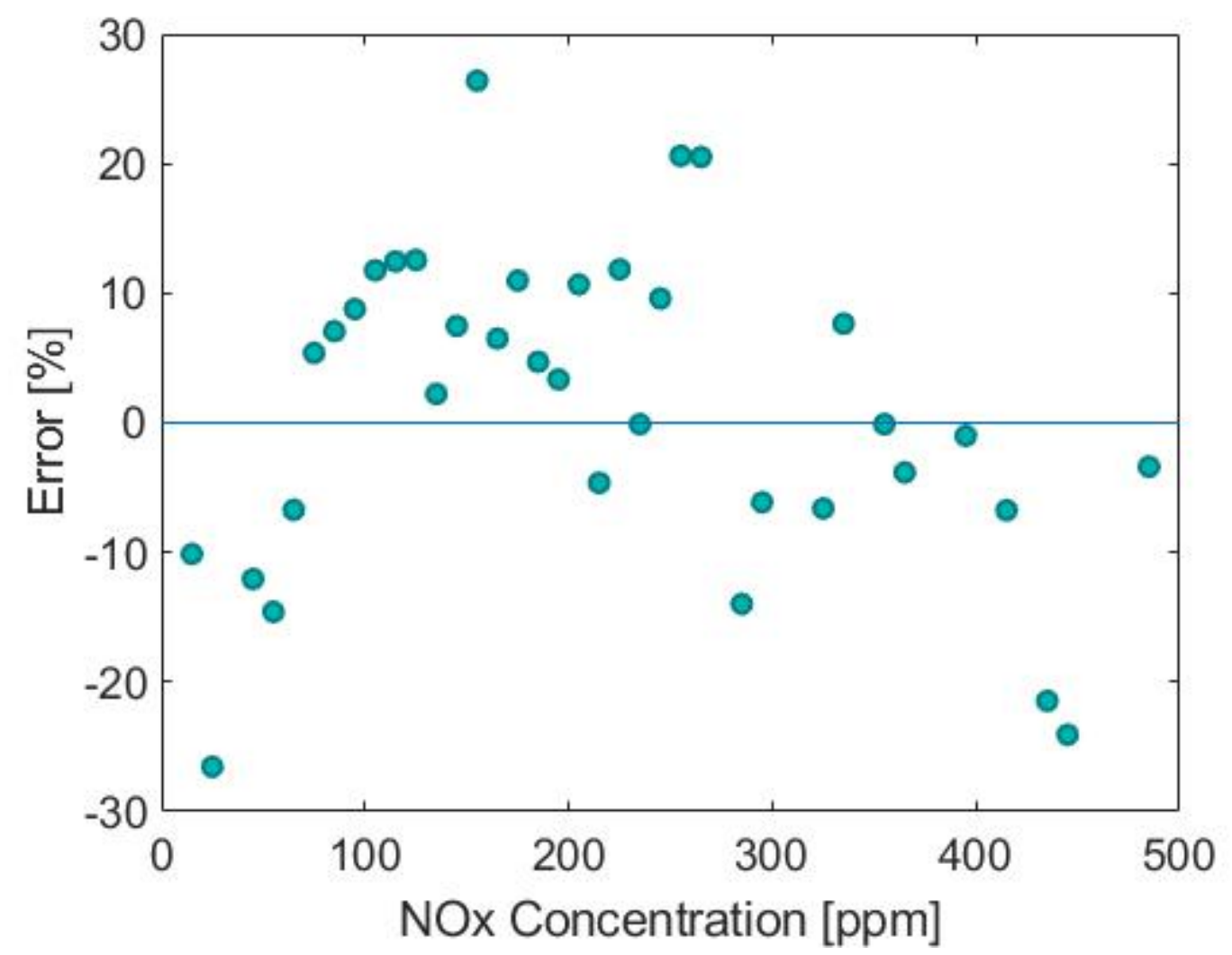

Figure 26: Error Percentage Tavannes $1 \mathrm{NO}_{\mathrm{x}}$ Concentration Binning - 10 ppm Bins 


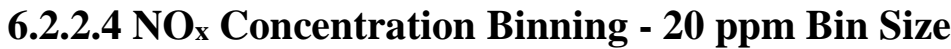

The 20 ppm increment binning technique was used again for the Tavannes routes. The Figure 27 below shows the 20 ppm binning. For the first Tavannes route, the $\mathrm{R}^{2}$ value is 0.97634 , this was highest $\mathrm{R}^{2}$ value for the both of the Tavannes test routes. For the Tavannes 2 route, the $R^{2}$ value associated with this graph is 0.94286 . The average $R^{2}$ value between the Tavannes 20 PPM binning graphs is equal to 0.9596. When compared to the 10 ppm binning, the 20 ppm takes a larger range of data points and takes the average. At the 100 ppm concentration level, the NCEM measured a value of 94.79 ppm, while the OBS measured a value of $107.7 \mathrm{ppm}$. At the $200 \mathrm{ppm}$ concentration level, the NCEM measured a value of $207.9 \mathrm{ppm}$, while the OBS recorded a concentration of $210.7 \mathrm{ppm}$. At the 500 ppm concentration level, the NCEM measured a value of $502 \mathrm{ppm}$, while the OBS recorded a concentration of $485.6 \mathrm{ppm}$. The corresponding percent errors associated with the differences are, $-11.987 \%$ for the 100 ppm concentration level data point. For the 200 ppm concentration level data point, the percent error was equal to $-1.3289 \%$. For the first 500 ppm concentration level data point, the percent error was equal to $3.377 \%$. The trend is displayed in this data point analysis is that the lower $\mathrm{NO}_{\mathrm{x}}$ concentration is associated with correlation between the sensors. 


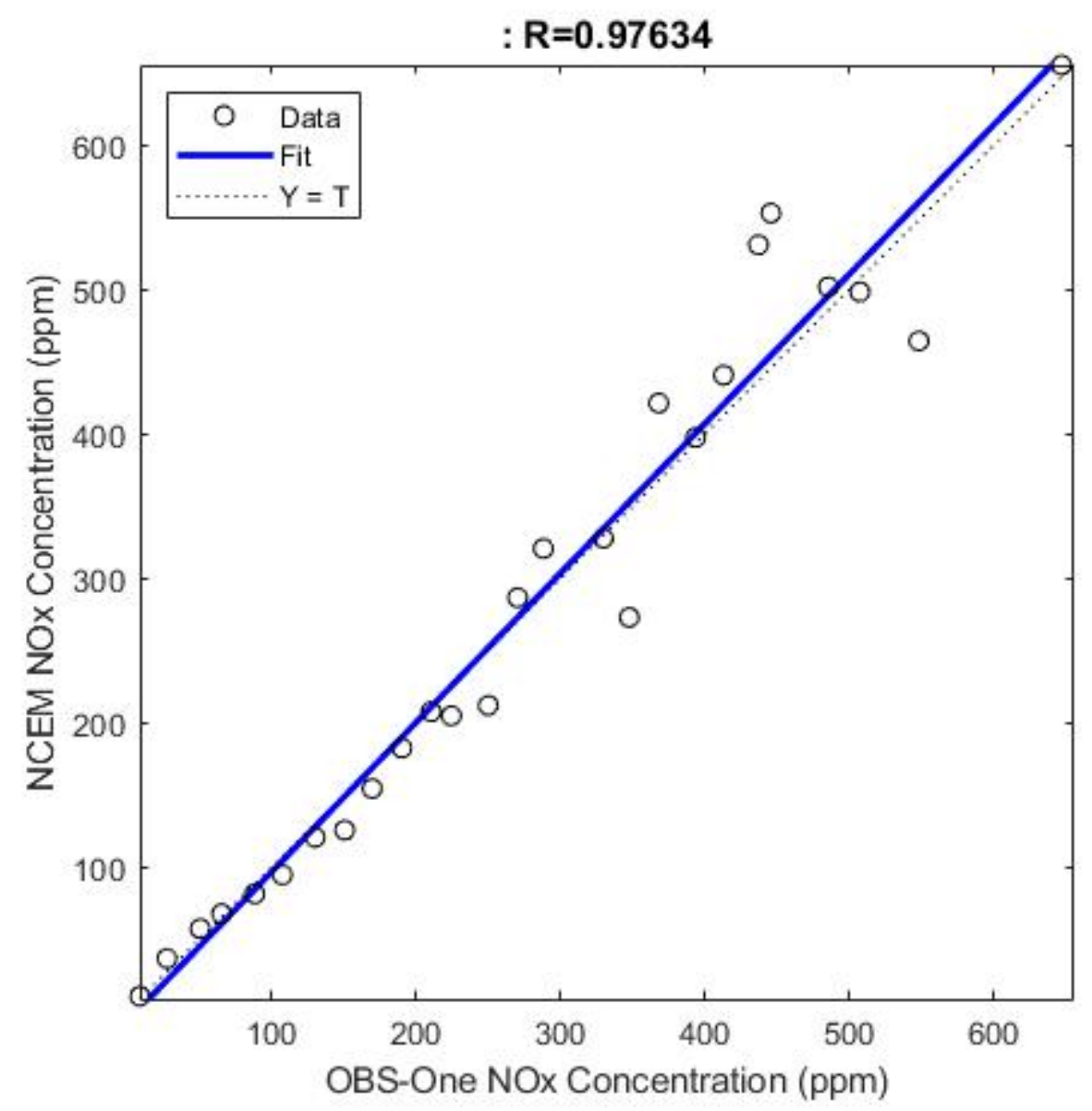

Figure 27: Linear Regression Tavannes 1 NO $\mathrm{x}_{\mathrm{x}}$ Concentration Binning - 20 ppm Bins

Table 10: Tavannes NOx 20 ppm Bins $\mathbf{R}^{2}$ Values

\begin{tabular}{|l|l|}
\hline Tavannes 1 & 0.97634 \\
\hline Tavannes 2 & 0.94286 \\
\hline
\end{tabular}

The 20 ppm bin error percentage shows the NCEMs error when compared to the same point associated to the OBS ONE. Figure 28 shows the error percentage that is calculated in the associated binning graph. The Tavannes routes showed a maximum range of $-25 \%$ and a minimum of $1 \%$ error. The Tavannes test route $20 \mathrm{ppm}$ error percentage displays a variation in error percentages, this correlation shows that the NCEM was 
measuring elevated and lowered data points, when compared to the OBS. The data shows the OBS reads higher $\mathrm{NO}_{\mathrm{x}}$ levels at lower $\mathrm{NO}_{\mathrm{x}}$ concentrations.

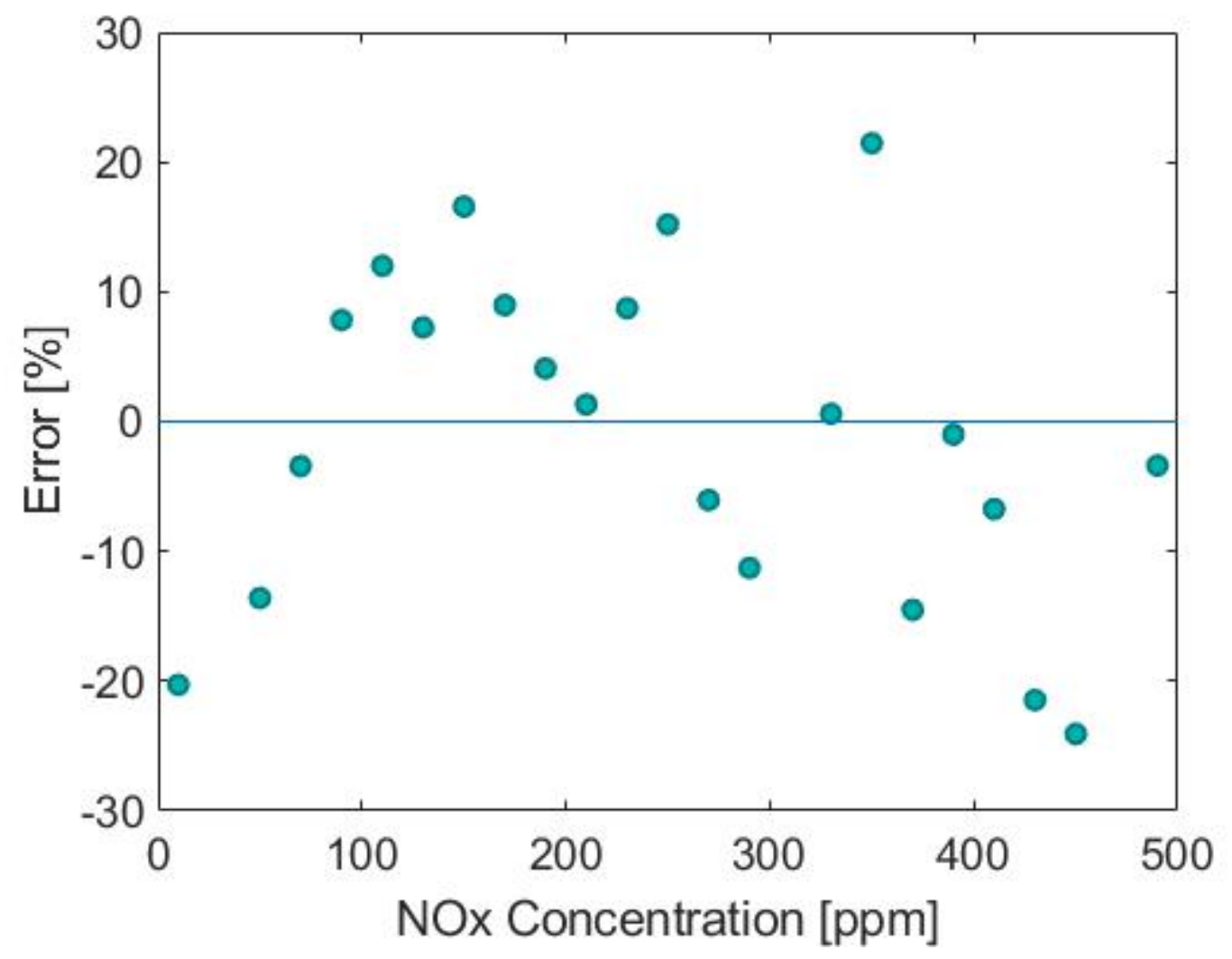

Figure 28: Error Percentage Tavannes 1 NO$_{x}$ Concentration Binning - 20 ppm Bins

\subsubsection{Highway Loop - Highway Operation on Flat Terrain}

The Highway loop route consisted of constant highway speeds. The engine when started was warm during both highway test routes. These constant high speed resulted in lower $\mathrm{NO}_{\mathrm{x}}$ concentrations. Figure 44 in the appendix can be used as a reference.

\subsubsection{Overall Highway Loop Route NOx Emissions Comparison}

The Figure 29 below shows the report data on a raw $\mathrm{NO}_{\mathrm{x}}$ gaseous emissions with the corresponding vehicle speed that was collected for the highway 2 from both PEMS units, the red is NCEM, and the blue is the OBS-ONE, and the green is the vehicle speed. The vehicle speed is correlated with the $\mathrm{NO}_{\mathrm{x}}$ concentrations, the duration of the constant highway speeds showed low $\mathrm{NO}_{\mathrm{x}}$ concentrations. The first 250 seconds of this test is 
similar to the Tavannes route, with respect to the warm start-up routine. Throughout this test route negative $\mathrm{NO}_{\mathrm{x}}$ concentration levels can be seen on the graph.

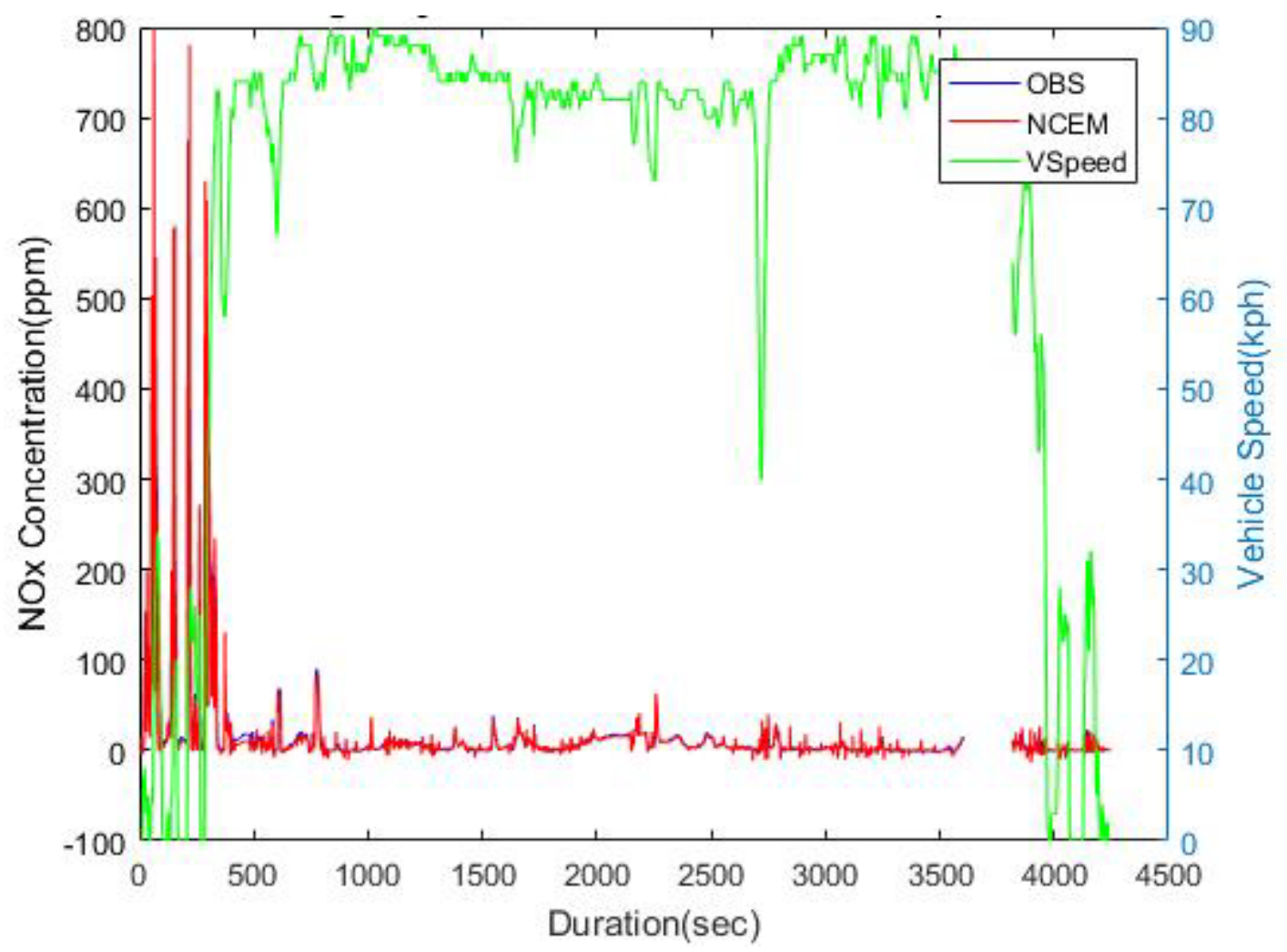

Figure 29: Highway 2 NO$_{x}$ Raw Data with Vehicle Speed

The Figure 30 below shows the report data on a QQ plot of the raw $\mathrm{NO}_{\mathrm{x}}$ gaseous emissions collected for the highway 2 from both PEMS units. The red line is the linear comparison line, the closer the blue marks are to the line they more comparable the data. The QQ plot displays the linearity of the two sensors, as the increase in $\mathrm{NO}_{\mathrm{x}}$ concentration. Some points at on the graph will show a representation of the data. At the $100 \mathrm{ppm}$ concentration level, the NCEM measured $79.5 \mathrm{ppm}$, while the OBS measured $96.23 \mathrm{ppm}$. At the 200 ppm concentration level, the NCEM measured 179 ppm, and the OBS measured $200.29 \mathrm{ppm}$. At the $600 \mathrm{ppm}$ level, the NCEM measured $780.5 \mathrm{ppm}$, and the OBS measured $619.0447 \mathrm{ppm}$. The corresponding percent error with these values are $-17.29 \%$ for the 100 ppm concentration, $-10.6296 \%$ for the 200 ppm concentration, $-26.0814 \%$ for the 600 ppm concentration. As shown in the trend provided by the values, at the higher $\mathrm{NO}_{\mathrm{x}}$ concentrations the NCEM measured higher values. 


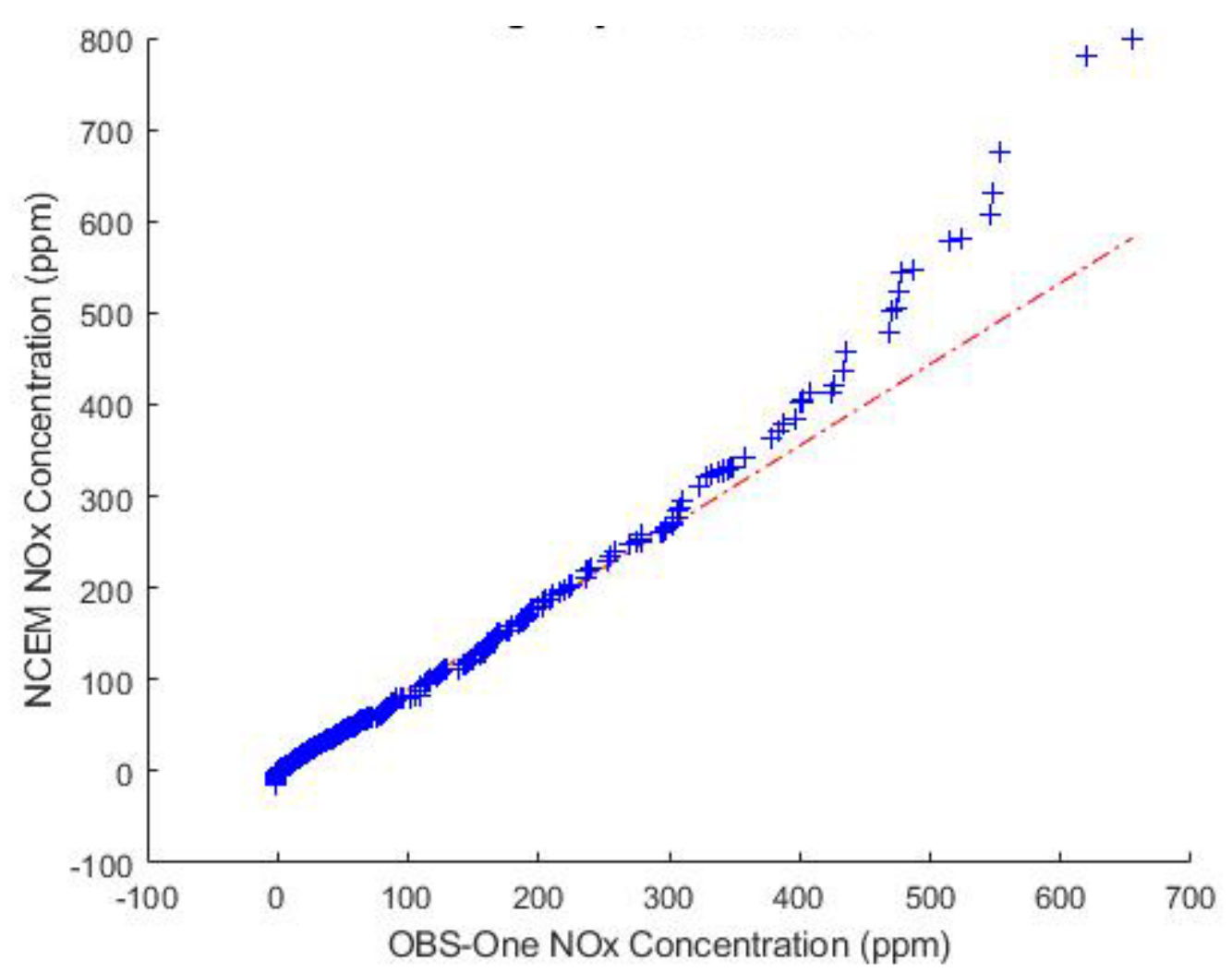

Figure 30: Highway $2 \mathrm{NO}_{x} \mathrm{QQ}$ Plot

The Figure 31 below shows the report data on a linear regression plot of $\mathrm{NO}_{\mathrm{x}}$ gaseous emissions collected for the second highway test route from both PEMS units. The corresponding $\mathrm{R}^{2}$-value to this linear regression is 0.97227 . This is the highest $\mathrm{R}^{2}$ value recorded for both highway test routes. The lowest being highway route 1 which was equal to 0.93313 . An overall trend that can be seen with the linear regression is that at higher $\mathrm{NO}_{\mathrm{x}}$ concentrations, the NCEM measured higher values. In example, the NCEM read a value of $101 \mathrm{ppm}$, while the OBS read a value of $104.7 \mathrm{ppm}$. Another example while the NCEM measured a value of $546 \mathrm{ppm}$, OBS read a value of $546 \mathrm{ppm}$. For these instances, there is a percentage error equal to $-3.5339 \%$, and $0 \%$, respectively. For the highway test route, there was a linear relationship. Both units' sensors measured negative $\mathrm{NO}_{\mathrm{x}}$. 


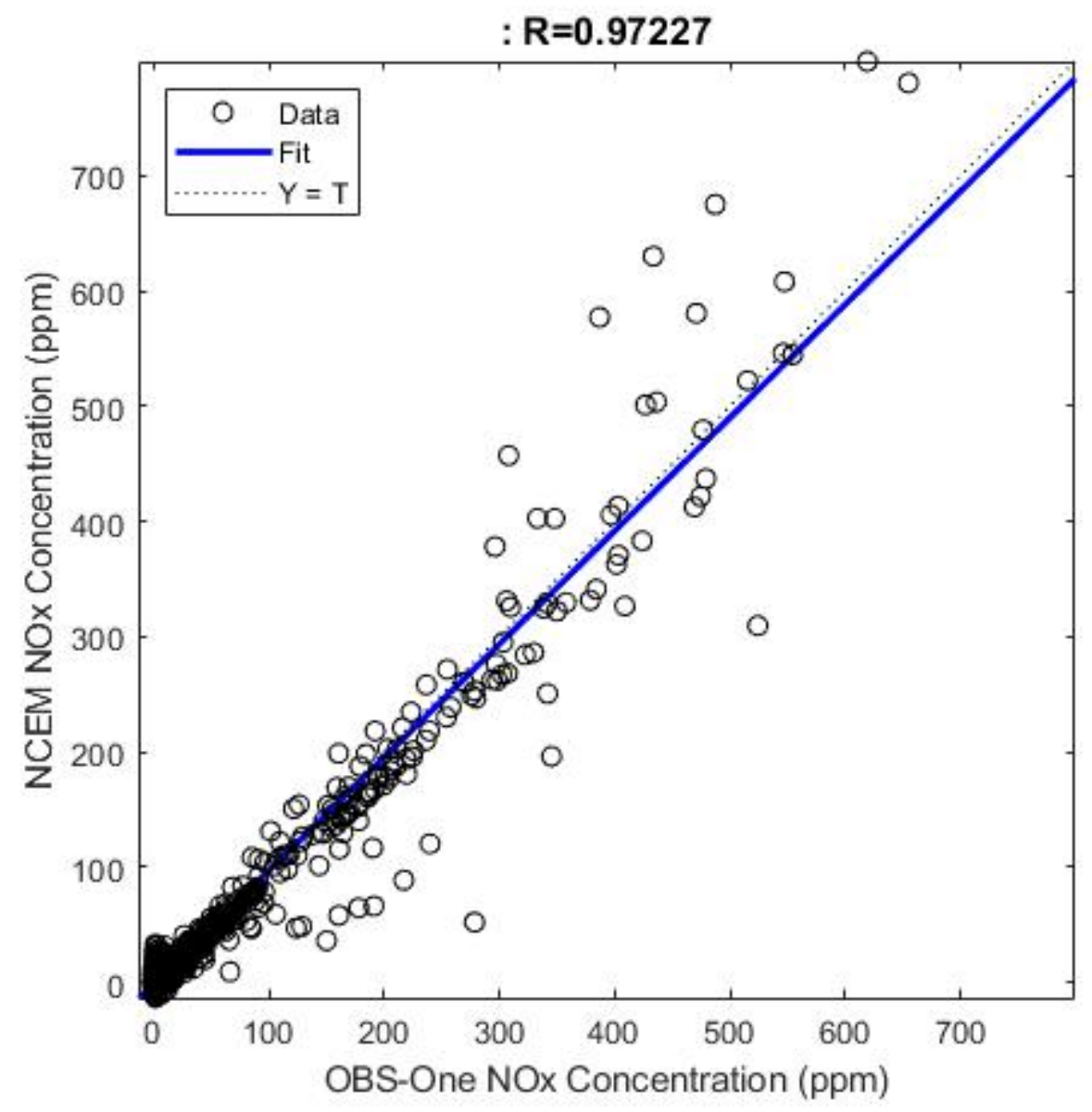

Figure 31: Linear Regression for Highway $2 \mathrm{NO}_{\mathrm{x}}$ Overall

Table 11: Overall Highway NOx $\mathbf{R}^{2}$ Values

\begin{tabular}{|l|l|}
\hline Highway 1 & 0.93313 \\
\hline Highway 2 & 0.97227 \\
\hline
\end{tabular}

\subsubsection{3 $\mathrm{NO}_{\mathrm{x}}$ Concentration Binning - $10 \mathrm{ppm}$ Bin Size}

The $10 \mathrm{ppm}$ bin data analysis was set up to analyze data from a $10 \mathrm{ppm}$ increment. This analysis averaged the $\mathrm{NO}_{\mathrm{x}}$ concentrations within a range of 0-10 ppm, 10-20 ppm, and etc. This technique of data analysis is used to take the average, and in some instances reduce outliers in the data set. In Figure 32 below, the data was recorded during the second test route highway route. This data was used because of its higher $\mathrm{R}^{2}$ values on the 
regression plots associated with this test route. The $\mathrm{R}^{2}$ value of highway 2 is equal to 0.9566. Highway 1 has an $\mathrm{R}^{2}$-value of 0.85369 , for the $10 \mathrm{ppm}$ increment binning technique. At the $100 \mathrm{ppm}$ concentration level, the NCEM measured a value of $102.5 \mathrm{ppm}$, while the OBS measured a value of $106.5 \mathrm{ppm}$. At the $200 \mathrm{ppm}$ concentration level, the NCEM measured a value of $186.7 \mathrm{ppm}$, while the OBS recorded a concentration of 205 $\mathrm{ppm}$. At the $400 \mathrm{ppm}$ concentration level, the NCEM measured a value of $405.5 \mathrm{ppm}$, while the OBS recorded a concentration of $396.6 \mathrm{ppm}$. The corresponding percent errors associated with the differences are, $-3.755 \%$ for the $100 \mathrm{ppm}$ concentration level data point. For the $200 \mathrm{ppm}$ concentration level data point, the percent error was equal to $8.9268 \%$. For the first $400 \mathrm{ppm}$ concentration level data point, the percent error was equal to $2.2441 \%$. The $100 \mathrm{ppm}$ binning technique showed a linear relationship between both sensors.

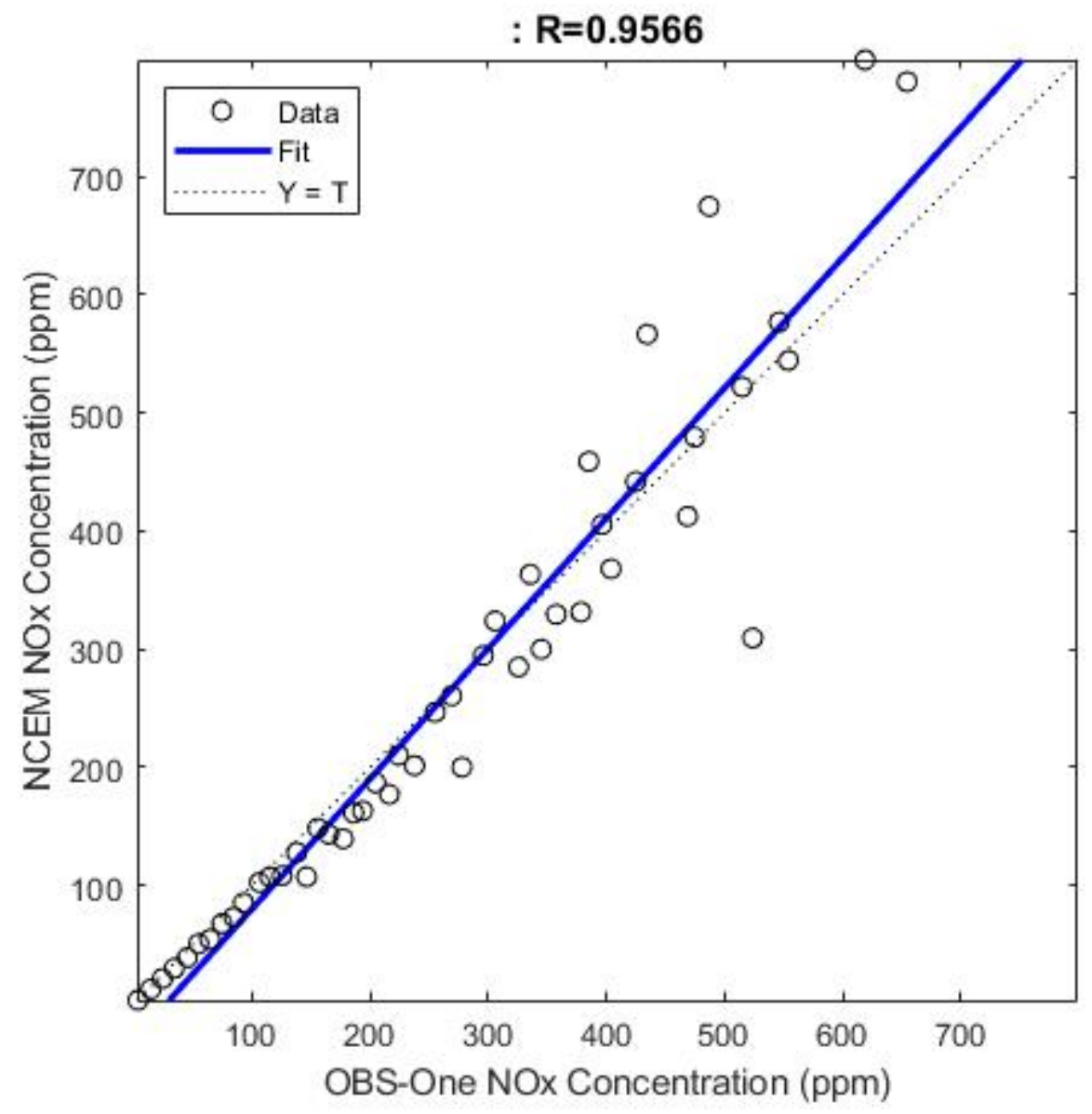

Figure 32: Linear Regression Highway 2 NO $_{x}$ Concentration Binning - 10 ppm Bins 
Table 12: Highway NOx 10 ppm Bins $R^{2}$ Values

\begin{tabular}{|l|l|}
\hline Highway 1 & 0.85369 \\
\hline Highway 2 & 0.9566 \\
\hline
\end{tabular}

The $10 \mathrm{ppm}$ bin error percentage data analysis was set up to analyze data in a 10 ppm average increment. Figure 33 show the error percentage that is calculated for the 10 ppm binning of the second highway test route. The highway 1 and 2 error percentage graphs show a correlation between error percentage and $\mathrm{NO}_{\mathrm{x}}$ concentration. The range on the graph below is $-20 \%$ to $28 \%$. With a data point that measured within $1 \%$ of the OBS.

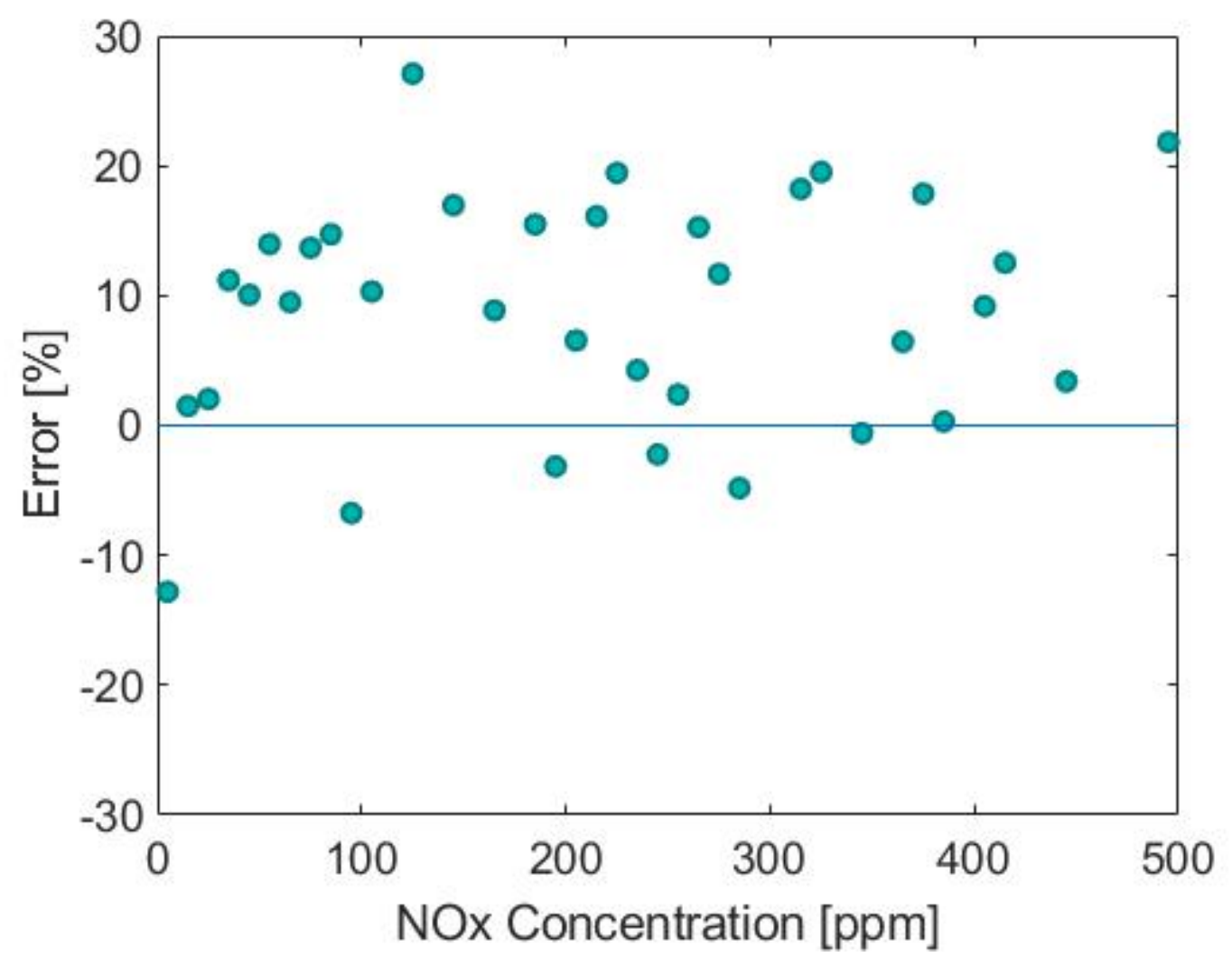

Figure 33: Error Percentage Highway $2 \mathrm{NO}_{\mathrm{x}}$ Concentration Binning - 10 ppm Bins 


\subsubsection{NO${ }_{x}$ Concentration Binning - 20 ppm Bin Size}

The $20 \mathrm{ppm}$ bin data analysis was set up to analyze data from a $20 \mathrm{ppm}$ increment. This analysis averaged the $\mathrm{NO}_{\mathrm{x}}$ concentrations within a range of 0-20 ppm, 20-40 ppm, and etc. This technique of data analysis is used to take the average, and in some instances reduce outliers in the data set. In Figure 34 below, the data was recorded during the second test route highway route. This data was used because of its higher $\mathrm{R}^{2}$ values on the regression plots associated with this test route. The $\mathrm{R}^{2}$ value of highway 2 is equal to 0.94872. Highway 1 has an $\mathrm{R}^{2}$-value of 0.88136 , for the $20 \mathrm{ppm}$ increment binning technique. At the 100 ppm concentration level, the NCEM measured a value of $104.4 \mathrm{ppm}$, while the OBS measured a value of $109.9 \mathrm{ppm}$. At the $200 \mathrm{ppm}$ concentration level, the NCEM measured a value of 162.2 ppm, while the OBS recorded a concentration of 189.7 $\mathrm{ppm}$. At the $400 \mathrm{ppm}$ concentration level, the NCEM measured a value of $368.1 \mathrm{ppm}$, while the OBS recorded a concentration of $404 \mathrm{ppm}$. The corresponding percent errors associated with the differences are, $-5.0045 \%$ for the 100 ppm concentration level data point. For the $200 \mathrm{ppm}$ concentration level data point, the percent error was equal to $-14.4966 \%$. For the first 400 ppm concentration level data point, the percent error was equal to $-8.8861 \%$. The 20 ppm binning technique showed a linear relationship between both sensors. 


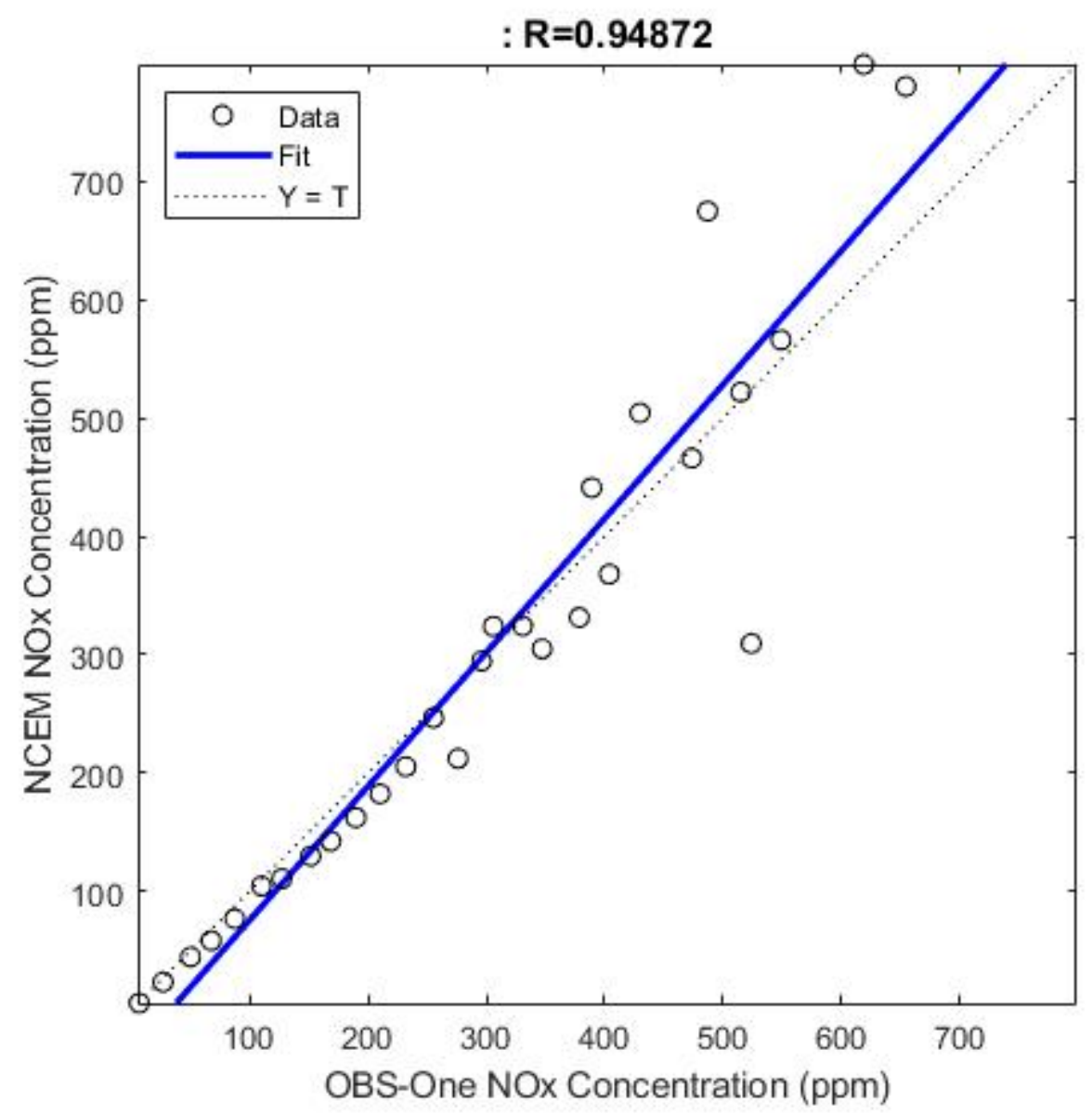

Figure 34: Linear Regression Highway $2 \mathrm{NO}_{\mathrm{x}}$ Concentration Binning - 20 ppm Bins

Table 13: Highway NOx 20 ppm Bin $R^{2}$ Values

\begin{tabular}{|l|l|}
\hline Highway 1 & 0.88136 \\
\hline Highway 2 & 0.94872 \\
\hline
\end{tabular}

The 20 ppm binning error percentage data analysis was set up to analyze data error in a 20 ppm average increment. Figure 35 displays the error percentage that is calculated for the highway 2 test route. The highway 2 route showed an error percentages range of $17.3 \%$ to $23.1 \%$. With the majority of the data points trending towards a negative error percentage. This trend shows that the NCEM was reading lower $\mathrm{NO}_{\mathrm{x}}$ concentrations than the reference unit. 


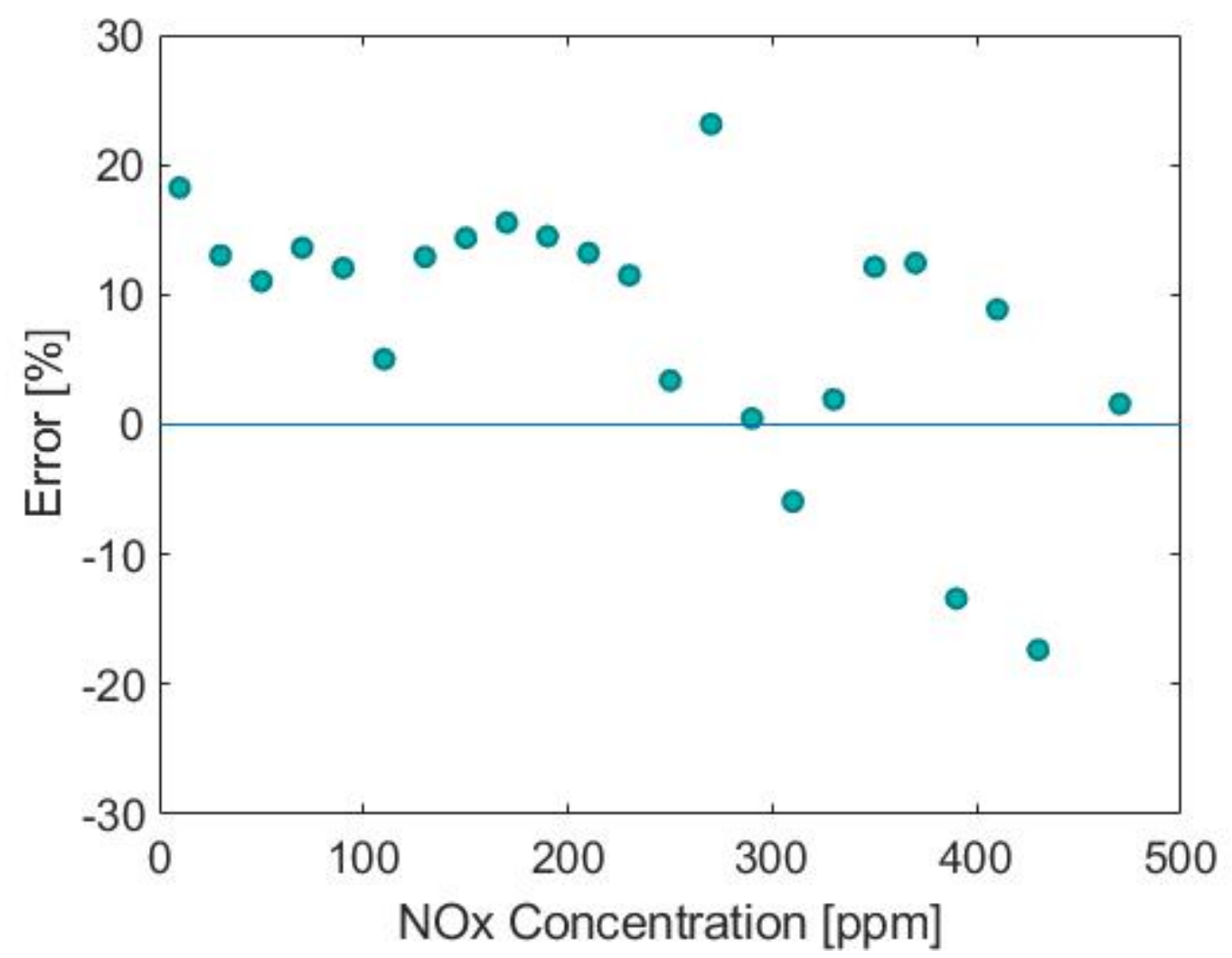

Figure 35: Error Percentage Highway $2 \mathrm{NO}_{\mathrm{x}}$ Concentration Binning - 20 ppm Bins

\subsection{Comparison of PN Concentration Measurements}

\subsubsection{Real Driving Emissions Routes}

This section covers the PN emissions analysis performed on all three RDE routes, these routes consisted of four portions. The first portion which had a duration of 500 seconds was considered the cold start portion. The second portion which lasted until the distance traveled reached a value of $25.1 \mathrm{~km}$, this portion was called the urban portion. The third portion which included data from the end of the second portion to a distance of 60.5 $\mathrm{km}$, was considered the rural portion. The last portion of the RDE test route, was called the highway portion it consisted of the data after $60.5 \mathrm{~km}$ had been traveled.

\subsubsection{Overall RDE 1 Route PN Comparison Analysis}

For the first RDE test route, Figure 36 shows the data that was collected over the duration of the entire test route. The first 500 seconds of this test was the cold start portion, 
during this time interval the NCEM measured elevated $\mathrm{NO}_{\mathrm{x}}$ concentration levels. For one data point, the NCEM recorded a value of $7.78 * 10^{6} \frac{\mathrm{A}}{\mathrm{cm}^{3}}$, while the corresponding OBS value recorded a value of $4.01 * 10^{6} \frac{\#}{\mathrm{~cm}^{3}}$, This is equal to a percent error equal to $-94.01 \%$. This was just one example of how inaccurate this dataset was. The NCEM would measure elevated values when compared to the OBS. The reason for this is because the OBS has a measurement cut-off point. The NCEM can measure down to $5 \mathrm{~nm}$, while the OBS cannot measure below $23 \mathrm{~nm}$.

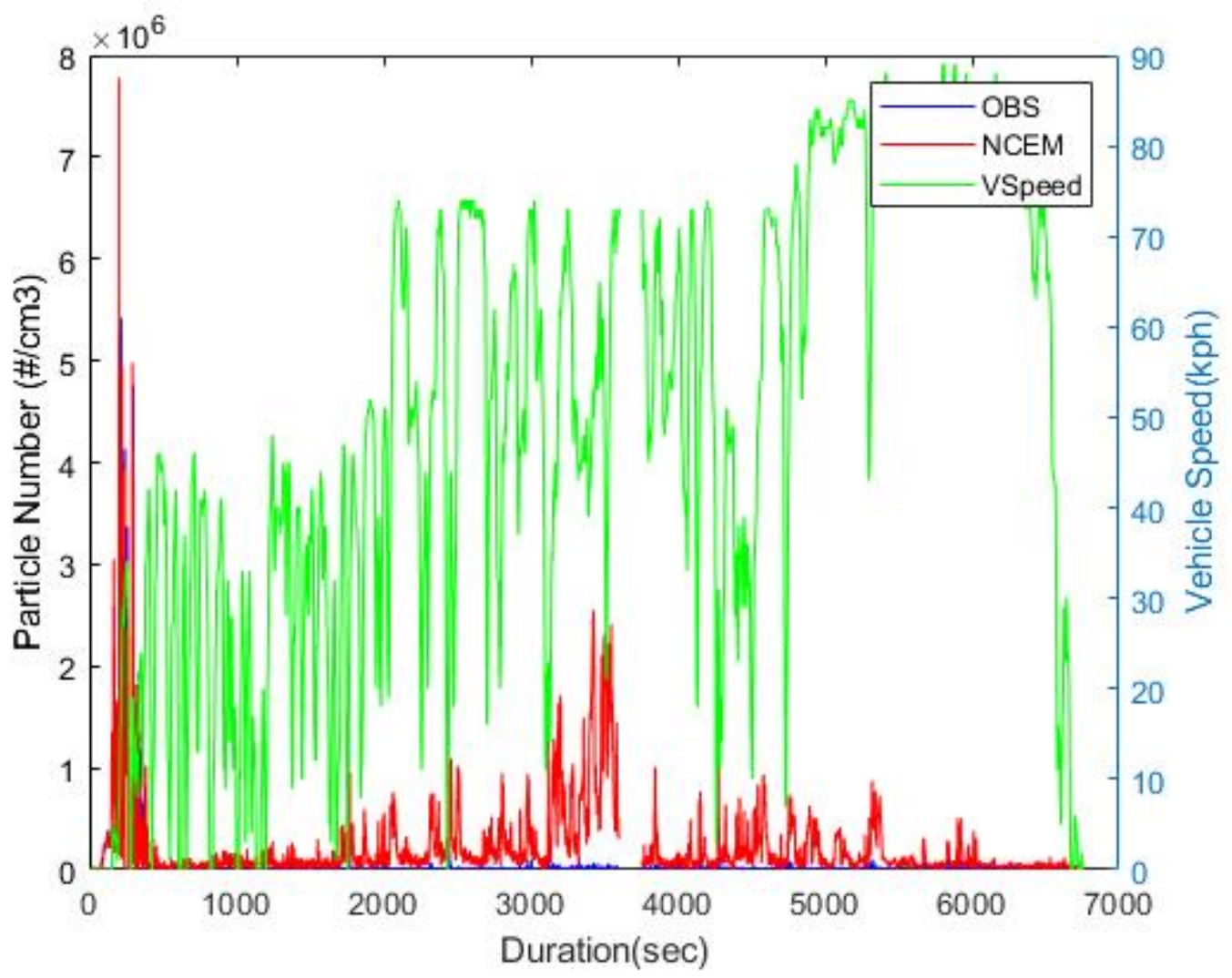

Figure 36: RDE 1 PN Raw Data with Vehicle Speed

For the first RDE test route, Figure 37 below shows the linear regression plot of the data collected over the duration of the test route. The $\mathrm{R}^{2}$ value associated with this graph is equal to 0.58044 . This low $\mathrm{R}^{2}$ value shows that the data shows little to no correlation. RDE 2 had an $R^{2}$ value equal to 0.93648 , and the RDE 3 data $R^{2}$ value equaled 0.92743 . These two graphs shown great correlation, they can be referenced in the appendix figures 
95 and 97. The NCEM read a value of $2.66 * 10^{5} \frac{\#}{\mathrm{~cm}^{3}}$, while the OBS read a value of $0 \frac{\#}{\mathrm{~cm}^{3}}$ . An example of correlation is the NCEM measured a value of $4.98 * 10^{6} \frac{\#}{\mathrm{~cm}^{3}}$, OBS read a value of $3.807 * 10^{6} \frac{\#}{\mathrm{~cm}^{3}}$. The percentage error equal to $-30.81 \%$. This might be associated with the different location of the $\mathrm{NO}_{\mathrm{x}}$ measurement equipment. For the NCEM the $\mathrm{NO}_{\mathrm{x}}$ measurement is a direct mount sensor, for the OBS, the gas emission sample must be routed to the unit.

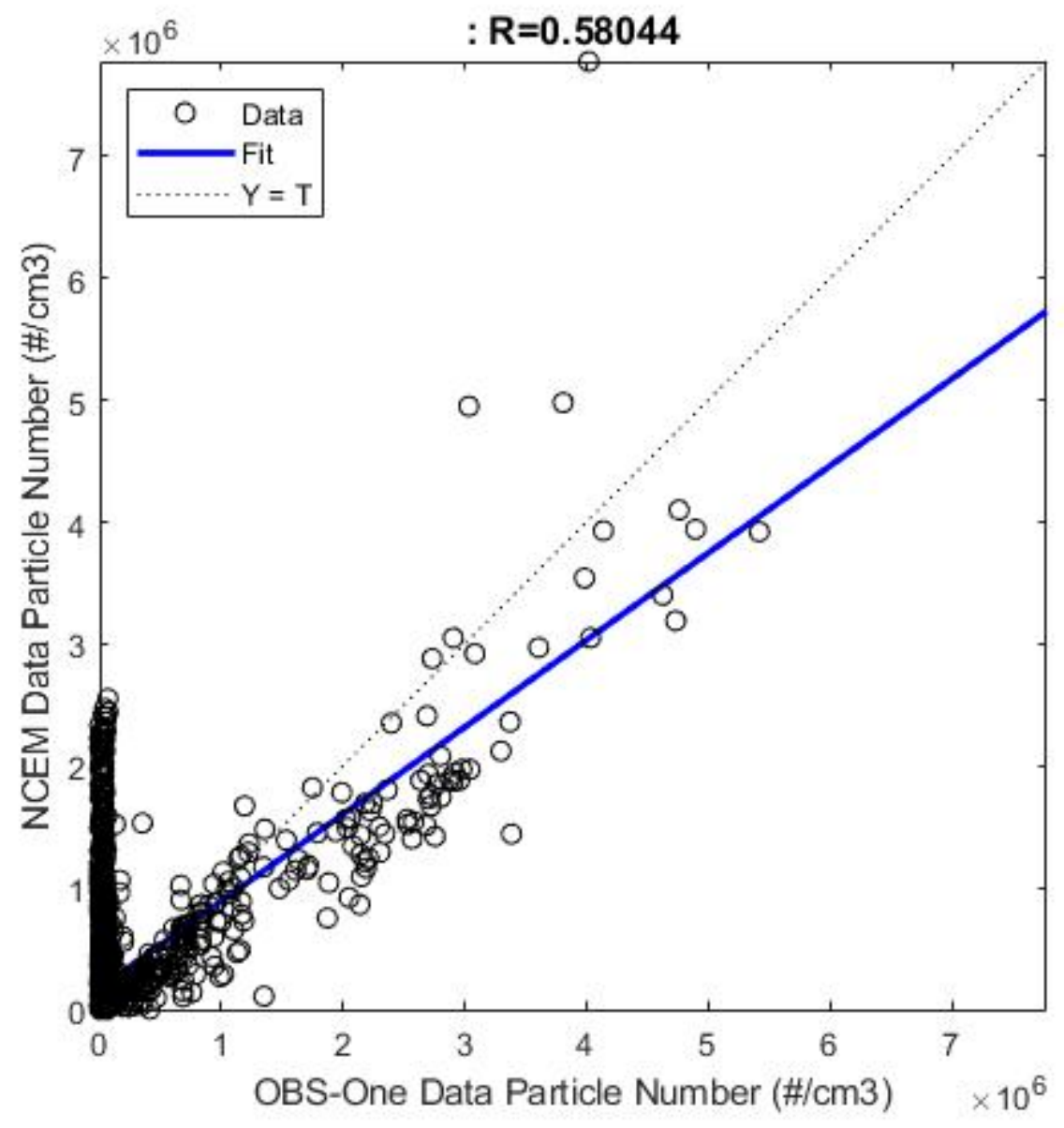

Figure 37: Linear Regression for RDE 1 PN Overall 
Table 14: RDE PN $\mathbf{R}^{2}$ Values

\begin{tabular}{|l|l|}
\hline RDE 1 & 0.58044 \\
\hline RDE 2 & 0.93648 \\
\hline RDE 3 & 0.92743 \\
\hline
\end{tabular}

\subsubsection{Tavannes Routes - Highway Operation with Grade}

The Tavannes test route was performed at a higher altitude. There are many different elevation changes, that are associated with this route. The first important trend to observe is whether or not the altitude effects the PN concentration levels emitted from this truck during operation. This test route began with a warm start which resulted in elevated $\mathrm{NO}_{\mathrm{x}}$ concentrations. This trip included what would be considered as highway speeds mixed with moderate to severe inclines that resulted in heavy load situations. The elevation changes also result in high load changes which can result in higher PN concentration levels.

\subsubsection{Overall Tavannes 2 Route PN Comparison Analysis}

For the second Tavannes test route, Figure 38 below shows the linear regression plot of the data collected over the duration of the test route. The NCEM measured higher levels of PN concentration when compared to the OBS. Similar to the Tavannes 1 the spikes in the data, is most likely due to acceleration and deceleration, although in this data set it is less prevalent. The NCEM is much more sensitive to PN concentration spikes due to its ability to measure lower particle sizes. 


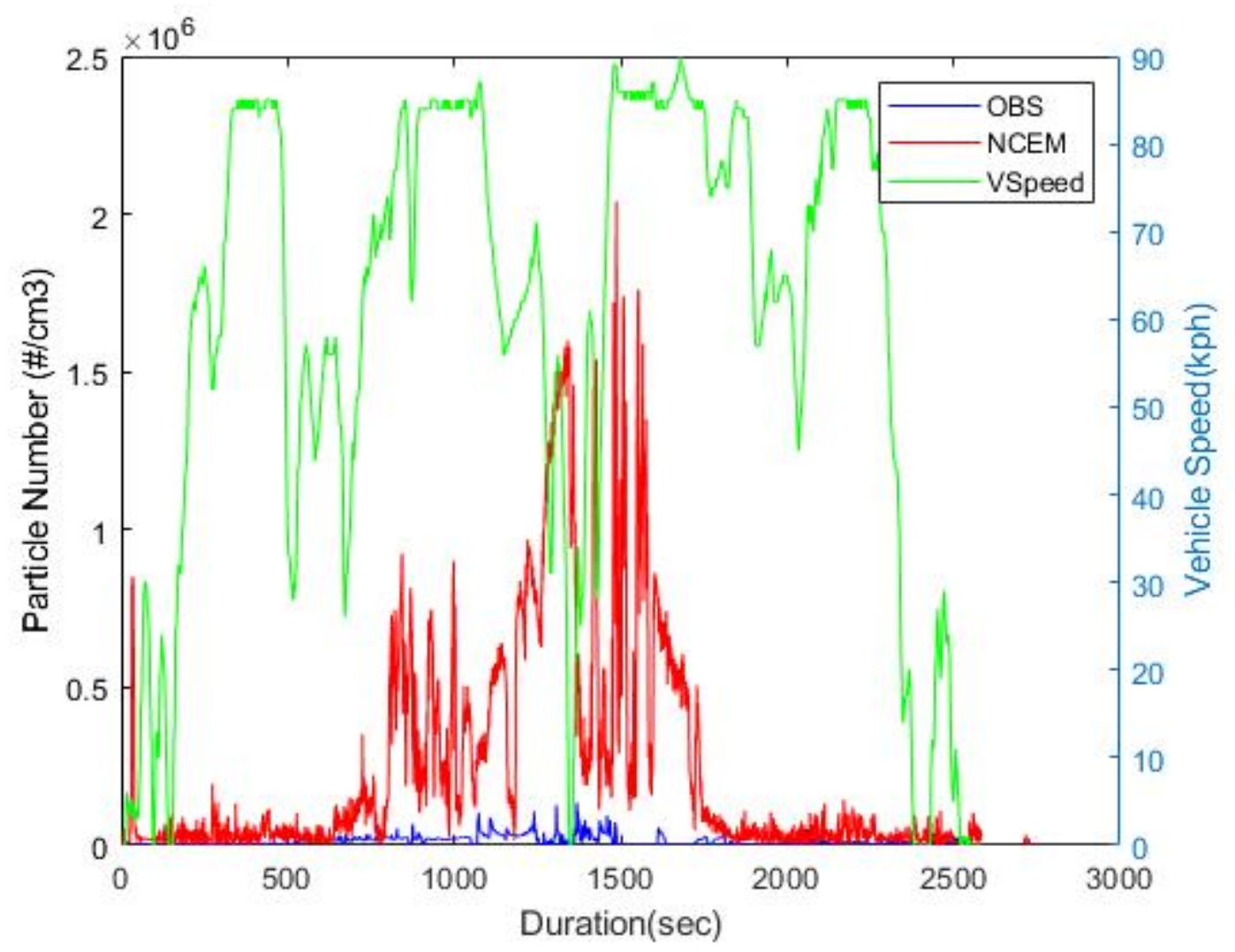

Figure 38:Tavannes 2 PN Raw Data with Vehicle Speed

For the second Tavannes test route, Figure 39 below shows the linear regression plot of the data collected over the duration of the test route. The $\mathrm{R}^{2}$ value associated with figure 39 is equal to 0.66314 . The $\mathrm{R}^{2}$ value associated with the Tavannes 1 route is equal to 0.60186 . The average of the both $R^{2}$ values is equal to 0.626625 . Although this $R^{2}$ value is lower than usual it still shows that there is a correlation of the data, and more data analysis should be performed. An in depth data point analysis is not necessary on this figure, the NCEM was measurement elevated PN concentrations due to the sensors ability to measure smaller particle sizes. 


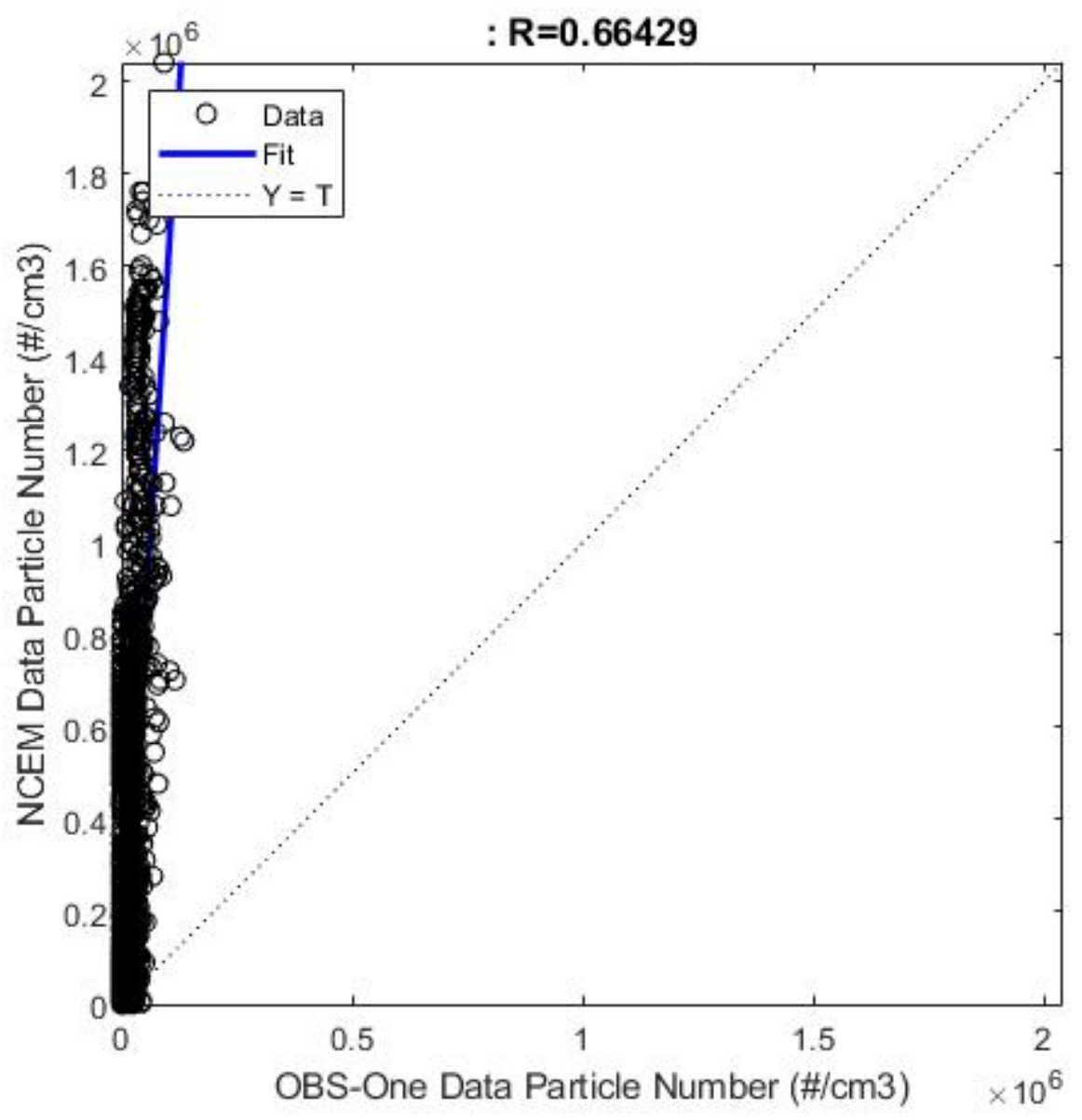

Figure 39: Linear Regression for Tavannes 2 PN Overall

Table 15: Tavannes $\mathbf{P N} \mathbf{R}^{2}$ Values

\begin{tabular}{|l|l|}
\hline Tavannes 1 & 0.60186 \\
\hline Tavannes 2 & 0.66429 \\
\hline
\end{tabular}

\subsubsection{Highway Loop - Highway Operation on Flat Terrain}

\subsubsection{Overall Highway Loop 1 Route PN Comparison Analysis}

For the first highway route, Figure 40 below shows the data collected over the duration of the test route. The highway test route showed some correlation in the raw data chart, but the NCEM still continues to read higher PN concentration levels. These data 
point spikes can be due to the DPF regenerating, because the truck is sensing steady state operation at high heat, and so the soot is being burnt off, spikes can be seen in PN data. Another explanation for these spikes is the truck acceleration which is consisted with high PN concentration spikes.

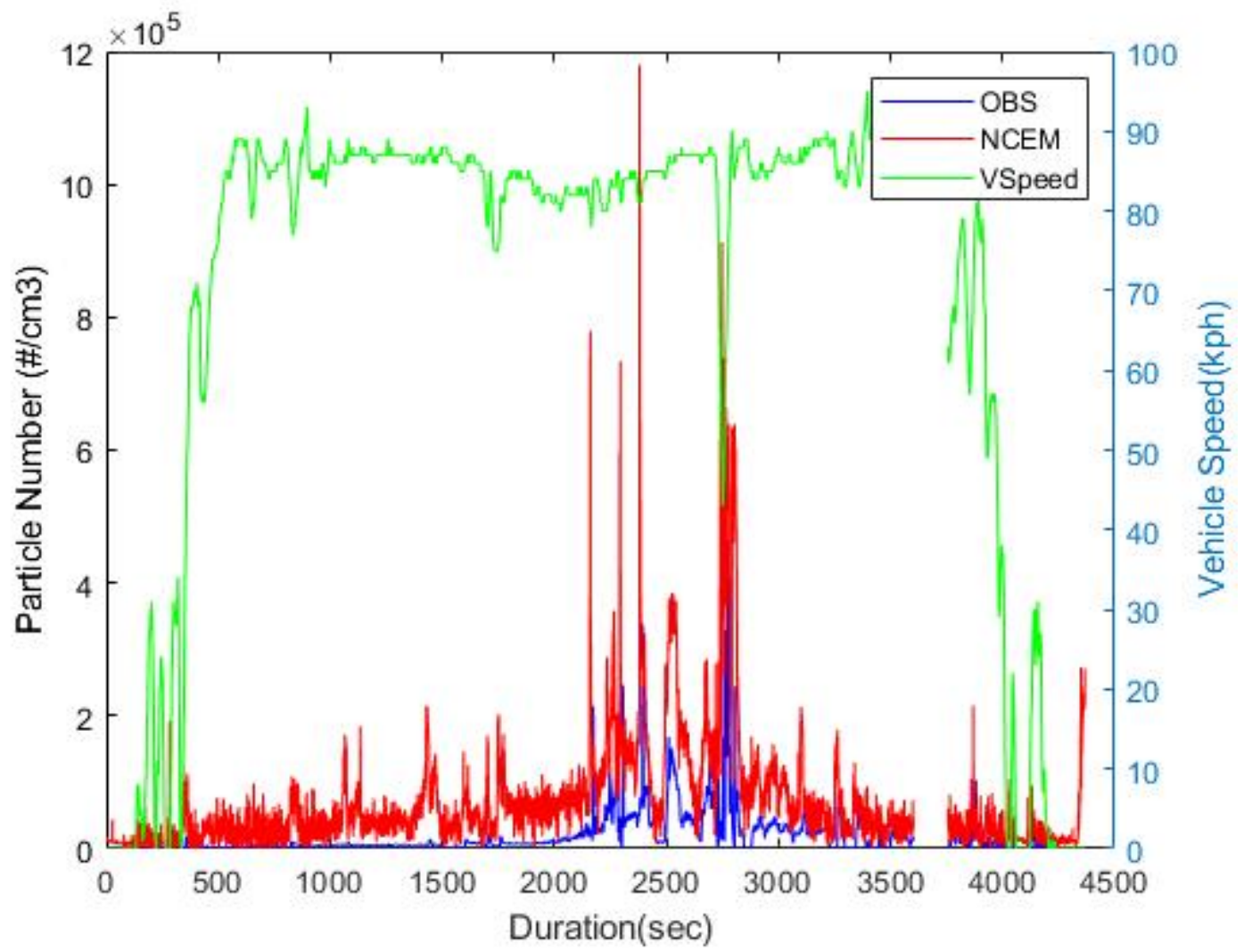

Figure 40: Highway 1 PN Raw Data with Vehicle Speed

For the first highway test route, Figure 41 below shows the linear regression plot of the data collected over the duration of the test route. The $\mathrm{R}^{2}$ value associated with this graph is equal to 0.8186 . This is the highest $\mathrm{R}^{2}$ value of the two highway PN tests. The $\mathrm{R}^{2}$ value associated with highway 2 is equal to 0.7864 . 


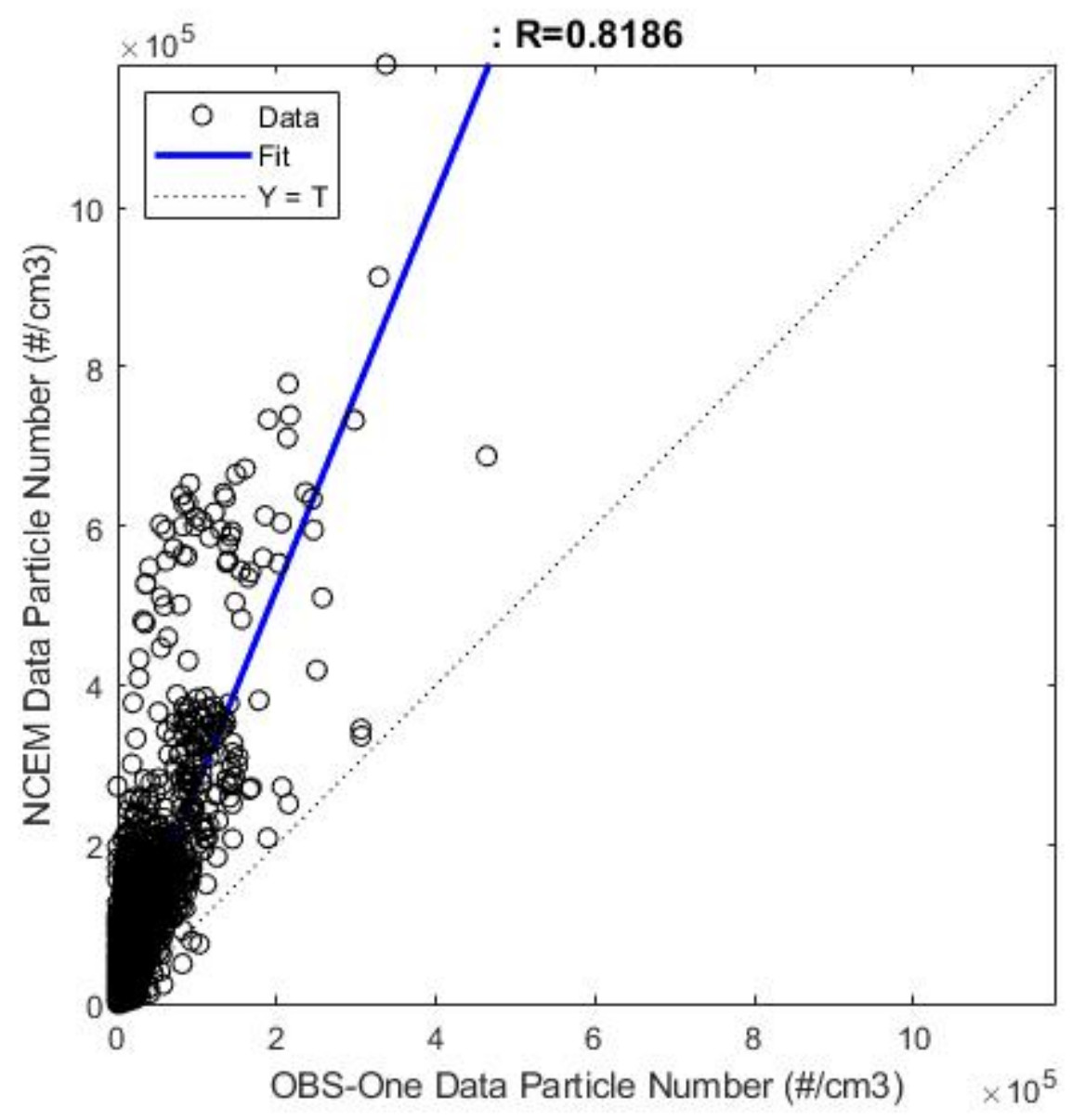

Figure 41: Linear Regression for Highway 1 PN Overall

Table 16: Highway PN $\mathbf{R}^{2}$ Values

\begin{tabular}{|l|l|}
\hline Highway 1 & 0.8186 \\
\hline Highway 2 & 0.78569 \\
\hline
\end{tabular}




\section{Conclusions and Future Work}

\subsection{Conclusions}

This study was conducted to compare the accuracy and repeatability of the sensors and analyzers associated with the NCEM, and the OBS-One. For the $\mathrm{NO}_{\mathrm{x}}$ portion of this study the following results were concluded. During the $\mathrm{NO}_{\mathrm{x}}$ data analysis, the RDE routes produced the highest $\mathrm{R}^{2}$ value of 0.96865 , this was recorded during the overall test of the third RDE route. With this $\mathrm{R}^{2}$ value, it shows that the $\mathrm{ZrO}_{2}$ sensor attached to the NCEM does have the ability to measure $\mathrm{NO}_{\mathrm{x}}$ levels comparable to that recorded by the CLD analyzer attached to OBS-One. The reasoning behind this conclusion is because of the high $\mathrm{R}^{2}$ value that was revealed during the linear regression analysis. During the Tavannes test route, the highest $\mathrm{R}^{2}$ value was present during the first route. The $\mathrm{R}^{2}$ value associated with the Tavannes 1 is equal to 0.96276 . This reinforces the conclusion that the NCEM sensor has the ability to record the values comparable to the OBS-One. The highway recorded the highest $R^{2}$ value during the entire study, it was equal to, 0.97227 . The $R^{2}$ value results display that across the three different test routes the NCEM was capable of measuring $\mathrm{NO}_{\mathrm{x}}$ concentration levels relative to the OBS-One.

The binning technique used in this study allowed for easier comparison of the two data sets from the PEMS units. The $10 \mathrm{ppm}$ increment binning allowed for a smaller population of data to be averaged and analyzed in a narrow spectrum with more data points. The 20 ppm increment binning allowed for a larger population of data to be averaged and analyzed in a broader spectrum with less data points. The error percentages were then used to analyzed the data with their respective binning interval. When comparing the error percentages associated with $10 \mathrm{ppm}$ and $20 \mathrm{ppm}$, a comparison is used to compare a smaller population average vs a larger population average. The binning allowed for smaller intervals of data to be analyzed. The NCEM showed equal variance when compared to the OBS-One. 
For the PN concentrations the following conclusions can be made about the results. In the RDE 1 test route, during the cold start, the NCEM was reading extremely high values compared to the OBS-One. For example, the highest data spike had a NCEM data point value of $7.78 * 10^{6}$ for PN concentration. The corresponding OBS-One data point value recorded a value of $4.01 * 10^{6}$. That is a $45 \%$ error percentage. The cold start portion of the $\mathrm{RD}$. Another instance where outliers were frequent was in the PN concentration for the highway test routes. One conclusion is that maybe these were occurring because the truck is sensing steady state operation at high heat, and so the soot is being burnt off. When the soot is being burnt off that is often associated in a large amount of particle emissions.

The following conclusions can be made about the comparison study performed in this study.

For $\mathrm{NO}_{\mathrm{x}}$ concentration levels

1. The NCEM's $\mathrm{ZrO}_{2}$ sensor measured elevated $\mathrm{NO}_{\mathrm{x}}$ concentration levels when compared to the OBS-One. Some reasons for this elevated measurement is due to the direct mount sensor found on the NCEM, compared to the OBS-One having to collect and transport the sample a measurable distance before being analyzed.

2. The NCEM's $\mathrm{ZrO}_{2}$ sensor measured small spikes of negative $\mathrm{NO}_{\mathbf{x}}$ concentration levels.

3. The negative error percentage calculated during the $10 \mathrm{ppm}$ and $20 \mathrm{ppm}$ binning technique concludes the NCEM $\mathrm{ZrO}_{2}$ measures elevated $\mathrm{NO}_{\mathrm{x}}$ concentrations compared to the OBS-One.

For PN concentration levels

1. The NCEM's diffusion charging PN sensor measured elevated PN concentrations during the entire study when compared to the OBS-One. This is because the NCEM's PN sensor has the capability to measure smaller particle sizes when compared to the OBS-One. The NCEM measures below $23 \mathrm{~nm}$, which is the OBS-One cutoff for the CPC PN measurement tool. 
From the results, and through data analysis it can be concluded that the NCEM has the capability to be used as a scanning tool, but not as a standard PEMS unit. This conclusion is on the basis of sensors, and measurement capabilities.

\subsection{Future Work}

The results and associated conclusions presented in this study were based on concentration levels from a variety of different test routes. Future work could include a mass rate calculation that includes ECU data, and tabulated with the NCEM data. The ECU data would have to be utilized due to the fact that the NCEM does not have exhaust flow rate measurement capabilities. This would prove for an easier comparison between other studies that conducted similar experiments. 


\section{Bibliography}

[1] * Thomas D. Durbin et al., "Evaluation and Comparison of Portable Emissions Measurement Systems and Federal Reference Methods for Emissions from a BackUp Generator and a Diesel Truck Operated on a Chassis Dynamometer,” 2007.

[2] B. Giechaskiel et al., "Framework for the assessment of PEMS (Portable Emissions Measurement Systems) uncertainty,” Environ. Res., vol. 166, pp. 251-260, Oct. 2018.

[3] “OBS-ONE GS Unit - HORIBA.” [Online]. Available: https://www.horiba.com/en_en/products/detail/action/show/Product/obs-one-gsunit-28/. [Accessed: 27-Nov-2018].

[4] O. US EPA, "Particulate Matter (PM) Basics.”

[5] T. L. Bougher, I. A. Khalek, C. A. Laroo, and D. K. Bishnu, "Determination of the PEMS Measurement Allowance for PM Emissions Regulated Under the HeavyDuty Diesel Engine In-Use Testing Program,” SAE Int. J. Engines, vol. 5, no. 3, pp. 2012-01-1250, Apr. 2012.

[6] O. US EPA, "Evolution of the Clean Air Act.”

[7] D. B. Kittelson, “Engines and nanoparticles,” J. Aerosol Sci., vol. 29, no. 5-6, pp. 575-588, Jun. 1998.

[8] J. Hoard, T. Chafekar, M. Abarham, R. Schwader, S. Upplegger, and D. Styles, "Large Particles in Modern Diesel Engine Exhaust," in ASME 2012 Internal Combustion Engine Division Spring Technical Conference, 2012, p. 521.

[9] O. US EPA, "Setting and Reviewing Standards to Control Particulate Matter (PM) Pollution.”

[10] M. Williams and R. Minjares, "A technical summary of Euro 6/VI vehicle emission standards,” 2016.

[11] “full-text.”

[12] J. Pignon, “Diesel Engines: Design and Emissions,” Platin. Met. Rev., vol. 49, no. 3, pp. 119-121, Jul. 2005.

[13] R. 01 US EPA, "Nitrogen Oxides Control Regulations | Ground-level Ozone | New England | US EPA.”

[14] “10/22/98: PR DOJ, EPA ANNOUNCE ONE BILLION DOLLAR SETTLEMENT WITH DIESEL ENGINE INDUSTRY FOR CLEAN AIR VIOLATIONS.” [Online].

Available: https://archive.epa.gov/epapages/newsroom_archive/newsreleases/93e9e651adeed 6b7852566a60069ad2e.html. [Accessed: 27-Nov-2018].

[15] Rasik Pondicherry, "Effects of boundary parameters on the Work-Based Window (WBW) and Not-to-Exceed (NTE) in-use emissions quantification methods,” 2017.

[16] Code of Federal Regulations (CFR), “40 CFR 86.1912 - United States Environmental Protection Agency, \&quot;Code of Federal Regulations, Title 40, 
Part 86, §1912, Vehicle-Pass Ratio Criteria.” [Online]. Available: https://www.law.cornell.edu/cfr/text/40/86.1912.

[17] B. Demirgok, "Development of an Emissions Monitoring Methodology Using OnBoard NO x Sensors and Revision to Current In-Use Emissions Regulatory Protocols," 2018.

[18] J. Czerwinski, Y. Zimmerli, P. Comte, and T. Bütler, "Experiences and Results with different PEMS,” online) Scienpress Ltd, 2016.

[19] J. Yang et al., "A comparison of a mini-PEMS and a 1065 compliant PEMS for onroad gaseous and particulate emissions from a light duty diesel truck," Sci. Total Environ., vol. 640-641, pp. 364-376, Nov. 2018.

[20] R. Varella et al., "Comparison of Portable Emissions Measurement Systems (PEMS) with Laboratory Grade Equipment,” Appl. Sci., vol. 8, no. 9, p. 1633, Sep. 2018.

[21] A. Frobert, S. Raux, Y. Creff, and E. Jeudy, "About Cross-Sensitivities of NOx Sensors in SCR Operation,” 2013.

[22] H. Zhou et al., "Effects of Environmental Parameters on Real-World NOx Emissions and Fuel Consumption for Heavy-Duty Diesel Trucks Using an OBD Approach,” 2018.

[23] “OBS-ONE PN Unit - HORIBA.” [Online]. Available: http://www.horiba.com/en_en/products/detail/action/show/Product/obs-one-pnunit-12/. [Accessed: 27-Nov-2018].

[24] "Scematic setup of a condensation particle counter [6] | Download Scientific Diagram.” [Online]. Available: https://www.researchgate.net/figure/Scematicsetup-of-a-condensation-particle-counter-6_fig2_323486023. [Accessed: 06-Dec2018].

[25] M. Vojtisek-Lom and J. E. Allsop, "Development Of Heavy-Duty Diesel Portable, On-Board Mass Exhaust Emissions Monitoring System With NOx, CO2 And Qualitative PM Capabilities,” 2001.

[26] “Chemiluminescence detector (CLD) principle | Cambustion.” [Online]. Available: https://www.cambustion.com/products/cld500/cld-principles. [Accessed: 06-Dec2018].

[27] “Compact Emissions Meter NCEM-8016 | NGK SPARK PLUG CO., LTD.” [Online]. Available: https://www.ntk-ncem.com/en/. [Accessed: 27-Nov-2018].

[28] V. Petrovic, S. Jankovic, M. Tomic, Z. Jovanovic, and D. Knezevic, "The possibilities for measurement and characterization of diesel engine fine particles: A review,” Therm. Sci., vol. 15, no. 4, pp. 915-938, 2011.

[29] N. Kato, H. Kurachi, and Y. Hamada, "Thick Film ZrO2 NOx Sensor for the Measurement of Low NOx Concentration,” 1998.

[30] B. Butz, R. Schneider, D. Gerthsen, M. Schowalter, and A. Rosenauer, "Decomposition of 8.5mol.\% Y2O3-doped zirconia and its contribution to the degradation of ionic conductivity,” Acta Mater., vol. 57, no. 18, pp. 5480-5490, Oct. 
2009.

[31] “1.3.3.24. Quantile-Quantile Plot." [Online]. Available: https://www.itl.nist.gov/div898/handbook/eda/section3/qqplot.htm. [Accessed: 07Dec-2018].

\section{Appendix}

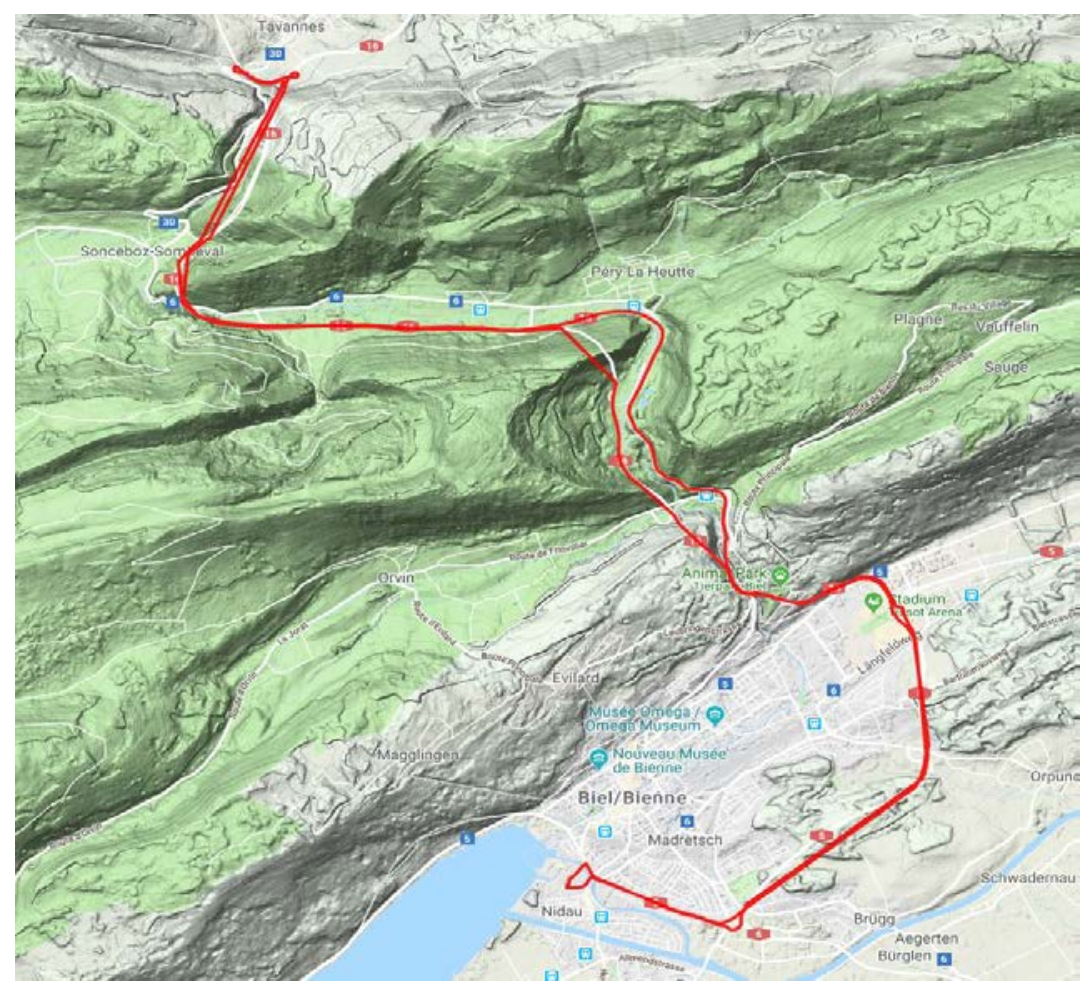

Figure 42: Tavannes Test Route 


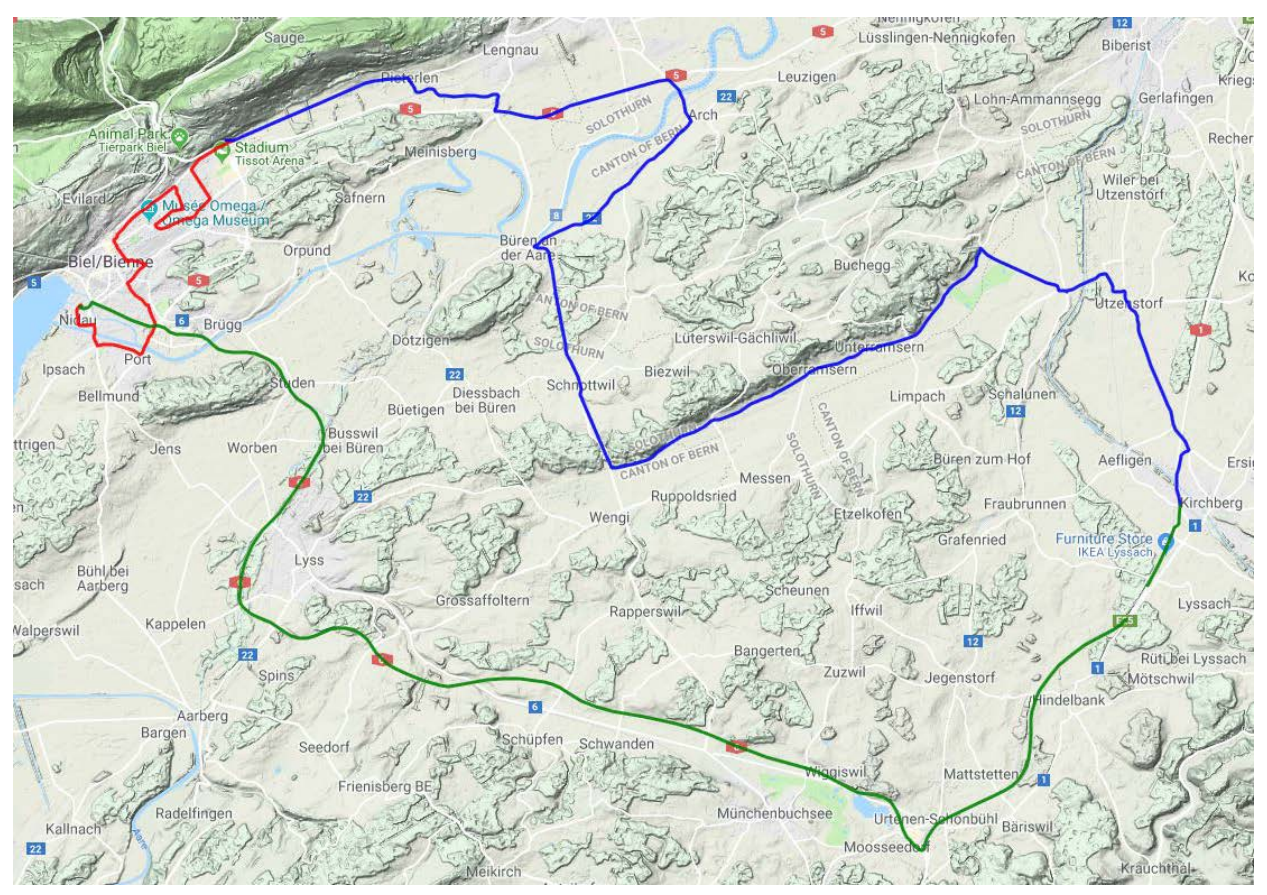

Figure 43: RDE Test Route

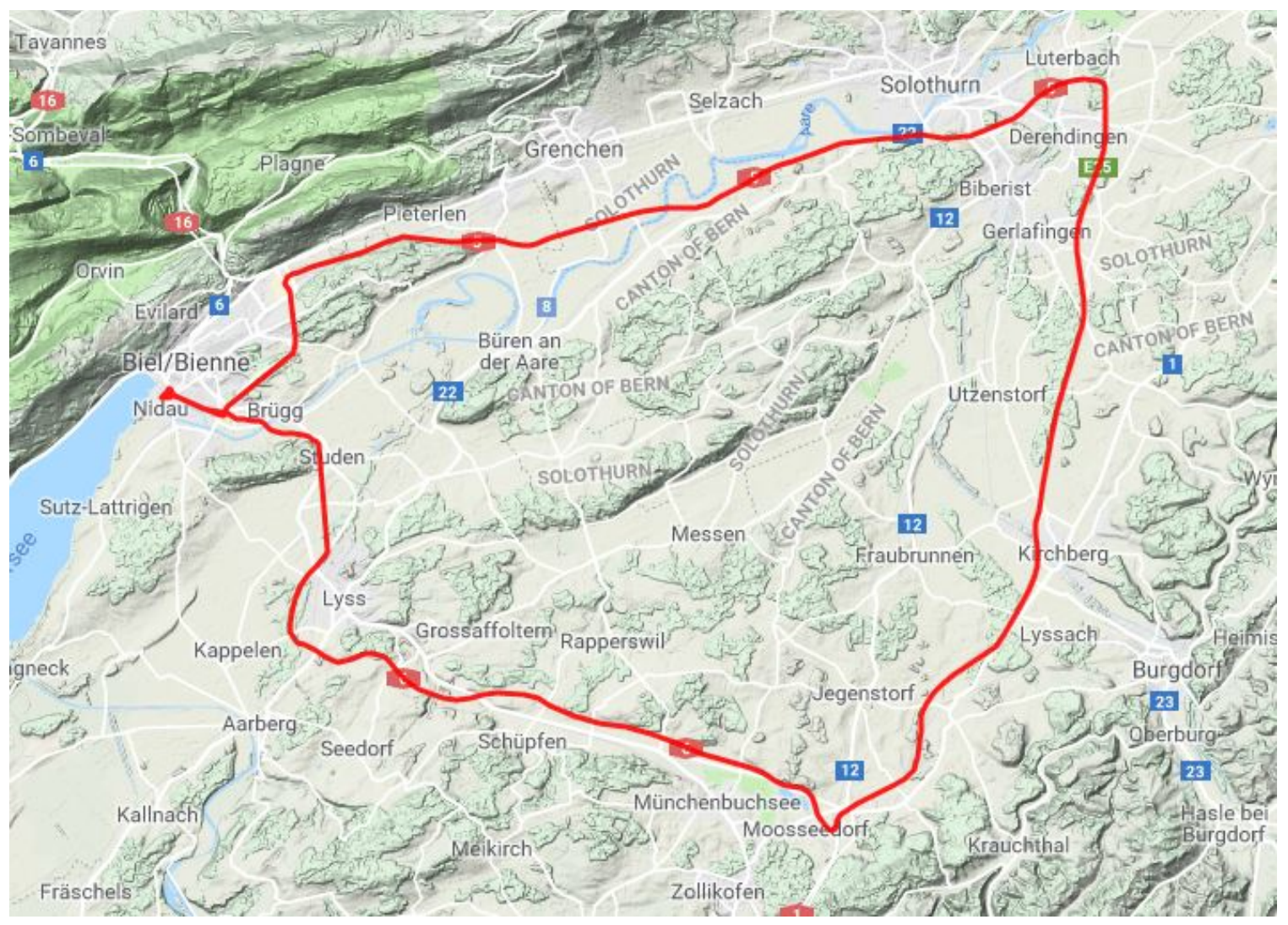

Figure 44: Highway Test Route 
Table 17: Horiba OBS-One Specifications Chart [18]

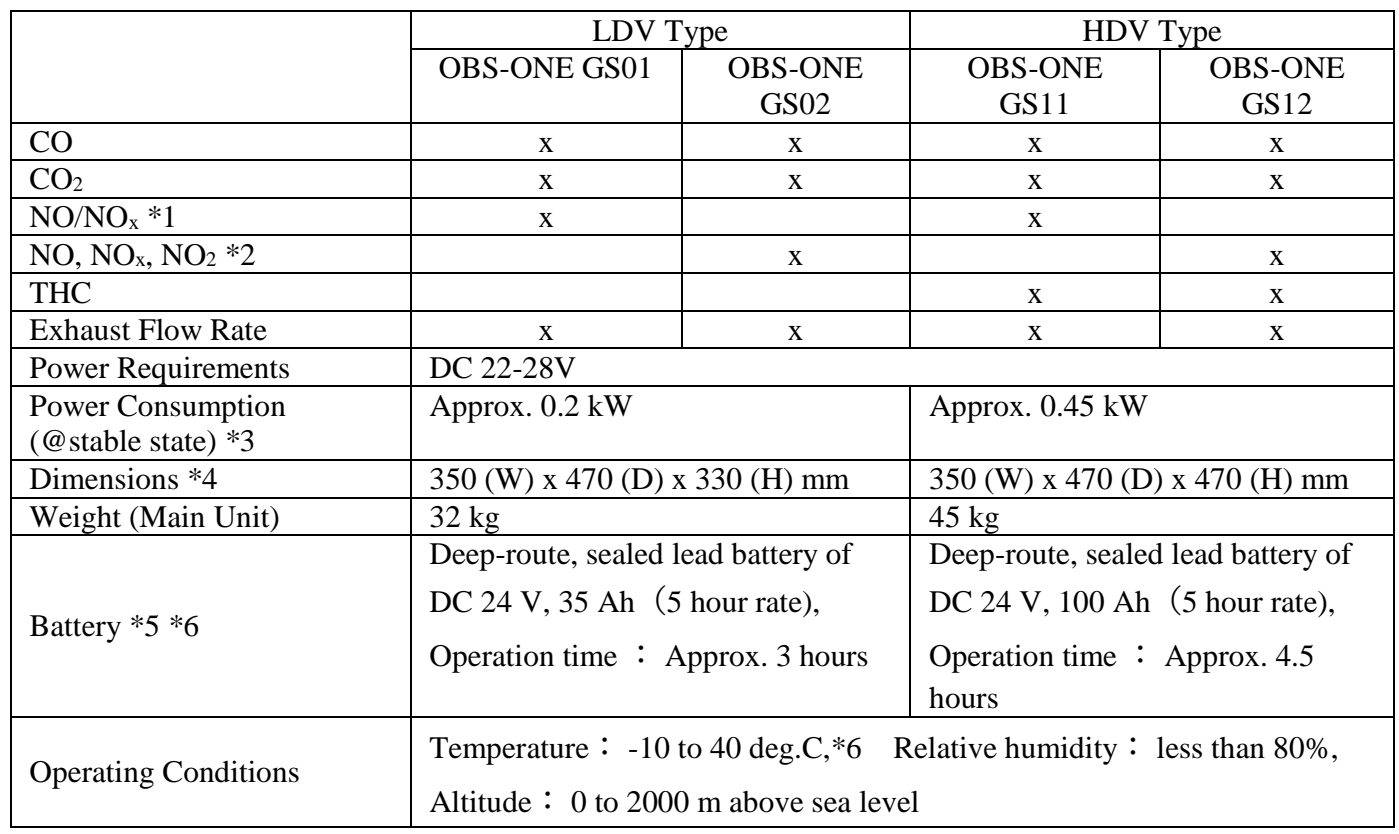

Table 18: Horiba OBS-One Measurement Principles of Gaseous Emissions [18]

\begin{tabular}{|c|c|c|}
\hline & Measurement Principle & Measurement Range \\
\hline $\mathrm{CO}$ & Heated NDIR & $0-0.5$ to $0-10 \mathrm{vol} \%$ \\
\hline $\mathrm{CO}_{2}$ & Heated NDIR & $0-0.5$ to $0-20$ vol\% \\
\hline $\mathrm{NO} / \mathrm{NO}_{\mathrm{x}}$ & Heated CLD & 0-100 to $0-3000 \mathrm{ppm}$ \\
\hline $\mathrm{NO}, \mathrm{NO}_{\mathrm{x}}, \mathrm{NO}_{2}$ & Heated-dual CLD & $0-100$ to $0-3000 \mathrm{ppm}$ \\
\hline THC & Heated FID & $\begin{array}{l}0-100 \\
\text { ppmC }\end{array}$ to $0-10000$ \\
\hline Sampling Method & Wet Measurement & \\
\hline Exhaust Flow Rate $* 7$ & Pitot Flow Meter & $0-0.2$ to $0-65.0 \mathrm{~m}^{3} / \mathrm{min}$ \\
\hline $\begin{array}{l}\text { Standard Signal } \\
\text { Measurements }\end{array}$ & $\begin{array}{l}\text { Exhaust Temperature } \\
\text { Exhaust Pressure } \\
\text { Atmospheric Temperature } \\
\text { Atmospheric Humidity } \\
\text { GPS Signal } \\
\text { Speed }\end{array}$ & \\
\hline
\end{tabular}


Table 19: Horiba OBS-One PN unit specifications [19]

\begin{tabular}{|l|l|}
\hline Measuring Principles & Condensation particle counter (CPC) \\
\hline Particle Diameter & $23-1,000 \mathrm{~nm}$ \\
\hline Measuring Range & $0-5 \times 10^{7}$ particles/ $\mathrm{cm}^{3}$ \\
\hline Power Supply & DC $24 \mathrm{~V}$ \\
\hline Power Consumption (MAX) & Approx. $0.25 \mathrm{~kW}$ \\
\hline Mass & Approx. $18 \mathrm{~kg}$ \\
\hline Operating Condition & $\begin{array}{l}\text { Temperature: }-10-40^{\circ} \mathrm{C} \\
\text { Altitude: } 0 \text { to } 2000 \mathrm{~m} \text { above sea level } \\
\text { Relative humidity: less than } 80 \%\end{array}$ \\
\hline Condensation fluid & $\begin{array}{l}\text { Isopropyl alcohol a special grade } \\
\text { reagent (99.5\%) correspond }\end{array}$ \\
\hline Option & $\begin{array}{l}\text { Outer cover for mounting outside the } \\
\text { vehicle using a hitch carrier }\end{array}$ \\
\hline
\end{tabular}

Table 20: NCEM Specifications [22]

\begin{tabular}{|l|l|}
\hline Item & Specifications \\
\hline Electric Supply Source & AC 100 to 240 V or DC 12 to $28 \mathrm{~V} * 1$ \\
\hline Power Consumption & $\begin{array}{l}\text { AC: about 400 VA (Max Act. Power) } * 2 \\
\text { DC: about 300 VA (Max Act. Power) }\end{array}$ \\
\hline External Dimensions & $348(\mathrm{~W}) \mathrm{x} 283(\mathrm{D}) \mathrm{x} 284(\mathrm{H}) \mathrm{mm} * 3$ \\
\hline Main Unit Weight & About $9.5 \mathrm{~kg} * 4$ \\
\hline Usage Environment & $\begin{array}{l}\text { Ambient Temperature: }-10 \text { to } 40^{\circ} \mathrm{C} \\
\text { Humidity: Relative humidity of } 85 \% \text { or less } \\
\text { Absolute Humidity of less than } 30 \mathrm{~g} / \mathrm{m}^{3}\end{array}$ \\
\hline External I/F & $\begin{array}{l}\text { CAN (Complies with ISO11898) } \\
\text { USB (PC Connection) } \\
\text { OBD2 (ISO15765, SAEJ1979) } \\
\text { GPS } \\
\text { Analog Input (1 Channel) }\end{array}$ \\
\hline
\end{tabular}

Table 21: NCEM Module Specifications [22]

\begin{tabular}{|c|c|c|c|c|}
\hline \multirow[t]{2}{*}{ Module } & \multirow[t]{2}{*}{ Weight } & \multirow{2}{*}{$\begin{array}{l}\text { Power } \\
\text { Consumption }\end{array}$} & \multicolumn{2}{|l|}{ Output Signal } \\
\hline & & & Signal Name & Range \\
\hline \multirow[t]{2}{*}{$\mathrm{NO}_{\mathrm{x}} / \mathrm{O}_{2}$} & \multirow[t]{2}{*}{$\begin{array}{l}\text { About } \\
0.7 \mathrm{~kg}\end{array}$} & About $21 \mathrm{VA}$ & $\mathrm{NO}_{\mathrm{x}}$ & $\begin{array}{l}0 \text { to } 1500 \\
\text { ppm }\end{array}$ \\
\hline & & About $56 \mathrm{VA}$ & $\mathrm{O}_{2}$ & 0 to $21 \%$ \\
\hline \multirow[t]{2}{*}{$\operatorname{AFR}\left(\mathrm{O}_{2}\right)$} & \multirow{2}{*}{$\begin{array}{l}\text { About } \\
0.7 \mathrm{~kg}\end{array}$} & About $21 \mathrm{VA}$ & $\mathrm{O}_{2}$ & 0 to $21 \%$ \\
\hline & & About 56 VA & $\mathrm{A} / \mathrm{F}$ & 9 to 20 \\
\hline \multirow[t]{2}{*}{$\mathrm{PM} / \mathrm{PN}$} & \multirow[t]{2}{*}{$\begin{array}{l}\text { About } \\
1.9 \mathrm{~kg}\end{array}$} & \multirow[t]{2}{*}{ About $13 \mathrm{VA}$} & PM & $\begin{array}{l}0 \text { to } 1500 \\
\text { ppm }\end{array}$ \\
\hline & & & $\mathrm{PN}$ & $\begin{array}{l}0 \text { to } \\
1.0 \times 10^{8} \\
\# / \mathrm{cm}^{3}\end{array}$ \\
\hline \multirow[t]{2}{*}{$\mathrm{PM} / \mathrm{PN}$ EX } & \multirow[t]{2}{*}{$\begin{array}{l}\text { About } \\
2.9 \mathrm{~kg}\end{array}$} & \multirow[t]{2}{*}{ About $50 \mathrm{VA}$} & PM & $\begin{array}{l}0 \text { to } 300 \\
\mathrm{mg} / \mathrm{m}^{3}\end{array}$ \\
\hline & & & PN & $\begin{array}{l}0 \text { to } 1.0 \mathrm{x} \\
10^{9} \mathrm{\#} / \mathrm{cm}^{3} \\
\end{array}$ \\
\hline
\end{tabular}




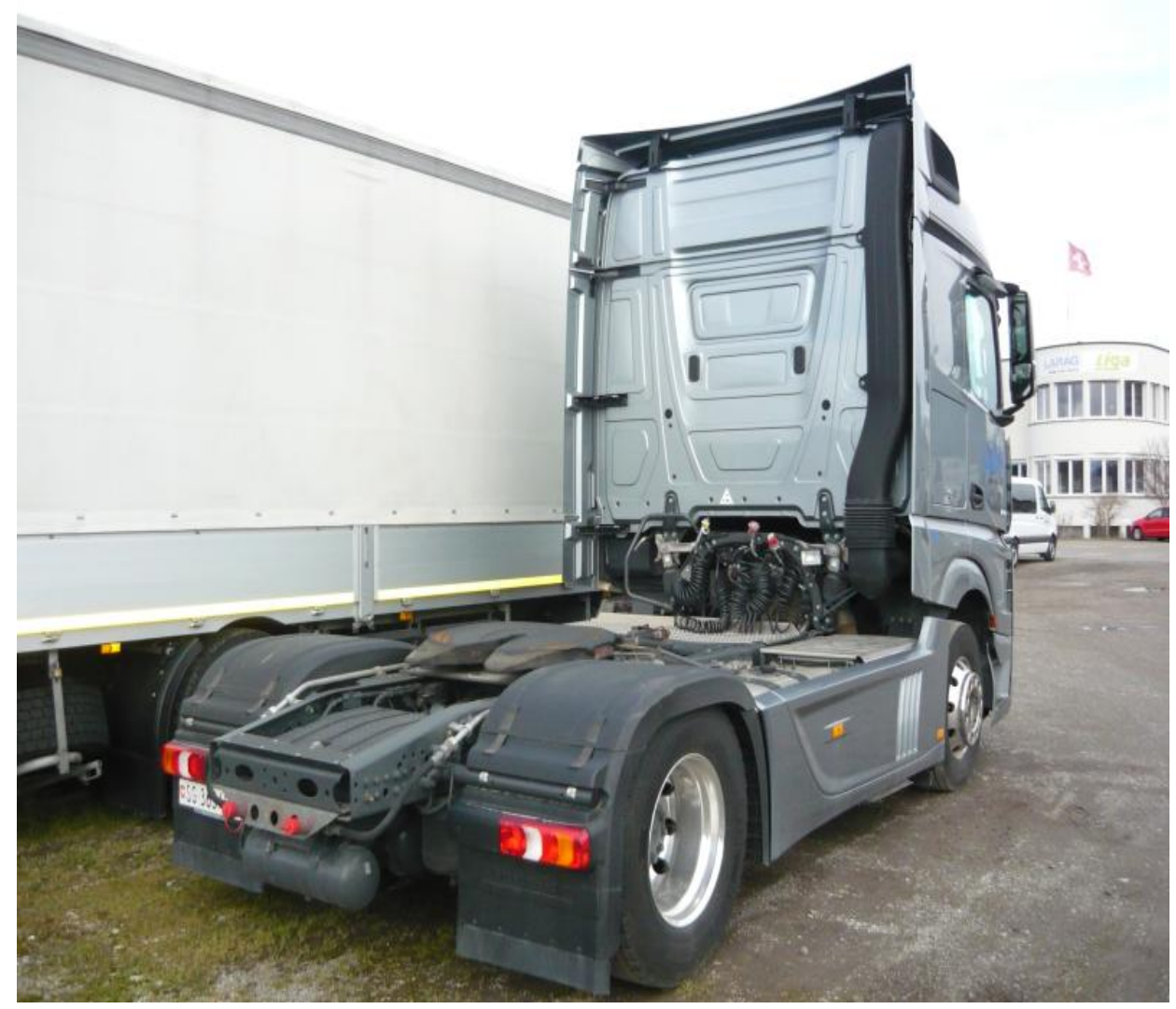

Figure 45: Mercedes Benz Actros

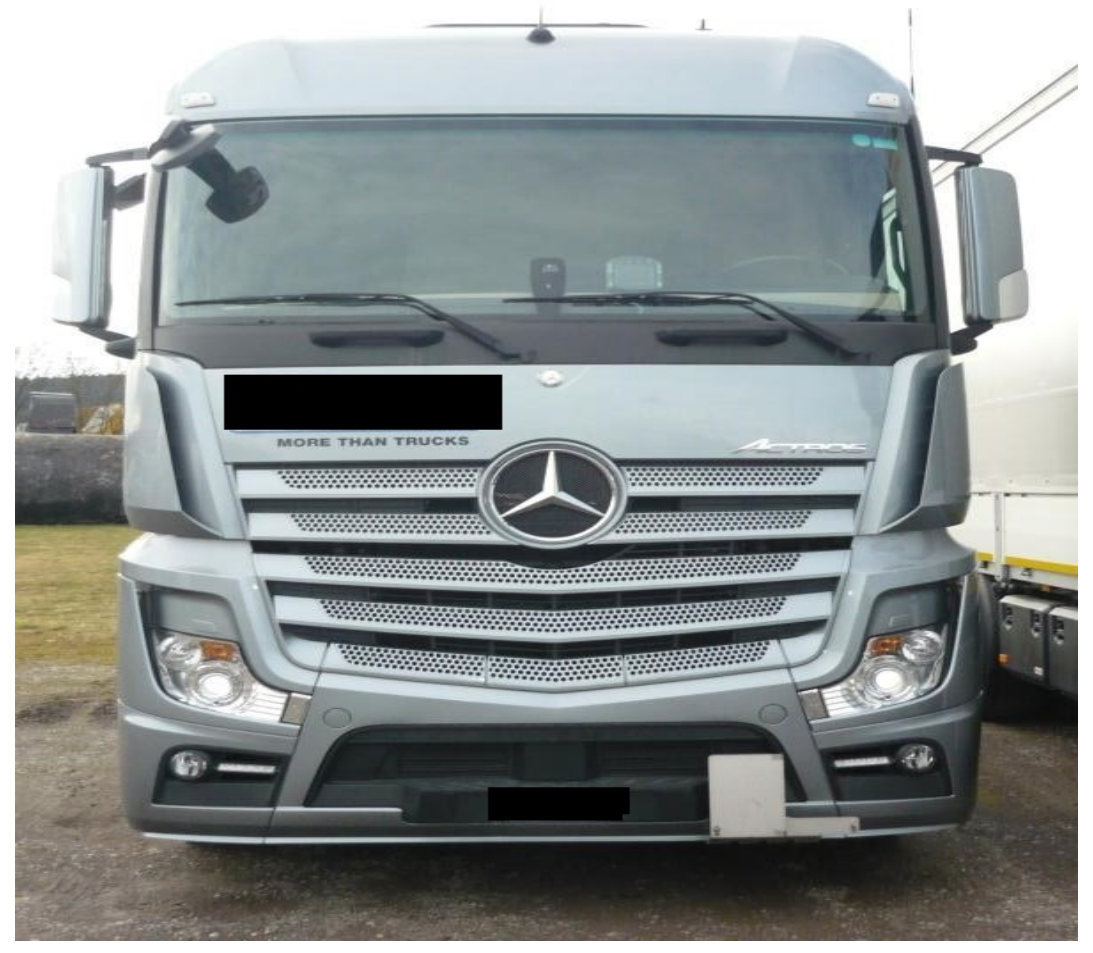

Figure 46: Mercedes Benz Actros 


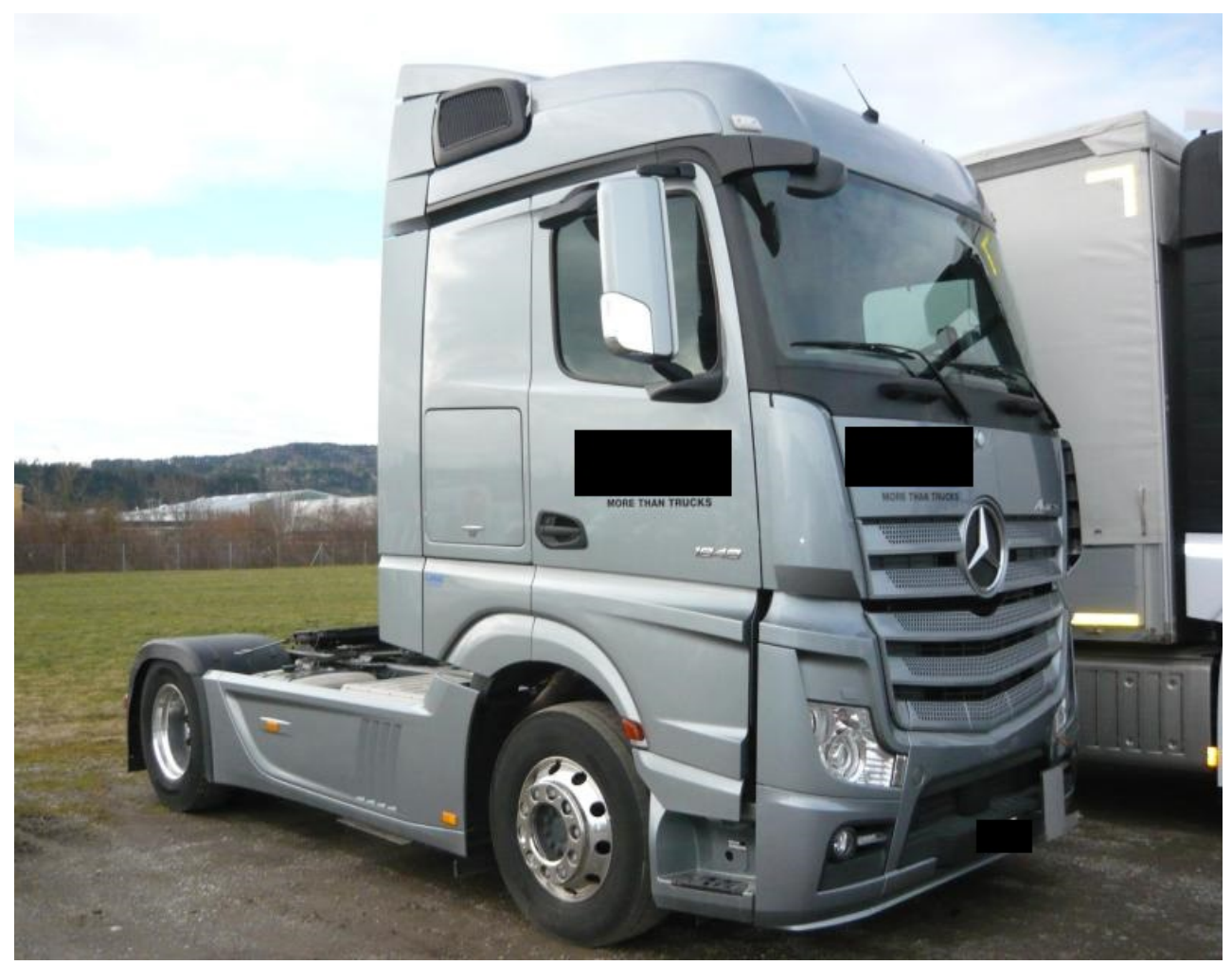

Figure 47: Mercedes Benz Actros 


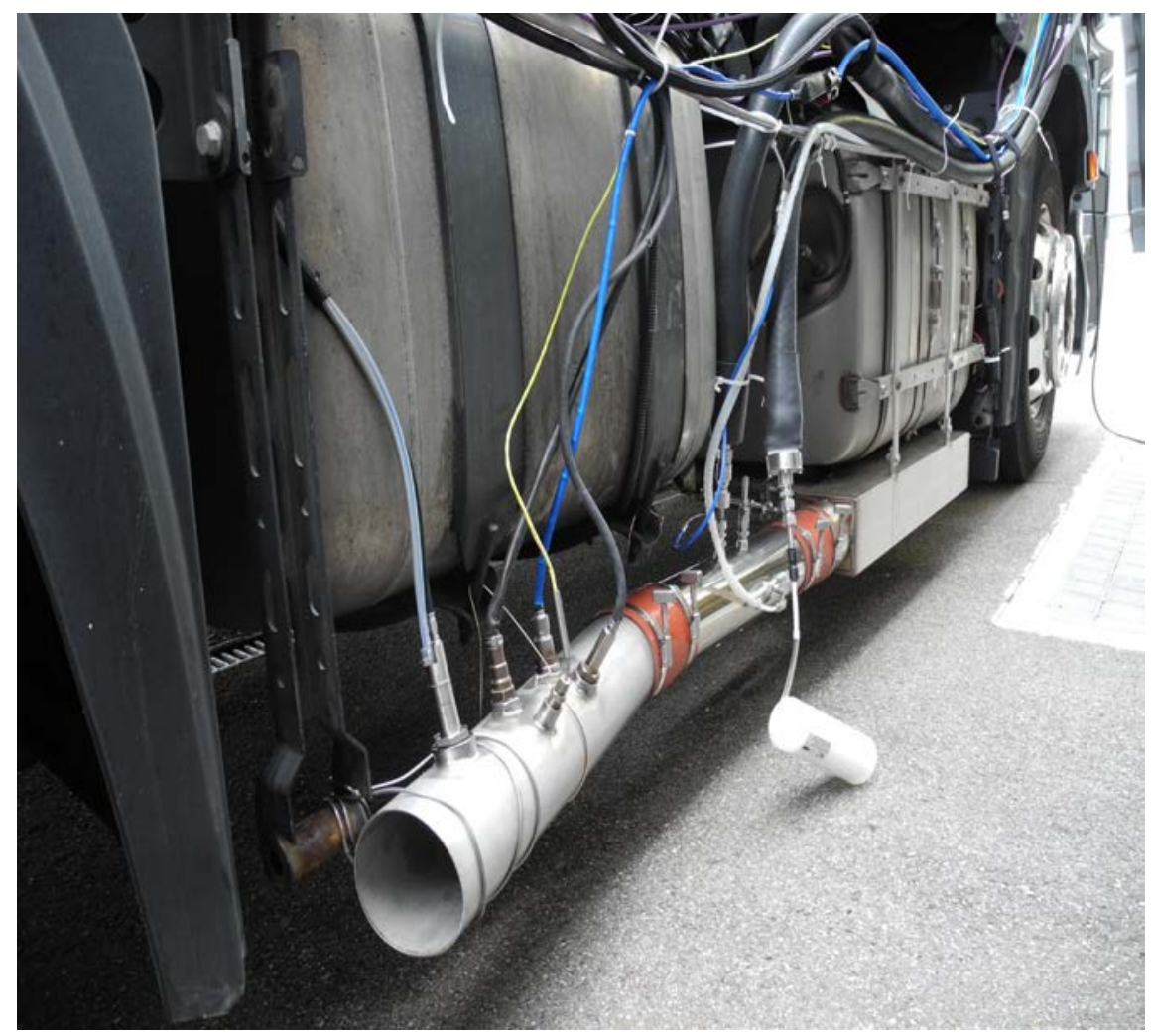

Figure 48: Truck Exhaust Tip, Sensor Layout

Table 22: Mercedes Benz Actros Specifications Chart

\begin{tabular}{|l|l|}
\hline Manufacturer & Mercedes-Benz \\
\hline Model & Actros 1848 LS 4x2 F13 \\
\hline VIN & WDB9634031L922238 \\
\hline MY & 2015 \\
\hline Cabin Type & Day Cab, Cab-Over \\
\hline Engine Manufacturer & Mercedes-Benz \\
\hline Engine Model & OM 471 \\
\hline Configuration & In-line 6 cyl. \\
\hline Displacement & 12.8 \\
\hline Power & $354 \mathrm{~kW}$ (476hp) \\
\hline Torque & $2300 \mathrm{Nm}$ \\
\hline Engine Technology Features & \\
\hline Engine SN & 471900 C0 129232 \\
\hline Emission Standards & Euro VI \\
\hline Emission Control & EGR, DOC, DPF, urea-SCR \\
\hline Transmission & G 281-12/14, 93-1, 0 \\
\hline Number of Gears & \\
\hline Axle Ratio & 2.611 \\
\hline Axle Configuration & $4 x 2$ \\
\hline Curb Weight & $8160 \mathrm{~kg}$ \\
\hline Odometer & 118,000 [km] \\
\hline
\end{tabular}




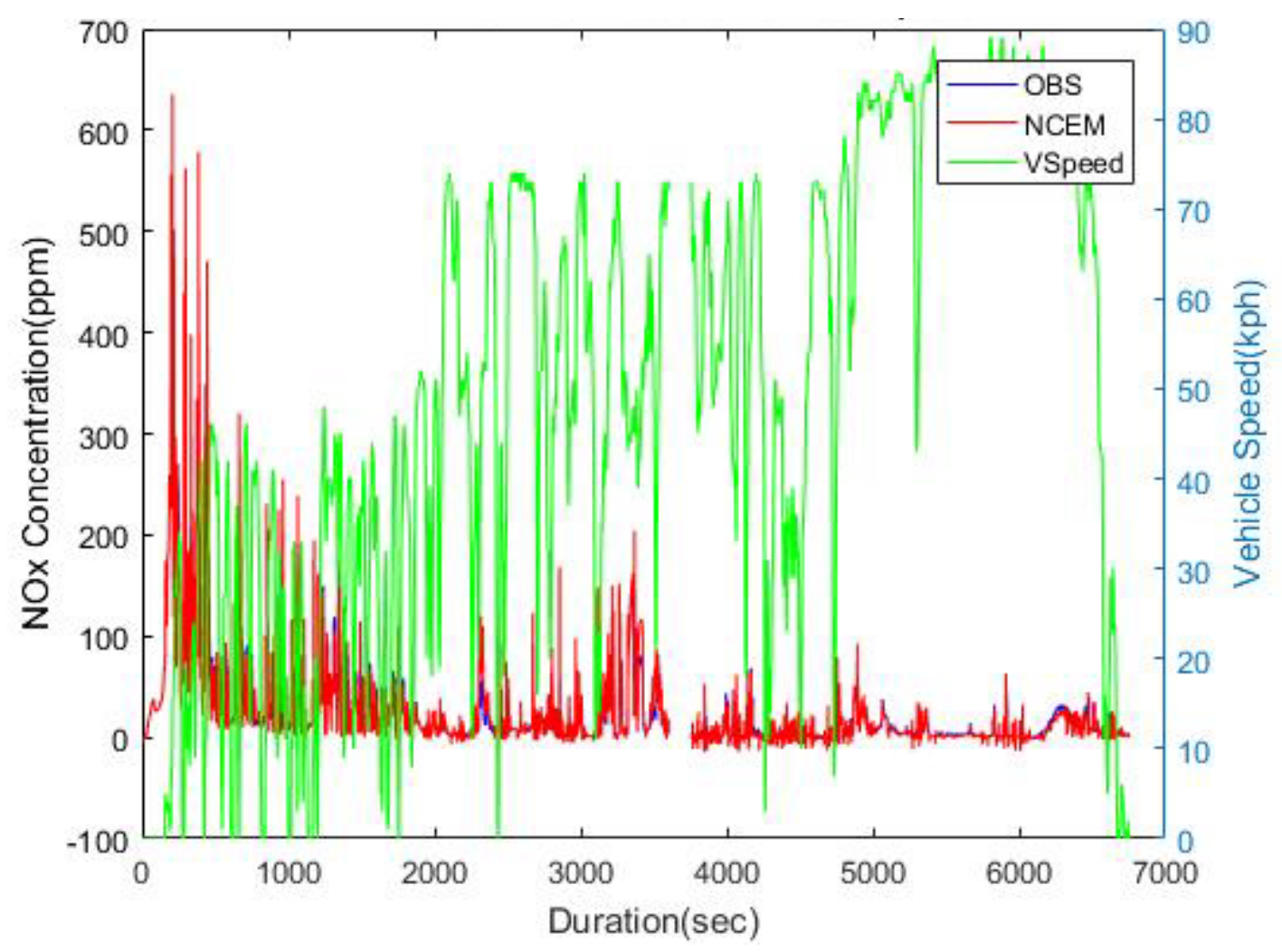

Figure 49: RDE 1 NOx Raw Data with Vehicle Speed 


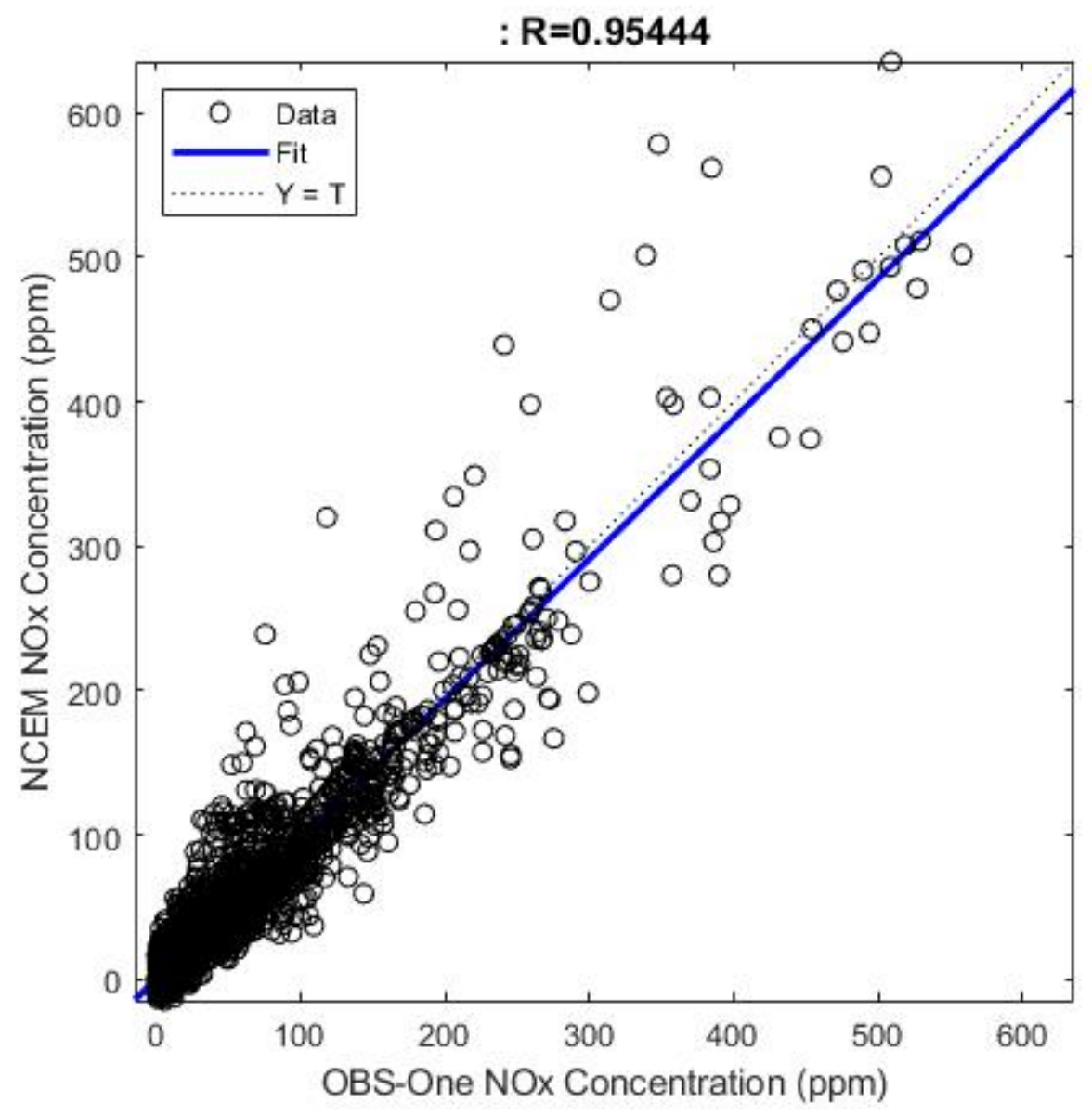

Figure 50: Linear Regression for RDE $1 \mathrm{NO}_{\mathrm{x}}$ Overall 


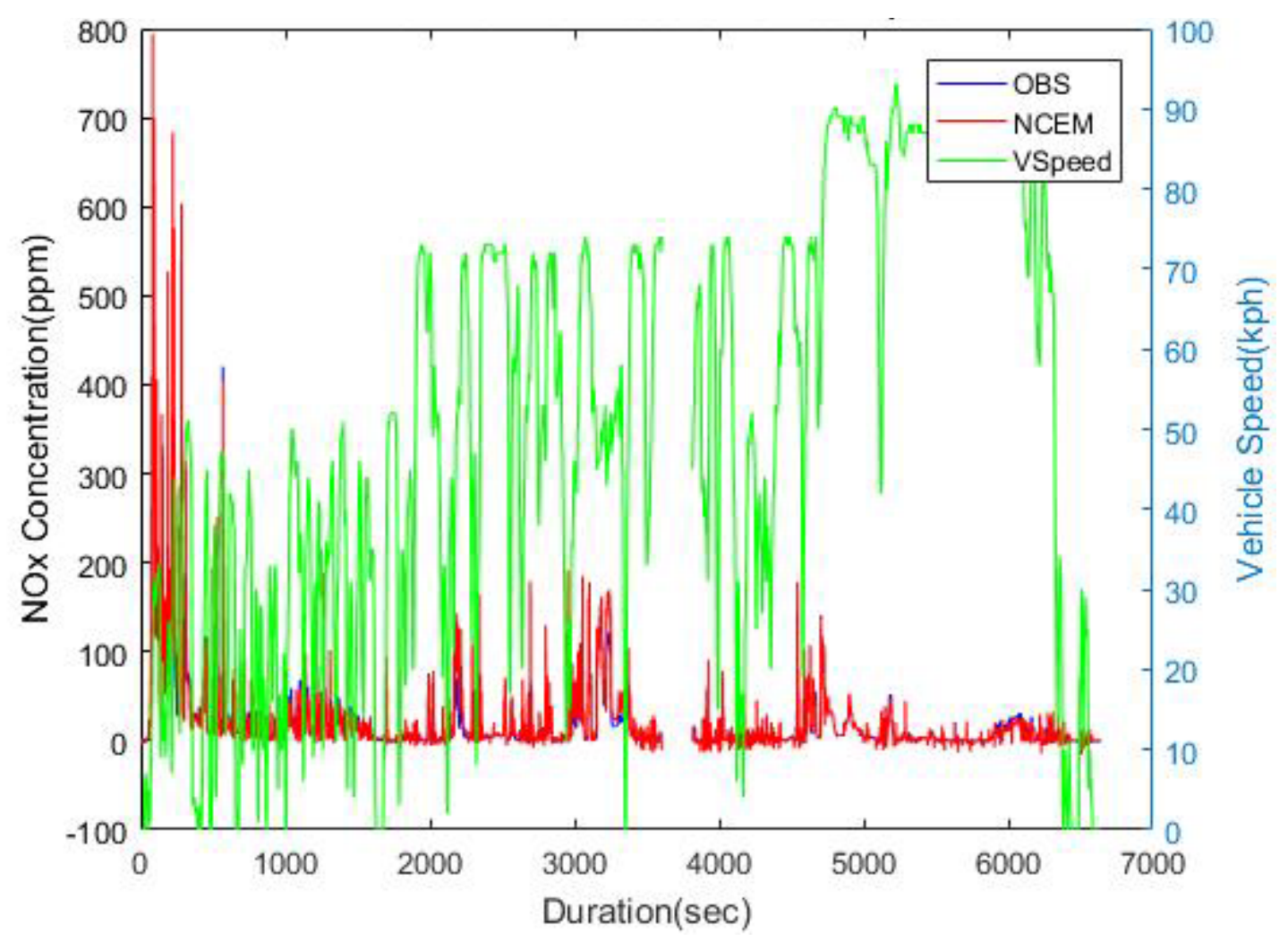

Figure 51: RDE 3 NO$_{x}$ Raw Data with Vehicle Speed 


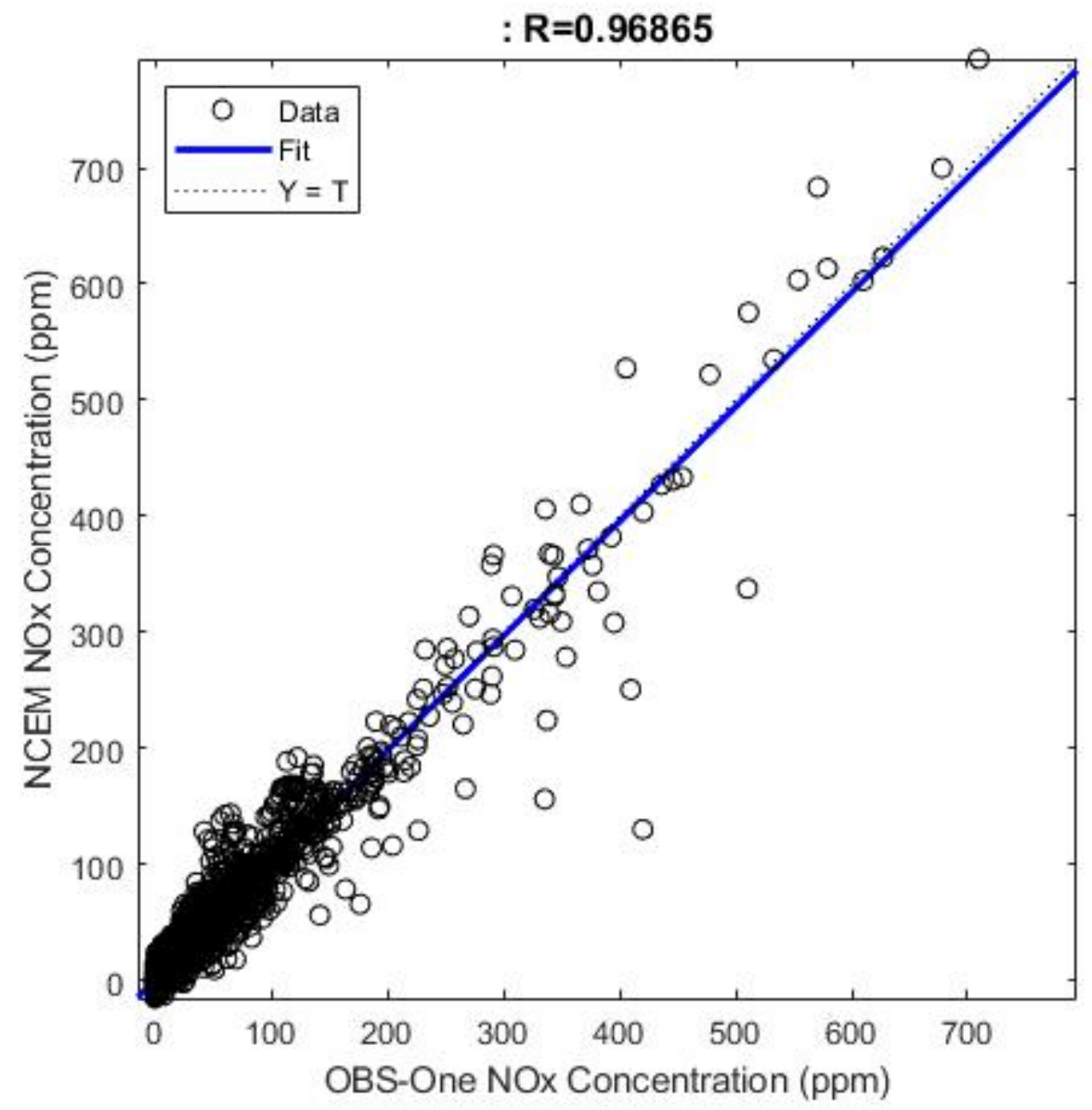

Figure 52: Linear Regression for RDE $3 \mathrm{NO}_{\mathrm{x}}$ Overall 


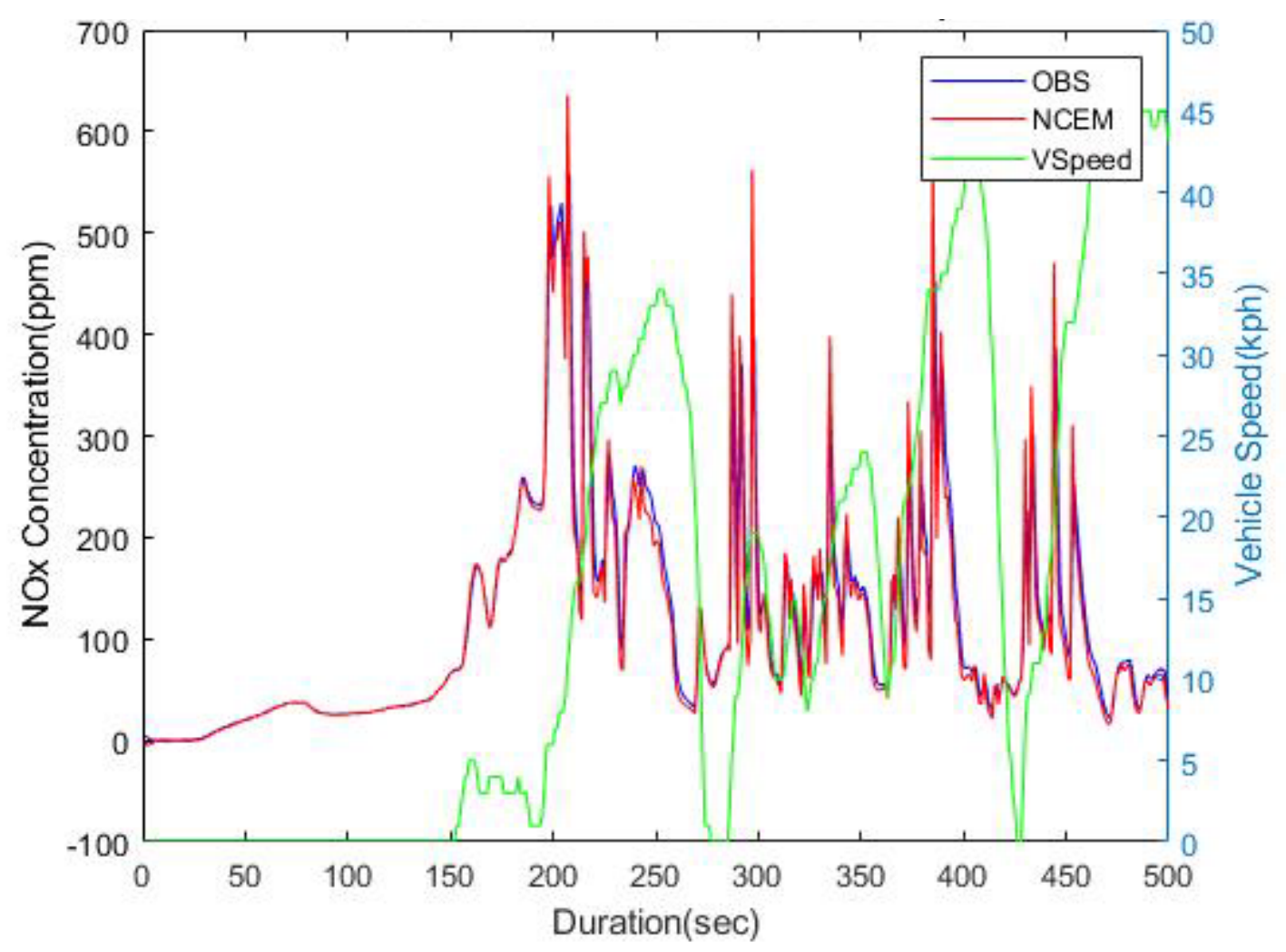

Figure 53: RDE 1 Cold Start NOx Raw Data with Vehicle Speed 


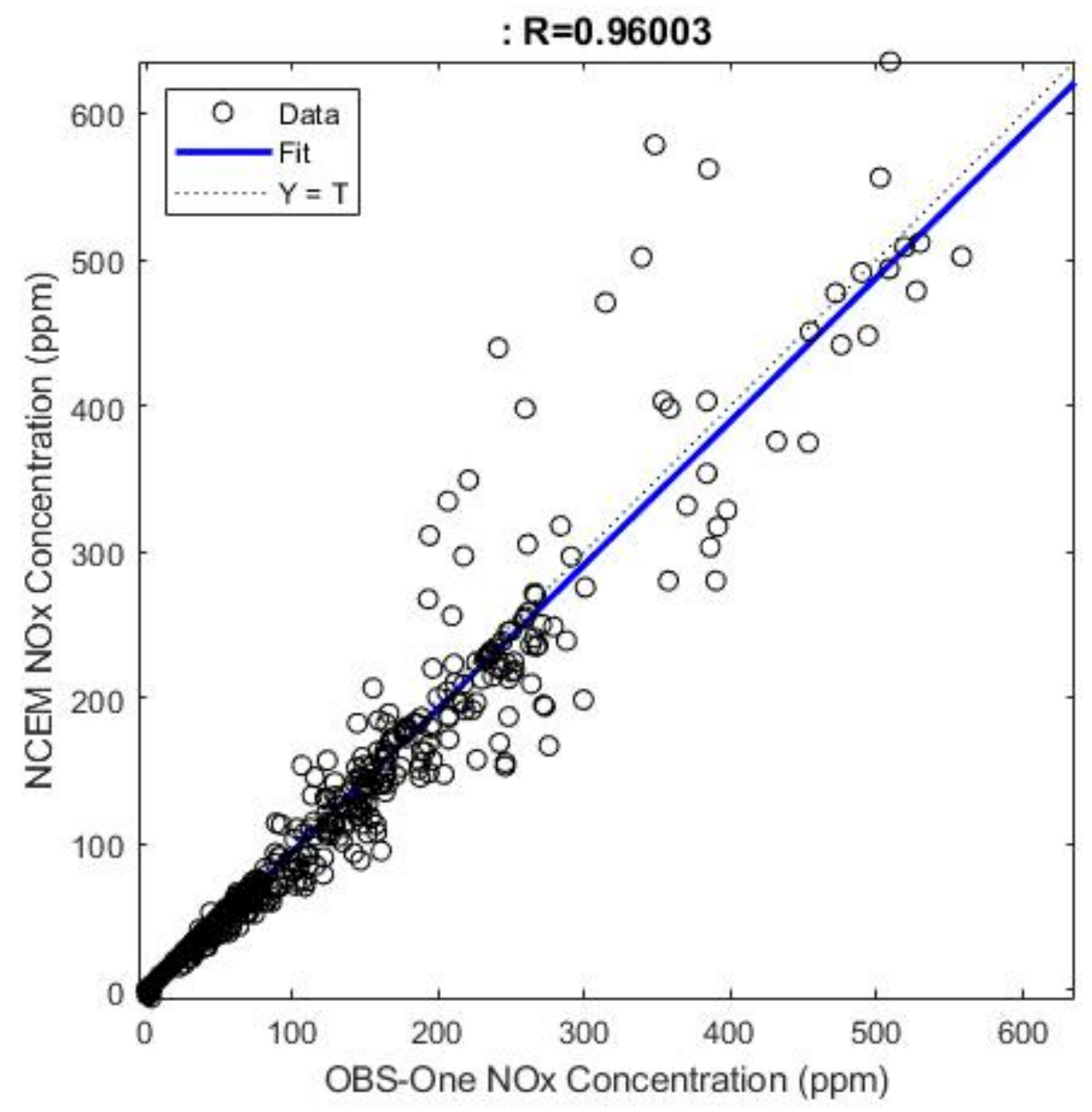

Figure 54: Linear Regression for RDE 1 Cold Start $\mathrm{NO}_{\mathrm{x}}$ 


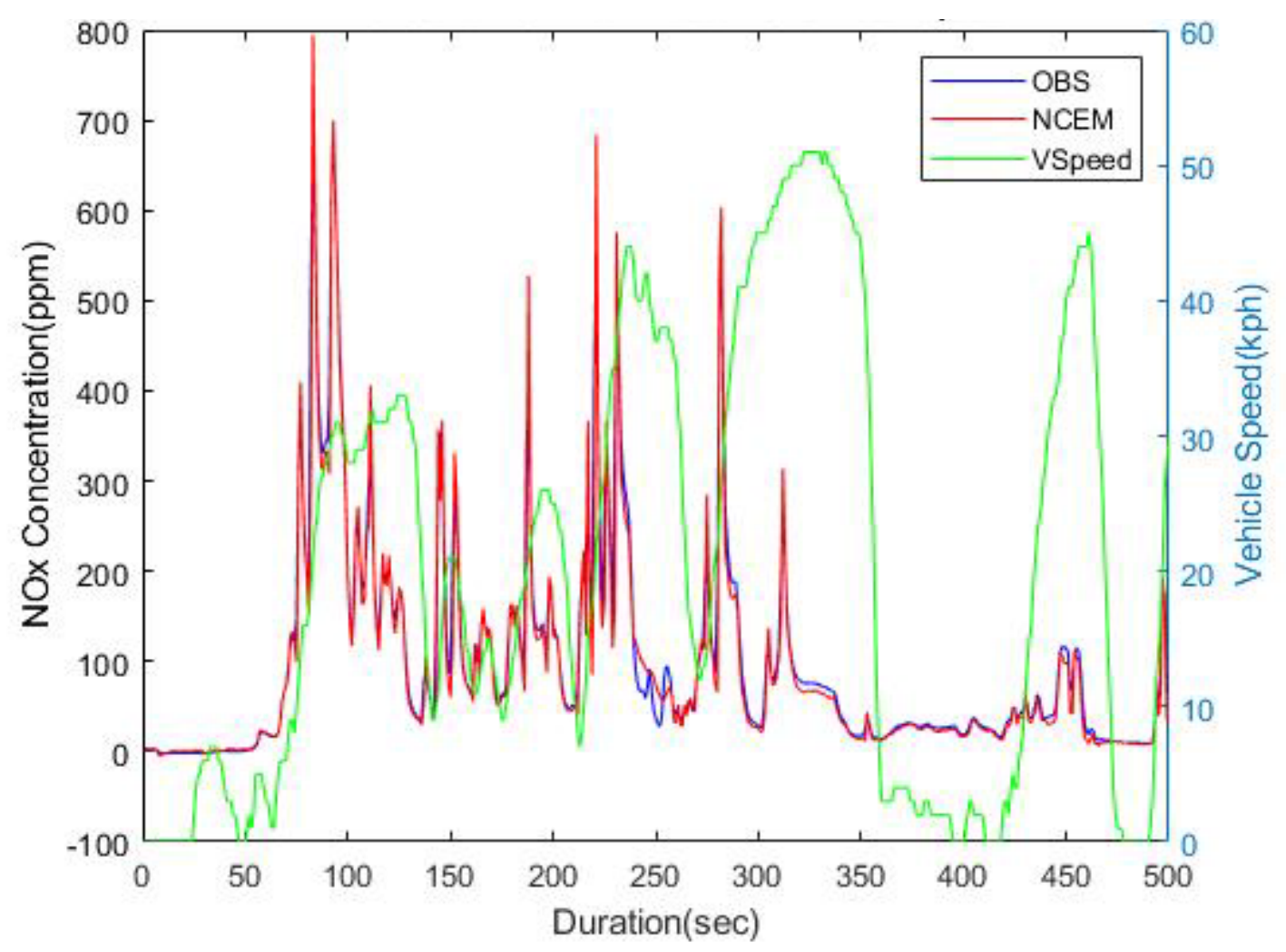

Figure 55: RDE 3 NO Cold Start Raw Data with Vehicle Speed 


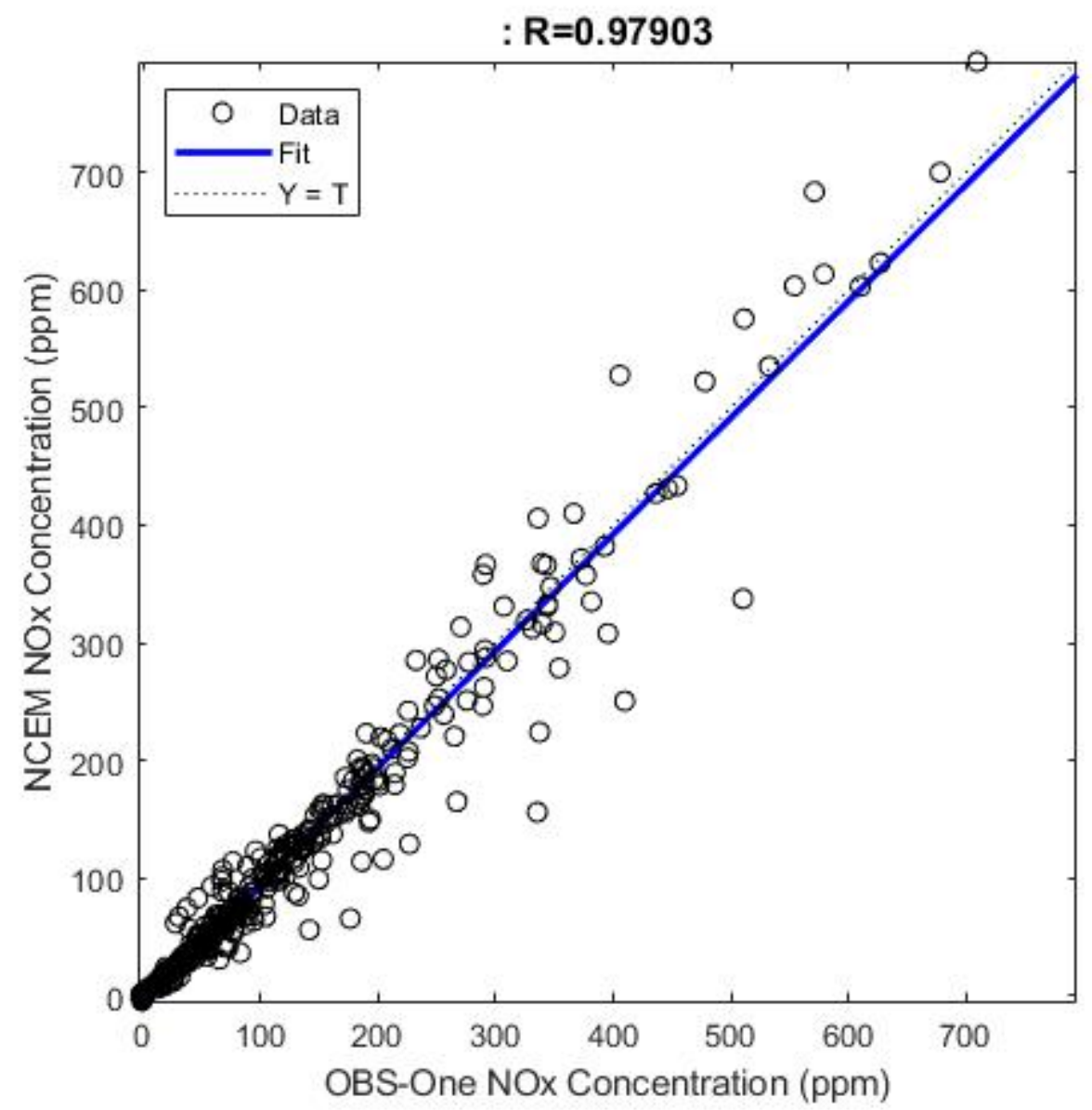

Figure 56: Linear Regression for RDE 3 Cold Start $\mathrm{NO}_{\mathrm{x}}$ 


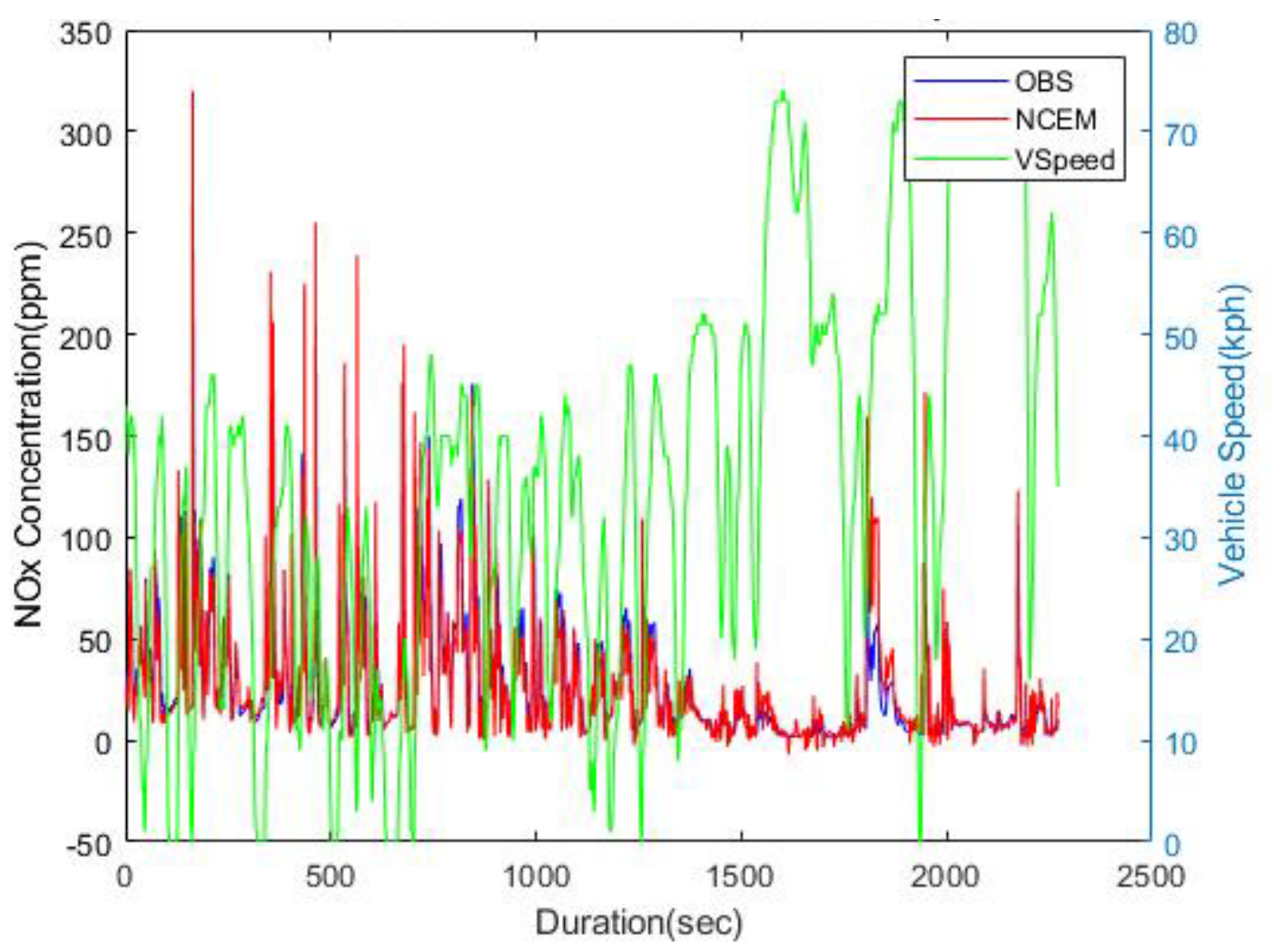

Figure 57: RDE 1 NO$_{x}$ Urban Raw Data with Vehicle Speed 


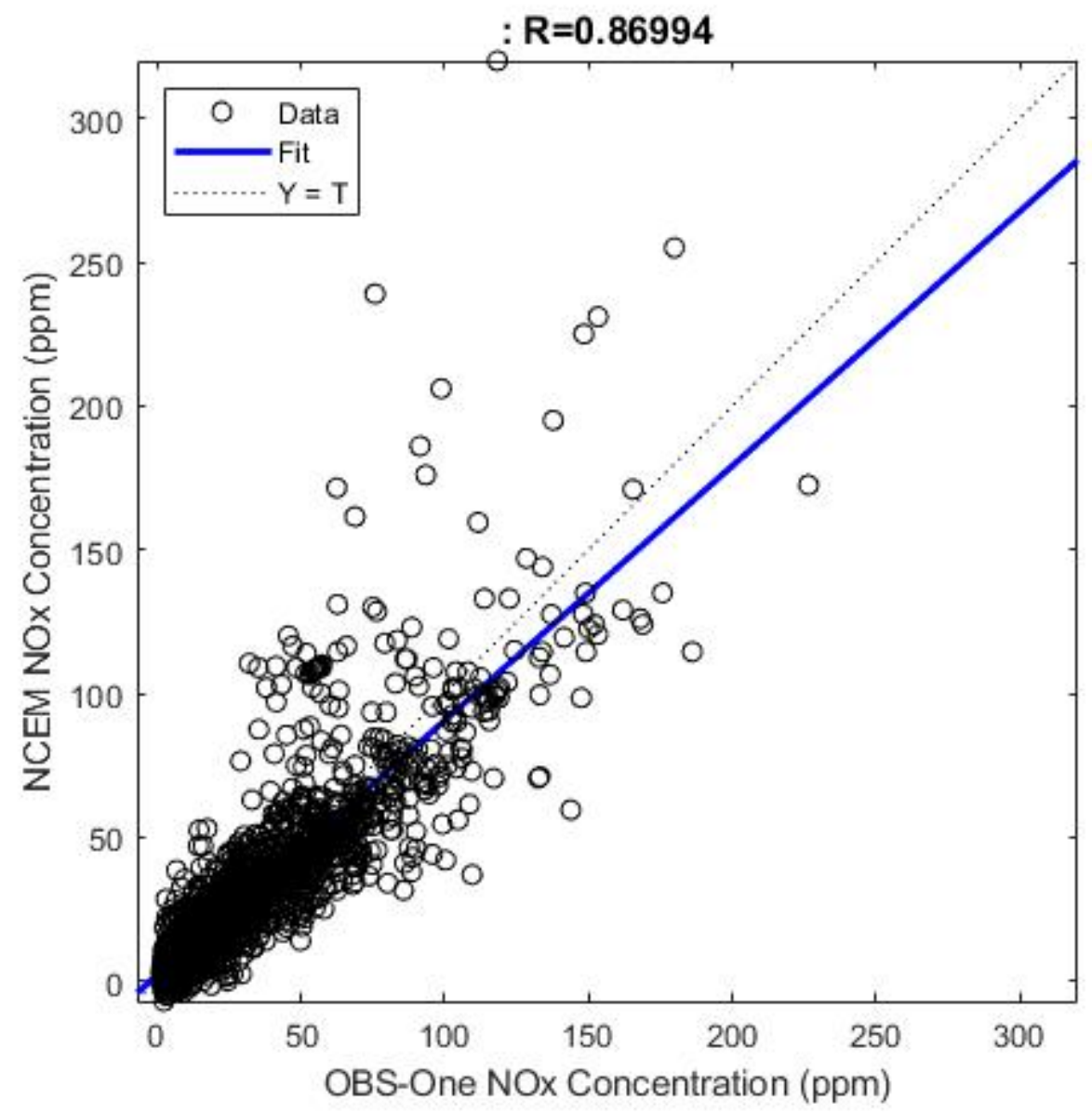

Figure 58: Linear Regression for RDE $1 \mathrm{NO}_{\mathrm{x}}$ Urban 


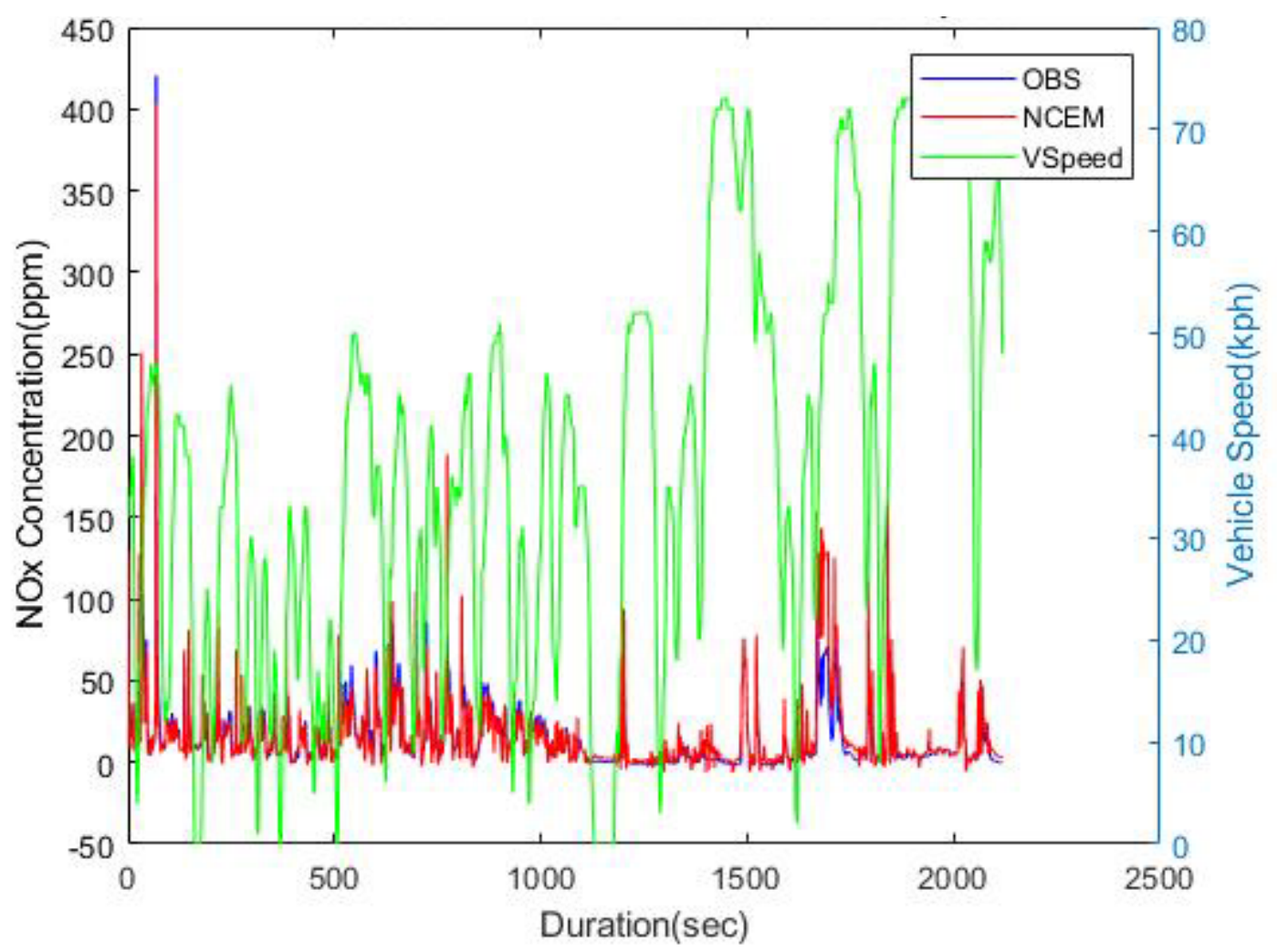

Figure 59: RDE 3 NO$_{x}$ Urban Raw Data with Vehicle Speed 


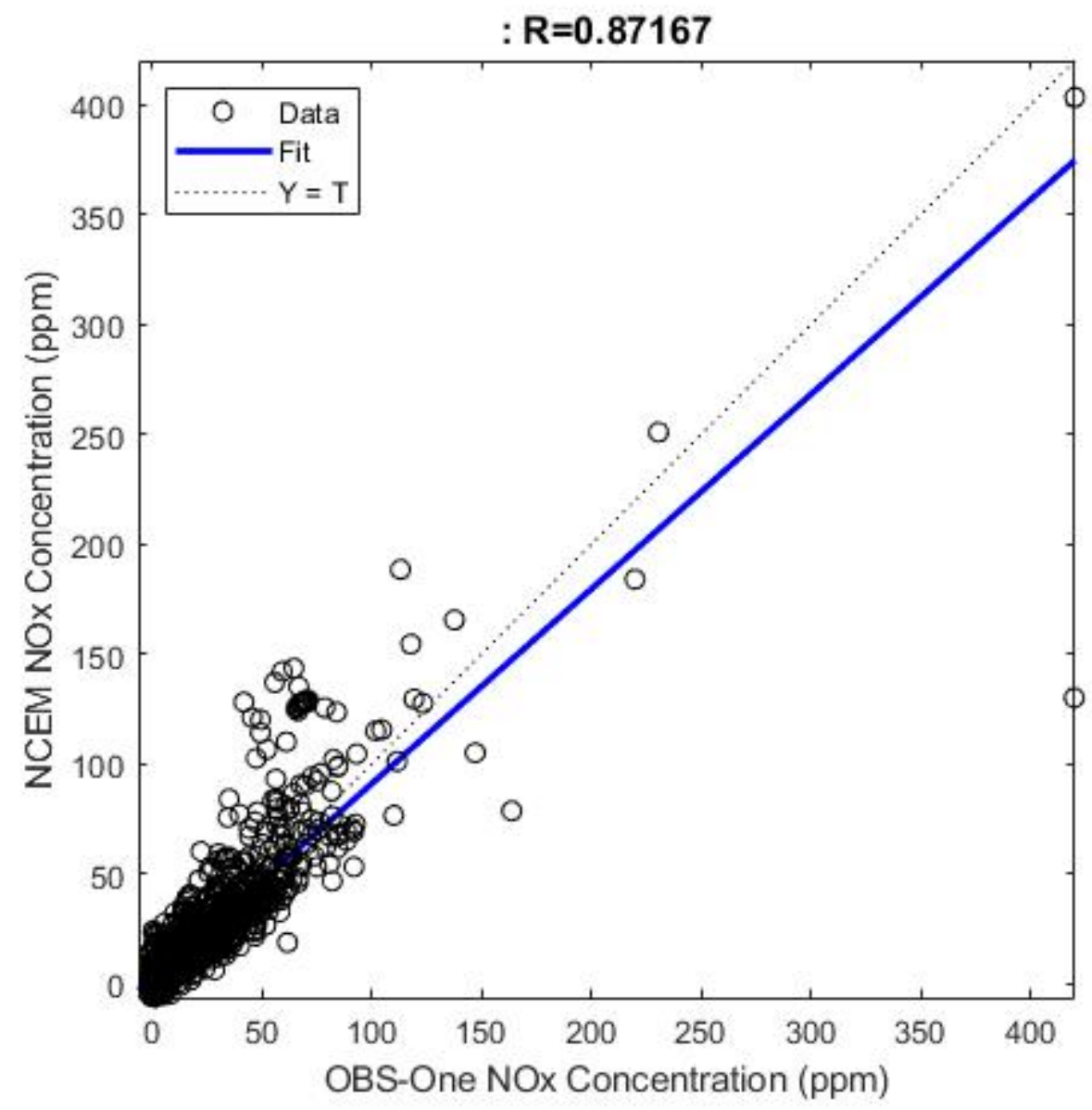

Figure 60: Linear Regression for RDE $3 \mathrm{NO}_{\mathrm{x}}$ Urban 


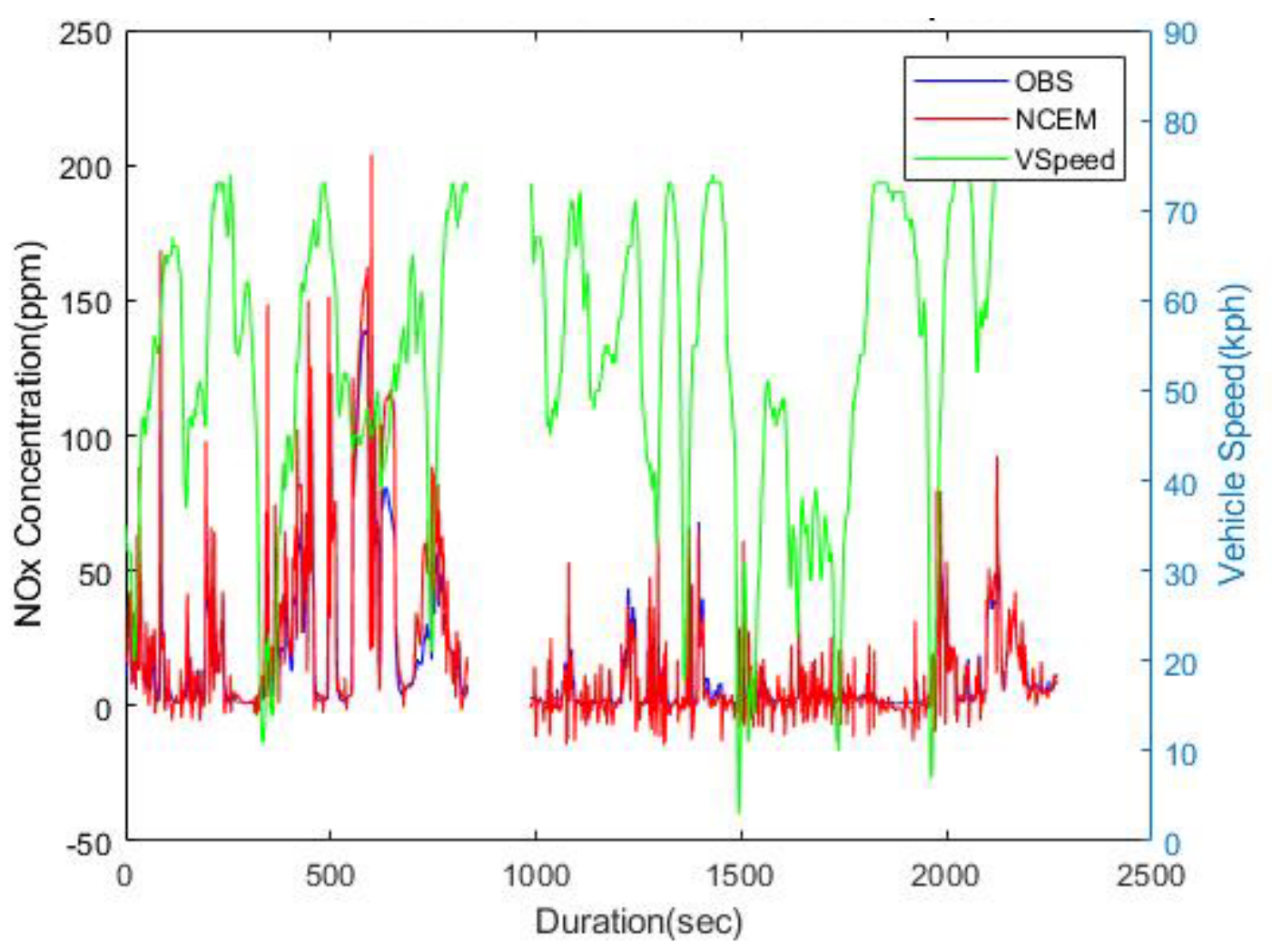

Figure 61: RDE 1 NOx Rural Raw Data with Vehicle Speed 


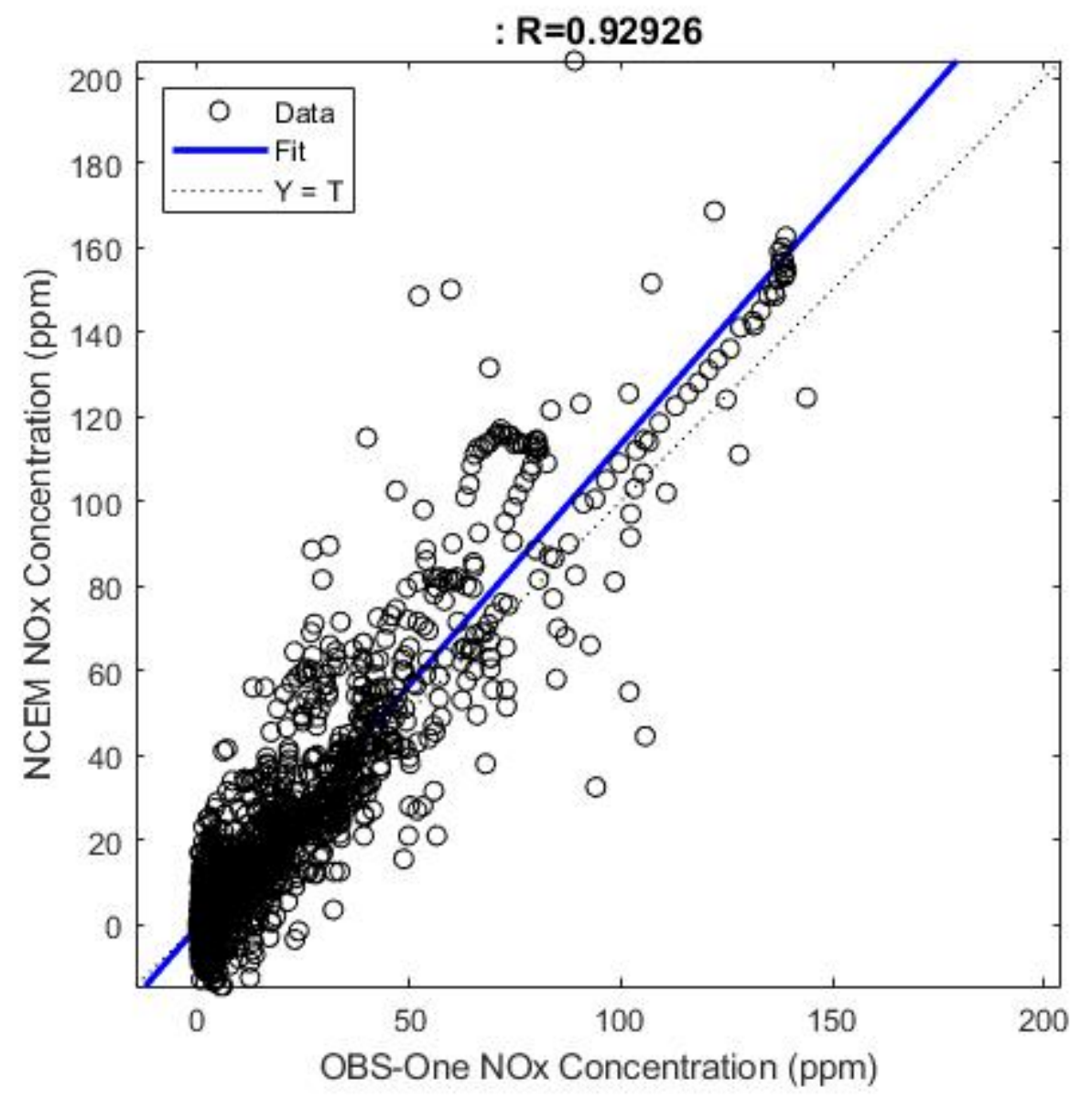

Figure 62: Linear Regression for RDE $1 \mathrm{NO}_{\mathrm{x}}$ Rural 


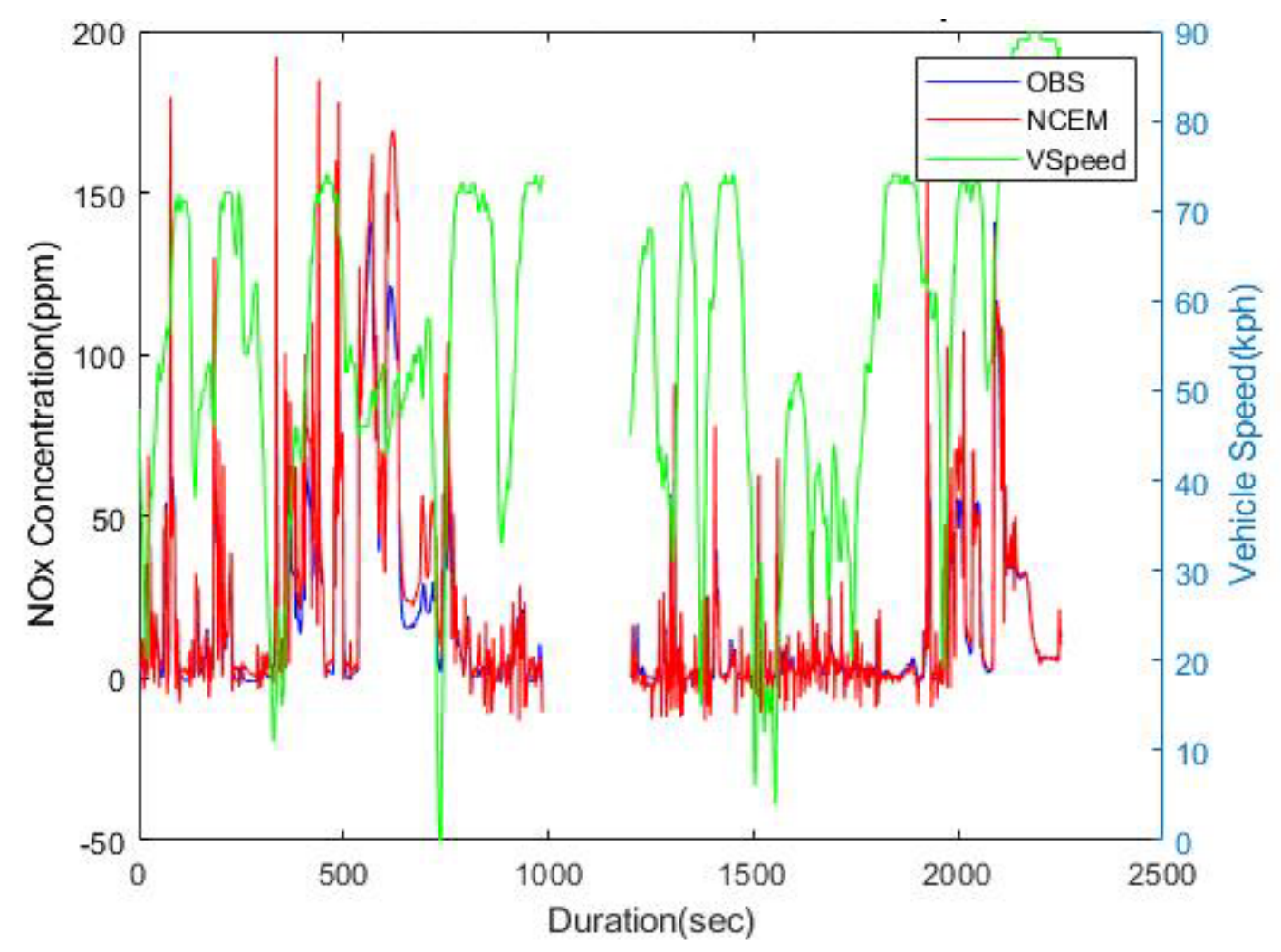

Figure 63: RDE 3 NOx Rural Raw Data with Vehicle Speed 


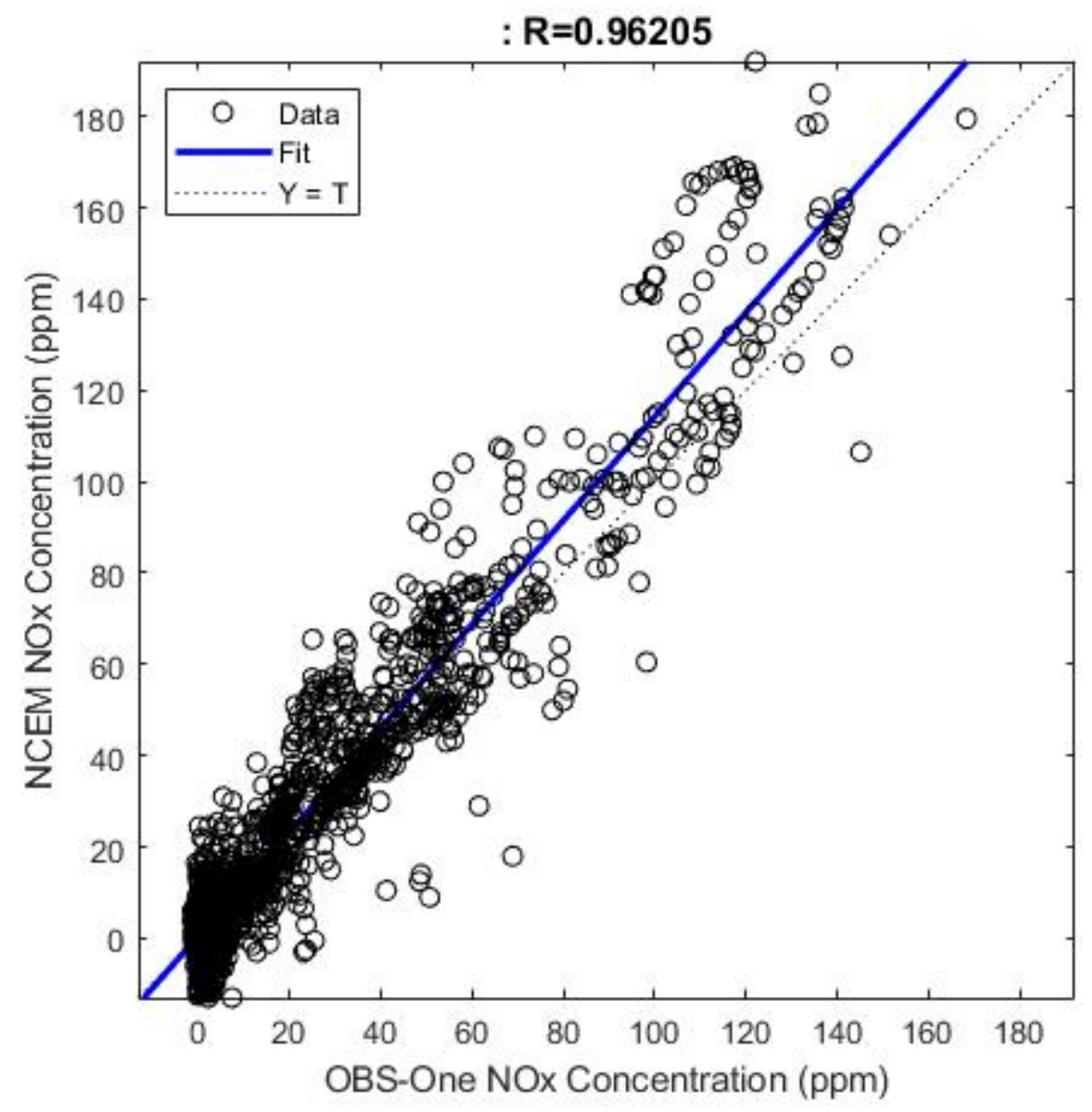

Figure 64: Linear Regression for RDE $3 \mathrm{NO}_{\mathrm{x}}$ Rural 


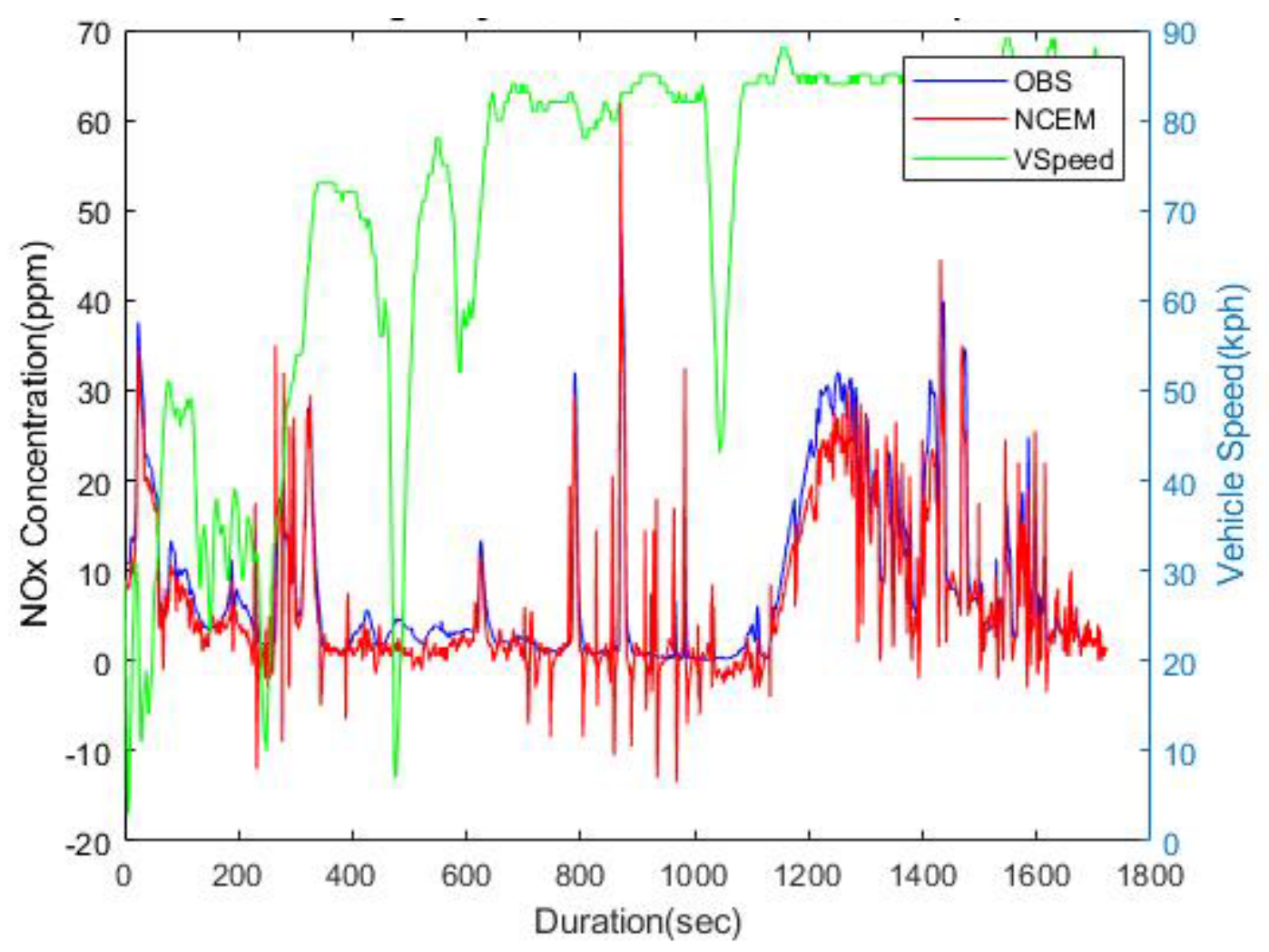

Figure 65: RDE 1 NO$_{x}$ Raw Data with Vehicle Speed 


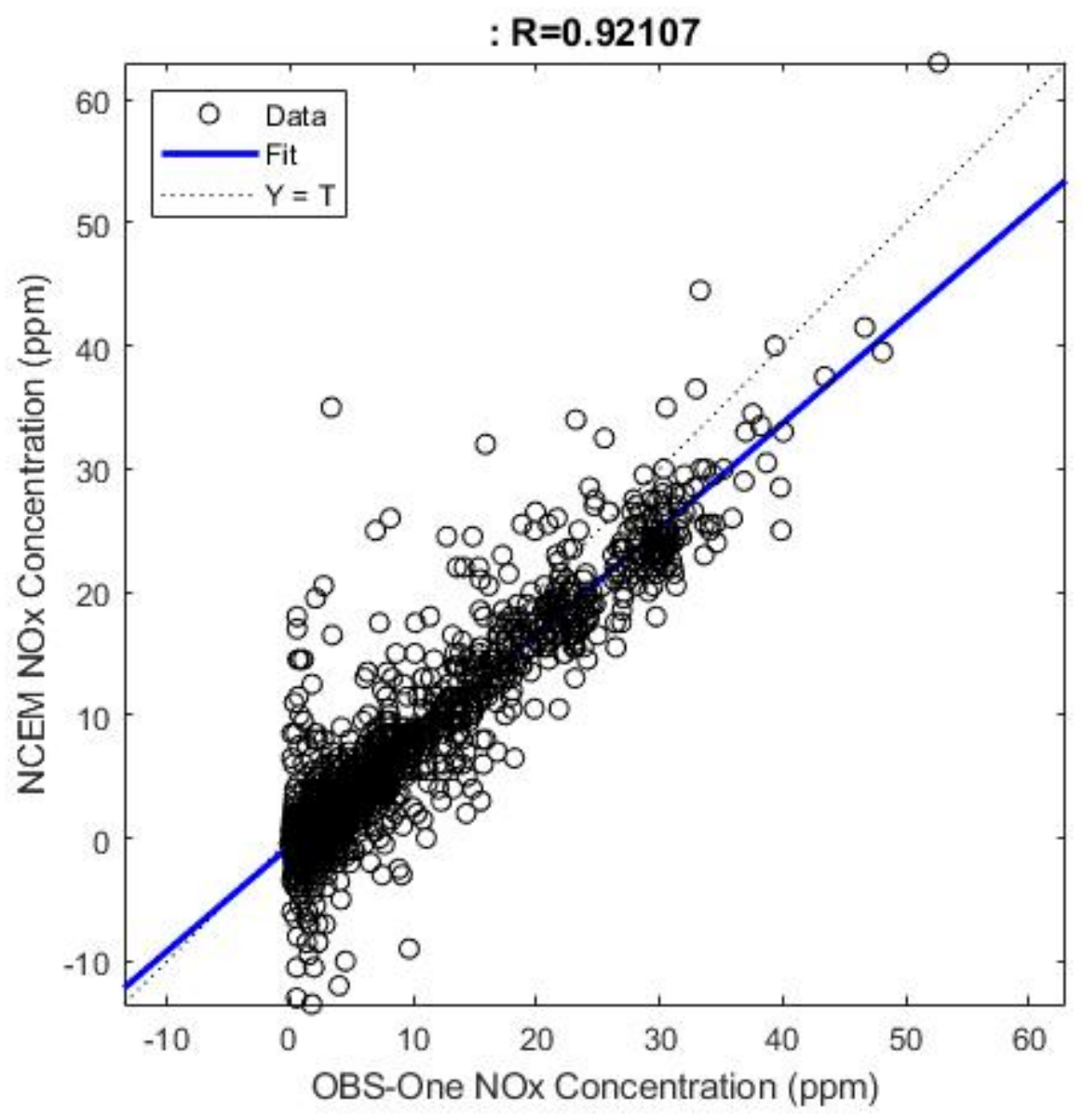

Figure 66: Linear Regression for RDE 1 NO $_{x}$ Highway 


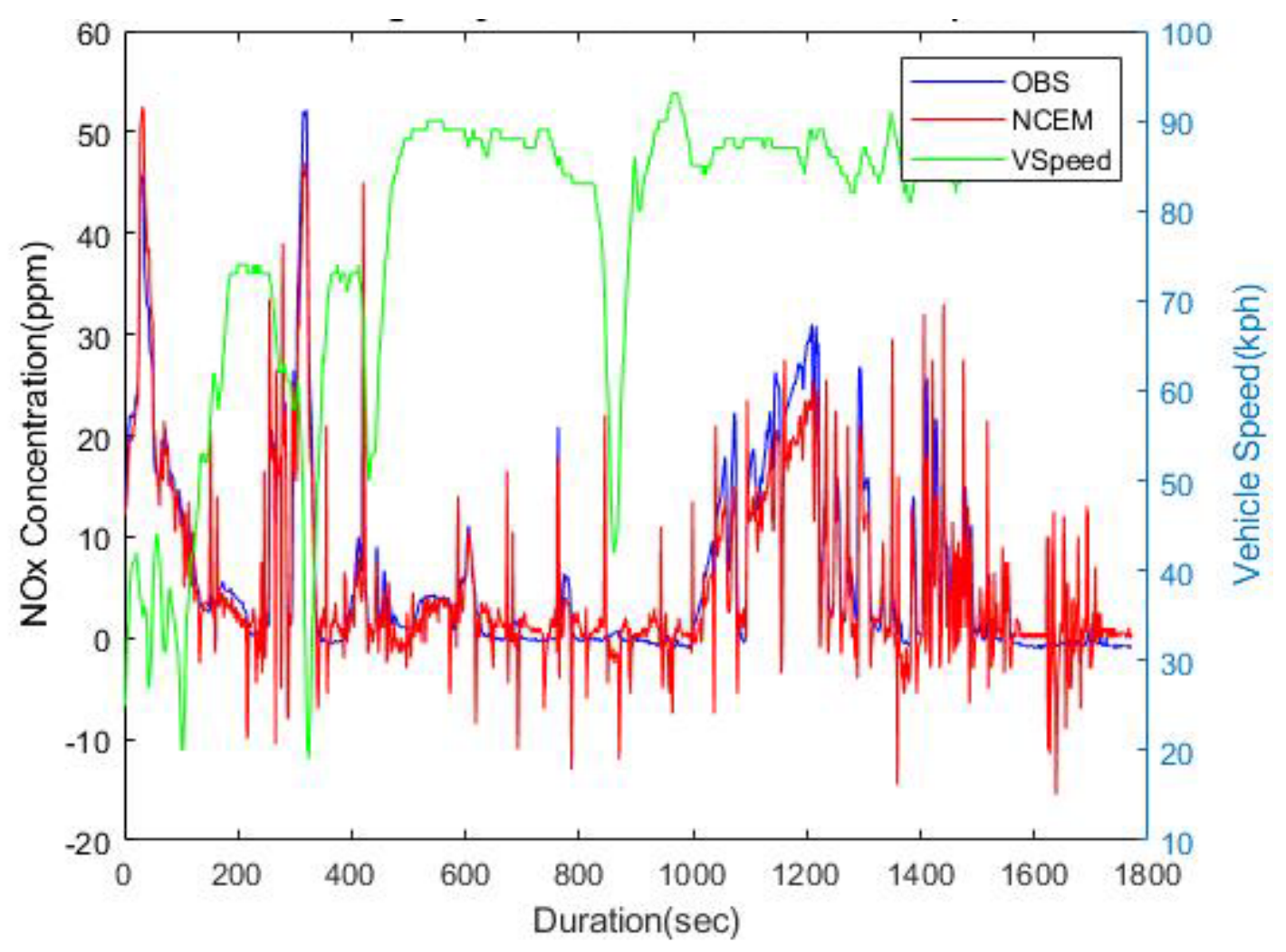

Figure 67: RDE 3 NO$_{x}$ Highway Raw Data with Vehicle Speed 


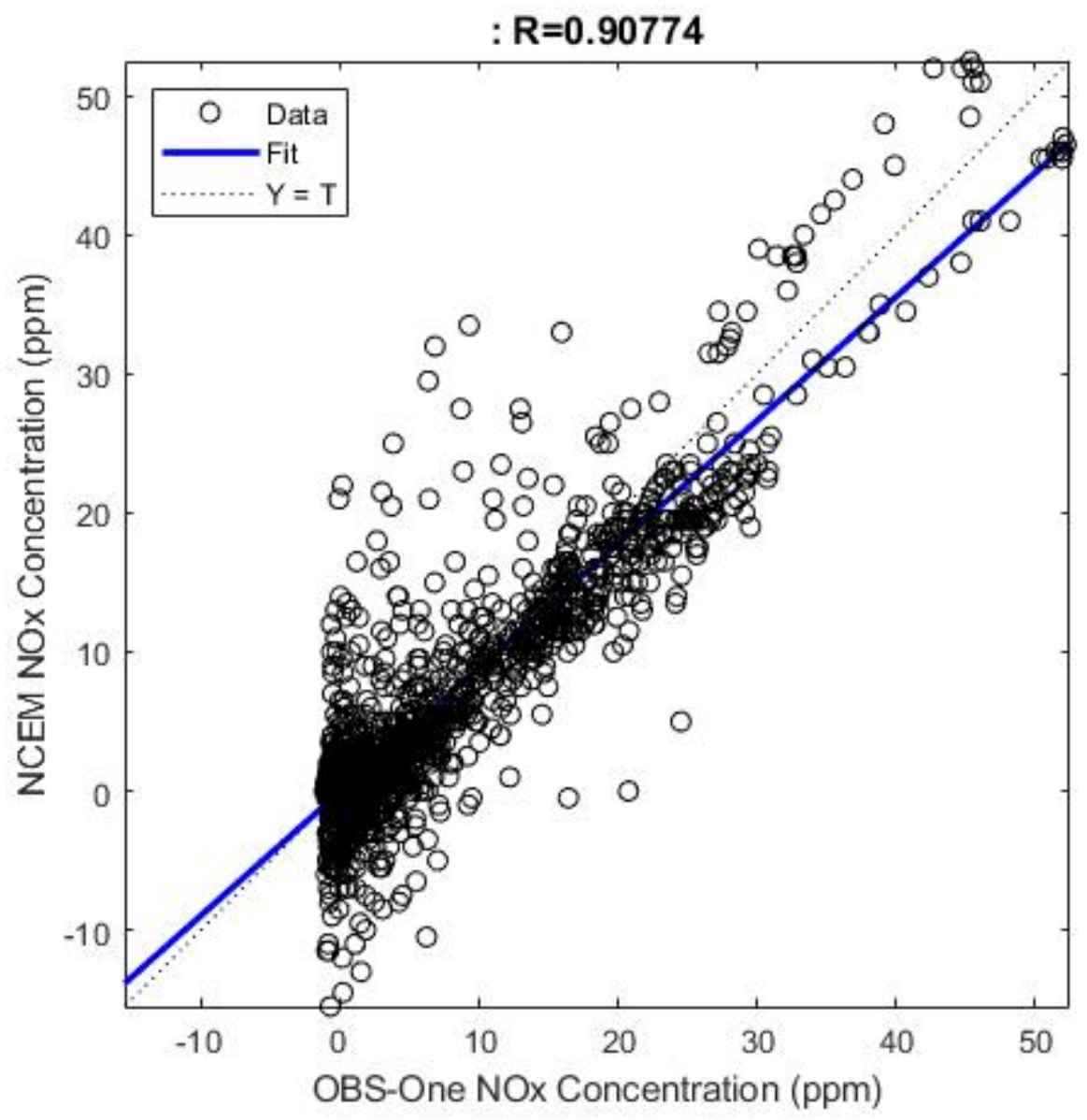

Figure 68: Linear Regression for RDE $3 \mathrm{NO}_{\mathrm{x}}$ Highway 


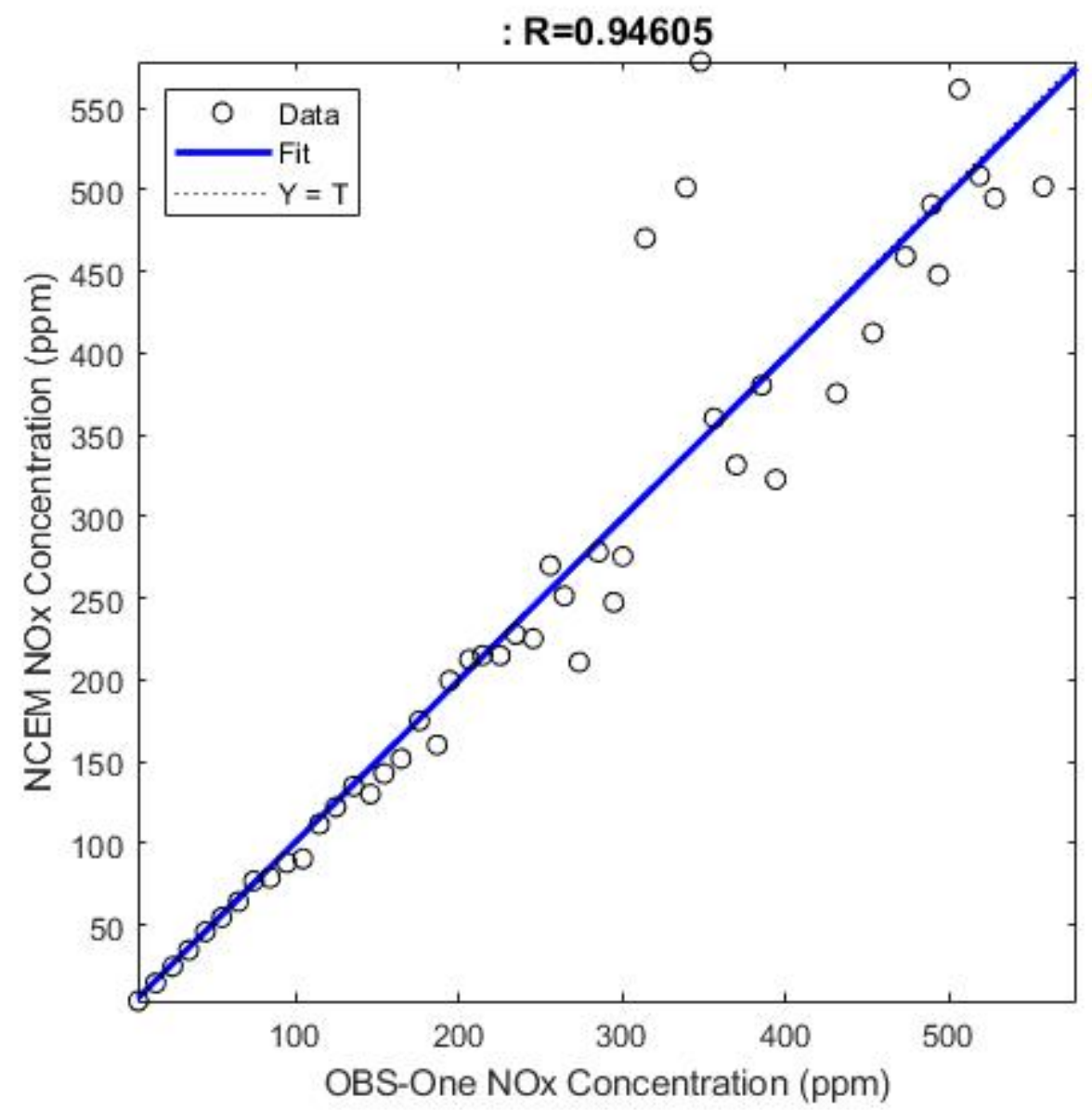

Figure 69: Linear Regression for RDE 1 NO ${ }_{x}$ Concentration Binning - 10 ppm Bins 


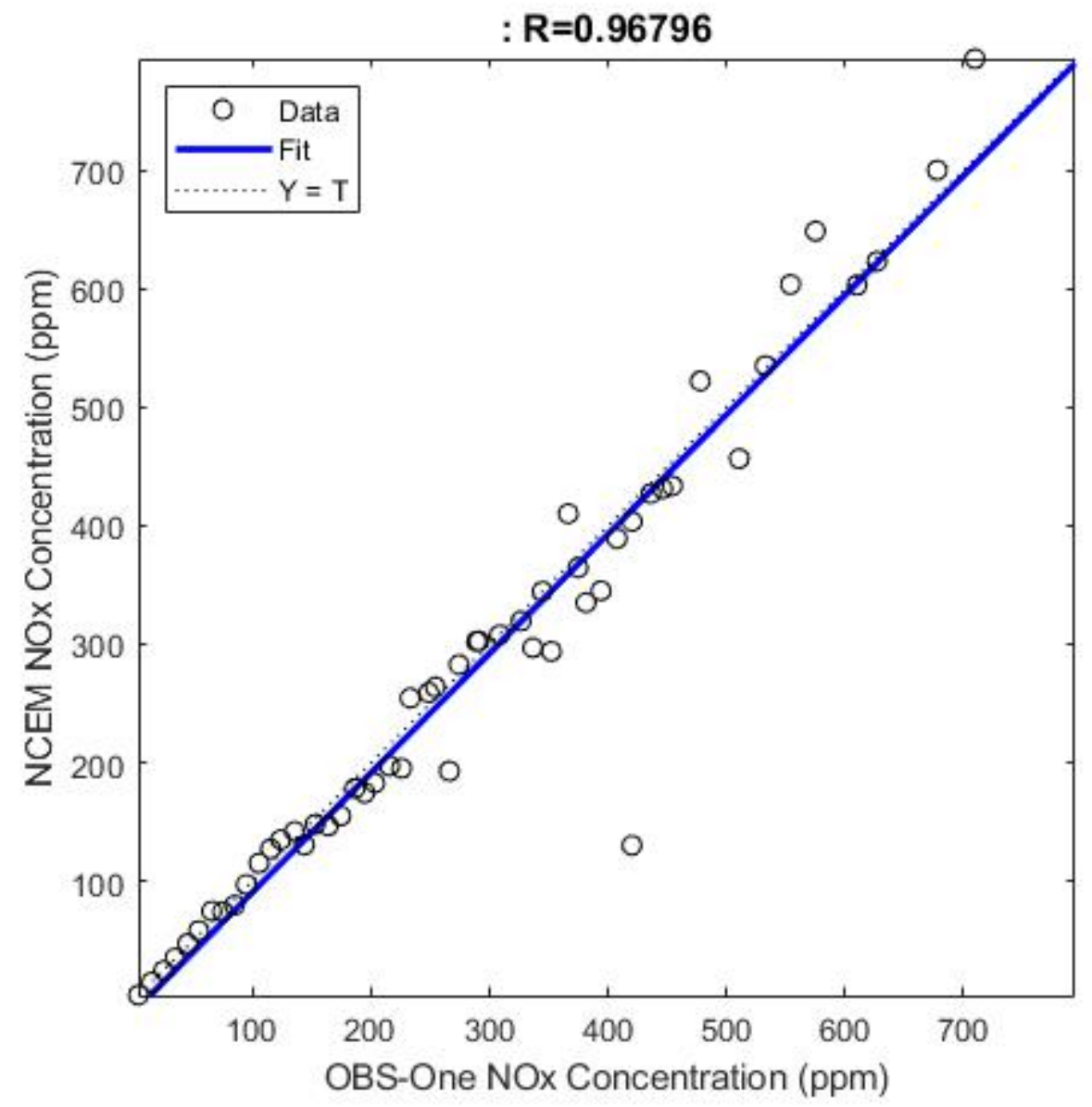

Figure 70: Linear Regression for RDE 3 NO$_{x}$ Concentration Binning - 10 ppm Bins 


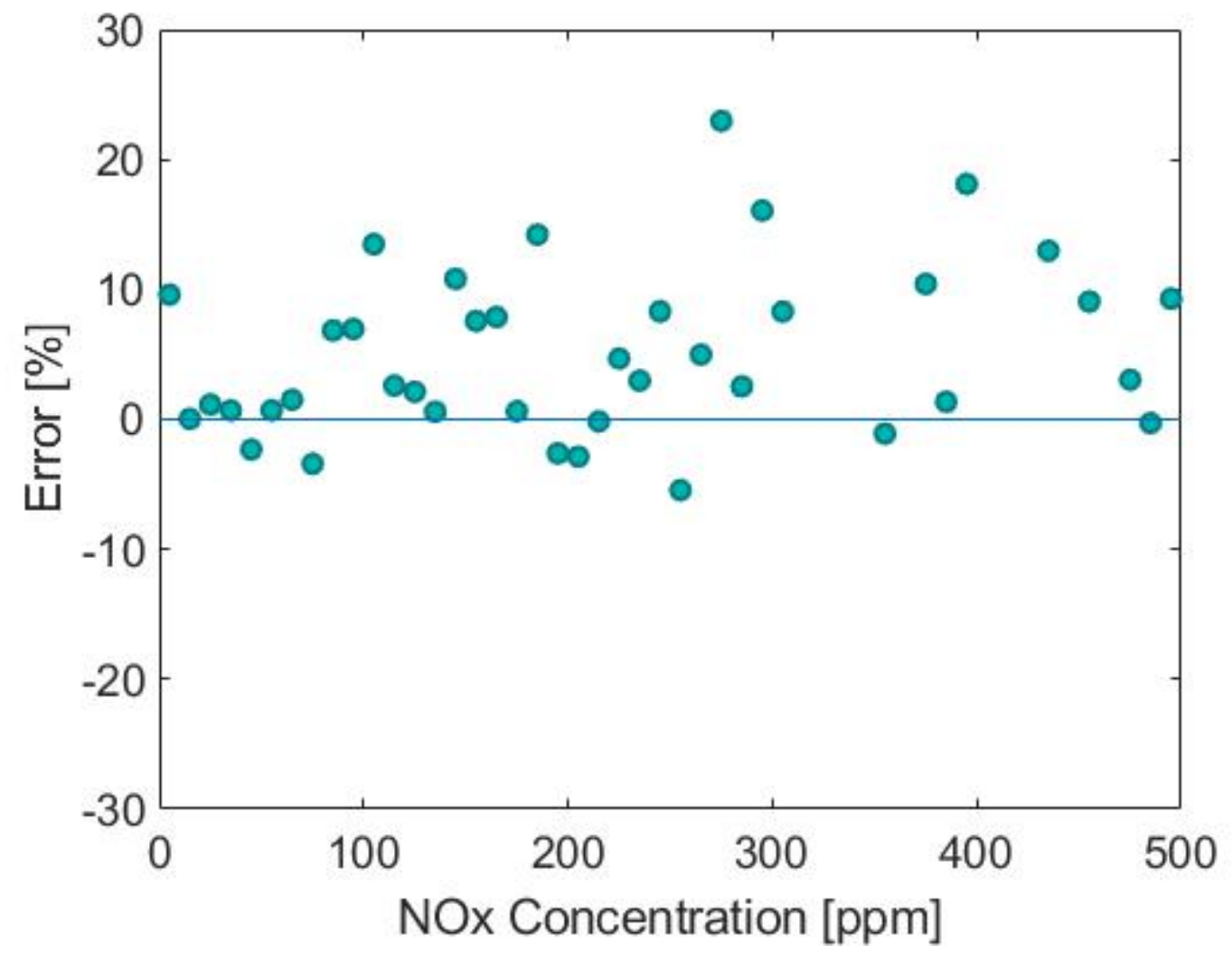

Figure 71: Error Percentage for RDE 1 NO$_{\mathrm{x}}$ Concentration Binning - 10 ppm Bins 


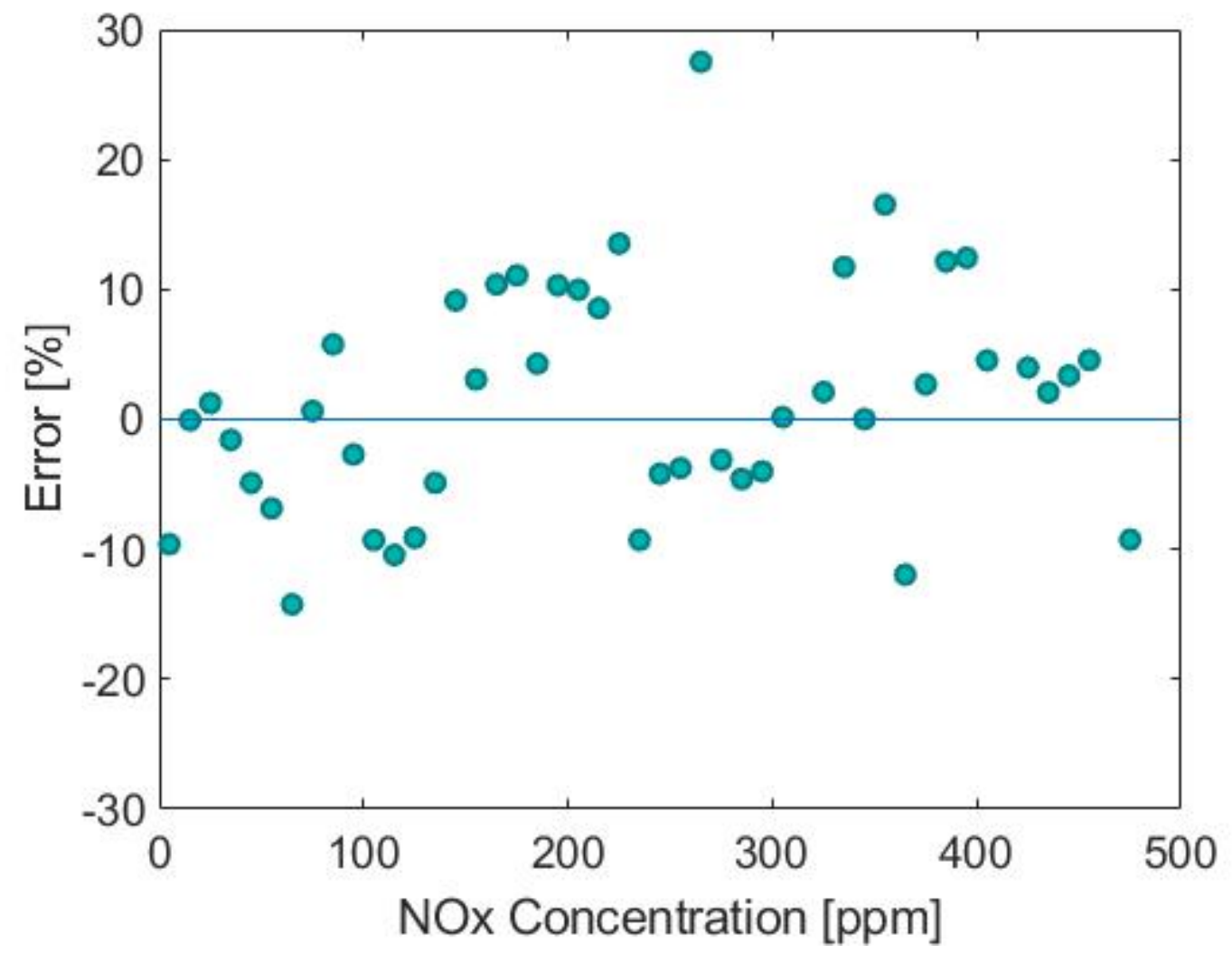

Figure 72: Error Percentage for RDE $3 \mathrm{NO}_{\mathrm{x}}$ Concentration Binning - 10 ppm Bins 


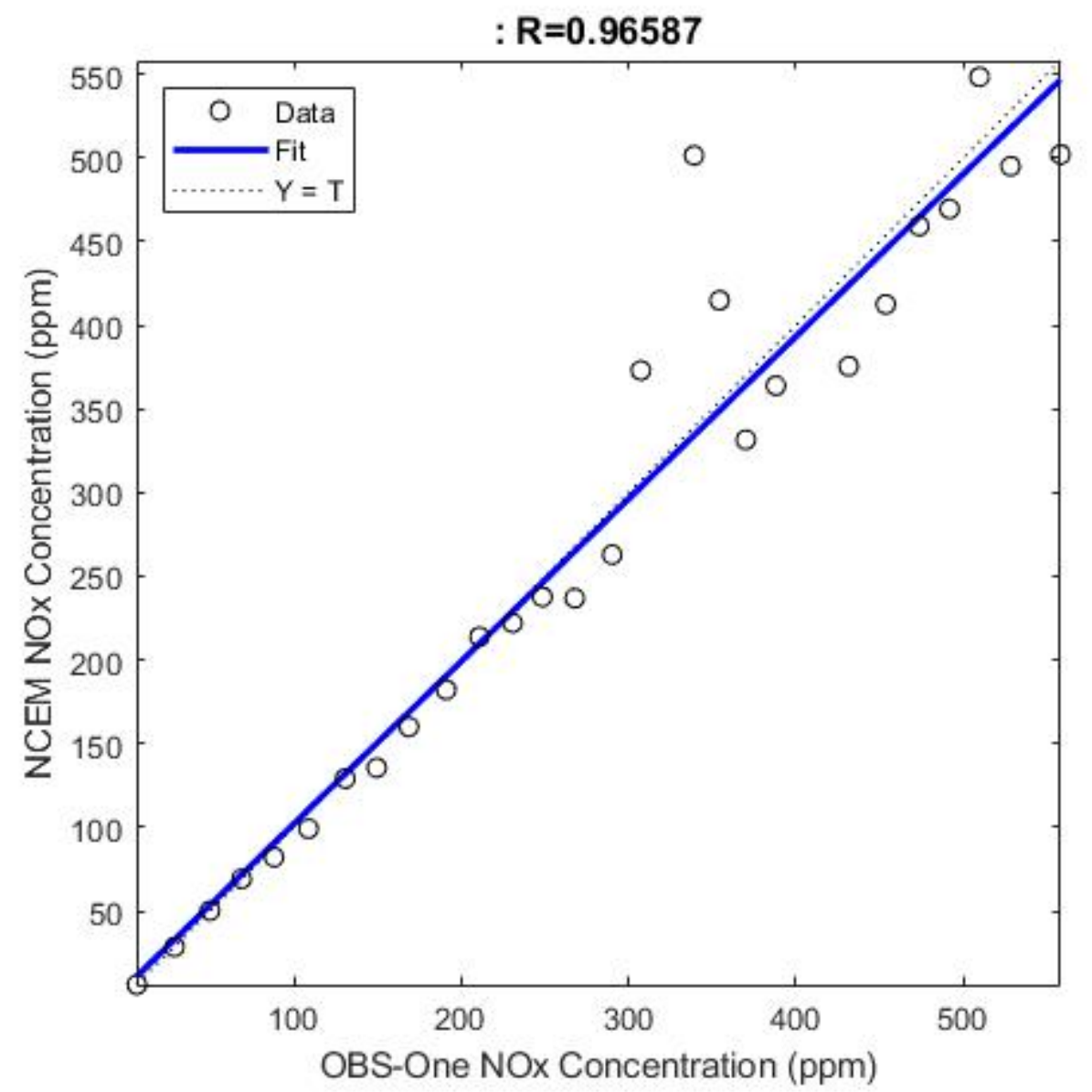

Figure 73: Linear Regression for RDE 1 NO ${ }_{x}$ Concentration Binning - 20 ppm Bins 


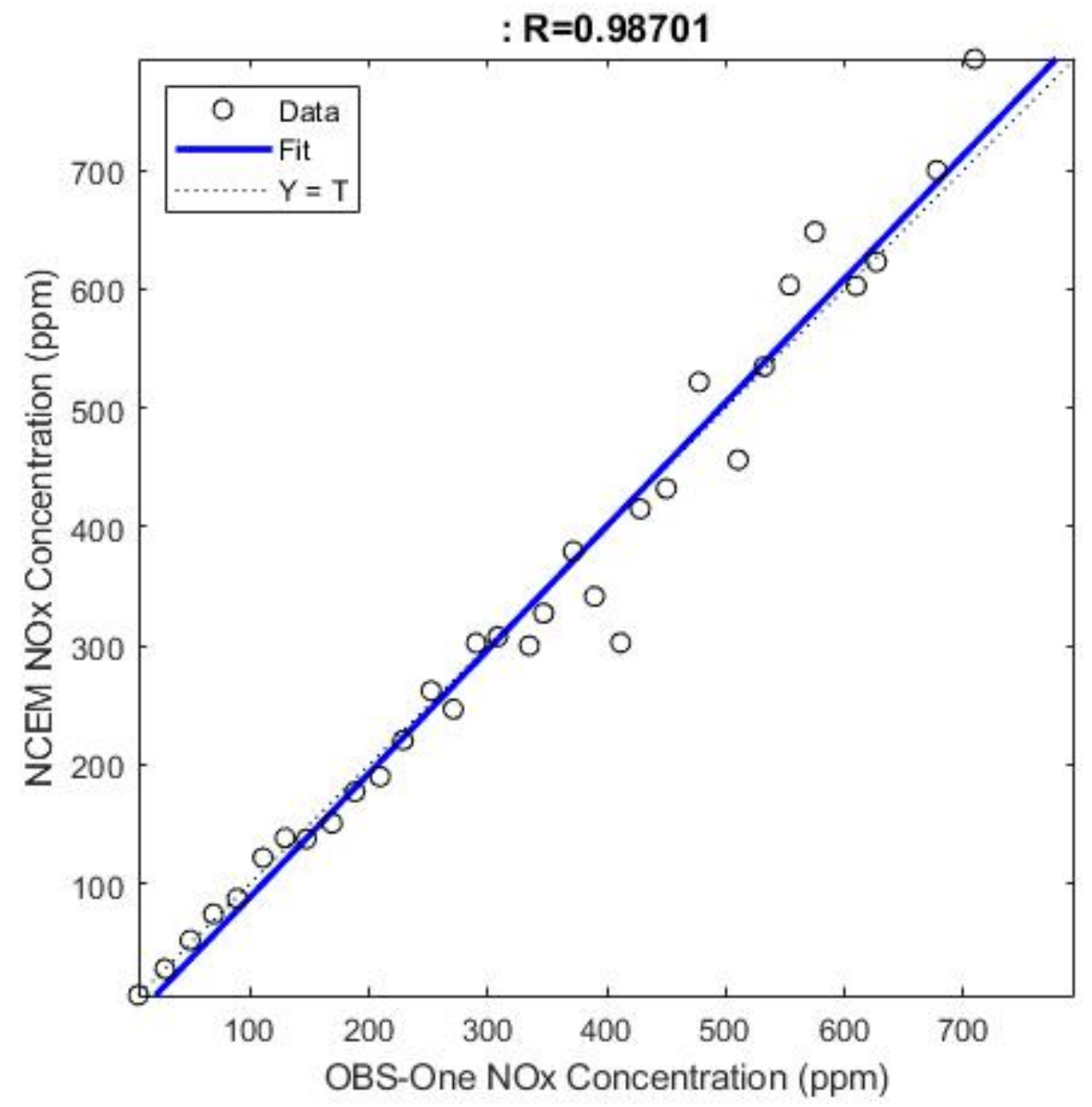

Figure 74: Linear Regression for RDE 3 NO$_{x}$ Concentration Binning - 20 ppm Bins 


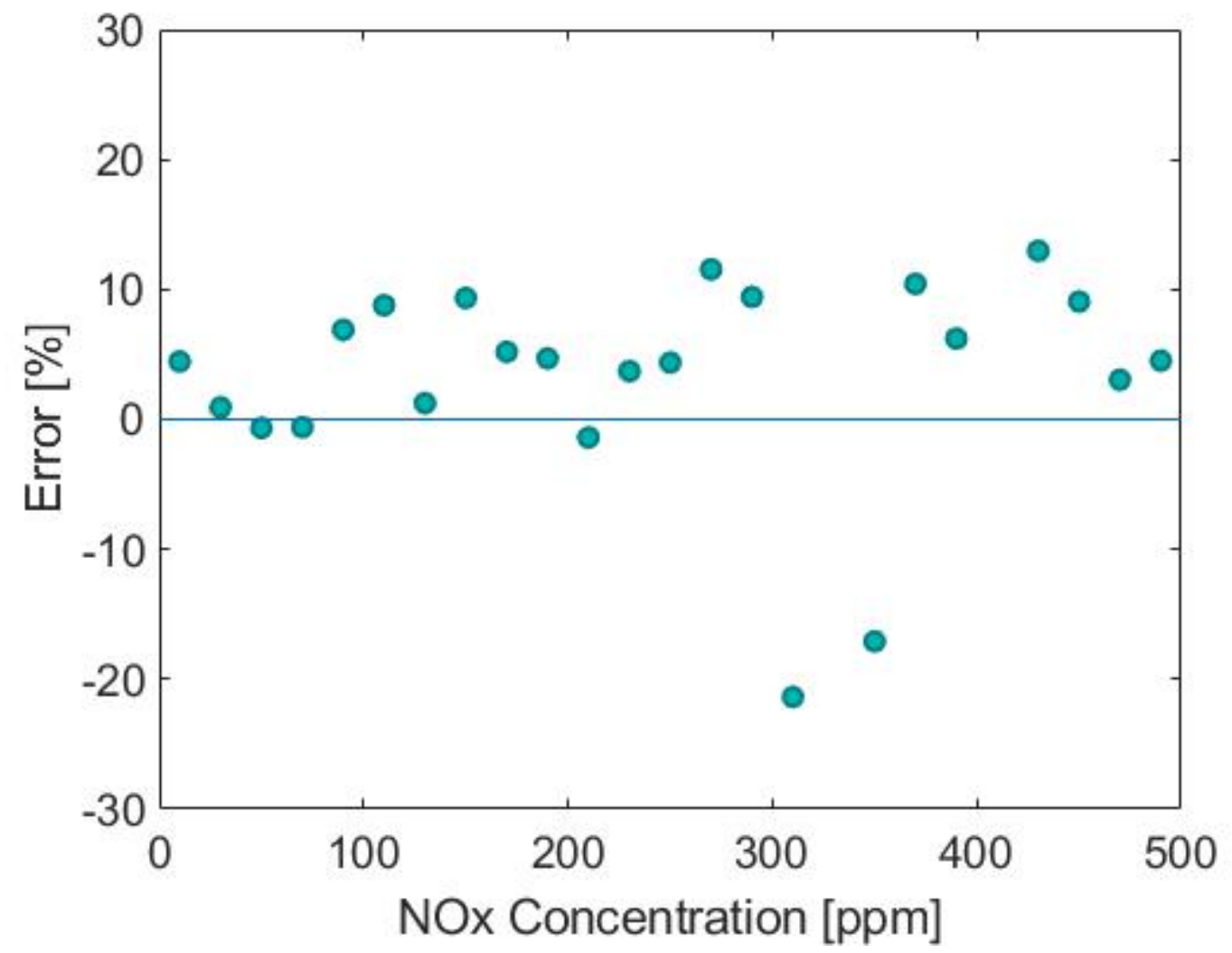

Figure 75: Error Percentage for RDE 1 NO$_{\mathrm{x}}$ Concentration Binning - 20 ppm Bins 


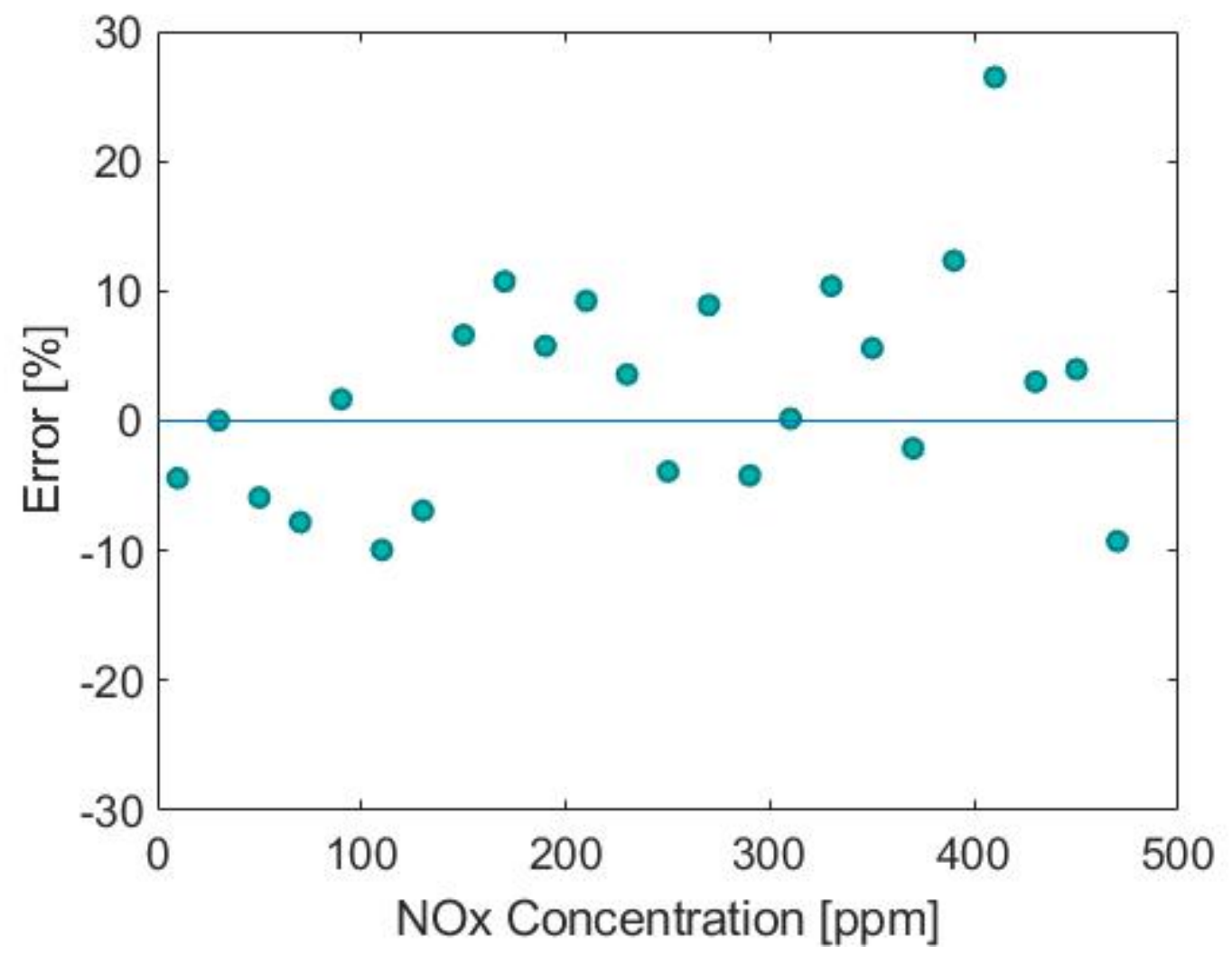

Figure 76: Error Percentage for RDE $3 \mathrm{NO}_{\mathrm{x}}$ Concentration Binning - 20 ppm Bins

Table 23: RDE R-squared values

\begin{tabular}{|l|c|c|c|}
\hline & \multicolumn{3}{|c|}{$\mathrm{R}^{2}$ Values } \\
\hline & RDE 1 & RDE 2 & RDE 3 \\
\hline Overall & 0.9524 & 0.9674 & 0.9687 \\
\hline Cold Start & 0.96006 & 0.97165 & 0.97903 \\
\hline Urban & 0.86994 & 0.95419 & 0.87167 \\
\hline Rural & 0.92926 & 0.95422 & 0.96209 \\
\hline Highway & 0.92107 & 0.96092 & 0.90777 \\
\hline $10 \mathrm{ppm}$ & 0.94602 & 0.97562 & 0.96796 \\
\hline $20 \mathrm{ppm}$ & 0.96582 & 0.98921 & 0.98701 \\
\hline
\end{tabular}




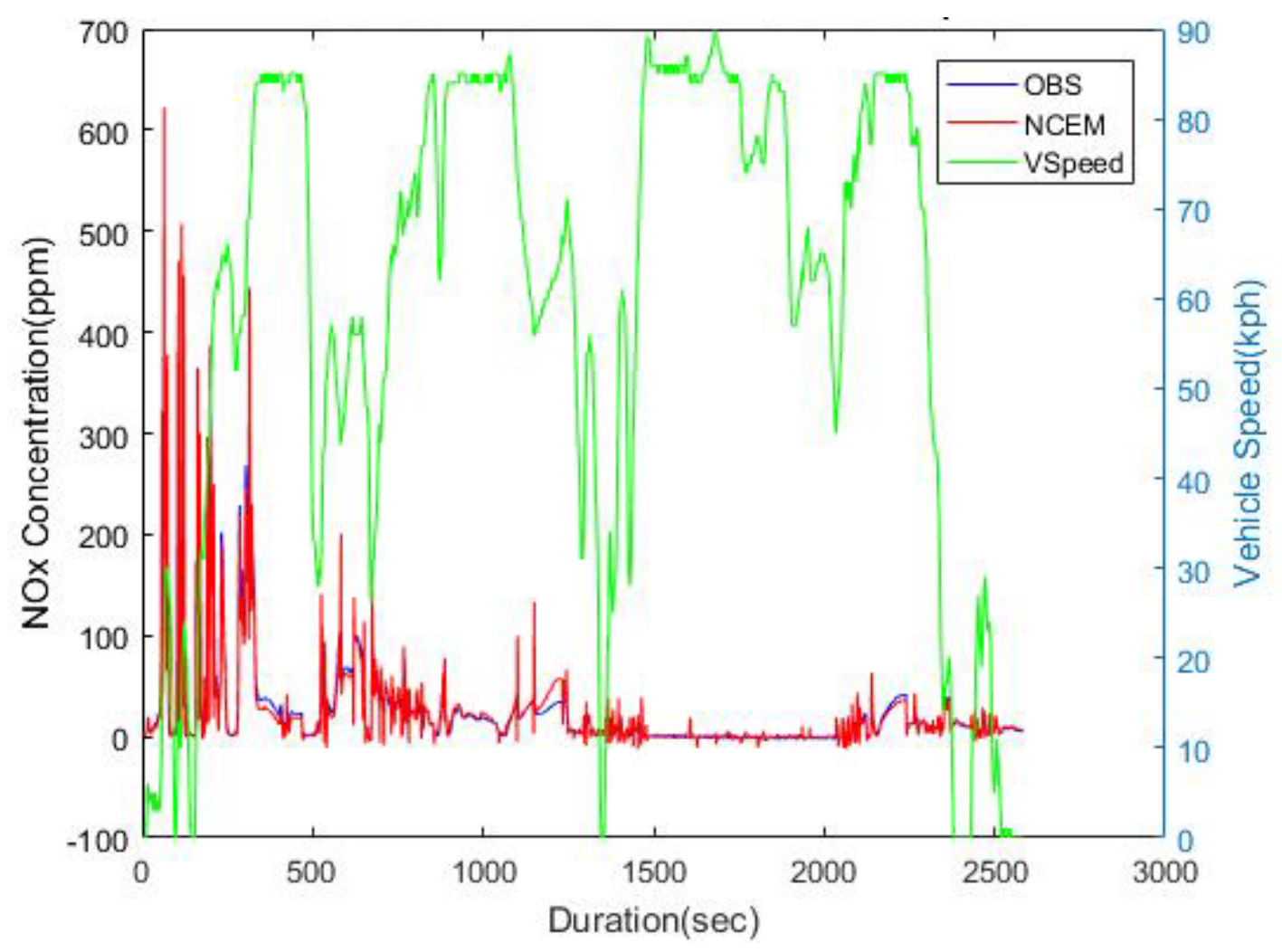

Figure 77: Tavannes 2 NO ${ }_{x}$ Raw Data with Vehicle Speed 


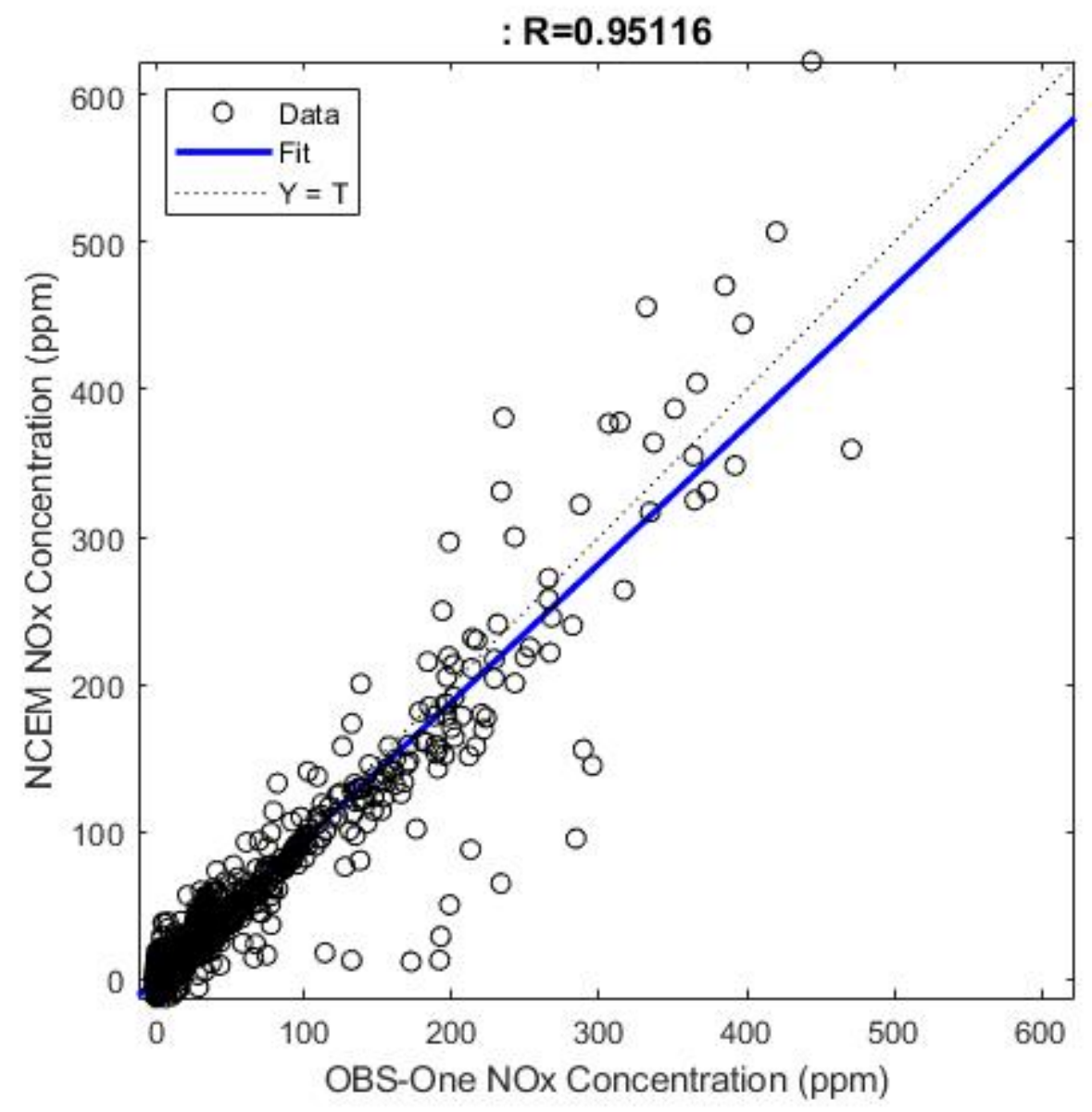

Figure 78: Linear Regression Tavannes $2 \mathrm{NO}_{\mathrm{x}}$ Overall 


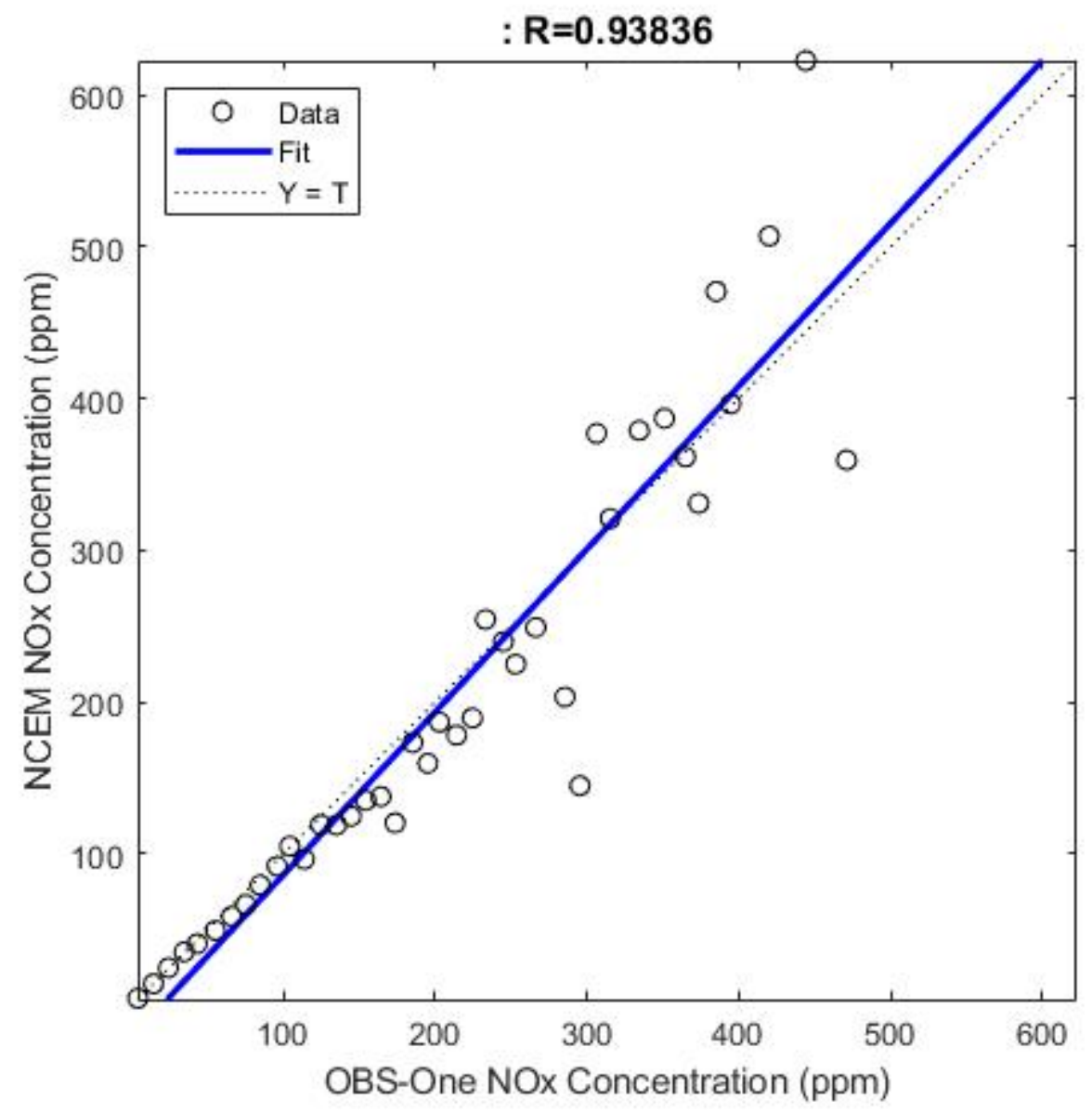

Figure 79: Linear Regression Tavannes $2 \mathrm{NO}_{\mathrm{x}}$ Concentration Binning - 10 ppm Bins 


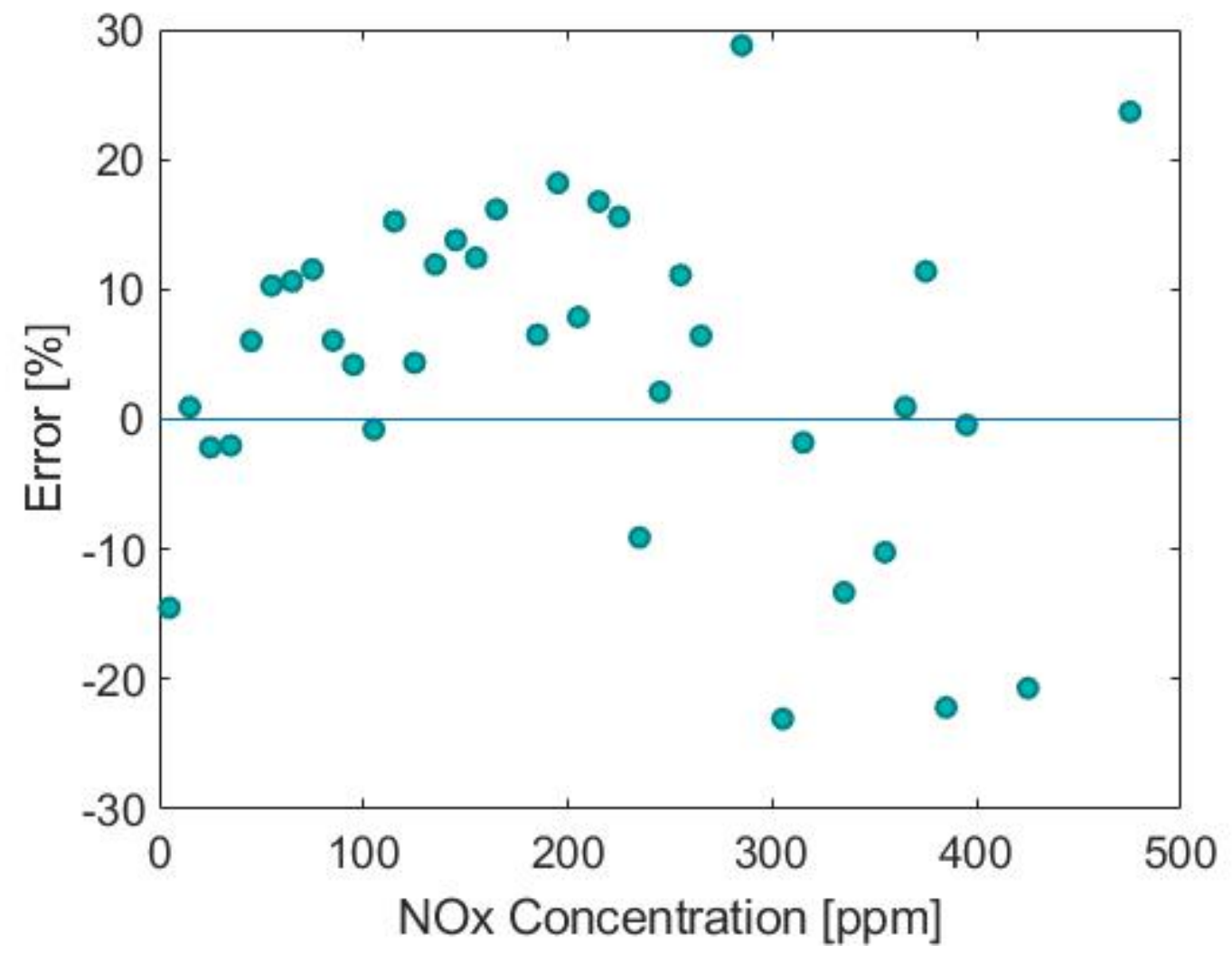

Figure 80: Error Percentage Tavannes 2 NO $_{\mathrm{x}}$ Concentration Binning - 10 ppm Bins 


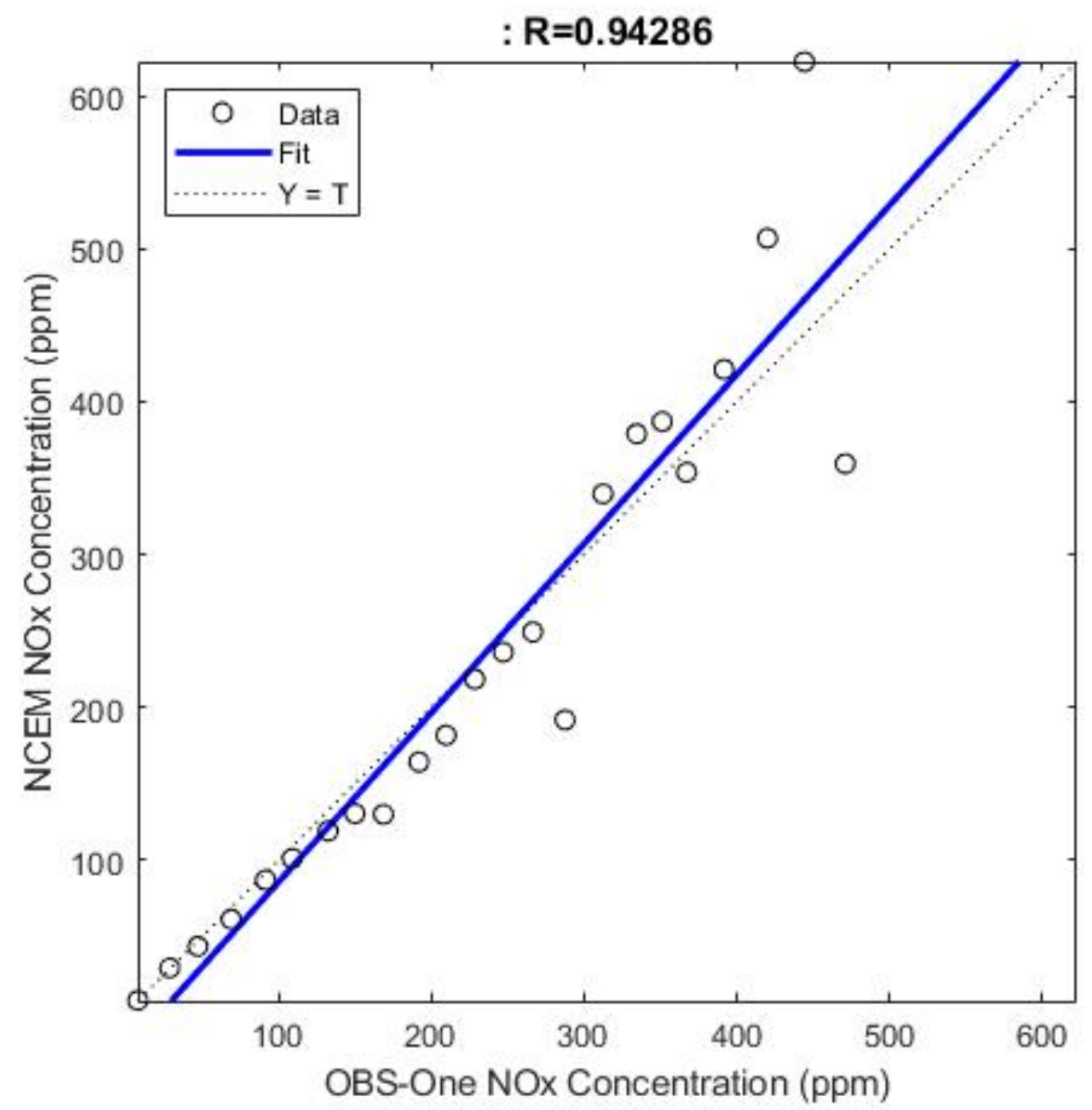

Figure 81: Linear Regression Tavannes 2 NO $_{x}$ Concentration Binning - 20 ppm Bins 


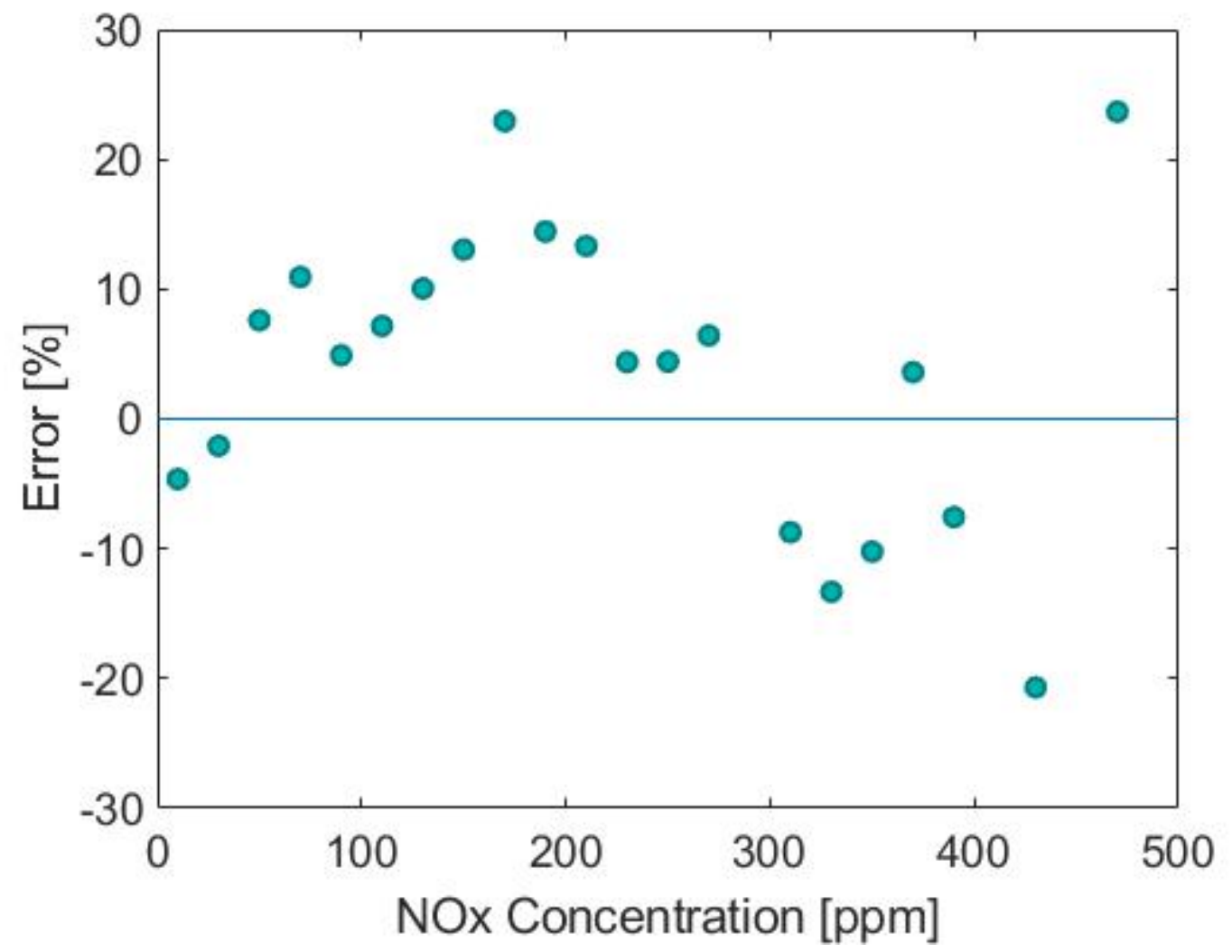

Figure 82: Error Percentage Tavannes 2 NO$_{x}$ Concentration Binning - 20 ppm Bins

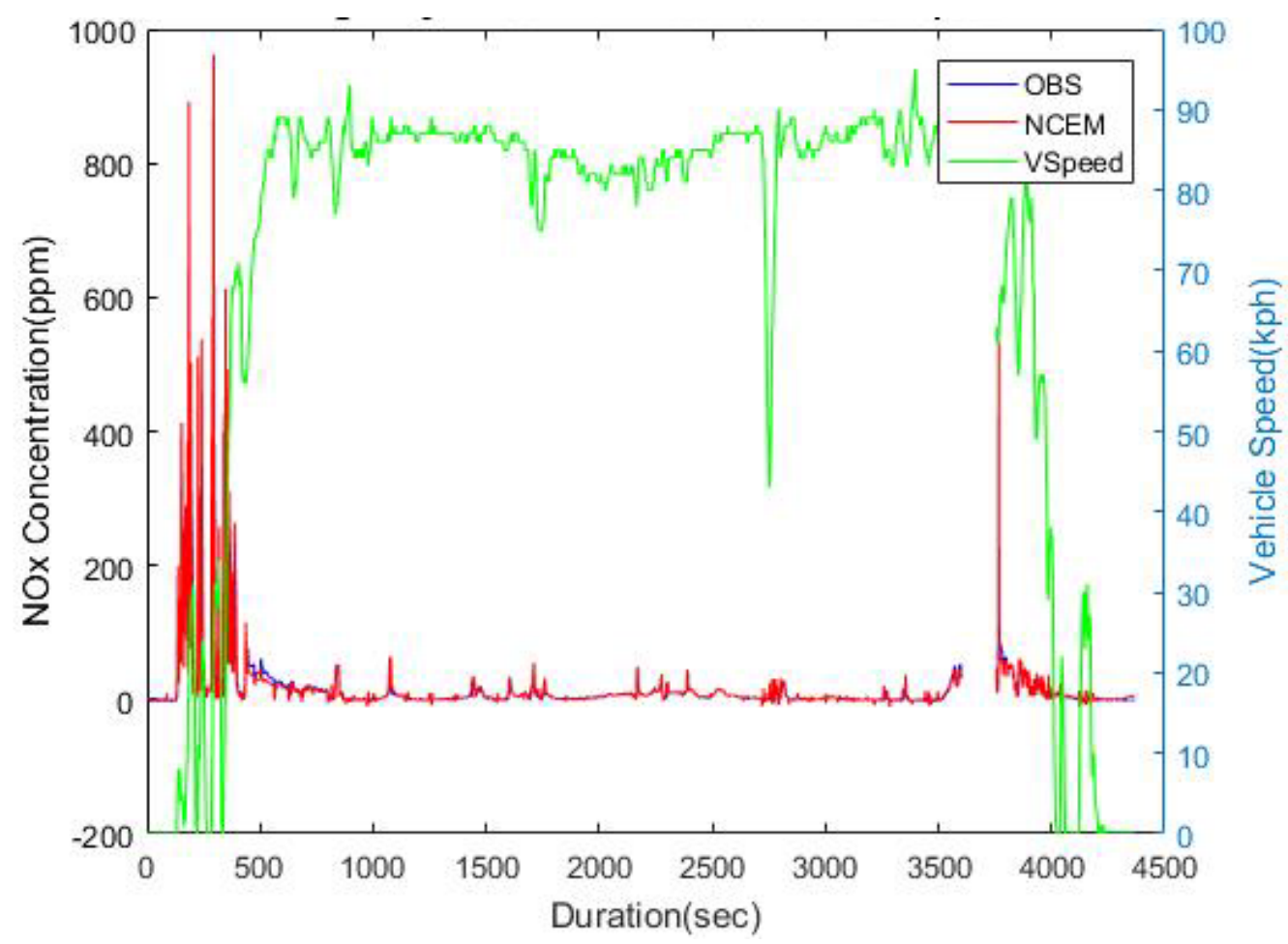

Figure 83: Highway 1 NOx Raw Data with Vehicle Speed 


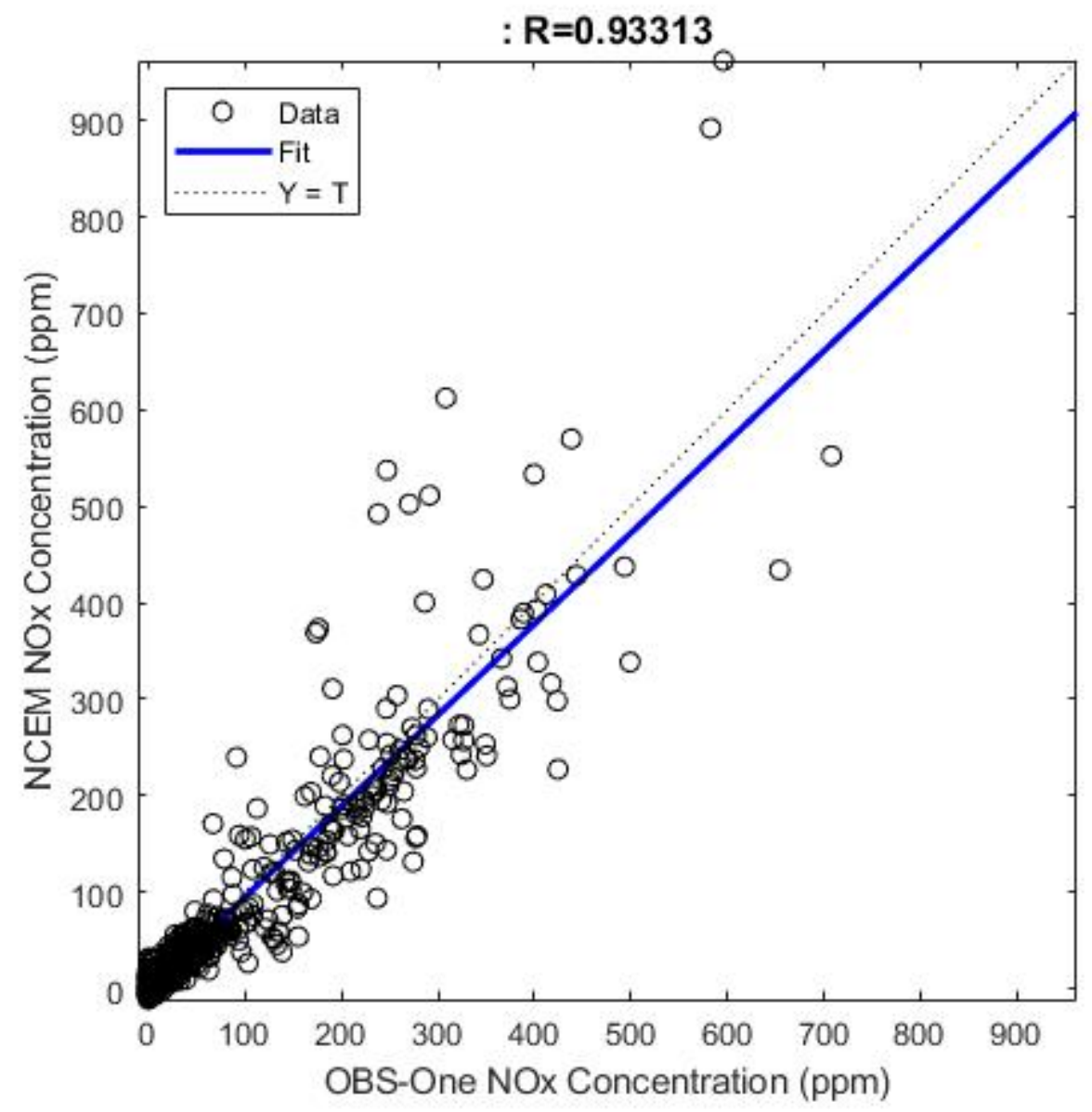

Figure 84: Linear Regression for Highway $1 \mathrm{NO}_{\mathrm{x}}$ Overall 


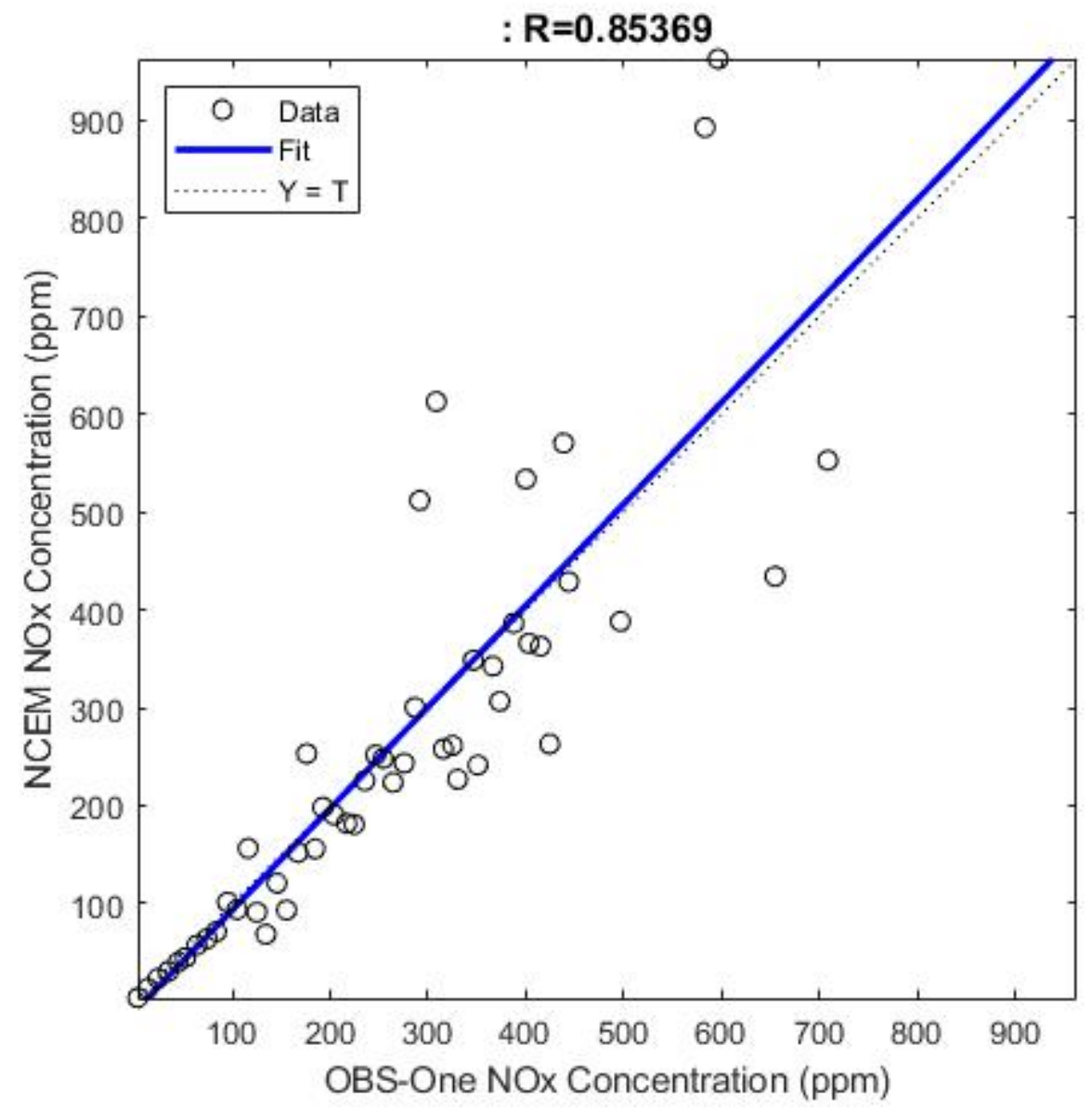

Figure 85: Linear Regression Highway 1 NO$_{x}$ Concentration Binning - 10 ppm Bins 


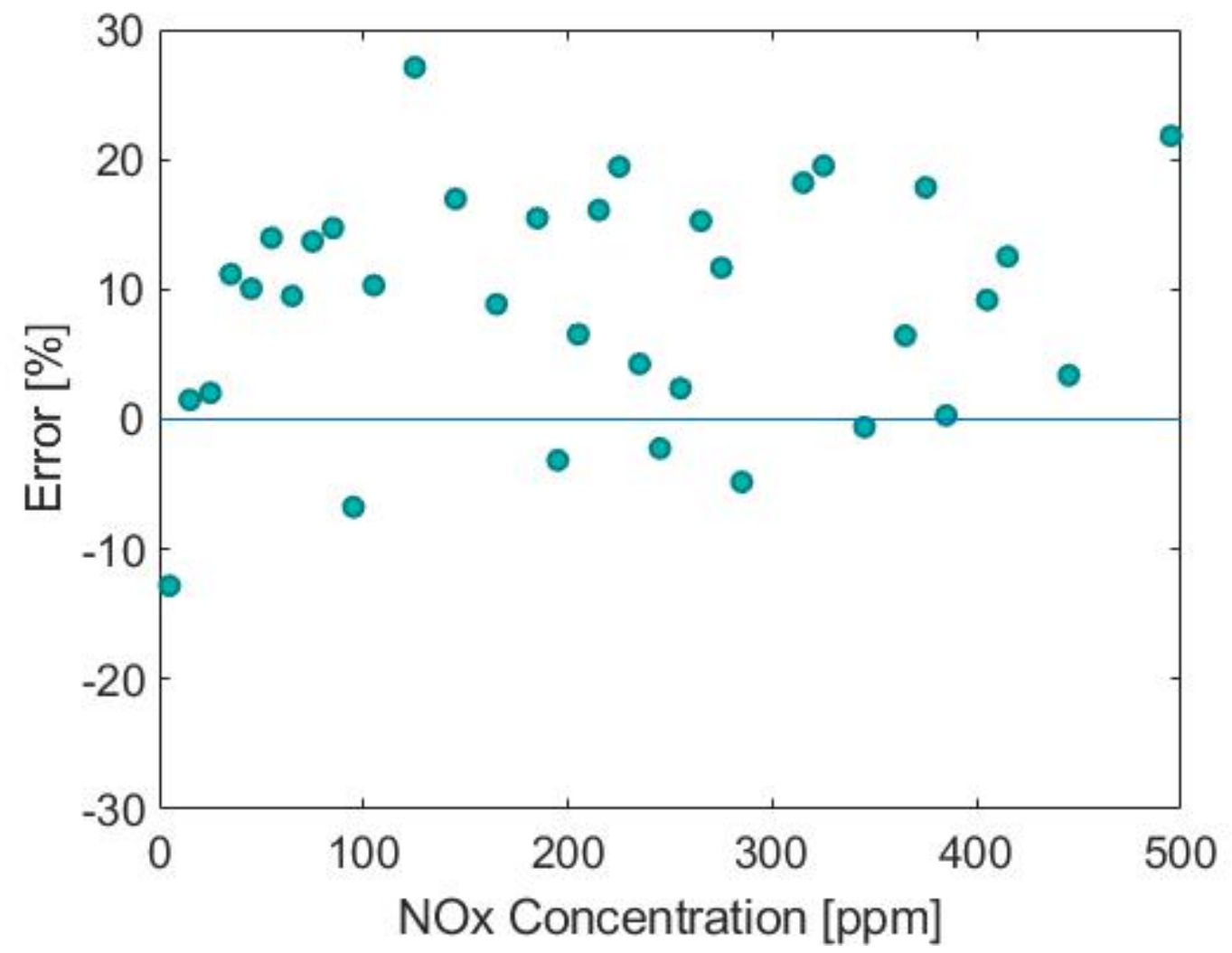

Figure 86: Error Percentage Highway 1 NO$_{\mathrm{x}}$ Concentration Binning - 10 ppm Bins 


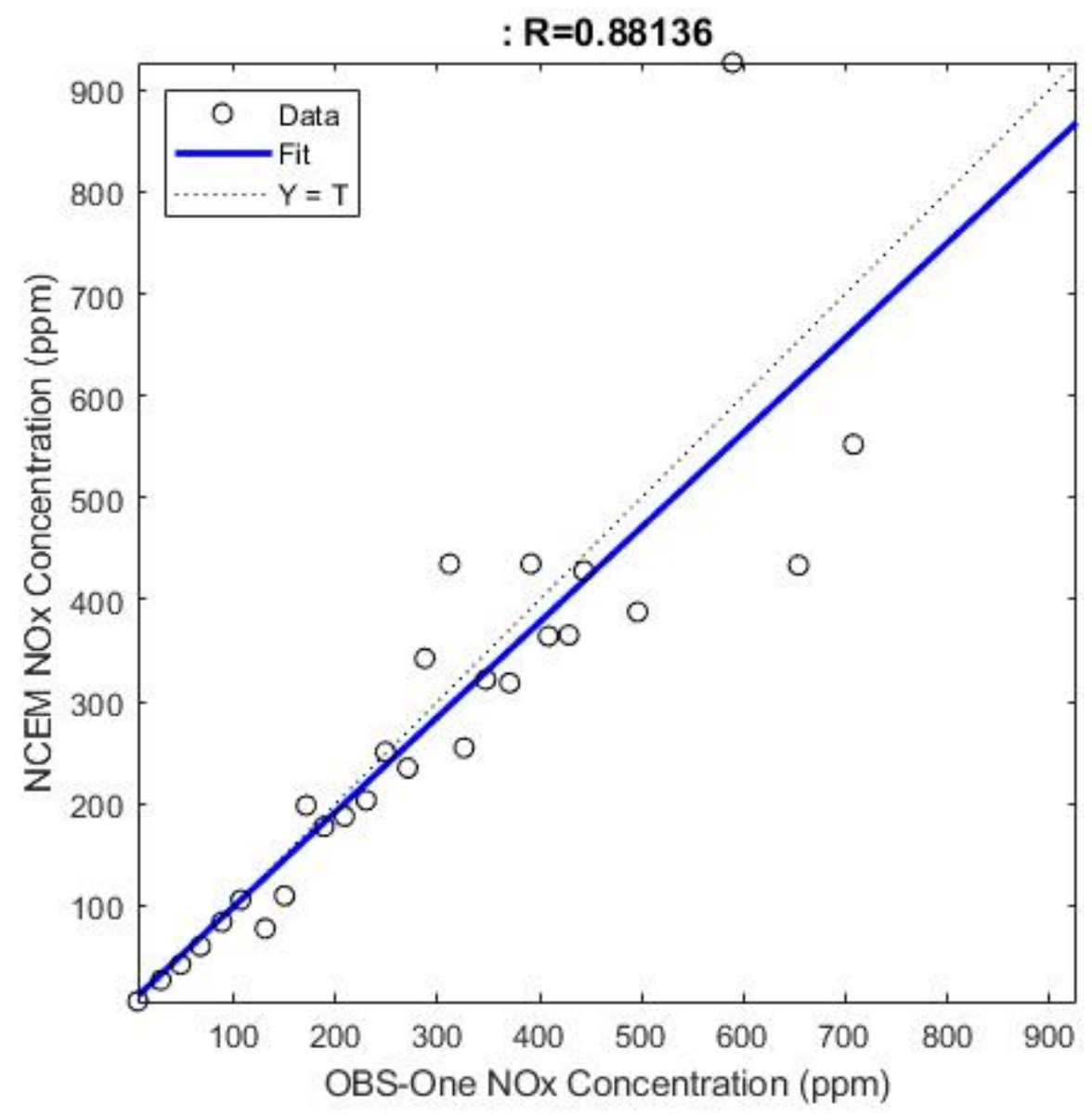

Figure 87: Linear Regression Highway 1 NO$_{x}$ Concentration Binning - 20 ppm Bins 


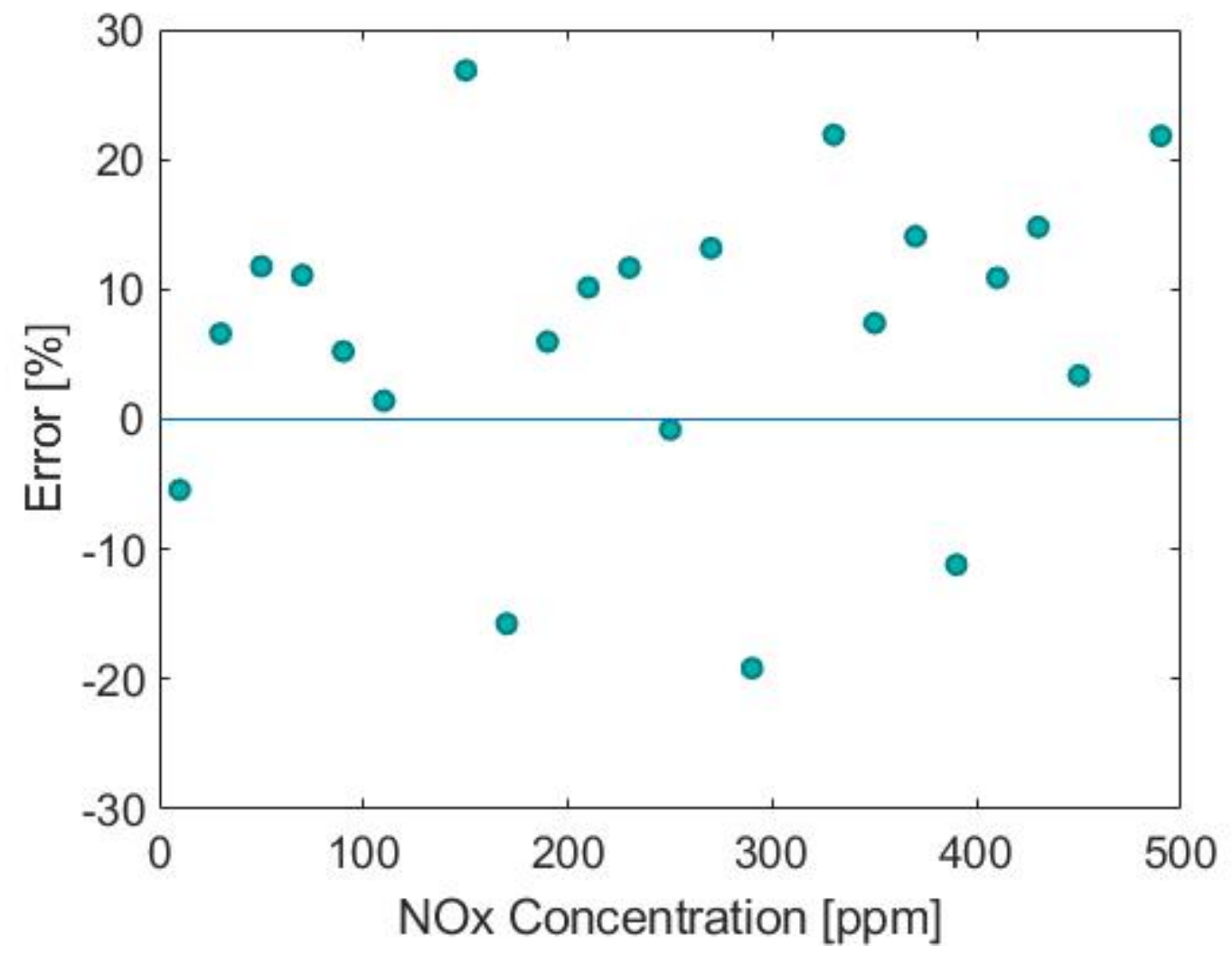

Figure 88: Error Percentage Highway 1 NO$_{\mathrm{x}}$ Concentration Binning - 20 ppm Bins 


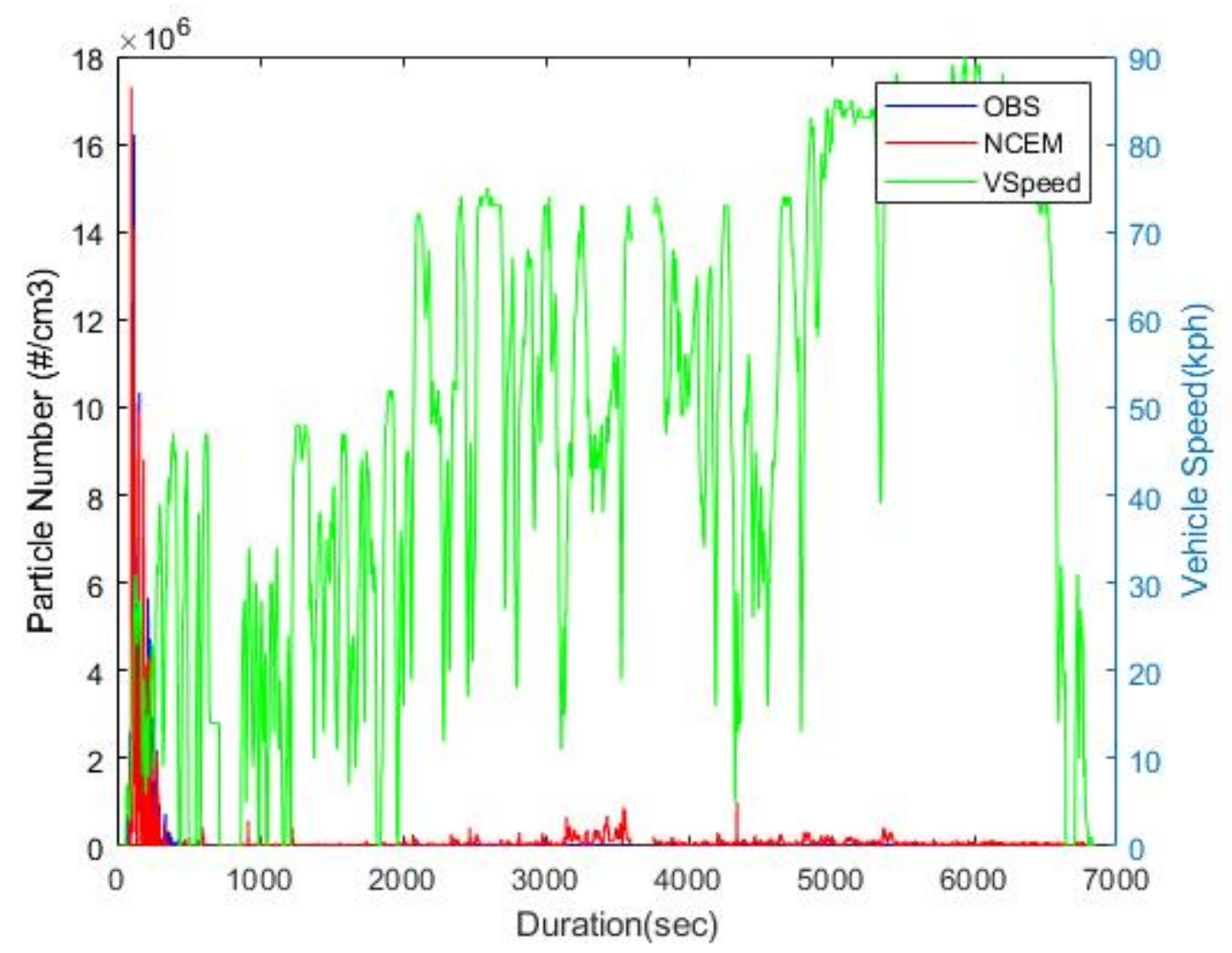

Figure 89: RDE 2 PN Raw Data with Vehicle Speed 


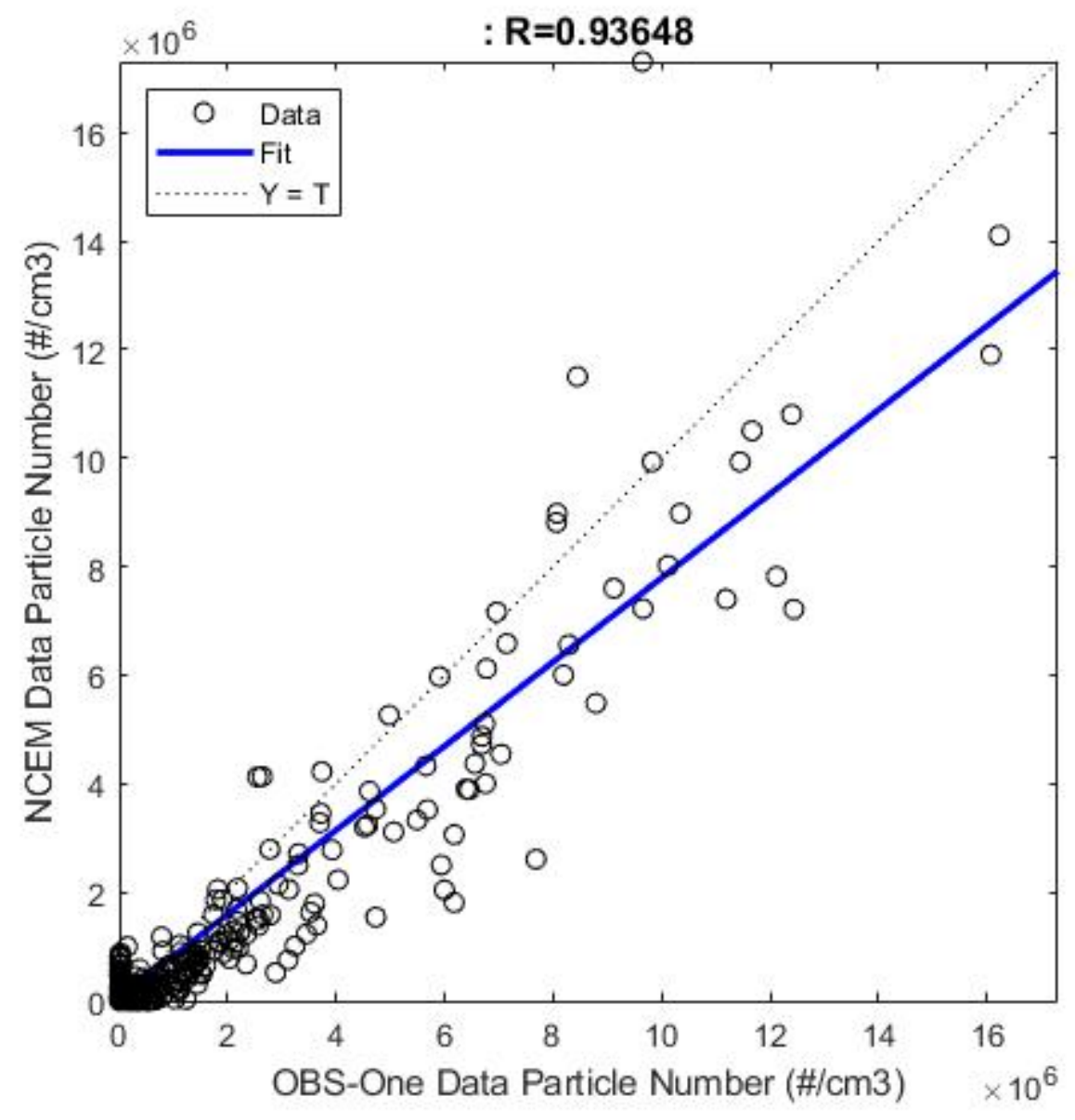

Figure 90: Linear Regression for RDE 2 PN Overall 


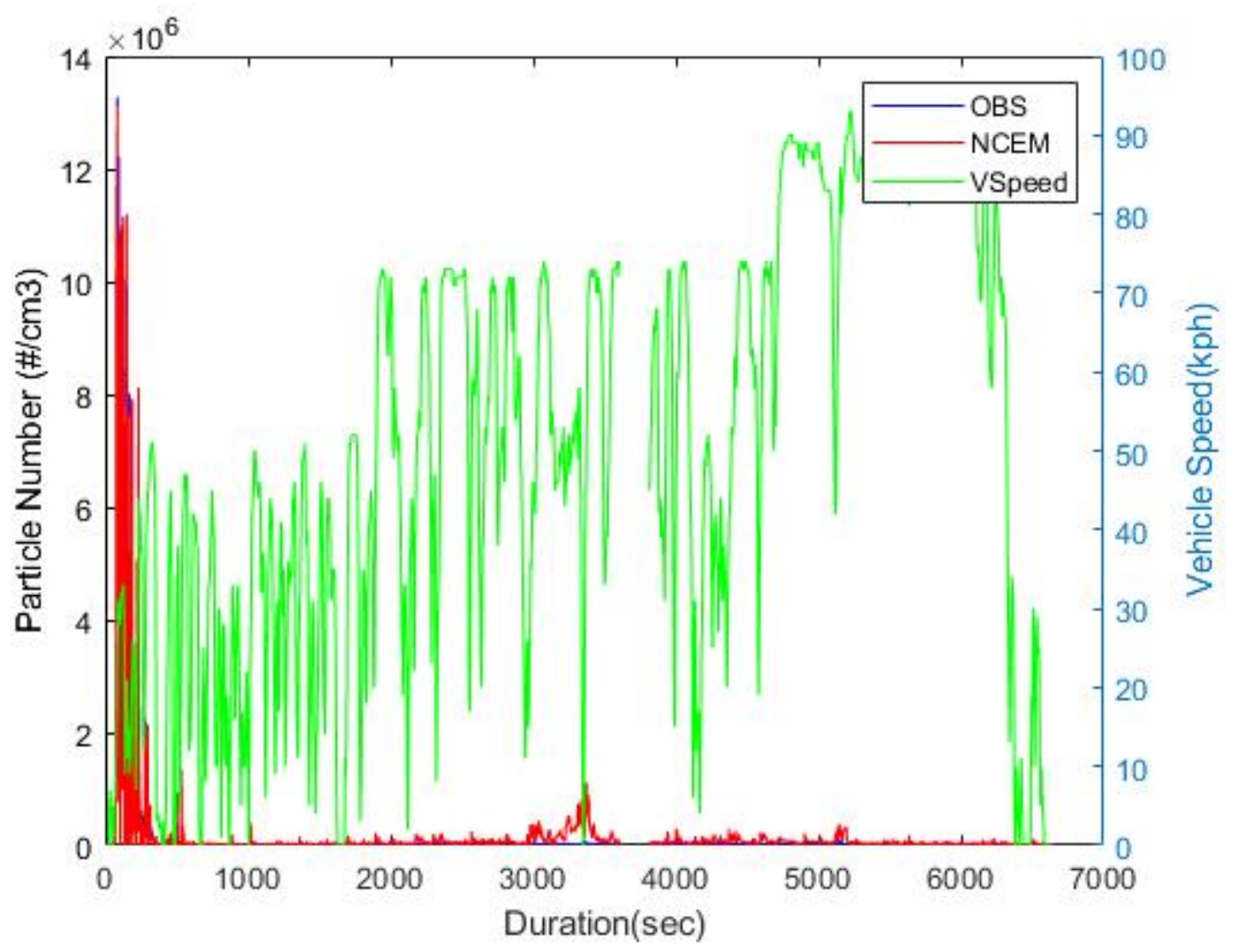

Figure 91: RDE 3 PN Raw Data with Vehicle Speed 


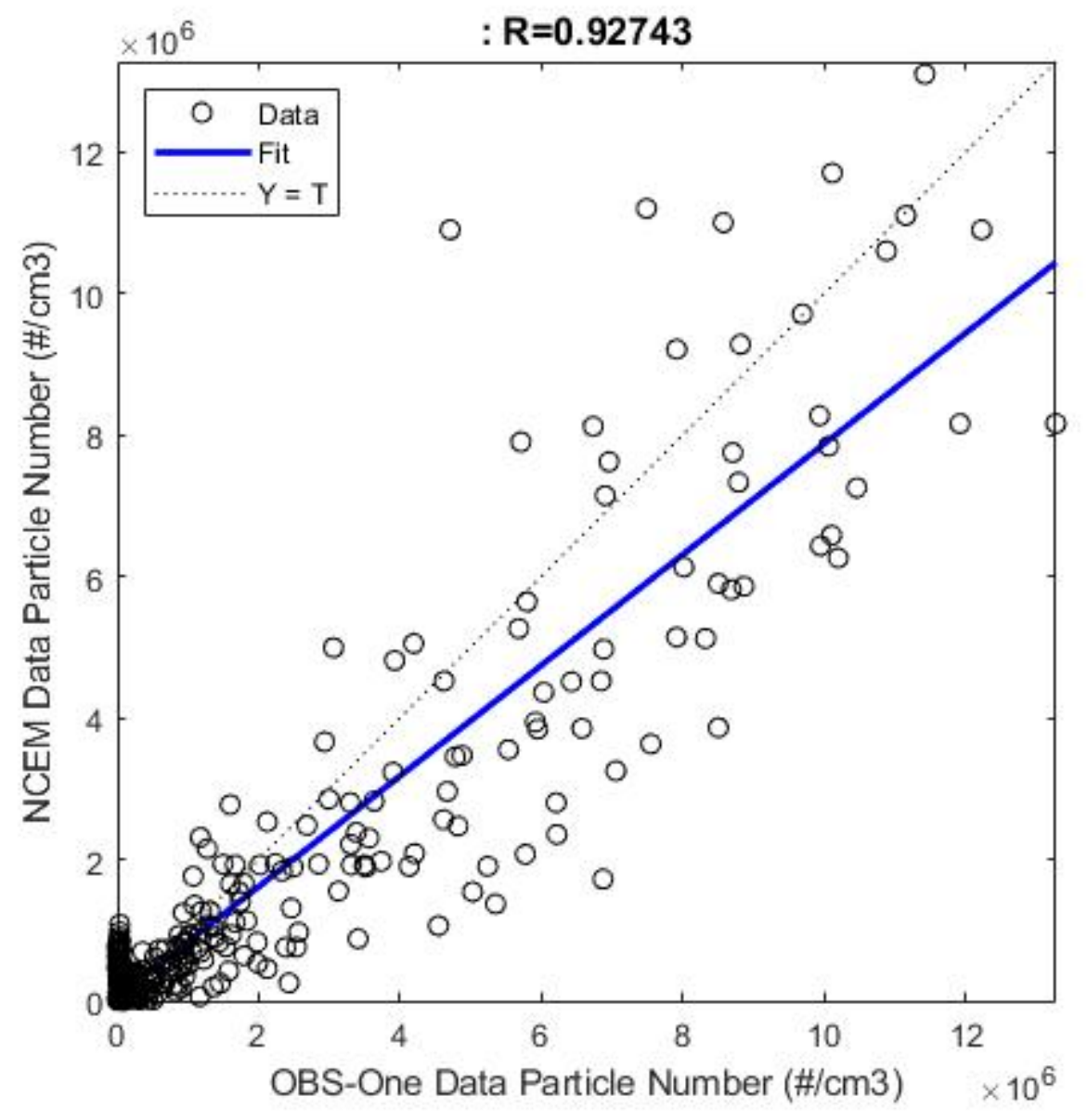

Figure 92: Linear Regression for RDE 3 PN Overall 


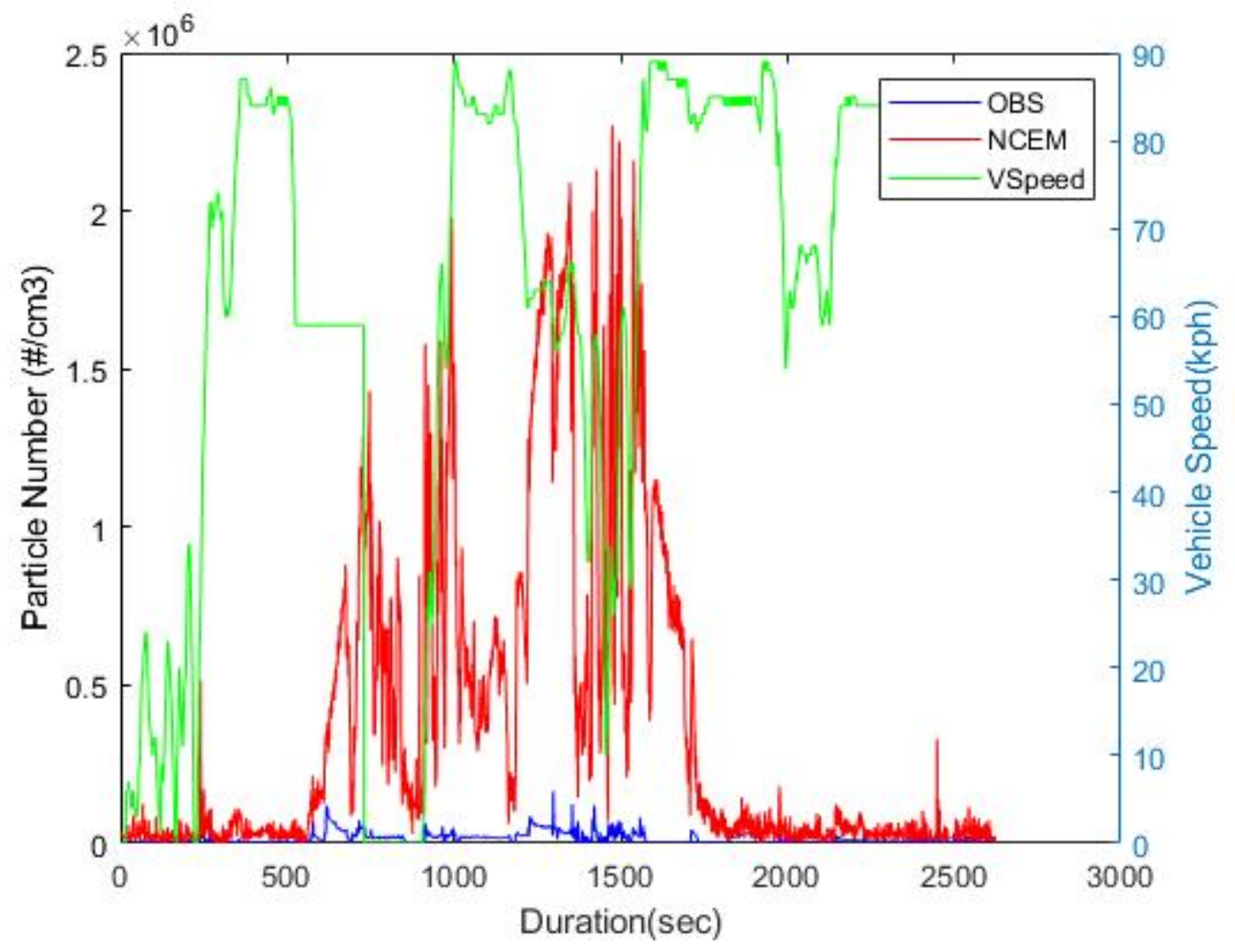

Figure 93: Tavannes 1 PN Raw Data with Vehicle Speed 


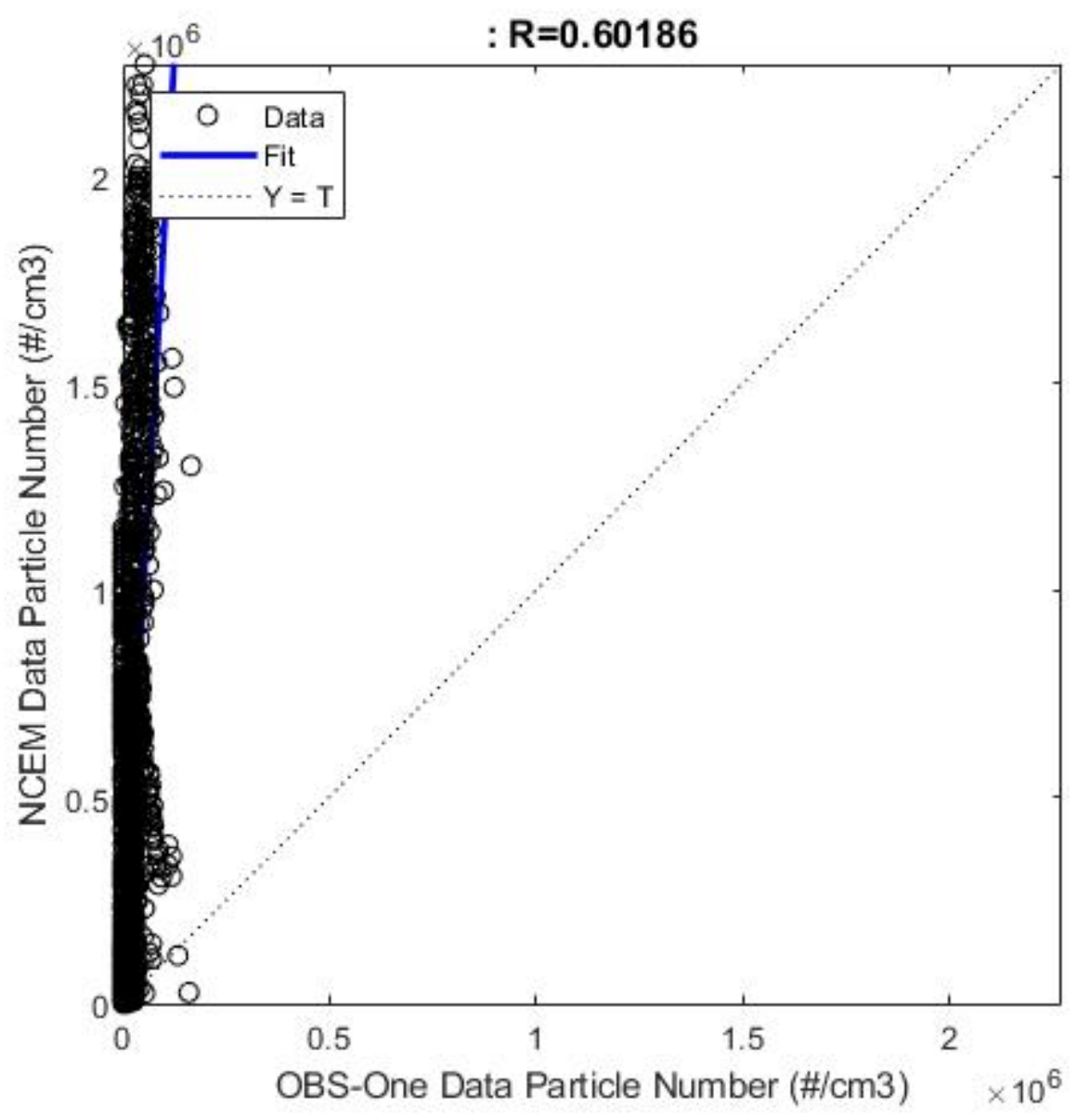

Figure 94: Linear Regression for Tavannes 1 PN Overall 


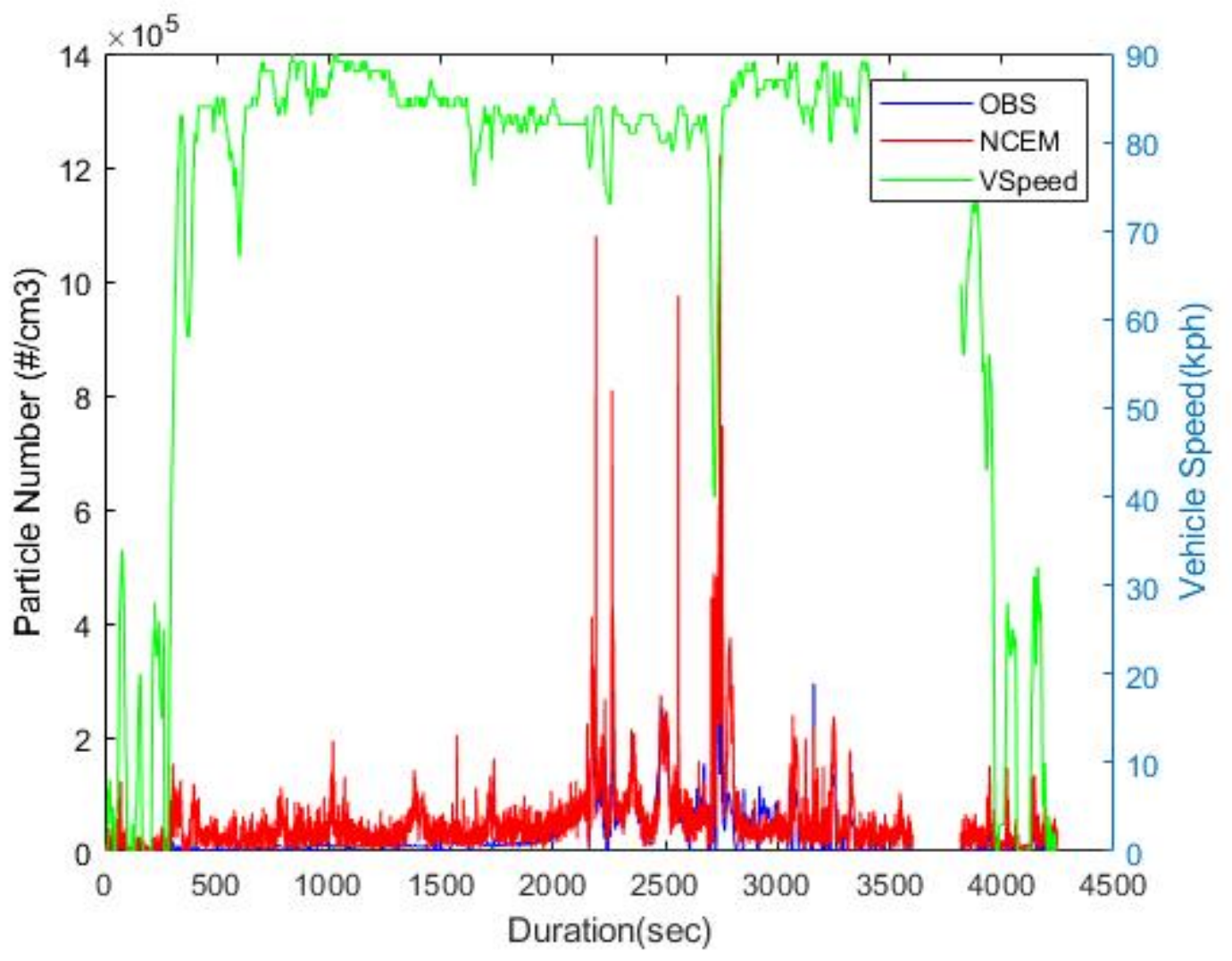

Figure 95: Highway 2 PN Raw Data with Vehicle Speed 


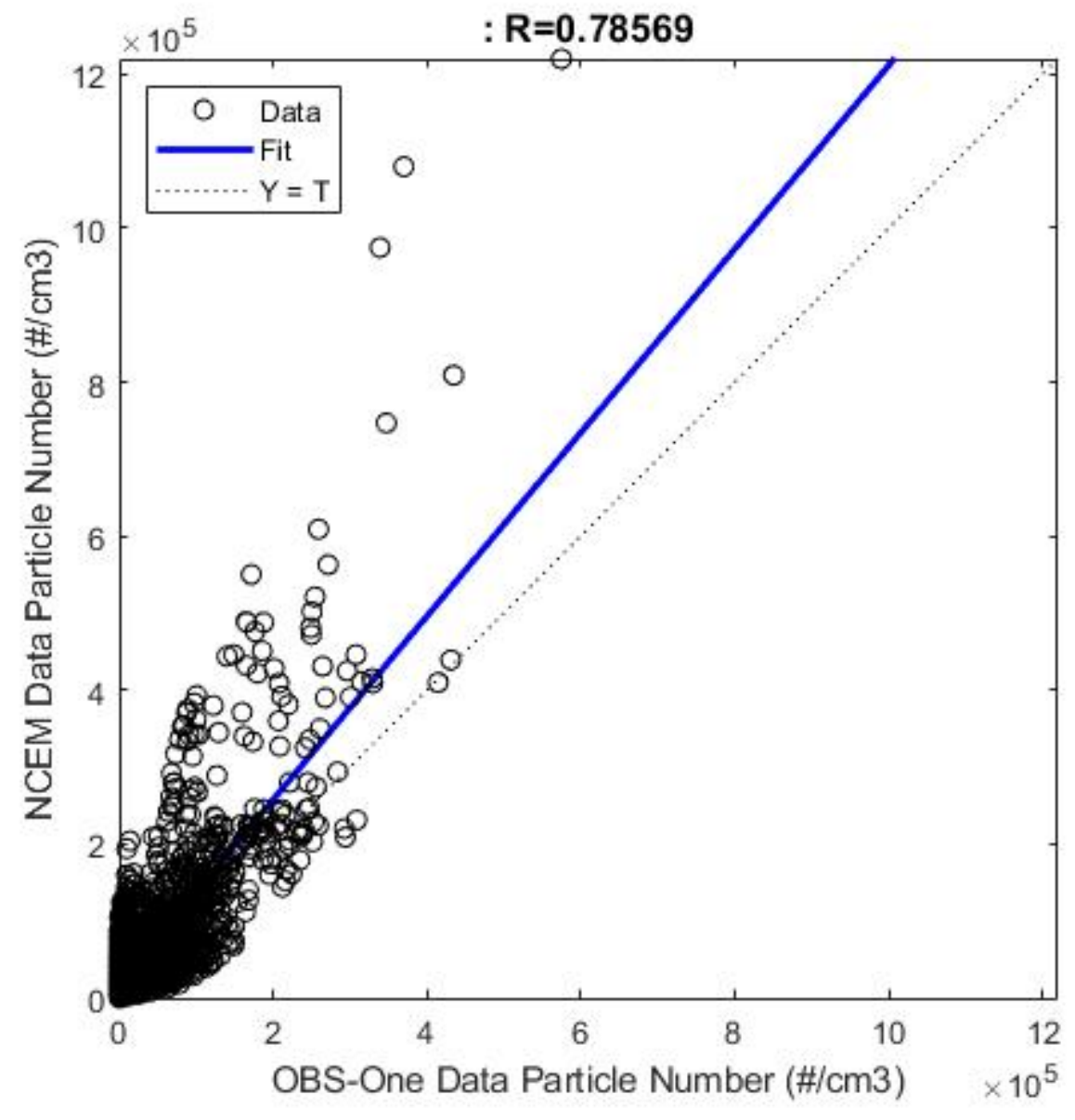

Figure 96: Linear Regression for Highway 2 PN Overall 